"The care with which police approach the use of force - whether lethal or less than lethal - is one of the most important measures of the quality of policing. Dr Dymond has produced the first significant analysis of the adoption and development of the use of the TASER. Her careful blending of the policy, theory and her own primary research provides a seminal study that deserved to be read by practitioners, policy makers and students of policing. A recommended read"

Peter Neyroud, Associate Professor in the Jerry Lee Centre for Experimental Criminology, Institute of Criminology, University of Cambridge.

"This thought provoking book provides a much-needed critical look at the use of electric-shock weapons and police use of force, as well as careful, well-considered policy recommendations and constructive challenge to all of us working in this area. Eschewing simplistic answers, and delving into the complexity of such topics, it makes a significant contribution to our understanding of the risks evident in poorly developed systems and how these can be mitigated against through robust policing professional standards. As a human rights practitioner, this book could not come at a more critical moment".

Oliver Feeley-Sprague, Amnesty International UK's Military, Security and Police Programme Director.

'Abi Dymond's long-standing and deep interest and experience in the use of conducted energy weapons is reflected in this book which encompasses her personal view of Taser, its use and implications. It is very widely referenced, and uses an extensive and enlightening range of information sources. As such it should be read by all those with an interest in this increasingly challenging field, whether from a law-enforcement, legal, medical, scientific or human rights background'.

Jason Payne-James, Specialist in Forensic \& Legal Medicine, Consultant Forensic Physician 


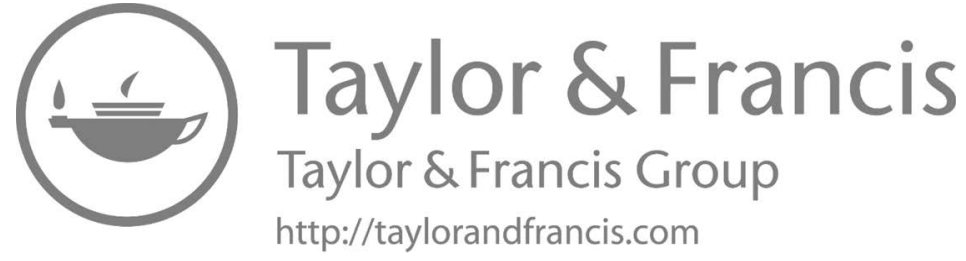




\section{Electric-Shock Weapons, Tasers and Policing}

Building on five years of research, and drawing on criminology, science and technology studies (STS), socio-legal studies and social psychology, this book is the first non-medical book written on electric-shock weapons, of which the best well known is the TASER brand.

The police's ability to use force is one of their most crucial powers, yet one that has been relatively neglected by criminology. This book challenges some of the myths surrounding the use of these weapons and considers their human rights implications and impact on members of the public and officers alike. Drawing on STS, it also considers the role and impact of electric-shock technologies, examines the extent to which technologies and non-human agency may also play a role in shaping officer decision making and discretion, and contributes to long standing debates about police accountability.

This is essential reading for policing scholars around the world, particularly those engaged with use of force, culture and accountability, as well as those engaged with Science and Technology studies.

Abi Dymond is a Senior Lecturer in Criminology in the Sociology, Philosophy and Anthropology Department at the University of Exeter and was previously an ESRC Future Research Leader. Prior to joining academia, she worked for over ten years for various human rights and international development NGOs, including the Omega Research Foundation. Impact is a large part of Abi's work. She won the ESRC Celebrating Impact Award in 2018 for her work on use of force, received travel costs from Taser International in 2014 to present her research to their Senior Management Team and regularly engages in a number of other impact activities in the UK and internationally. 


\section{Routledge Studies in Policing and Society}

Series Editors

Jenny Fleming, University of Southampton, UK

Jennifer Wood, Temple University, USA

Routledge Studies in Policing and Society aims to establish an inter-disciplinary, international intellectual space of original contributions to either classic or emerging debates about the nature and effects of policing in society. The works in this series will advance our theoretical, methodological and/or empirical knowledge of policing in various societies across the world. It is the hope of the series editors that the works in this series will help fill gaps in our global understanding of policing and society.

\section{Criminal Futures}

Predictive Policing and Everyday Police Work

Simon Egbert and Matthias Leese

Women Police in Contemporary China

Gender and Policing

Anqi Shen

\section{Electric-Shock Weapons, Tasers and Policing}

Myths and Realities

Abi Dymond 


\section{Electric-Shock Weapons, Tasers and Policing}

Myths and Realities

Abi Dymond 
First published 2022

by Routledge

2 Park Square, Milton Park, Abingdon, Oxon OXI4 4RN

and by Routledge

605 Third Avenue, New York, NY 10158

Routledge is an imprint of the Taylor \& Francis Group, an informa business

(C) 2022 Abi Dymond

The right of Abi Dymond to be identified as author of this work has been asserted by her in accordance with sections 77 and 78 of the Copyright,

Designs and Patents Act 1988.

The Open Access version of this book, available at www.taylorfrancis.com, has been made available under a Creative Commons Attribution-Non Commercial-No Derivatives 4.0 license.

Trademark notice: Product or corporate names may be trademarks or registered trademarks, and are used only for identification and explanation without intent to infringe.

British Library Cataloguing-in-Publication Data

A catalogue record for this book is available from the British Library

Library of Congress Cataloging-in-Publication Data

A catalog record has been requested for this book

ISBN: 978-0-367-43387-I (hbk)

ISBN: 978-I-032-I3459-8 (pbk)

ISBN: 978-I-003-00286-4 (ebk)

DOI: $10.4324 / 9781003002864$

Typeset in Bembo

by KnowledgeWorks Global Ltd. 
For my wonderful family, both human

(Gill, Martin, Keira and Matt) and non-human

(Kanga, Baloo and Skye), with thanks. 


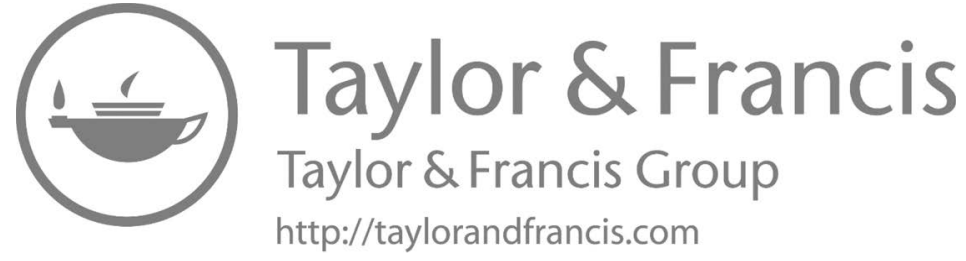




\section{Contents}

Acknowledgements $\quad \mathrm{x}$

List of abbreviations $\quad$ xi

1 Introduction 1

2 Technologies, tools, and TASERs 19

3 'Better stunned than gunned'? Origin myths and mission creep 30

4 A 'nicer' weapon? Projectile electric-shock weapons and public safety

5 'There's nothing bad I can say about TASER':

$\begin{array}{ll}\text { TASER and officer safety } & 71\end{array}$

6 'There's no right or wrong': Laws, policies and training 89

7 'Just a tool': Revisiting human and non-human agency 109

8 'You cannot obtain accountability': Officer accountability for use of force

9 Conclusion 141

Reference list $\quad 165$

$\begin{array}{ll}\text { Index } & 188\end{array}$ 


\section{Acknowledgements}

I'd like to start by thanking all the research participants and those in the three police forces, NPCC (previously ACPO) and the College of Policing who facilitated access and/or assisted with the research. For reasons of confidentiality they will remain nameless, but I trust they know who they are, and that they are appreciated. A particularly harrowing part of the research was attending inquests into the deaths of two young men-Jordan Lee Begley and Marc Anthony Cole-following police use of force, including TASER. I would like to thank the staff who made it possible to attend and I am humbled and saddened at the opportunity to do so.

My interest in TASER and other electric-shock weapons was cemented during my PhD thesis and I would like to thank the Economic and Social Research Council and the South West Doctoral Training Partnership for their support and funding, as well as 'Future Research Leaders' funding from the ESRC [Grant Number (ES/N016564/1)], which made this book possible and available via open access.

I was lucky enough to have Professor Brian Rappert, Professor Rachel Murray, and Dr Katharine Boyd initially as supervisors and now as supportive colleagues; thank you! Many thanks, too, for those who kindly commented on an early draft of the book, including Professor Rappert and Professor Peter Neyroud. I've also benefitted from the support of many others, including but not limited to: Professor Susan Banducci, Cillian Blake, Professor Stuart Casey-Maslen, Tristan Coleshaw, Professor Dave Cowan, Kevin Donoghue, Dr. Hannah Farrimond, Oliver Feeley-Sprague, Professor Jenny Fleming, Dr. Ashley Frayling, Professor Nick Gill, Ian Gould, Dr. Emily Kakoullis, Professor Antonia Layard, Dr David Manley, Professor Susan MolyneuxHodgson, the late Anneke Osse, Professor Jason Payne-James, Professor Peter Squires, Clare Stack, Dr. Chris Thorpe, Martyn Underhill, Dr. Dana Wilson-Kovacs, and all those at the Omega Research Foundation. All mistakes and opinions expressed are my own. 


\section{List of abbreviations}

ACPO: Association of Chief Police Officers. (The NPCC replaced ACPO in 2015).

AFID: Anti-Felon Identification.

ANT: $\quad$ Actor-Network Theory.

AEP: Attenuating Energy Projectile.

APP: $\quad$ Authorised Professional Practice.

CED: Conducted Energy Device, sometimes also referred to as Conducted Electrical Device (often used to refer to projectile electric-shock weapons).

CEW: $\quad$ Conducted Energy Weapon, sometimes also referred to as Conducted Electrical Weapon (often used to refer to projectile electric-shock weapons).

CS: 2-chlorobenzylidene malononitrole, commonly used in chemical irritant sprays.

DOMILL: Defence Scientific Advisory Council Sub-committee on the Medical Implications of Less-lethal Weapons.

ECHR: European Convention on Human Rights

ECtHR: European Court of Human Rights

HMIC: Her Majesty's Inspectorate of the Constabulary. (Please note the organisation's name changed to Her Majesty's Inspectorate of Constabulary and Fire \& Rescue Services, HMICFRS, in 2017, and both acronyms are used in the book).

INQUEST: INQUEST is a London based charity providing expertise on state related deaths and their investigation to bereaved people, lawyers, advice and support agencies, the media and parliamentarians. It is referred to in capitals so as to differentiate it from inquest proceedings.

IPCC: Independent Police Complaints Commission.

IOPC: Independent Office for Police Conduct

LLWs: Less Lethal Weapons

MPS: $\quad$ Metropolitan Police Service.

NDM: National Decision Model. 
NMI: Neuro-Muscular Incapacitation.

NPCC: National Police Chief Council. (The NPCC replaced ACPO in 2015).

PALG: $\quad$ Police Action Lawyers Group.

PCC: $\quad$ Police and Crime Commissioner

PPE: $\quad$ Personal Protective Equipment.

PST: $\quad$ Personal Safety Training, also referred to as Officer Safety Training (OST).

OST: $\quad$ Officer Safety Training, also referred to as Personal Safety Training (PST).

SACMILL: Scientific Advisory Committee on the Medical Implications of Less Lethal Weapons.

STS: $\quad$ Science and Technology Studies.

TPC: $\quad$ Traditional Police Subculture.

UNCAT: United Nation Convention against Torture and Other Cruel, Inhuman or Degrading Treatment or Punishment. 


\section{Chapter I}

\section{Introduction}

In 2014, I was invited to visit the Headquarters of TASER International in Scottsdale, Arizona, and offered the opportunity to experience the effects of the electric-shock weapon the TASER. And so it came to pass that on a bright November day, I would find myself standing on a mat, in an empty conference room, waiting to be 'Tasered'. Despite having volunteered for this experience, I am extremely nervous. I stand tall and wait for the loud 'pop' that accompanies the firing of the weapon. The short time it takes for the two metal probes to hit me feels like an eternity and when they do, I involuntarily scream in agony as the electricity passes through me. The sensation is like nothing I have felt before: an agonising pulsing and cramping that seems to take over my body at regular intervals. As well as being a painful experience, it is also a disorientating, unfamiliar, and panic-inducing one. The part of my brain that is able to reflect on the experience is frantically trying to classify it and compare it to something more familiar in order to reassure myself that I am safe-but to no avail. Thankfully, the shock lasts only five seconds. I am lowered to the ground by company officials, shaken but not too badly affected by the experience.

\section{Introduction}

My personal experience of being 'Tasered' that I recount above is in some ways unique, yet in other ways increasingly common. The terms TASER ${ }^{1}$, tasering, and being 'tasered' are widely used to describe exposure to any electric-shock weapon. However, TASER is a brand name which refers to electric-shock weapons manufactured by the American company previously known as TASER International, now Axon Enterprise, Inc (henceforth Axon). From a patent filed in the 1970s, experimentation with multiple designs, concepts, and rationales throughout the 1980s and 1990s (Rejali 2009), and increasingly widespread adoption of the technology in the 1990s onwards, TASER weapons are in use in 100 countries worldwide TASER International 2013 (Axon undated, a). 
While TASER weapons are the most widely used worldwide, other electricshock weapons are also available. Alternative electric-shock products have also sprung up in a number of other countries, with Condor Non-Lethal Technologies (undated) launching the 'Spark, the first 100\% Brazilian electronic control device' and March Group (undated a) claiming to be the 'first manufacturer of remote contact (shooting) stun guns... in Russia'. Companies in China are also reported to be manufacturing or trading electric-shock weapons, including ones designed to be used at a distance (Amnesty International and Omega Research Foundation, 2014).

While such weapons can be used in a number of different ways, this group of technologies are distinctive for their purported ability to administer electricity at a distance via tethered probes or projectiles (hence the terms 'projectile electric-shock weapons' and 'probe firing mode' used throughout the book $)^{2}$. Used in this mode, certain weapons can, under certain conditions, impair one's ability to move, via an effect often referred to as 'neuro-muscular incapacitation' (SACMILL 2016: 1-2) ) $^{3}$ Many of us will be familiar with this type of use-and visual representations of the freezing, pain, and/or falls that sometimes accompany it-from (in)famous YouTube videos, police documentaries, promotional adverts, and even Hollywood films. Following the introduction of TASER to England and Wales in 2003, the use of these weapons, and the use of probe firing mode, has steadily grown. Nowadays, they are reportedly discharged in probe firing mode at an average of seven times a day in England and Wales alone (author's calculations from Home Office 2019a ${ }^{4}$ ). It seems I am far from alone in experiencing the effects of such weapons.

This increased use of projectile electric-shock weapons-linked, as they are, to trends in the use of less lethal weapons and police use of force more broadly-should concern us all. It is often argued that policing in England and Wales and, indeed, good policing worldwide relies on policing by consent. In other words, securing co-operation not through the use of force or coercion but through the common consent, even the good will, of the public, for which the police need to be broadly regarded as legitimate. As such, the argument goes, police should not generally be armed, and when they are equipped with weapons, the force used must be proportionate and necessary.

Questions around the use of electric-shock weapons go to the heart of this rather benign characterisation of the police. With the roll out of TASER, and the similarities some draw between TASER and conventional firearms (Marsh et al 2019, Police Foundation 2009), it is increasingly difficult to claim that the police in England and Wales are unarmed. Instead, it is often claimed that the weapon is fully in keeping with policing by consent because it represents a lower use of force than the alternative.

Such justifications are not unique to England and Wales, or to projectile electric-shock weapons such as TASER, but are found worldwide, including countries where officers are routinely armed. Indeed, the broader class of 
less lethal weapons-defined as those 'which are intended to subdue or incapacitate rather than to cause serious harm or death' (Bozeman and Winslow 2005) - is often initially justified as an alternative to firearms and as a way of decreasing the amount of force police use ${ }^{5}$. Some go as far to call TASER the 'tool of the pacifist' (Tangye 2016) and cite incidents where they feel the use of the weapon prevented recourse to deadly force. The manufacturer of the TASER weapon, Axon, states that there have been over 240,000 lives 'saved from death or serious bodily injury'(Axon undated, b). Condor NonLethal Technologies (undated) state that they 'devote special attention to the spread of the non-lethal concept with an aim to educate police and military authorities about the importance of gradual and proportionate use of force' and that such technologies 'enable law enforcement to use proportional force, which substantially reduces the number of cases needing the use of firearms'.

Yet there are concerns that electric-shock weapons are, in contrast, increasing the amount of force used. Emblematic incidents-discussed in more detail in this book-in England and Wales include the case of Colin Farmer, who was registered blind / partially sighted and Tasered while walking with his cane; Ras Judah Adunbi, a community elder who was Tasered following a case of mistaken identity; and, in an incident widely circulated on social media at the time of writing, Desmond Ziggy Mombeyarara, Tasered while at a petrol station in front of his young child. Nor is this an isolated concern; similarly controversial cases of electric-shock use are reported worldwide and are not restricted to incidents involving the TASER brand (see, for example, Institute for Security Studies 2016). Such incidents raise concerns that this class of weapons, far from helping to decrease the use of coercive force of the State and the negative consequences associated with it, may allow for a greater intrusion, and greater use of force, than ever before. Such a profound shift would, in turn, have implications for police legitimacy, the much-proclaimed notion of 'policing by consent', and, ultimately, state-civilian relations.

Yet the increased use of TASER is of interest not just for the light it can shed on the police role and the relationship between state and citizen. It also has multiple, far-reaching implications for those subjected to the weapon. In the incidents cited above, Colin Farmer, Ras Judah Abundi, and Desmond Ziggy Mombeyarara lived to tell the tale and were able to discuss their experiences of electric-shock weapons. Others were not so lucky.

Michael Gilchrist, who was bipolar and on the autistic spectrum, had TASER and CS spray repeatedly used on him in an incident in 2014. A subsequent court case found that while an initial use of TASER was justified, a further use of the weapon by a different office-who deployed it for a cumulative total of 72 seconds-was not (English and Welsh High Court 2019). His mother, Novlyn Graham stated that:

'Michael did not die that day, but in many ways, he has been taken from us, his family. He is no longer able to communicate and he is largely 
verbally mute... All we have ever wanted is answers and meaningful engagement with the police. Instead, we have been made to feel subhuman. The officers on the scene did not see beyond the colour of Michael's skin'.

(quoted in Resistance Lab 2020)

Reuters Investigates (2017) records that more than a thousand people have died in the United States 'after being shocked by police with a Taser (often in combination with other forms of force)'. Nor are such issues unique to the United States. In Canada, the death of Robert Dziekański resulted in a public commission of inquiry both into the immediate circumstances relating to the case, and into conducted energy weapons more broadly. In England and Wales, the inquest jury in the death of Marc Cole recorded the cause of death as 'use of cocaine, episode of altered behaviour including self-harm, exertion, excitement, the use of x26 Taser Device and restraint' (Cornwall and the Isle of Scilly Coroner 2020a), finding that the use of a TASER had 'more than a trivial impact' (Cornwall and Isles of Scilly Coroner 2020b). Many of those who have died following TASER use-including Robert Dziekański and Marc Cole-were disorientated, emotionally disturbed (Braidwood 2009), and/or experiencing mental health crisis (INQUEST 2020a) at the time the weapon was used.

Further, as such cases indicate, the likelihood of TASER being used is not dispersed equally throughout the population. Some studies in the United States indicate that Black, Asian and Minority Ethnic (BAME) people and those with mental health issues are more likely to have TASER used on them (see, for e.g., Brandl and Stroshine 2017, Crow and Adrion 2011; Gau et al 2010, c.f., Lin and Jones 2010). Nor is this an issue confined to the United States. As I discuss further in Chapter 3, similar patterns have been found elsewhere, including in New Zealand (New Zealand Police 2018; O'Brien et al 2011), Australia (Ombudsman of New South Wales 2012), and England and Wales (Home Office 2019a, 2019b, Quinton et al 2020). For example, work by the author and colleagues (Quinton et al 2020) found that TASER use was patterned along lines of ethnicity and perceived mental health status, with people perceived by the officer to be Black or Black British or to be 'mentally disabled'6 more likely to have TASER drawn (but not fired), even after controlling for confounding factors ${ }^{7}$. Such issues are also increasingly headline news, with calculations by Shiner-which indicated that black people are nearly eight times more likely to have the weapons used against them - picked up by a number of national news outlets, including the Telegraph (Southworth 2020) and the Guardian (Busby 2020). At the time of writing, the NPCC and the College of Policing (NPCC) have just established an Independent Review into Disproportionate Effects of Use of TASER to 'identify, understand and tackle the root causes of racial disproportionality in police use of Taser' (NPCC and College of Policing 2020). 
Such concerns urgently highlight the need to examine the regulatory framework around TASER and other projectile electric-shock weapons. The debates here are not just empirical, although the content and sufficiency of police training and guidance is an important point of contention and one that will be discussed in the book. There are also important implications for how less lethal weapons can and should be regulated, how prescriptive guidance and training should be, and how much leeway officers should be given to make their own decisions around the use of the weapon. Such issues are particularly pressing given the increasingly broad range of less lethal weapons with which the police are equipped - with officers worldwide having access to handcuffs, batons, irritant spray and, increasingly, spit hoods, TASER, other electric-shock weapons and kinetic impact projectiles-and the growing market for such weapons globally. Indeed, the market for less lethal weapons is currently valued at over $\$ 8$ billion (Marketwatch 2021), and there are few legally binding limitations on the trade and use of such weapons internationally.

This, in turn, further raises important questions about the role and responsibility of the State in providing training and regulation around police use of force; the kinds of decisions that can-and should-be left to police officers, and the balance between allowing the police to exercise their own discretion and providing them with sufficient guidance. When, for example, the current standard for TASER use in England and Wales - that it is 'one of a number of tactical options available when dealing with an incident with the potential for conflict' (College of Policing 2020a) — is so vague and markedly different to international standards around the use of the weapon (see UN Committee Against Torture 2013 for their assessment of TASER policy in England and Wales), one has to ask whether we have got the balance right and what effects this has for officers charged with carrying the weapon and for people on the receiving end of it. Such concerns are particularly pressing because, as we will see, TASER policy in England and Wales is held up as a good practice model internationally.

The current guidance, with its loose wording, also reinforces pre-existing concerns about police accountability and the extent to which officers and others are accountable for their use of force: a key principle in democratic society. All too often, concerns about the guidance given to police officers are dismissed with claims that they are subject to robust accountability for their use of the weapon. Yet, as I will detail in this book, real concerns exist about the possibility of holding officers to account, both for their use of TASER and for their use of force more broadly. Questions about TASER and projectile electric-shock weapons, then, are inextricably intertwined with a number of other crucial debates in policing.

Further, discussions about TASER easily spill over into debates about (policing) technology and technological change. This is particularly pertinent given the range of technologies implicated in policing-from IT systems 
(Manning 2008; Willis et al 2018) to body-worn cameras and complex surveillance systems (Joh 2016) — the ethical dilemmas they raise (Neyroud and Disley 2008) and the relative inattention given to weapon technologies within this. In examining projectile electric-shock technologies such as TASER, I hope to start filling this gap and also to demonstrate that technologies, in policing and elsewhere, do much more than is often suggested. Drawing on the vast amount of sociological literature in the field of constructivist Science and Technology Studies (STS), I will show that, far from being mere tools, technologies can impact upon human agency and produce unexpected, and sometimes unwelcome, outcomes. As I will show throughout the book, this insight, in turn, has implications for the key theoretical approaches in policing-with consensus and conflict approaches, interactionist and security governance perspectives alike being curiously inattentive to issues around technologies - for classic concepts such as discretion, police subculture, and accountability and perhaps even for STS.

Taken together, then, TASER and police use of force are crucial issues for criminology to tackle because they raise crucial questions about the police role, police legitimacy, human rights, police discretion, accountability, and technological change. Such issues have always been of paramount importance (United Nations Human Rights Office of the High Commissioner (2020a). Nevertheless, recent reports of excessive use of force, including less lethal weapons, in response to the coronavirus (Omega Research Foundation 2020; United Nations Human Rights Office of the High Commissioner 2020b); the death of George Floyd and the militarised response to protests in the United States; and what Gimbel and Muhammad (2019: 1454) describe as a 'mass awakening' to racism and ethnic disproportionality in the exercise of use of force (United Nations Human Rights Office of the High Commissioner $2020 \mathrm{bc}$ ) all underscore the need for attention to be given to this area.

\section{Backgrounds and contexts}

It is, therefore, surprising that despite increased interest in police use of force in recent years, the topic remains relatively understudied (Bittner 1974, Buttle 2007, Quinton et al 2020)—particularly in light of the centrality of use of force to the police role. While there is some literature on electric-shock weapons - mainly on TASER - the literature that does exist tends to focus on the United States. Yet, given the notable ways in which policing in the United States differs from policing in other countries, it is important to test such findings internationally-particularly as many of the studies conducted have been reliant on a very small number of datasets (Neuscheler and Freidlin 2015).

Further, while it has enriched our understanding in many ways, much of this prior work is quantitative in nature and is concerned with relatively narrow questions around effectiveness and comparative injury rates to officers and 
members of the public. Yet the (social) construction of these terms are often under-explored in this literature (Terrill and Paoline 2012) and this body of work is ill-placed to explore how police officers interpret, interact with, and make sense of TASER and other use of force options (Sierra-Arévalo 2019, Neuscheler and Freidlin 2015). Moreover, many studies look at one or two isolated aspects of the TASER weapon-for example, its introduction (White 2014), its impact on injury rates and officer safety once introduced (e.g. Smith et al 2007; Womack et al 2016), or the guidance surrounding the weapon (Terrill and Paoline 2013) - but few, if any, works provide a more expansive approach.

Moreover, much of the prior work is sponsored by the manufacturer of the TASER weapon (Azadani et al 2011), written by company employees (Stanbrook 2008) and/or written by serving police officers (e.g., Stevenson and Drummond-Smith 2020). However, a study by Azadani et al (2012) found that studies that were affiliated with TASER International had nearly 18 times greater odds of concluding that the device was safe as compared to studies without such an affiliation. Concerns have also been raised that academics, too, uncritically adopt police rationales and definitions of crucial terms (see Terrill and Paoline 2012; ) and make little or no attempt to engage with those on the receiving end of police use of force, or with a broader range of stakeholders.

For example, Jauchem argues that academics can play an important role in pointing out 'misconceptions' around the TASER weapon, which he sees as 'an important law enforcement tool' (2015: 53). Jenkinson et al (2006: 239) are keen to argue that the weapon should be made available more widely in England and Wales and are quick to dismiss concerns that it 'will be deployed as instruments of torture'. Kaminski et al criticise researchers who use definitions of use of force and injury that are not accepted by police officers and who produce accounts 'unhelpful to practitioners and police executives seeking to better understanding correlates of force' (2013: 618). This echoes much broader concerns about a shift from the 'sociology of the police' to 'sociology for the police' (Reiner 2012: 91). Overall, then, there is a paucity of critical, reflexive, academic work on police use of force and electric-shock weapons and, as Neyroud (2014: 93) notes, a broader pattern whereby advocates of particular technologies are 'more focused on the technical and less on the social and legitimacy impacts'.

In contrast, this book explores how the technology is introduced, regulated, and trained, how it is used in practice-and the consequences of this use-and also examines accountability after the weapon is used and the limits thereof. Further, instead of providing often decontextualized, somewhat abstract statistical analysis, as I have done myself in previous works (e.g. Dymond 2018, I aim to provide a close analysis of a weapons technology in situ. This involves looking at TASER technology not just as a mere object, as a neutral venue in which discussion can occur, but as a key interlocutor in 
this discussion and an important actor-one which can only be understood by a close observation of the relationships that it is shaped by and, in turn, helps shape.

It is worth noting too that the origin and funding of this research is quite different from many of the previous studies in this area. This book stems from my background working for human rights and international development NGOs, including those working directly on the implications of less-lethal weapons, and is funded from public (ESRC) funds. Perhaps due to this background, I also have a different conception of what it means to produce 'helpful' or 'unhelpful' research in this area, seeing researchers less as having a duty to conduct research that is helpful to the police, but more as having a duty to provide them with robust and sometimes challenging insights. In this vein, this research is unusual in conducting research both with those who are armed with the weapon and those who are on the receiving end of it, a topic I return to later on in the chapter when discussing the methodology.

\section{Aims of the book}

Against this backdrop, my aims with this book are three-fold. First, I aim to advance and internationalise our understanding of projectile electric-shock weapons by challenging commonly held beliefs and 'myths' around such weapons. I aim not only to provide a careful empirical critique of the claims often made about such weapons, pointing out where those are unsupported by the evidence. Taking a leaf from constructivist thinkers in STS, I also aim to challenge how electric-shock technology is understood and how evidence and facts around the weapon come to be assembled, constructed, and seen as persuasive and 'real' in the first place.

I discuss the term 'myths', as well as the specific myths that will be explored in this book in more detail later on in the chapter. For now, it is important to note that, in discussing myths, I pay particular attention to the views espoused by proponents of the weapon-including the police and high-ranking officials, multinational corporations, and other key stakeholders-because these claims are highly influential, widespread, and often taken for granted. As Becker (1967: 241-243) might argue, such perspectives enjoy a 'hierarchy of credibility' and manifest as facts which 'everybody knows'. Further, Woodhouse et al (2002: 302) remind us, in their call for more work attending to weapon technologies, that those who seek to improve social outcomes have a 'better chance' of achieving their goal by working to 'counteract existing biases'. Moreover, in conditions where the case for advanced policing technologies and weapons can be easily made by its advocates (Bowling and Marks 2008), it is important to adopt a sceptical orientation (see, for example, Rappert et al 2011), not only subjecting the claims of the powerful to scrutiny but examining the sources and origins of this power. 
As such, in contrast to much criminology research on less lethal weapons which aims to reveal the 'empirical reality' (Terrill and Paoline 2012), I aim to acknowledge and interrogate the difficulties involved in coming up with one, definitive, 'true' picture of what projectile electric-shock technology 'is' and what it 'does'. In that vein, the views and accounts presented here are just that - accounts and views - and I make no claim to their special or 'objective' status (a point to which I return shortly).

At the same time, however-and this is my second aim-I hope to demonstrate the need for urgent change and far-reaching reforms around the use of TASER, electric-shock weapons, and police use of force more broadly in order to improve outcomes for members of the public and officers alike, and I make recommendations to this end. I want to recognise the pain and suffering caused by the status quo, to try to alleviate this and contribute to bringing about progressive change-for the benefit of all, members of the public and officers alike. In so doing, instead of trying to resolve the controversies, uncertainties, and ambiguities around electric-shock weapons once and for all, I also aim to build on work by Rappert (2003) and Lee (1999) and show that the way in which these uncertainties and ambiguities are currently managed puts far too much responsibility on, and is unfair for, both the officers carrying the weapon and those subjected to it.

Third, I aim to provide a close, deeply situated case study of one particular (electric-shock) technology and demonstrate the need to pay more attention to, and to take seriously, technologies of all kinds. With this renewed attention to technologies, I aim to contribute to broader discussions in criminology and to reimagine conventional understandings of key concepts, theories, and debates; not just those around use of force and the use of less lethal weapons, but also those around police subculture, discretion, and around our understanding of the police, policing theories, and police role.

\section{Qualifications and limitations}

Before discussing how the book will attempt to meet these aims, it seems important to reflect on the limitations and tensions within them-and to clarify not just what this book aims to do, but also to clarify what it does not aim to do. Five points of clarification are necessary.

First, my interest here is in projectile electric-shock weapons. To the extent that this book focuses on TASER, it is because it is the market leader and most frequently used. As a consequence, information about how the weapon has been received and perceived by officers and members of the public, patterns of use and misuse, and other associated issues are better documented, and more readily available, than they are for other, rival electric-shock manufacturers - and, perhaps, for other weapons technologies too. In addition, TASER is the only projectile electric-shock brand in use in England and Wales, where the research for this book was conducted. However, this is not 
a book about the TASER 'brand', or the multinational corporation associated with it, and I do not wish to imply that the issues discussed within are necessarily unique to TASERs per se. As such, as noted above, I often use the term 'projectile electric-shock' throughout the book to refer to this broader class of weapons more generally ${ }^{8}$ and, where I refer to TASERs throughout the book, I do so in capitals as it is a trademarked brand name (TASER International 2016) ${ }^{9}$.

Second, while I look at in-depth case studies of TASER use throughout the book, my knowledge of these events is taken from inquest proceedings, court cases, interviews, and other sources, and I have no first-hand knowledge of the events in question. Third, as may be apparent from the preceding discussion, I do not have a medical or scientific background. I make no claims to offer a medical, scientific, or technical appraisal of electric-shock weapons, or to provide some kind of 'objective', 'real' assessment-indeed, I aim, often, to challenge these very kinds of assessments. Instead of providing a set of definitive 'facts', then, this book aims to set out my honest opinions based on the extensive empirical research I have conducted; no more, or less. As such, I offer interpretations and make policy recommendations reflexively and tentatively, acknowledging the 'artifice' (Kling 1992: 381) in my own accounts and aiming more to start debates than to close them.

Fourth, and relatedly, some might argue that there is a tension between my desire to draw on constructivist STS to challenge and deconstruct myths and accounts suggested by others, while daring to reconstruct and to suggest remedies and policy recommendations of my own based on such 'subjective' foundations. It seems appropriate, then, to clarify my overall approach. Taking a somewhat pragmatic stance, I adopt what Seale calls a 'middle way' (1999: 470). This makes room for constructivism and interpretation-in particular, to make room for multiple interpretations of reality and to focus on how facts and 'realities' are constructed-yet equally seeking to retain some notion of reality, truth, and material objects existing outside of such interpretations. As Seale (1999: 470) notes, the researcher treading the 'middle way' is aware of the 'somewhat' constructed nature of research but 'avoids the wholesale application of constructivism to his or her own practice, which would result in a descent into nihilism' ${ }^{10}$. I note, too, that I am also in good company in this endeavour, with many inspired by STS keen to conduct work that is 'normative in orientation and activist in sympathies' (Woodhouse et al 2002: 299). Indeed, it is a 'small step' (Hamlett in Woodhouse et al 2002: 298) from asking how technologies are (mutually) constructed to asking normative questions around how they could, or should, be constructed in the future: a key challenge for this book.

Likewise, I hope to tread a middle way, appreciating the limitations and constructed nature of the arguments made here, while still recognising the need to challenge existing myths, 'hierarchies of credibility' (Becker 1967: 241-243), and avoiding the 'descent into nihilism'. Moreover, as previous 
work has shown (Rappert 2003), such an endeavour need not involve reaching a final, definite conclusion about the capacities and effects of technologies and closing or resolving controversies once and for all. It can be equally important to note how indeterminacies and uncertainties around controversial technologies - such as the vague, ambiguous language in the guidance about when TASER should be used-can have far-reaching consequences, including for those lower down in the hierarchy.

Fifth, caution needs to be taken when making broader generalisations and sweeping statements about the international applicability of the findings on the use of the weapon. There will be, of course, many local differences in how TASER and other electric-shock weapons are used, regulated, and held to account both within and between countries, and I have sought to put my findings in international context and to bring in empirical evidence from a range of jurisdictions throughout the book. At the same time, however, there is a strong tradition of conducting detailed case studies in policing research (see, for example, Oram et al 1991; Jackson 2020) for further discussion of the case study approach) and a careful empirical study of TASER in England and Wales has resonance internationally for multiple reasons.

England and Wales is often seen as the gold standard for police use of force and policing by consent, and held up as a role model for other countries (Ariel et al 2019; Vitale 2017) - even while authors recognise that it a somewhat problematic one (Vitale 2017). Highlighting substantive issues and points of concerns here can, thus, shed light on issues of concern in other countries, too. Further, as I demonstrate throughout the book, the myths around projectile electric-shock weapons that are identified here are found worldwide. Similarly, many features of the legal framework, policies, guidance, and training which I critique here are not unique to England and Wales. Rather, as I demonstrate in Chapters 6, 7, and 8 similar systems can be found worldwide, sometimes with explicit recognition that they are based on a 'UK model' or with explicit exhortation to agencies to adopt such a model. As such, providing critical analysis of such systems is more important than ever - particularly in light of TASER's rapid expansion across the globe.

\section{Methods}

This book aims to provide one such analysis by drawing on a range of methods. It benefits from unique, unprecedented access to the police and extensive qualitative research at three anonymised police forces in England and WalesCountryshire, Townsville, and Big City-between 2013 and 2019, as part of an ESRC funded $\mathrm{PhD}$ and post-doctoral research award. Countryshire and Townsville were selected following a presentation at the Association of Chief Police Officer's National Conference on the use of Taser, where I outlined the planned research and asked for interested forces to volunteer. As the 
research progressed, Big City also volunteered to participate in the research at a later date.

As the names suggest, Countryshire covers a mainly rural area, Big City's remit includes a large urban area, and Townsville covers some rural areas, towns, and a city. Taser is available to firearms officers and specially trained non-firearms officers (often referred to as Specially Trained Officers, or STOs) in all three forces. Officers are also equipped with other force options, including irritant spray and batons.

A range of research activities were conducted in the three forces, including interviews with officers ${ }^{11}$, the observation of TASER initial and refresher training, officer safety training, and observation of TASER trained officers on patrol (sometimes referred to as 'ride-alongs'). To the author's knowledge, this is the first time an academic has been given such extensive access to use of force training in individual police forces (for example, previous work by Buttle 2007 and Cushion 2020, focused on training in just one force, and did not look at TASER). This was also complemented by unique access to the College of Policing's three day Lead Instructor's Training. My focus here is on understanding how officers and trainers - those most closely involved with the everyday use and roll out of TASER on the ground-use, understand, talk about, and experience the weapon, as well as how training, guidance, and accountability operate in practice ${ }^{12}$.

As such, the primary focus of this research is on police officers; on their guidance, training, and decision making around TASER, and their views on the weapon. As Lipsky (2010) has underscored, police officers-in keeping with many other 'street-level bureaucrats' — can wield considerable power and it is important that this power is investigated and held to account. However, the police are central to our lives (Banton $1964 \mathrm{ix}$ ) and have legal powers that can far surpass those of other 'street-level bureaucrats' - up to and including the right to use force and even to take a life, in certain circumstances. When this is combined with the extraordinary capabilities associated with TASER, it is crucial that this power is investigated and held to account.

Yet I was also keen not just to speak with police officers, but also to speak with those who might have a different perspective on the weapon: in particular, individuals who had been subject to TASER and their representatives. This is important as very few works have looked at this area (Rojek et al 2012) or at the consequences of police use of force for those subjected to it and, as such, our understanding in this area is 'underdeveloped' (Meade et al 2015: 1). In order to address this gap, three main methods were used. First, a search of academic and non-academic sources (NGO reports, newspaper articles, radio interviews, blogs, and other fora, gathered through systematic online searches) was conducted to gather testimony from people subjected to the weapon. Second, auto-ethnographic techniques-volunteering myself to be exposed to the weapon in probe-firing and drive-stun mode and reflecting on my own experiences-were also used to generate new insights into the topic in question. 
Third, interviews with people affected by TASER and/or their representatives were conducted. Lawyers and advocacy organisations working with those subjected to TASER were contacted to ask if they would be interested in being interviewed for the research. They were also asked to consider forwarding my details to other lawyers and representatives, who might be interested, and to clients who were deemed at a suitable stage in their legal proceedings, and to be mentally well enough, to provide informed consent to the research, should they be interested in participating.

As a result of these enquiries, I was able to secure interviews with five legal representatives/advocates, who circulated details of my research to their clients, and to interview three people affected by TASER. I also observed the Inquests into the tragic deaths of two young men, Jordan Lee Begley ${ }^{13}$ and Marc Anthony Cole, that juries linked more than trivially and/or minimally to the use of Taser, and two court cases ${ }^{14}$. The first court case involved an alleged assault by Claire Boddie, an Avon and Somerset police officer, and involved the use of TASER against Ras Judah Abundi. The second so-called 'W80' case, named after the pseudonym given to the officer, arose from the death of Jermaine Baker (for background to this case and the IOPC's views on it, see IOPC 2019).

I discuss this part of the research, research methods, and limitations in more detail in Chapter 4, but for now note that, despite the relatively small number of interviews, it seems important to include such experiences here, as they are an important and valid part of a much broader range of experiences around the weapon. Moreover, proponents of the weapon often face fewer barriers to getting their voice heard than those who have had negative experiences (Bowling and Marks 2008). For example, following the death of brother, Marc Cole, in the circumstances described above, his sister Lisa Cole noted that 'you are gagged, you don't really have a voice. You are marginalised as a family' (in Morris 2020). It is important to make space to hear 'marginalised' voices from those who may otherwise have trouble getting their voices heard, particularly in the context of pervasive myths around the weapon. Such accounts can also provide a useful counterpoint to a debate dominated by quantitative analysis of officer accounts.

Finally, the research also benefitted from a number of international trips and research visits. These included a trip to the Headquarters of Taser International (now Axon) which was funded by the company and where I had the opportunity to meet senior officials and researchers associated with the company and to be exposed to TASER (as discussed above). I also helped lead a number of international workshops organised by various UN agencies and/or the Organisation for Security and Co-operation in Europe. This involved working with human rights bodies and torture prevention monitors in Poland, Slovenia, Uzbekistan, and elsewhere, on issues around use of force. These rich experiences gave me the opportunity to put discussions around the use of TASER in England and Wales into a broader international context, 
to develop my understanding of issues around the use of less-lethal weapons worldwide, and draw out valuable points of comparison and contrast.

In total, more than 350 hours of observations and over 60 interviews were conducted. The evidence generated by these methods was coded and categorised into different themes. These categories were identified according to their frequency and prominence, as well as with regard to any contradictions within and between interviews, interviewees and different research methods. This was combined with analysis of publicly available documents and statements from the College of Policing, the National Police Chief's Council, the Independent Office for Police Conduct, Her Majesty's Inspectorate of the Constabulary and Fire and Rescue Services, and weapons manufacturers in order to better understand the way in which the weapon and issues around it are presented to the public.

\section{Book structure and overview}

Drawing on these aims and research methods, the book is structured so as to explore and challenge a set of distinct yet inter-related myths around projectile electric-shock weapons, with most chapters dedicated to examining a particular myth in detail. At first glance, a focus on myths might sound strange. Myths are commonly understood as traditional stories typically involving supernatural beings and are often focused on creation stories and on the origins of particular behaviours, institutions, and societies (Eliade in Engel 1993). Some elements of these traditional myths can be found in the debates around projectile electric-shock weapons. For example, as we will see in Chapter 3, these weapons have their own origin mythand, as will be discussed in Chapter 4, are described as having almost supernatural powers, with the ability to 'take over' one's body. Yet not all myths are fantastical, supernatural, and immune to empirical examination. As Meyer and Rowan (1997) argue, post-industrial society is characterised by the existence of 'rational myths' (Meyer and Rowan 1997, see also Edelman et al 1999). Far from being far-fetched, these myths are so convincing that they are often 'taken for granted as legitimate' (Meyer and Rowan 1997: 340), spread rapidly across organisations and individuals and are seen as having considerable power to (re)define situations, organisations, and behaviours.

This second meaning is also at play in the debate around projectile electricshock weapons and throughout this book. It should be noted then that the use of the word myth does not imply a completely implausible, illogical, or otherworldly story or narrative. Instead, I will argue that it is precisely because these narratives appear so convincing, and so common sense, that they need careful examination. Put another way, the task is not to somehow reveal whether particular beliefs around technology are a 'myth' or are 'reality' but to examine the ways in which they may be myths and realities, may be fact and fetish simultaneously (Latour 2011). 
As such, to say that such statements constitute a 'myth' does not mean that there is no validity to them at all. Indeed, projectile electric-shock weapons such as TASER are a popular use of force option for police officers, bring a range of benefits and can have an important role to play in policing under certain, limited circumstances. Yet, as Latour (2011) reminds us with his discussion of 'factish', there are inherent limits to attempts to draw distinctions between 'fact' and 'fetish', to separate the knower from the known, belief from reality and to centre one's world view around binary either/or distinctions. Further, then, as Kurki (2017) reminds us, it is important to look at how claims about myth, reality, and fact operate, and what consequences they have. After all, myths fulfil a number of roles in post-industrial society (Meyer and Rowan 1977). As Brown (1994: 863) notes, myths can permit and legitimise certain actions and, simultaneously, 'shape and conceal political interests'. Far from being neutral or inevitable, they are a means by which individuals, groups, and organisations can legitimise their actions and so maintain their successful, privileged position (Brown 1994: 863, see also Waddington 2011).

Taken as a whole, then, the myths discussed in this book not only seek to explain why projectile electric-shock weapons have become so popular but also help justify and legitimise this popularity, to the benefit of powerful vested interests, multinational corporations, and what has been described as a 'police-industrial complex' (Brodeur 2010). This popularity makes it even more important that the myths around the weapon-particularly the myths and narratives presented by those in positions of power and those advocating for the weapon-are critically examined. In so doing, it is not my intention to formulate a final analysis of whether such beliefs constitute a 'myth' or 'reality; but, rather, to see them as myths and realities, exploring their constraints as well as their possibilities and productive capabilities.

Chapter 2 reviews the mainstream theories in policing and the literature around police use of force and projectile electric-shock weapons, arguing that, while they have advanced our understanding in multiple, complex ways, they are insufficiently attentive to technologies, the role they can play, and the way they can impact individual officers, police agencies, and the police role more generally.

Each of the following chapters examines, in turn, a key myth around the use of projectile electric-shock weapons, often drawing on concepts from STS in order to do so. Chapter 3 addresses what I argue is a widespread 'origin myth' of electric-shock weapons as an alternative to firearms, which is, itself, underpinned by broader beliefs about technological innovation. I critique these accounts, provide evidence that projectile electric-shock weapons are not used as an alternative to firearms and develop my own, alternative narrative about their origins. Chapters 4 and 5 address the myth that projectile electric-shock weapons are, respectively, 'nicer' and safer for members of the public and safer for police officers than other alternatives. 
In so doing, Chapter 4 aims to give a voice to the views and experiences of some of those who have been subjected to TASER, negatively affected by it and/or have lost loved ones following its use. Far from describing the weapon as a 'nicer' alternative, these interviews highlight pain, fear, humiliation, and loss of control and locate these experiences in broader concerns about the weapon being used disproportionately on Black people and those experiencing mental health crisis and ongoing doubts about whether it was necessary or appropriate to use the weapon. Chapter 4 also uses Law's (1992, 1999, 2009) notion of technical development and engineering as a multifaceted 'heterogeneous' process to help understand how, despite this powerful evidence, claims about projectile electric-shock weapons being a 'nicer' form of force come to seem real and appear persuasive. Chapter 5 looks at officer views of the weapon and its impact on their safety. It demonstrates that, while the technical features of the weapon appear to enhance officer safety, the broader frameworks and arrangements around it may be putting officers at more risk.

Having interrogated and critiqued myths around how electric-shock weapons are used in practice, the remaining substantive chapters address the regulatory framework around the weapon. Chapters 6 and 7 are concerned with dispelling myths as to the content, quality, and quantity of the training and guidance. In Chapter 6, I provide an introduction to the legal framework, training, and guidance, both in England and Wales, and internationally, and argue that these mechanisms fail to provide sufficient advice to officers about when, how, and under what conditions the weapon should be used. Instead, they simply devolve these decisions down to individual officers. After providing, in Chapter 6, a detailed analysis of the content of guidance and training, in Chapter 7, I critique the implicit (and sometimes explicit) beliefs that underpin them. Specifically, I critique the myth that decision making around TASER is, and should be, an individual responsibility for individual officers, and the complementary myth that TASER and, indeed, technologies more broadly are no more than mere tools. In Chapter 8, I argue against the view, held by police agencies and oversight bodies alike, that there is 'robust' accountability when police officers use the weapon. Instead, I demonstrate that there are a number of barriers, such that-even with the in-built accountability features of the weapon-it is almost impossible to hold officers to account for their use of force, including electric-shock weapons. The final chapter concludes and provides recommendations for theory, practice, and policy.

Further, the book is structured so that each of these empirical chapters also engages with key debates in policing and criminology more broadly. These include technological innovation in policing (Chapter 3), methodological debates, the importance of qualitative, mixed methods research and 'following the actors' (in Chapters 4 and 5); police discretion (in Chapters 6 and 7), police subculture (Chapters 5 and 7), and accountability (Chapter 8). 
Overall, the picture that emerges is that the effects associated with projectile electric-shock weapon are more wide-spread than is often claimed, while the regulatory and accountability frameworks surrounding it are less wide-spread than they should be and require urgent improvement. In short, a convincing case can be made that such weapons are over-used and under-regulated. Overall, then, claims that they are alternatives to firearms, are a 'nicer' form of force for members of the public, are 'safer' for officers, and are subject to strict guidance, training, and accountability mechanisms should be treated with a considerable degree of scepticism. This particular take is, of course, just one (highly contested and constructed) account and should be assessed as such-but nevertheless has such concerning implications that demand careful consideration and action.

\section{Conclusion}

I argued at the start of this introduction that my experience of being Tasered is of interest because it is increasingly commonplace. I wish to close the chapter by noting that it is also of interest because it is unique. After all, I am in an unusual position. Unlike many subjected to the weapon, I am in white, middle-class and in good health, have been exposed to the weapon in a controlled and safe environment and-crucially-have volunteered to be Tasered, in order to enhance my research on the topic. I am also in a position to be able to write and publish about the experience from a position of (some) credibility that many of those who have been subjected to TASER lack (Sussman 2012). This book is my attempt to do just that, and I return to issues around the use of the weapon, and those on whom it is used, shortly. First, however, I seek to put debates around TASER into their broader context by situating it in the criminology literature.

\section{Notes}

1. The term TASER, TASER X26, TASER X2, and TASER T7 are trademarks of Axon (previously TASER International, Inc.), some of which are registered in the United States and in other countries. All rights reserved. At the time of writing, several different Taser models, including the single shot X26 and dual shot weapons the X2 and T7, were authorised for use in England and Wales.

2. They are markedly different from contact electric-shock weapons-such as stun 'guns' or stun 'batons' - which need to be pressed directly up against the individual to result in a shock and which do not incapacitate in the same way.

3. For example, SACMILL have noted the neuro-muscular incapacitation associated with different TASER models (see e.g., SACMILL 2016).

4. According to the Home Office (2019a), the use of Taser in probe firing mode was reported 2, 585 times between the 1st April 2018 and 31st March 2019, roughly equating to seven times a day. This is an average, approximate figure but, of course, some days will have more Taser discharges than others.

5. The term less-lethal, as opposed to non-lethal, is used throughout this book in recognition of the fact that lives have been lost following the use of such weapons (see, for example, Haar et al 2017). 
6. This term was used on the use of force monitoring form in England and Wales and is to be changed to a more appropriate term from 2020/21.

7. When compared to use of force incidents where officers had carried TASER but neither drawn or fired it. Odds were relative to a person perceived to be White or White British and a person perceived to not have a mental disability, respectively.

8. This term is favoured over commonly used terms such as conducted energy/electrical weapon (CEW) or conducted energy/electrical device (CED) because it offers a more precise characterisation. A range of different technologies could be described as 'conducting energy', in one form or another.

9. Although dated 2016, this was the most recent trademark policy document available on the Axon UK website at the time of writing. In cases where I am quoting directly from a source that has used the term without capitalisation, I retain the original usage. For ease of reading, the term also appears in lower case when it forms a part of a longer word (e.g. 'tasered', 'tasering').

10. Further, Bijker (2010: 63) notes that 'constructivist technology studies can be agnostic about...(the) idealism-realism question: both ontological positions are compatible with constructivist sociology of technology, and the sociology of technology cannot provide empirical arguments to choose for either ontological position' (also see Whittle and Spicer 2008, and Mackenzie and Wacjman 1999: 32).

11. In Countryshire, 21 individuals were interviewed, 2 of whom were TASER trainers and/or single points of contacts, and 3 of whom were officer safety trainers. 3 interviewees had oversight of TASER trained officers (typically at the rank of Sergeant or higher) and 13 of who were TASER trained officers or were in training to be (these included 8 males and 5 females, typically lower ranked). In Townsville, 10 individuals were interviewed, comprising 2 TASER trainers and/or Single Points of Contact, 1 individual with oversight of TASER trained officers, and 7 TASER trained officers (four males and three females). In Big City, 19 individuals were interviewed. This included 6 STOs, 10 TASER and officer safety trainers, and 3 individuals participating in their Initial TASER Training. TASER trainers in 3 other forces (who were participants on the College of Policing Lead Instructor Training) were also interviewed.

12. In order to enhance transparency while also maintaining anonymity, I adopt a number of measures throughout the book. When quoting from interviews conducted with officers, I specify the force (Countryshire, Townsville or Big City) to which the officer belongs and cite their interview number (for example, Officer 1, Countryshire, to represent the first interview conducted in the Countryshire force). When quoting trainers, I similarly list the interview number in cases where the quotes were taken from interviews or otherwise, specify the context in which comments were made (most often during training). As there are fewer TASER trainers than TASER trained officers, I do not specify the force they are attached to, in order to minimise the risk of inadvertent identification. On occasion, I also use pseudonyms for individuals and for police forces (see Allen and Wiles, 2016 for details on the importance of anonymisation and pseudonymisation). For reasons of clarity, pauses, repetitions, and fillers such as 'um' or 'err' have been removed from the interview extracts used.

13. Also known as Jordon (IOPC 2018a).

14. Throughout the book, I sometimes make reference to and/or quote from these judicial and coronial proceedings, drawing on my contemporaneous notes. While I have endeavoured to make these as full, precise, and comprehensive as possible, as no recording is allowed of court proceedings I cannot guarantee they are a completely accurate, word by word account of what was said. 


\section{Technologies, tools, and TASERs}

\section{Introduction}

As the introductory chapter has demonstrated, in order to understand projectile electric-shock weapons such as TASERs, we need to examine not only the literature pertaining to the weapon itself, but the broader literatures and theories around police use of force, discretion, technology, and technological change. This proves quite a challenge, however. Theories of policing and, in particular, theories pertaining to police use of force are underdeveloped (Ariel et al 2019; Terrill 2014). As I demonstrate here, those that do exist can be described as inherently human centric in nature. They are insufficiently attentive to technologies, the role they can play, and the way they can impact individual officers, police agencies, and the police role more generally.

This chapter is structured as follows. I start by discussing the limited literature around projectile electric-shock weapons-which focuses, almost exclusively, on TASER - and the use of force more generally. I demonstrate that, focused as it is on human agency, the injury potential of different force options and police militarisation, it is largely inattentive to the role and agency of weapons technologies. In the second part of the chapter, I demonstrate that such limitations are also found in each of the main theories of policing, from macro approaches (consensus, conflict, and predatory policing approaches) to micro and 'transformational' (Reiner 2010) approaches. In sum, while the existing literature on TASER, the use of force and broader theoretical debates in policing can aide our understanding in many ways, it is often unable to adequately conceive of the full role, scope, and impacts of technologies such as less lethal weapons.

\section{Technologies and debates around use of force}

The existing literature on TASER and use of force can be broadly divided into three categories. Firstly, much work is closely associated with the concept of police discretion, commonly understood as freedom to choose (Davis in Holmberg 2000) or 'decisional freedom' (Bambauer in Joh 2016: 15). 
It is commonly understood that, in decisions around use of force-as in many areas of policing-officers have considerable flexibility around what action(s) to take and indeed, whether to act at all. Terrill and Mastrofski's (2002) classic study differentiates between two approaches explaining discretionary decisions around the use of force: a psychological approach which focuses on the characteristics, experiences, and views of police officers and a 'sociological perspective' that focuses on the characteristics and behaviours of those subjected to force. Despite their differences, both approaches focus on human characteristics in use of force outcomes, be it at the level of the officer, the civilian, or both. Later work by Paoline and Terrill (2007) differentiates between situational variables (including the number of officers and bystanders at the scene), offender level variables (including sociodemographic characteristics and their level of resistance), and officer level variables (including education and length of service) that impact use of force decisions. Bolger's (2015) meta-analysis similarly differentiates between 'encounter' or situational characteristics (including the resistance offered by the member of the public and incident location), characteristics of the member of the public, officer characteristics, and community and neighbourhood characteristics that may help explain the use of force in general. A related strand of work focuses on identifying factors associated with the use of specific use of force options (Avdi 2013; Crow and Adrion 2011; Dymond 2018; Gau et al 2010; O’Brien et al 2011; Quinton et al 2020; Sousa et al 2010; Stroshine and Brandl 2019, White and Ready 2010), almost always in the USA and often looking at the use of TASER.

While findings from these studies are mixed, these works provide some evidence that use of force is impacted by civilian characteristics (including mental health and ethnicity, a point to which we will return in the next chapter) and situational variables (including the number of police officers and the reported conduct and behaviour of the member of the public), with officer level variables seen as less important. However, the differences between these categories should not be overstated, as they all focus on human attributes (for example, officer and offender characteristics), with less emphasis on technologies and other non-human influences. Indeed, previous authors have often been concerned with demonstrating that the choices officers make are 'a product of social control' and fully influenced by people' (Pepinsky 1984: 266), with other considerations downplayed (Dymond 2020). Often, too, the choice of which weapon to use is seen as something to be explained by 'social' factors. It is explicitly cast as the outcome of interest, as the dependent variable, not as an actor with explanatory power in its own right (see, for example, my own previous work on TASER; Dymond 2018, as well as works by Crow and Adrion 2011; Gau et al 2010, all of which see TASER as an outcome variable ).

Relatedly, in such conceptions, excessive use of force is seen as resulting from human intentionality (as in the bad apples hypothesis), as resulting through 
'transmission' and proximity to problematic police officers or 'bad apples' (Ouellet et al 2019), or through human omission or flaws (lack of training, inability to become a skilled user of force, continuation of a culture supportive of the use of force). As Griffin and Bernard (2003: 3) note, explanations of excessive force tend to focus on 'police subculture or personality characteristics'. Little attention is given to how excessive force may be produced, encouraged, or 'afforded' by the technologies officers carry and their characteristics.

Another strand of work within criminology explores the relative risk of injury, and other negative consequences, for officers and members of the public that are associated with different force options, again often with a focus on TASER and projectile electric-shock weapons (Castillo et al 2012; Jenkinson et al 2006; Kaminski et al 2013; Lin and Jones 2010; Paoline et al 2012; Smith et al 2007; Smith et al 2010; Taylor and Woods 2010; Terrill and Paoline 2012). Relatedly, a few studies attempt to assess the relative effectiveness of different force tactics, including TASER (Brandl and Stroshine 2017; Lin and Jones 2010; White and Ready 2010), although this literature has been described as limited and subjective (Stevenson and Drummond-Smith 2020). Unlike much of the medical and technical literature on TASER (e.g., Ho et al 2012; Jauchem 2010) this draws on and analyses police data in an attempt to assess 'real world' outcomes, not laboratory conditions (for further studies on the medical literature around TASER see, e.g., Braidwood 2009, the Council of Canadian Academies and Canadian Academy of Health Sciences 2013, and SACMILL 2016).

Taken as a whole, these strands of work are highly quantitative and tend to treat the effects of the weapon as a set of objective, given, independent facts (also see Innes et al 2005 for a similar observation in the context of crime intelligence analysis). They are seen as an 'empirical reality' (Terrill and Paoline 2012: 153) that can be demonstrated, a singular 'truth' that can be uncovered (Ho 2009; Truth Not Taser 2008), and as a set of 'misunderstandings' that can be clarified (Jauchem 2015), often via statistical analyses. These are worthy topics of investigation yet, as others have noted, few commentators ask fundamental questions about how the weapon and it's use are understood and portrayed (Anais 2015; Moreau De Belliang 2015; Rappert 2004b) and how it might be reshaping interactions between the police and members of the public. Further, with some notable exceptions (De Angelis and Wolf 2013; Rojek et al 2012), little qualitative work has been done exploring use of force guidance and training, and how it is understood and operationalised (for exceptions, see, Buttle 2007; Cushion 2020; Keating-Jones 2017). Where studies have been done they have tended to focus on capturing the range of policies available (see, e.g., Thomas et al 2010), or on the impact of a particular policy shift (Bishopp et al 2014) instead of exploring a particular policy and associated training, and its varied effects, in detail.

A final strand of work focuses on the militarisation of the police and the acquisition of new weapons, tactics, and equipment. Yet, ironically, 
technology is side-lined even in these debates. In the classic debates between Waddington (1987) and Jefferson (1987; 1990), discussion focuses on the nature and role of the police, and how this plays out and is manifested in interactions with members of the public, especially in crowd-control situations. As such, it falls back on broader questions of the function and agency of the police.

The debate may be occasioned by, and may ostentatiously be about, paramilitary policing-but often seems more about underlying debates about how to conceive of the polic, with debates about paramilitarism providing the case study or venue. Paramilitarism - and, in particular, paramilitary, quasi-military, and new technologies - are seen as a symptom, as a manifestation of, these inherent, underlying roles and functions and the technologies are rarely studied in their own right. Similarly, with the partial exception of Lawson's work (Lawson 2019), few works look at the effects of militarisation and weapons acquisition on police behaviour. As Haggerty and Ericsson (2000: 43) note, 'the issue of technology transfer constitutes an important and underexamined form of militarisation of criminal justice'. Overall, then, there is a surprising lack of literature on a topic that is central to the police mandate, and which goes to the very heart of being a police officer (Bittner 1974) and an inattention to police technologies and weapons within the existent literature.

Many of these works are underpinned, implicitly or explicitly, by what might be referred to as a 'sociologist' (Latour 1992), 'instrumental' (Bourne 2012) or 'neutral' (Kaplan 2009) approach to technologies. Under this approach, what matters is the intent of humans, not the technologies they carry - a belief sometimes summed up in the argument that 'guns don't kill people, people kill people' (Latour 1992: 31). Other implications also flow from this anthropomorphic departure point. Technologies are seen as mere tools and little attention is paid to the specific material features and characteristics of the weapon, how they come into being and the differing interpretations that may be attached to them. Instead, technologies are taken for granted. With some exceptions, by and large, their success and effectiveness (or lack thereof) are seen as self-evident and not explored further: the assumption is that, once introduced, technologies fulfil their pre-defined functions, with largely predictable results. As such, little attention is paid to the distinct contributions that technologies may make, the way in which they may make things happen, and their complex interactions with officers, members of the public, and others.

Instead, TASER and other projectile electric-shock weapons are seen as a tool, a neutral means for achieving human ends, whether positive or negative. Hence, for Jauchem, they are an 'important... tool' for officers seeking to carry out a wide range of legitimate 'law enforcement activities' (2010: 53), for Spriggs they are particularly useful as 'a tool for safely incapacitating belligerent drug and alcohol users' (2009: 515). Conversely, for others, 
TASER helps the police to 'terrorise the down-trodden' (Oriola et al 2012: 66) and 'socially disempowered' individuals and is a visible manifestation of the 'aggressive' and 'repressive' policing of the working class. For Wright, less-lethal weapons such as TASER are similarly 'tools' for 'mass repression' (1991: 35). Characterised by this 'instrumental' approach, much work on less-lethal weapons tends to assume human intentionality and neglect the non-human.

\section{Technologies and criminological theory}

Nor is this failing restricted to the literature on electric-shock weapons. Brown (2006: 225) notes, in her classic call for a 'criminology of hybrids', that the discipline has long excluded non-human entities such as technologies. More recently, Robert and Dufresne have argued that criminology still needs to attend to, and emphasise 'the relevance of technology, materiality and objects' (2015: 2) in its work. Developing this critique, I argue that instrumental accounts are widespread in each of the main criminological theories-be they macro, micro, or 'transformational' (Reiner 2010) - and the way in which they conceive of police use of force.

\section{Consensus and conflict theories}

Turning first to classic, macro level theories, both consensus and conflict approaches - and attempts to combine them-tend to assume human intentionality and to neglect the non-human. Consensus theorists, often drawing on Durkheim's work on the police (Terpestra 2011), understand the police as using force for the public good, symbolically reaffirming social norms, and protecting social order as a whole (Kitossa 2016; Lee et al 2013; Marenin 1982; Terpestra 2011). Sherman argues that police use of force is like 'a subcontract to collect garbage'; an arrangement which may leave the police with dirty hands, but which 'makes our lives infinitely more pleasant' (Sherman 1980: 2). Waddington (1987: 37) observes that the police of the nineteenth century may have appeared as 'instruments of class oppression'. However, in more recent years, decreasing levels of police violence and the reluctance of police to 'use their... coercive might to do anything that could be interpreted as the suppression of legitimate political activity' (Waddington 1994: 379) casts doubt on this hypothesis. Instead, the police are keen to assert their political independence and impartiality to prevent criminality and maintain order-although he does note that the maintenance of order is inherently 'a conservative function' (1987: 37).

Conflict or critical perspectives - with their roots in Marxist and even Weberian sociology (Terpestra 2011) — understand the police as acting less in the public good and more for dominant elites (Marenin 1982; McMichael 2017; Mitrani 2014; Petrocelli et al 2003; Shantz 2016; Vitale 2017; Wacquant 
2009). For example, O’Neill and Loftus' (2013: 439) study of surveillance finds that 'it is the poorest and most marginalized citizens in society who are becoming ever more policed'. Hallsworth and Lea (2011: 142) posit the existence of coercive security state which aims to manage a growing 'surplus' population that is structurally irrelevant to capital accumulation. Wacquant (2009: 1) notes that there is a close relationship between neo-liberalism and the punitive law enforcement policies aimed at those 'trapped in the margins'. Nor is this a recent development, as Mitrani's (2014: 1) history of the Chicago Police shows. Similarly, Vitale's work powerfully argues that the police are a tool for 'managing inequality and maintaining the status quo' (2017: 13). Mutsaers' study of police discrimination in The Netherlands (2019: 8) concludes that, when compared to the consensus model of law enforcement, conflict models have much to recommend them.

More recently, attempts have been made to go beyond these classic debates by developing new macro-level theories. One strand of work seeks to combine consensus and conflict approaches (Marenin 1982; Reiner 2010; 2012; Terpestra 2011). In a classic turn of phrase, Marenin notes that police agencies can fill multiple roles simultaneously, engaging both in 'class repression' and issuing 'parking tickets'. Others also see the police as serving multiple functions. Gerber and Mendelson's study of the police in Russia finds that officers often engage in 'predatory policing' (Gerber and Mendelson 2008), with officers motivated by individual self-interest, as well as the interests of the police as an organisation. Police officers are concerned less with maintaining order, or with protecting elites and are more focused on personal enrichment, self-preservation, and the preservation and promotion of the police themselves. As Gimbel and Muhammad (2019) note, it is not just corrupt police departments that benefit from policing initiatives such as the 'war on drugs'; such schemes also bring benefits in terms of revenue from seizures and fines and help to justify police presence and expansion. Such theories also dovetail well with critical perspectives and should not be seen as mutually exclusive (Gerber and Mendelson 2008: 5).

At the macro level, then, the emphasis is very much on police officers furthering broader human goals, be they order maintenance, elite protection, self-preservation of the police as an institution, individual, and financial interests of the police officer, or some combination of the above. Technologies simply help the police to fulfil these objectives and pre-existing goals, however these are conceived. Hence, for Waddington (1987; 1993; 1994), key debates are around which technologies and tactics are more or less effective in helping police-manage crowds and maintain order. O'Neill and Loftus (2013: 439, emphasis added) note that 'the enduring ambitions of state policing have been greatly enhanced by the dramatic expansion of technologies'. Wacquant (2009: 1) posits that punitive and proactive law enforcement policies are characterised by 'an insatiable craving' for technologies, including TASER - although he does not address this at any length. Hallsworth and 
Lea (2011: 152) argue that 'technologies of power' (2011: 142) such as CCTV, new legal powers, and crowd-control tactics help the State constitute identify and handle 'drug addicts, the homeless, (and) the permanently unemployed'. However, they pay little attention to the agency of the non-human in this rendering. Technologies are, more often than not, seen as a means to an end, a way of 'tooling up (the) leviathan' and achieving 'efficient control' of target populations (2011: 146).

Although there are fundamental differences between many of these classic works, then, there are also similarities. While these accounts may vary on the focus, aims, and theoretical underpinnings of their work, they nevertheless share a conception of technologies as a means to (various) end(s). Technologies may be intermediaries, tools to passively relay, and accomplish human goals, but they are not mediators or active agents.

\section{Interactionist approaches}

Other theories focus less on the macro and more on micro-level interactions. Drawing on Goffman's work, Rojek et al (2012) look at the use of force interactions between officers and members of the public. They demonstrate that the amount of force and coercion used in a given incident is related to the extent to which the citizen demonstrates, or fails to demonstrate, deference and respect, and the social dynamics and interactions that take place (2012; 305). Wolf and De Angelis (2011: 659) also draw on interactionist, constructivist approaches to discuss TASER in more detail, exploring how proponents and opponents of the weapon seek to construct and define the 'reality' around the weapon in different ways. They focus not on 'objective' facts around the weapon but, rather, on the ways in which constructions of the weapon and its effects are made, and challenged, by different groups. Using Goffman's notion of 'keying', they show that 'opponents' of TASER responded to claims of 'proponents' by appropriating and repurposing claims made around the effectiveness and accountability of the weapon.

Such approaches are not necessarily incompatible with more macro and conflict-based approaches (Rojek et al 2012). Nevertheless, like macro approaches, they maintain a focus on human intentionality, how humans understand and interact. Even when technologies are in the frame, they provide the backdrop against which action takes places and are not typically seen as key actors in the incident. For example, Rojek et al's research discusses a number of incidents involving the use of TASER, amongst other use of force options. However, the role of the technology is not explored in any detail and the focus is on how the different human actors interpret and account for the use of force incidents. The discussion centres on human interactions - for example, members of the public (dis)regarding officers' orders and officer decisions and responses - that make force more or less likely and how these are accounted for. There is no consideration given to how such 
interactions may themselves be shaped by the presence and affordances of different technologies such as TASER, and the kind of actions, interpretations, and accounts technologies may encourage, facilitate, or make possible.

Similarly, Wolf and De Angelis $(2011 ; 669)$ challenge researchers to 'move past simply examining the ...merits of the TASER' in order to examine the discursive struggle around the weapon and how different groups try to define and claim the 'reality' around it. This is a crucial step and this topic is both important and under-examined. Yet it may also be worth examining the reverse. Perhaps, just as groups try to define TASER, so TASER technology shapes, defines, and (dis)empowers certain groups, simultaneously constructing new interests and identities in the process.

A lack of attention to technology and a theory of how it constitutes (as well as being constituted by) the 'social' is an understandable omission in these innovative and methodologically sophisticated works. However, this omission is not restricted solely to these authors, but is found more broadly in much interactionist work within criminology. As Brown (2006: 225) notes, interactionism places a strong emphasis on the 'social construction of crime'. In such renderings, the interactions between society and technology remain underexplored, with technology often seen as socially constituted and as a means of social control. This risks neglecting how society and human action may be shaped and co-produced by non-humans and-more fundamentally-how the former cannot be understood without, and is seemingly inseparable from, the latter.

\section{Nodal security and transformative approaches}

While many of the aforementioned schools of thought have roots tracing back to the classical sociologists (Terpstra 2011), in recent years, a new perspective on policing — what Reiner (2010) calls the 'transformation thesis' has emerged. Documenting the wide range of transformations that have occurred in modern day policing and security, these approaches challenge us to move beyond the central focus on the police and to look more broadly at a range of privatised, hybrid, and transnational actors providing policing and security services. Such approaches regard the police as one of many security providers in a transnational and diversified field (Sheptycki 2012). As such, the focus is less on uniformed police patrols and more on multiple, interlocking, imperfectly connected actors drawn from a range of areas-a notion captured by terms such as 'plural policing', 'policing webs', and 'policing assemblages' (Brodeur 2010).

Whatever terminology is used, such notions rightly draw our attention to actors beyond the traditional police service. Yet, more often than not, these actors tend to be exclusively human in origin. Take, for example, Shearing and Johnston's (2010) conceptions of 'security governance' and 'nodal governance', which posit that the police are just one node among many in 
networks that act to govern security in more or less streamlined ways. On some occasions, Shearing and Johnston pay little attention to technologies in their description of the nodes in the networks. Nodes are seen as entities comprised of 'individuals, groups (and parts of groups), organizations (and parts of organizations) or states' (2010: 502). In other descriptions, nodes are seen as being comprised of four 'elements': 'mentalities (relating to how nodes think about security); technologies (relating to the methods they might use to facilitate it); resources (relating to the social, cultural, economic or other means they might deploy in its furtherance); and institutions' (2010: 495). While this description has a place for technologies, they are again seen as a means, a 'method...to facilitate' different ends. Thus, despite acknowledging that technology is 'vitally important' (Shearing 2005: 58), it is hard to argue against Brodeur's claim (2010: 305) that the governance of security perspective tends to ignore technological developments and 'is more relevant for...understanding...manned security than for explaining the proliferation of security equipment and its impact on policing'.

Perhaps this critique can also be extended to the transformation thesis more broadly. For example, Sheptycki's (2002: 330-311) work on post-modern policing looks at different 'sectors of the field', including police detectives and the secret service, but also encompassing corporate security guards and specialists, private security guards, and private investigators. In this discussion, technologies are mentioned fleetingly, if at all, and are seen simply as tools. He notes, for example, that 'access to secure sites...is frequently controlled by a variety of technical devices... tools by which the guardians of corporate 'territory' perform their roles'.

Moreover, even when writers in this vein attend to technologies, they are often focused, at least in part, outside of the police and seem reluctant to turn their gaze inwards. Haggerty and Ericson's (2000) fascinating work on the 'surveillant assemblage' captures the meshing of human and non-humanvia, for example, the creation of 'data doubles' - as well as the transformatory potential of such hybrids. For Haggerty and Ericson, desires for control, governance, security, profit, and entertainment energize the surveillant assemblage, a provisional, contingent entity that includes and merges together the human and non-human. Components include CCTV, police databases and drug tests, forensic laboratories, implanted silicon chips, social workers, and health professionals. Police and state agencies are certainly present in Haggerty and Ericsson's fascinating account, but the surveillant assemblage reaches beyond the police and is characterised by transformative effects in a number of areas, from policing to insurance, marketing to medicine. Yet it would be equally interesting to explore human and non-human assemblages within the police and to address what implications technologies have for the police role itself.

Moreover, despite Brodeur's $(2010 ; 301)$ plea that 'the scope of the investigation (should) be extended beyond the people involved in private policing 
activities and also include police technology', and that analysts should not ignore the 'crucial technological component' of the policing web (see also Diphoorn and Grassiani 2016), his own work is not immune from this critique. Noting that 'security technology', in particular, intermediate weapons such as TASER have 'the potential for transforming policing'. Brodeur briefly discusses some of the issues around the security manufacturing industry, and TASER, in particular, identifying a number of issues with their use. Yet only a small part of one chapter of The Policing Web is dedicated to a discussion of technology, and Brodeur (2010: 4) sets out the key components of the policing web as being predominantly human in nature, encompassing 'the uniformed constabulary, criminal investigation, the political police and police informants and private security'. As Brodeur himself notes, the discussion around technologies and the notion of a police-industrial concept contained in the book are 'still too hypothetical and is meant above all to stimulate further research'. Overall, then, as Diphoorn and Grassiani (2016: 431) state, there is a need for further attention to the non-human within the transformation approach-and, I would argue, more broadly within criminology.

\section{Conclusion}

The theories outlined in this chapter have advanced our understanding of the police role and police use of force, in particular. Macro-level theories debates have enhanced our understandings of the role of the police, broadly conceived; of why, when, and on whom force may be used; and how police actions may be in the service of multiple aims simultaneously. Such theories remind us that, even when the police issue 'parking tickets' and use force for some vaguely defined notion of a broader 'societal good', they retain an oppressive, critical edge-and that police use of force cannot be understood without this context. As Waddington (1987) demonstrates, order maintenance is inherently and inescapably conservative, inevitably privileging the status quo and those who benefit from it. Micro-level, interactionist theories have enhanced our understanding of the interactions between officers and members of the public that comprise use of force incidents and the discretionary decisions that officers make. They have also clarified the importance of social dynamics in discretionary decisions, while noting, again, that such dynamics do not occur in a vacuum and are inseparable from the 'class, race, and gender of the citizens' (Rojek et al 2012: 323). Nodal security perspectives broaden our focus away from the police, to policing agents more broadly, and focus on networks, assemblages, and actors that need not be (but yet often are) purely human in nature.

Nor should such traditions be seen as mutually exclusive. Precisely because of their unique ability to use force in situations where it may be required, the police have the potential to do good, preventing and minimising severe harm to others. Yet, precisely because of the unique power they possess and 
their unique mandate to maintain a social order which — in today's societyis profoundly unequal, rigged against the poorest and most vulnerable, and striated with ethnic and other forms of bias, the police also have the potential to cause great harm. Too, as interactionist work by Rojek et al reminds us, while use of force incidents take place against this backdrop, and share many common features, each incident is also unique and shaped by the specifics of the interaction, those in attendance and the roles they adopt.

While these theories bring many benefits, they are-as this chapter has shown-implicitly (and sometimes explicitly) 'instrumental' in their approach, often highly human centric and tend to ignore or minimise the role of technologies altogether. As such, while consensus, conflict, critical, predatory, and interactionist approaches may differ greatly in their understandings of the role of the police and police use of force, they are united by their human centric assumptions and the lack of attention given to technologies. While 'transformation' approaches (Reiner 2010) are more attentive to technologies and non-human actors they tend, too, to prioritise the human and to look beyond the police and not within them.

Hampered by their notions of technologies as 'tools' with predictable effects, the literature on TASER and police use of force-and it's focus on discretion, militarisation, and quantitative assessments of injury rates and factors associated with the use of different force options - remains less well placed to attend to the ways in which technologies may interact with humans and non-human to provide a range of unexpected outcomes. Hence, although the literature on police use of force has enhanced our understanding in many ways, there is much more to be done.

Instead of conceiving technologies as mere tools, it seems important to explore how they can interact with officers and members of the public and how they may impact how force is used and experienced. Instead of assuming that police weapons are successful and effective, it seems prudent to question how they came to be seen as such and how they came to be adopted. Instead of looking just at the 'empirical reality' (Terrill and Paoline 2013) around weapon use, it seems important to look at what stories and myths arise around them. I think this will help us to further interrogate the power and influence held by the police and by external actors; to look at how such power arises and operates in practice; and to complement the valuable insights from critical and interactionist approaches. In turn, perhaps this can help to identity new points of purchase, opportunities for challenge, and ways of reimagining the role of the police. I start this journey by turning in the next chapter to one of the foundational, origin myths of electric-shock weapons; that such technologies provide an alternative to the use of firearms. 


\section{'Better stunned than gunned'? Origin myths and mission creep}

\section{Introduction}

The claim that projectile electric-shock weapons protect life by providing an alternative to the use of firearms is one of the most oft-cited rationales for their adoption and use. Such claims make for an appealing 'origin story', purportedly explaining the creation and success of the weapon, but have been subject to little academic scrutiny or empirical examination (Ferdik et al 2014; Neuscheler and Friedlin 2015).

This is critically important in its own right - to the extent that no book on the topic would be complete without addressing this issue. Yet it is also important because it reveals a set of underlying assumptions about technologies. It is often assumed that humans see a problem, gap, or area to address (such as deaths from firearms shootings); technologies (such as projectile electric-shock weapons) are designed to fulfil that gap; those that have been well-designed and are technically superior are adopted; once adopted, they fulfil their promise and help to resolve the initial problem. The end result is a world in which people are 'stunned' rather than 'gunned' (Nova Technologies quoted in Dymond and Corney 2014). I set out this 'conventional' myth-of electric-shock weapons as an alternative for firearms - and the various beliefs that underpin it in the first part of this chapter. While such claims are often espoused by proponents of the weapon, I also demonstrate that opponents and other interlocutors in debates around technological developments often share many of these underlying beliefs.

In the second part of the chapter, I challenge the myth of projectile electricshock weapons as a substitute for firearms, by reviewing the academic literature on the topic and providing empirical evidence to the contrary ${ }^{1}$. I present evidence which suggests that projectile electric-shock weapons have been associated with lethal outcomes; that projectile electric-shock weapons are used when lethal force is not justified - and that this use is patterned by a number of factors, including ethnicity and mental health — and that they are not used when lethal force is justified. I also suggest that the introduction of projectile electric-shock weapons has not had a readily observable impact on the number of shootings in a number of police forces and jurisdictions, including England and Wales. 
I then move onto address the underlying assumptions about the role of technology in policing which underpin this myth. In order to do this, I set forward my own origin myth of the weapon, inspired by Callon's (1986) notion of 'translation'. I advance an alternative interpretation that, far from the weapon being successful because it satisfied pre-determined objectives and intentions, it was successful because it altered these objectives. In so doing, I put the notion of 'mission creep' - the process by which objectives around a technology are changed and a common critique of projectile electric-shock weapons - on a firmer theoretical footing. Yet I also suggest that while some degree of mission creep has occurred, it may not be in the way that is often implied by critics and NGOs. I conclude by discussing the implications of this account for our understanding of projectile electric-shock weapons, for commonly held beliefs around technology more broadly, and for Callon's theory of translation.

\section{Conventional origin myths}

\section{Projectile electric-shock weapons as an alternative to firearms}

It is a widely held tenet that projectile electric-shock technologies save lives. In the words of Nova Technologies, as detailed above, people are 'better stunned than gunned' (quoted in Dymond and Corney 2014). In the words of Axon, their TASER weapons 'help protect life' (Axon undated, b). The company website claims that over 240000 lives have 'been saved from death or serious bodily injury' (Axon undated, b) and studies 'partial(ly) funded' by the company have claimed a ' $2 / 3$ reduction in fatal shootings when CEW (Conducted Electrical Weapon) usage is not overly restricted' (Kroll et al 2019: 1). Information on Axon's website describes the company's Chief Executive Officer and Founder, Rick Smith, as 'a pioneer of technology with the vision of making the bullet obsolete' (Axon undated, c). The website further claims that:

'TASER weapons exist to save lives. Law enforcement officials rely on our weapons to protect life... Our Smart Weapons specifically target the motor nerves that control movement, which enhances the effectiveness of restraint while minimizing harm-an alternative far superior to using firearms in many contexts'.

(Axon undated, d)

Similarly, Brazilian company Condor Non-Lethal Technologies (undated) state that so-called 'non-lethal' technologies can 'substantially reduce the number of cases needing the use of firearms'. Russian company March Group (undated b: 7) describes their electric-shock products as 'designed to 
temporarily incapacitate a person while reducing the likelihood of serious injuries or death'.

This idea of projectile electric-shock weapons saving lives is also perpetrated by governments and police forces in England and Wales and further afield. Internationally, the original objectives, stated rationales, and claims made for less-lethal weapons were closely associated with lethal force. For example, the 1968 Report of the National Advisory Commission on Civil Disorders in the United States of America recommended that officials 'develop guidelines governing the use of control equipment and provide alternatives to the use of lethal weapons' (Davison 2006: 3). Similarly, in 2004, the then Home Secretary, David Blunkett, stated that he had authorised Chief Constables across England and Wales to make TASER available 'as a less lethal alternative for use in situations where a firearms authority has been granted' (as reported in BBC News 2004) - implying that TASER would be used to save lives in situations where firearms would otherwise be used. Furthermore, the Metropolitan Police's review of the TASER pilot (as cited in Rappert 2007a: 479) noted that:

'On almost every occasion that it has been 'used' it has provided a positive outcome to a violent incident allowing officers an alternative option to that of reverting to conventional firearms. It is no coincidence that the number of police shootings has been significantly reduced since its introduction...the option to avoid recourse to conventional firearms is welcomed by all. There are many instances where those who have been the subject of a Taser discharge would have been shot with conventional firearms had the officer not had a less lethal option'.

Recalling his involvement in the introduction of TASER, Dr. Peter Neyroud, QPM, CBE, who at the time was the deputy chief constable of West Mercia and the head of the Association of Chief Police Officers' firearms committee, noted that 'my main motivation was to reduce the number of fatal shootings by police and, especially, give the police more options to prevent the need to use lethal force when handling the mentally ill armed with edged weapons'. He notes that, amongst other influences ${ }^{2}$, important factors included concerns raised by the Home Secretary about a cluster of fatal shootings by the police and the need to review the Police Use of Firearms Manual against the requirements of the European Convention on Human Rights, following the passing of the Human Rights Act in 1998, which meant a shift towards 'absolute necessity' for the test for appropriate use of force (email correspondence with author).

Similar appeals to the ability of projectile electric-shock weapons to save lives and reduce the use of firearms have been reportedly been used by the police in Nigeria (Alternative Africa 2019), India (The Indian Express 2020), Australia (Crime and Corruption Commission 2010), and the United States of America (New York Times 2016), amongst others. 
The idea that such weapons are an 'alternative to firearms' and can help 'protect lives' is implicitly or explicitly endorsed by many academic papers on the topic. Some studies-although not many-have examined the topic directly. A study commonly cited in support of this claim is Ferdik et al 2014 (see, for example, discussions in Axon undated, d; Neuscheler and Friedlin 2015). Ferdik et al.'s (2014: 1) work in the United States of America looked at the association between different policies on the use of projectile electricshock weapons and fatal shootings by the police and found that 'less restrictive CED (Conducted Energy Weapon) policies are associated with increased CED usage and fewer fatal shootings by police'. Further evidence was provided by Jeffrey Ho and Donald Dawes (Ho et al 2007), both of whom were described, at one stage, as 'own(ing) shares of stock in the company (TASER International' (Ho et al 2012). They analysed over two thousand incidents involving mentally ill or suicidal people who were voluntarily reported by police agencies to TASER International and found that 'deadly force would have been justified in almost $50 \%$ of the reported encounters during the study period if not for the presence of a CEW... (translating) to more than 1100 lives potentially saved over a 6-year period' (Ho et al 2007: 783). Sousa et al. (2010: 35) conducted a randomised control trial where American police officers were randomly given (or not given) TASER and were then asked to participate in different training scenarios. They found that officers equipped with TASER were less likely to discharge their firearm when faced with a potentially lethal situation (in this case, someone armed with a 'cinder block' who was advancing on officers).

\section{Broader beliefs about technologies}

In such accounts-provided by corporations, politicians, police chiefs, and academics alike - the focus is on (benign) human intent and technological superiority. Under this narrative, far-sighted 'heros' (description of Jack Cover, the inventor of TASER, in Woo 2009) and pioneers had a noble desire to prevent the use of bullets and reduce police shootings. Projectile electric-shock weapons were designed to meet certain criteria in order to satisfy this need and address this problem. They became successful due to their technical superiority and success in so doing. For example, an obituary of Jack Cover explains how 'US authorities were searching for a weapon to subdue an attacker without killing him. Their need was met by Jack Cover, inventor of the TASER stun gun' (The Independent 2009).

Many academic studies, too, make assumptions about the technical superiority of the weapon and the intent and design motivation behind it. For Bleetman et al. (2004: 136), they are 'designed to act as a low risk replacement for police firearms' and for Ferdik et al, they are 'intended to reduce citizen deaths resulting from police use of force'. White (2014: 6) argues that TASER results from the desire of innovative police departments to 'reduce 
the potential for encounters to end in lethal force', and its popularity is a 'rational consequence' of the interplay between the innovators, the environmental context, and the weapon's 'key features' (2014: 6).

Such assumptions make for a compelling and satisfying origin myth; one that is not just about electric-shock weapons but about technologies in policing-and in other domains. New inventions are often assumed to have been adopted because they are technically superior, capable of fulfilling pre-determined criteria for use, and satisfying human desires and intentions. Pre-existing human intent is crucial and it is the vision, intention, and perseverance of a few good men (from inventors such as Cover and Smith to States and police forces aiming to end killing), combined with the technical superiority of the weapon, which explain their adoption. Once adopted, technologies have predictable outcomes, overcoming the problems that prompted their introduction.

\section{Differing conclusions, similar beliefs?}

These beliefs are so pernicious that even the counter-narratives and alternative 'origin myths' around technologies-which often focus on the notion of mission creep - rest on some of these assumptions. The term mission creep traditionally captures the notion that there has been a shift in how a particular technology is used, such that it has drifted away from its intended objectives. It is used widely in discussions around a range of actors, to describe organisations as varied as the World Bank (Einhorn 2001) and Universities (Gonzales 2013) to technologies including new-born screening (Wilcken 2018), customs and border protection (Barnett 2019), and facial recognition systems (Andrejevic and Selwyn 2020).

In the context of TASER, the term mission creep is often used to refer to the use of the weapon in a broad range of circumstances, sometimes as a first resort, and not as an alternative to firearms. In their investigation into TASER use, the Australian Corruption and Crime Commission (2010: 24) defined it as 'the use of a weapon (or other application of force) in situations that extend beyond those for which the weapon was originally designed or introduced' - and the term has also been used by a range of others, including oversight bodies (IPCC 2014a, Ombudsman New South Wales 2012), academics (Ryan 2008), and NGOs (see evidence to the London Assembly Police and Crime Committee, 2013).

At first sight, these accounts might appear dramatically opposed to the conventional view listed above; the former holds that projectile electric-shock weapons are used as an alternative to firearms, the other holds that it is used as a 'first resort'. Yet, in some ways, this second account is a slight variation on the conventional origin story, rather than a dramatic departure. In both accounts, human intent, objectives, and 'missions' - in this case, the desire for the weapon to be an alternative to firearms - are important; the difference is 
only that, in the conventional account, the weapon has stayed true to these initial objectives and, in the second account, it has 'extend(ed) beyond' them. Moreover, both accounts see the weapon as being initially successful due, in part, to its technical superiority and the way in which it has fulfilled preexisting social criterion (in this case, around lethality and effectiveness) and 'missions' (in this case, firearms substitution) - even if, in the second account, the technology later goes on to move beyond these. Finally, both accounts locate the adoption of the weapon in the context of avoiding the use of firearms. To some extent, then, these are differences in degree, not in kind.

In order to question such beliefs, I turn, next, to claims that projectile electric-shock weapons are an alternative to firearms. I then move to the questions that this raises for our understanding of technologies more broadly and the origin myths around them.

\section{An alternative to firearms?}

\section{Challenging the academic evidence}

I start by returning to the academic literature often used to support claims of firearm substitution. While the Ferdik et al. (2014) paper cited above is one such case, on a close reading the evidence it provides is more equivocal. The paper used two different ways of measuring the restrictiveness or permissiveness of projectile electric-shock policies. One of these measures (which involved ranking different types of force, including projectile electric-shock weapons, from 1 to 10 , and then calculating the relative restrictiveness of policies for the use of such weapons) was not significantly associated with the number of fatal shootings at all. The second measure (which assessed whether the use of projectile electric-shock weapons would be authorised at different levels of subject resistance) was associated with fatal shootings, but the outcomes were mixed. When compared to policies that allowed the use of the weapon on 'combative subjects', policies that allowed its use on 'passive resisters' were associated with decreases in the number of fatal police shootings. However, policies that allowed the use of the weapon on 'actively resistive suspects' were associated with increase in the number of shootings. Hence, while this study found some evidence of a link between projectile electric-shock weapons and firearms, overall the evidence was inconsistent and the authors themselves called for 'future studies ... using more rigorous designs' (2014: 329). As such, one of the key studies often used to support claims around the weapon saving lives provides mixed and partial evidence.

Moreover, many studies do not find a link between projectile electricshock weapons and firearms use, or find mixed evidence. Researchers for the National Institute of Justice (2009) looked at 13 forces and concluded that the weapons 'do not appear to have much of an effect on officer use of 
firearms' (2009: 41), while Ba and Grogger's (2018) study of the Chicago Police Department found no decline in the use of firearms following the introduction of projectile electric-shock weapons. Eastman et al. (2008) studied the use of these weapons in a large city police force in the United States of America in a period of just over a year (November 2004-January 2006). They found that, in $5.4 \%$ of deployments (totalling 23 cases), the use of the weapon 'clearly prevented' the use of lethal force $(2008$; 1567) — a percentage which simultaneously serves to underscore the number of cases where this was not the case. Lin and Jones's (2010: 161) study of the Washington State Patrol found a possible decrease in the use of lethal force-from $1.9 \%$ to $1.1 \%$ of recorded use of force incidents - but did not find 'the dramatic reduction of frequency of use of lethal force (that was) hoped for'.

Furthermore, some overarching limitations with this literature should be noted. First, as Ba and Grogger (2018: 157) observe, there have been few studies on this topic. Second, the evidence around the safety of projectile electric-shock weapons is 'dominated by studies whose authors have financial interests in the commercial production, sale, and promotion of TASERs by police. ... and this has the potential to influence the volume and content of publications' (O'Brien and Thom 2014: 422). Indeed, as discussed in the introduction, a paper written by Azadani et al. (2011), and criticized by Vilke et al. (2012) and Kunz (2012), found that those studies with an affiliation to TASER International had nearly 18 times greater odds of concluding that the device was safe as compared to studies without such an affiliation. Third, all of these studies were conducted in the United States of America, where officers routinely carry firearms and levels of firearms usage appear relatively high-despite a notable lack of data in this area.

Few, if any, detailed studies have been conducted in other jurisdictions, but a look at data from England and Wales-where, comparatively speaking, there are relatively few cases of firearms use-reveals no clear evidence of firearms deaths and incidents being reduced. If anything, incidents involving the discharge of firearms and deaths following police shootings appeared to increase following the roll out of TASER to firearms officers 2004. However, the number of cases are so small and there is such a degree of variability across years that no causal conclusions can be drawn ${ }^{3}$. In Canada, the Braidwood Commission (Braidwood 2009: 279) found that the number of police-shooting deaths in British Colombia had seen a 'modest increase, not a decline', since the introduction of projectile electric-shock weapons.

The idea of less lethal technologies, such as electric-shock weapons, not reducing deaths from police use of firearms may seem paradoxical at first glance. But it makes more sense when we consider that projectile electricshock weapons have been associated with fatal outcomes; that they are not used when lethal force is justified; and that they are used when lethal force is not justified-three considerations I advance now in turn. 


\section{Projectile electric-shock weapons have been associated with fatal outcomes}

Like any use of force, projectile electric-shock devices are not risk free. While this is not the right place to address debates around the medical impact of the weapon (for external investigations into this, see Braidwood 2009, Canadian Council of Academics 2013, DOMILL 2012, SACMILL 2016), it is important to note that people have died subsequent to the weapon's use-although exactly how many have died, and the causes of death, remain a matter of considerable controversy. Writing in 2016, Kroll et al. (2016) counted ' 16 probable cases of fatal brain injuries induced by electronic control from electrical weapons' out of what they estimated were ' 3 million field uses'. Reuters counted over a thousand deaths that occurred in the United States of America following police incidents in which TASERs were used, often in combination with other forms of force (Reuters Investigates 2017) - although this does not mean that such deaths were caused by the use of the weapon.

In England and Wales, inquest juries have cited the use of TASER (either on its own or in combination with other forms of force) in relation to the deaths of several men, sometimes explicitly concluding that the use of the weapon had a 'more than trivial' or 'material' impact. In the case of Darren Cumberbatch, who died in 2017, the Jury found that the 'medical cause of death...(was) multi-organ failure, rhabdomyolysis, acidosis and hyperpyrexia, (and) cocaine use in association with restraint and related physical exertion' (Warwickshire Coroner's Court 2018a). They noted that 'police used considerable restraint on Darren... including baton strikes, other physical strikes, multiple punches, stamping, PAVA spray, Tasers, and handcuffing... restraining him in a prone position for a period, as well as leg restraints, physical force and rear handcuffing', some of which 'may have been excessive and, at times, was probably avoidable' and found that 'the police's restraint of Darren contributed to his death' (Warwickshire Coroner's Court 2018b).

Marc Cole's death, in the same year, was found by the inquest Jury to have been caused by 'use of cocaine, episode of altered behaviour including self-harm, exertion, excitement, the use of x26 Taser Device and restraint' (Cornwall and Isles of Scilly Coroner 2020a). They found that the use of a TASER had 'more than a trivial impact on Mr Cole's cardiac arrest' (Cornwall and Isles of Scilly Coroner 2020b).

An inquest jury found that the death of Adrian McDonald, in 2014, was caused by the 'effects of cocaine and stress of incident' and that 'the police acted with the acceptable use of force. However, due to [Mr McDonald's] cocaine induced paranoia, the level of force may have increased his stress levels which may have contributed to his death'. The jury note that force used included '(being) bitten by the police dog', 'Taser... discharge', and 'handcuffs' (Stoke on Trent and North Staffordshire Coroners Court 2018). 
In the case of Jordan Begley (who was also known as 'Jordon'), the jury found that 'the stress of the (TASER) discharge and restraint more than minimally and materially contributed to...(his) death' in 2013 (Manchester Coroners Court 2016). In the case of Andrew Pimlott, who died in the same year, the inquest heard that he had doused himself in petrol. The jury found that the TASER was the most likely source of ignition of the subsequent fire (Royds Withy King 2015). At the time of writing, it is understood that inquests into the deaths of Spencer Beynon and Dalian Atkinson are still to conclude, and it has been announced that charges of murder and assault will be brought against the officers involved in the latter case (Crown Prosecution Service, 2019).

As the findings of these Inquest juries underscore, the likelihood of death may be 'low to very low' (DOMILL 2012: 12) but is not non-existent. Indeed, Axon's User Manual for the TASER X2 notes,

'it is important to remember that the use of force and physical incapacitation, by their very nature, involve risk that someone will get hurt or may even die from factors that include, but are not limited to: physical resistance, exertion, individual susceptibilities, and/or unforeseen circumstances. Any use of force, including the use of a CEW ${ }^{4}$ or physical exertion involves risks that a person may get hurt or die'.

(Axon undated, d: 5)

Moreover, attempts to evaluate the relative safety of the weapon are complicated by the gaps in our understanding and by areas of 'undone science' (Frickel et al 2010). Many assessments of the weapon focus on weighing up the 'known benefits' versus the 'known negatives' (Sussman 2012; 1345), but we also need to focus on the unknowns. As a report by DOMILL - the Defence Scientific Advisory Council Sub-committee on the Medical Implications of Less-lethal Weapons, which was tasked with providing advice to the UK government-noted, the 'overall risk of serious injury associated with UK use of ... [the weapon] is low'. However, the report also stated that important issues - such as the 'risk of cardiac capture' associated with certain shots to the chest and concerns over prolonged exposure and prolonged discharge of the weapon-remain 'unknown' or 'unexplored' (DOMILL 2012: 12). Indeed Sheridan, a doctor with the Defence Science and Technological Laboratory tasked with providing advice on the physiological effects of TASER to the UK Home Office and to the Scientific Advisory Committee on the Medical Implications of Less Lethal Weapons (SACMILL) ${ }^{5}$, has called for more studies on the risk of cardiac capture posed by projectile electric-shocks including newer TASER models. He notes a 'major knowledge gap in our understanding of the cardiac effects of the TASER X2 and X26P' and calls for more research into the association (or lack thereof) between the position of TASER barbs and 'the induction of arrhythmias' (Sheridan, 2014: 167). 
Such issues were also underscored by the inquest into the tragic death of Marc Cole, where the Coroner stated, in part, that:

'in my opinion there is a risk that future deaths will occur unless action is taken... there is no understanding about the potential for incremental risk with multiple Taser activations and no training provided as to the maximum number of activations nor of their duration which is appropriate or safe... I am concerned, based upon the evidence that was led before the jury, that there is insufficient independent data as to the lethality of Taser use'.

(Cornwall and the Isle of Scilly Coroner 2020)

As with many use of force options, then, the risk is not non-existent and is difficult to quantify. Less-lethal does not mean non-lethal and no force option is completely safe, including projectile electric-shock weapons.

\section{Projectile electric-shock weapons are not used when lethal force is justified}

While projectile electric-shock weapons are often seen as an alternative to firearms, in many cases it is not feasible to use the former in place of the latter. They generally have a shorter range than firearms and, like any weapon, may not always be effective for several reasons (some of which are discussed in Chapter 5). No use of force option, up to and including firearms, are $100 \%$ effective and there are important differences between different brands of electric-shock weapons (Mesloh et al 2008) and between different models from the same company. Nevertheless, because projectile electric-shock weapons, in general, operate at a shorter distance than many firearms, they may risk putting officers directly in harm's way if they are ineffective. As such, there are multiple circumstances in which these weapons are simply unable to be used as an alternative to firearms.

There are also legal considerations. Under international law, deadly force can only be used under certain strict conditions where absolutely necessary to save life. If these criteria are met, almost by definition, it is often too risky to use a less lethal-and potentially less effective-weapon. As Rick Guilbault, the Vice President of Training for TASER International, notes, in such circumstances 'one missed probe or a clothing disconnect can result in tragedy' (2007: 1). It is unsurprising, then, that despite talk about projectile electric-shock weapons being an alternative to firearms, and saving lives, guidance often states that the weapon should not be used where lethal force is justified. Certain police forces in the United States of America allow the use of projectile electric-shock weapons only 'when deadly force is not justified or necessary' (Amnesty International 2008: 99), and a study by Terrill and Paoline (2013) found that, out of 244 police agencies in the United States of 
America, roughly two-thirds placed the technology at the same level as baton strikes and the remaining third placed it at the same level as hands-on force. Only $2 \%$ placed the use of such weapons along with deadly force.

Similarly, in England and Wales, the College of Policing Authorised Professional Practice (College of Policing 2020b) states that 'less lethal weapons should not be regarded as a substitute for firearms. Officers armed only with less lethal weapons should not, therefore, expose themselves or be exposed to unnecessary risks by confronting subjects who may be armed with a firearm' and New Zealand's policy (undated a: 6) states that 'police firearms remain the most appropriate tactical response for situations where a subject is armed with a firearm but circumstances may exist where the use of a TASER may be appropriate when deployed with or in support of conventional firearms'.

\section{Projectile electric-shock weapons are used when lethal force is not justified}

If such weapons are not used as an alternative to firearms, then when are they used? Studies from the United States of America have found that officers are using them in response to lower levels of resistance, including verbal resistance (Crow and Adrion 2011: 380), that they are using the weapon instead of using 'verbal de-escalation' (Gau et al 2010: 42) and that the weapon is the police officer's 'response of choice' (Alpert and Dunham 2010: 251). Earlier work by the author, based on analysis of use of force data from a force in England and Wales between 2007 and 2014 found that TASER was used infrequently (in around 1\% of use of force incidents) and was associated with the presence or use of a weapon-but that, despite this, over half of cases of TASER firings involved use on individuals reported as being unarmed (Dymond 2018).

Moreover, the use of electric-shock weapons are not evenly dispersed throughout the population but are patterned by ethnicity, mental health, gender, and other socio-demographic considerations-as well as, likely, intersectionality between them. Ethnicity plays a significant role; Lin and Jones (2010) found that non-white male citizens were more likely to be subject to the weapon. Similarly, Crow and Adrion (2011) found that non-white members of the public were nearly twice as likely to have Taser used on them than white members of the public. In New Zealand, official statistics show that 'both Māori and Pacific peoples were more likely to experience a TASER deployment than subjects of other ethnicities; this pattern holds when considering TASER deployment relative to offender proceedings and relative to overall population numbers. The TASER show to discharge ratio also varies by subject ethnicity: the show to discharge ratio was $4: 1$ for both Māori and Pacific peoples, but 5:1 for European subjects' (New Zealand Police 2018: 7). 
In England and Wales, Black people were subject to $12 \%$ of reported TASER uses between 2010 and 2015 at a time when they constituted 4\% of the population (Gayle 2015), and the most recent national statistics on TASER show that approximately $17 \%$ of incidents where TASER was discharged, and $20 \%$ of incidents where the weapon was used in non-discharge mode, involved people reported to be Black or Black British (Home Office 2019b; 18). Work by the author (Quinton et al 2020) has also examined use of force records from 16 police forces in England and Wales. After controlling for a number of relevant factors, it found that the odds of TASER being drawn (but not fired) were higher when cases involved a person who was Black or Black British compared to someone who was White, although there was no difference in the odds of TASER being discharged. Nationwide, Shiner's analysis found that Black people were nearly eight times more likely to have TASER used on them.

Similar analyses have also been conducted at the regional level. An analysis by Stopwatch (2016: 4) on TASER use in London found that 'BME communities, when grouped together, are almost twice as likely to have a TASER deployed against them than their white counterparts....(and that) the black community are 4.3 times more likely to have a TASER used against them', while Resistance Lab (2020) calculated that, in 2018/9, 'Black people were subject to the use of Taser by Greater Manchester Police at nearly 4 times the rate of white people' Noting that 'Home Office statistics for 2019/20 showed that Black people were eight times more likely than White people to experience Taser being drawn on them or discharged (and) in $86 \%$ of all uses the Taser was not discharged', as this book went to press the National Police Chief's Council and College of Policing established an Independent Review into Disproportionate Effects of Use of TASER to 'identify, understand and tackle the root causes of racial disproportionality in police use of Taser' (NPCC and College of Policing 2020).

Mental health is also an important consideration and issue of concern. O'Brien et al's analysis of the TASER pilot in New Zealand showed that the introduction of TASER would 'disproportionately impact' people with mental illness (2011: 39), while research from one force in England and Wales found that, after controlling for other factors, reported mental health issue was a significant factor and associated with an $80 \%$ increase in the odds of TASER firing (Dymond 2018). Such findings are particularly concerning in light of medical statements which suggest that 'some drugs used in the treatment of certain mental health conditions... may predispose [a person] to an adverse cardiac event' (DOMILL 2012: 24).

Hence, evidence around the use of the weapon worldwide suggests that, far from being used as an alternative to firearms, it is used on unarmed individuals, on black and ethnic minority groups, and on those with mental health issues. Instead of just accepting myths about the weapon as an alternative to firearms, we may wish to take a leaf from Grint and Woolgar's (1992: 366) 
book, asking not only 'what's social about being shot' but perhaps, also, what is social about being 'Tased'.

\section{Origin myths revisited}

Thus far, I have set out the conventional 'origin myth' around TASER as an alternative to lethal force and challenged it on a number of grounds. Yet the myth of TASER as an alternative to firearms does not arise in isolation. It is supported by, and reflective of, a number of conventional views which are often shared by proponents and opponents of particular technologies alike. These views often seek to understand technologies with reference to preexisting human intent, to the technology's superiority, and its ability to address these pre-determined problems (for example, providing an alternative to firearms). Yet the evidence presented above not only disputes the idea of projectile electric-shock weapons as alternatives to firearms. It also provides an initial indication that such underpinning beliefs are, themselves, insufficient and incomplete.

This, in turn, raises more questions than answers. If conventional explanations are insufficient, then how, why, and through what processes do technologies come to be adopted, both in policing and elsewhere? If human intent is insufficient to understand technological development and adoption, then what else should be considered? If the success of technologies cannot be explained by their technical capabilities and ability to meet pre-existing criteria, then how should they be explained? Challenging myths around projectile electric-shock weapons thus offers an opportunity to examine these questions and to challenge these broader myths.

In order to achieve this, in this penultimate section, I put forward my own origin story of projectile electric-shock weapons. This is based on Callon's (1986) notion of translation which seeks to capture the way in which different actors try to 'impose themselves and their definition of the situation on others', or in other words, how different actors attempt to ensure that their preferred definitions, understandings, and solutions are adopted over alternative interpretations. Callon argued that this process of translation could be broken down into four stages - problematisation, interessement, enrolment, and mobilisation - each of which we will discuss in turn.

I start by examining records around the introduction of TASER in the UK. These suggest that projectile electric-shock weapons were introduced not simply as an alternative to firearms-although, as we have seen above, this did form an important part of public and private rationales - but to fulfil a broader function. Indeed, the stated aim of less-lethal weapons programmes was specifically not to find an alternative to firearms. Early publications stated that work on less-lethal weapons is 'not focussed on identifying a replacement for conventional firearms' (Police Scientific Development Branch 2001: iii) - but to 'find an acceptable, effective and less potentially lethal alternative 
to the Plastic Baton Round...(and to equip the police) with a broader range of public order equipment' (UK Steering Group 2006: 1.23). This followed on from the Report of the Independent Commission on Policing for Northern Ireland (the so-called Patten Report), which recommended that 'an immediate and substantial investment should be made in a research programme to find an acceptable, effective and less potentially lethal alternative to the Plastic Baton Round (PBR)' (quoted in UK Steering Group 2006: 1.3).

Similarly, while TASER was initially piloted with firearms officers in England and Wales, the evaluation of the pilot assessed the weapon not just in the context of firearms but much more broadly. The terms of reference asked for an evaluation of 'how successfully TASER devices have been used as a supplementary option to other deployment methods, namely firearms, dogs, baton rounds and irritant spray' (PriceWaterhouseCoopers 2004: 2 emphasis added).

Hence, the original mission was for a public order weapon that was an acceptable, effective, and less lethal alternative to the Plastic Baton Round-a long-range weapon, capable of delivering a number of rounds to multiple people in crowd control situations. This is quite different to TASER and other projectile electric-shock weapons which, in contrast, work best at relatively close ranges, on individual aggressors, and can be slow to reload. Indeed, as Dr. Peter Neyroud noted, 'as far as I was concerned the TASER was (at the time it was introduced) less important than... (the new kinetic impact projectiles) which gave an option to reduce the risk of someone armed with a knife at distance. TASER was a less attractive option at this stage' (email correspondence with author).

How, then, did projectile electric-shock weapons come to be adopted? It is here that Callon's (1986) translation framework is helpful. The first 'moment' of translation, problematisation, involves (re)defining the problem or issue at hand. Weapons manufacturers attempted to redefine the problem of incapacitating multiple aggressors at long range as a problem of incapacitating a sole individual at (relatively) close quarters - an equally crucial, yet different, challenge. In effect, they attempted to answer the question 'what less lethal weapons are suitable for crowd control at medium to long range' with the response 'projectile electric-shock weapons are helpful in dealing with a single individual at short range'. In so doing, goals were translated from 'finding a safe alternative to the baton round that is capable of incapacitating at a distance' to 'finding a weapon that fulfils a completely different function'.

Having attempted this redefinition, the next stage of translation is interessement, a process by which actors attempt to secure or 'lock' down their preferred definition of the problem by excluding 'other entities who want to define their identities otherwise' (Callon 1986: 9). In this case, I posit, interessement worked on two levels; by preventing attempts to challenge the new definition of the problem and preventing attempts by others to solve the problem, as it had been redefined. Attempts to challenge the new definition 
of the 'problem'-and to return to the stated objective of incapacitation at a distance-were thwarted by a range of non-human actants. For example, the relative inaccuracy of many of the long-range kinetic impact projectiles available at the time meant that they were not able to reliably incapacitate at a distance (for a contemporaneous assessment of kinetic impact projectiles, see Penn State University Applied Research Laboratory, 2001). Meanwhile, assessments indicated that TASER International's weapons were more reliable than alternative projectile electric-shock weapons (Mesloh et al 2008). Rival manufacturers were failed by components and materials that were unruly and unpredictable, with probes failing to travel the necessary distance, weapons malfunctioning, and devices shocking those who used them (Mesloh et al 2008). At the same time as other alternatives appeared limited, electric-shock weapons were increasingly portrayed as essential for 'saving lives' and as a way for police forces to demonstrate their commitment to this cause. Hence the question '(how) can we justify adopting TASER' was cleverly reframed into the question 'how can we justify not adopting TASER'.

After problematisation and interessement, Callon argues that processes of enrolment and mobilisation occur. Under these processes, roles are 'defined' and successfully 'attributed' to various actors, with these actors acting as 'spokesmen' or representatives for broader constituencies. Enrolment and mobilisation is achieved through a number of strategies including 'negotiations, trials of strength and tricks' (1986:10). These include 'concessions', 'negotiations' 'physical violence', 'seduction, transaction (and), consent without discussion' (1986: 12).

In Callon's classic study, actors included fishermen, the scientific community and scallops, who were represented by designated spokespeople, attendees at conferences, and selected scallop specimens. In the case of electricshock weapons, actors similarly included non-human entities, including animals, components, and individual weapons. For example, technical assessments relied on a small number of weapons and cartridges, which stood in for the broader model under examination. Actors and spokespeople also included the Association of Chief Police Officers as well as other organisations such as DOMILL (a Committee of experts tasked with providing a coherent medical statement on the weapon). In such ways, negotiations and discussions were held, not with all police agencies, officers, or medical professionals, but with a small number of individuals, organisations, weapons, and components that could be portrayed as representing, or speaking for, broader constituencies.

In order to convince these spokespeople of the merits of electric-shock weapons, again the silences, ambiguities, and areas of 'undone science' around the weapon had an important role to play, alongside other tactics. As the first DOMILL statement on the medical implications of the use of TASER stated, 'the body of manufacturers' experimental evidence...is not substantial... (and) the peer-reviewed evidence is even more limited' (2002: 35). Yet the statement noted that it drew its conclusions from 'the available 
evidence on the use of the device', despite these limitations. It was, therefore, able to conclude that 'the risk of life threatening or serious injuries... (from TASER) appears to be very low', despite-or because-of the lack of evidence on the topic. This was, perhaps, particularly convincing in a context where the lethal potential of the weapon it sought to replace - the PBR-had been well documented (Independent Commission on Policing for Northern Ireland 1999).

It was not sufficient, however, for senior officials from ACPO, DOMILL, and other organisations to be convinced as to the merits of such weapons. This view needed to be shared-or, at least, not completely repudiatedby the constituencies they represented. For example, in England and Wales, Chief Constables had to choose whether, and to what extent, to deploy the weapon in their force. Further, as non-firearms officers had to volunteer to carry the weapon, they ultimately had to be convinced of its merits. If any of these links - or attempts at mobilisation-failed, then the weapon would not be successful.

In this case (at least according to the account provided here), translation was successful, with TASER being widely adopted, despite not meeting the original stated objectives set out for the less lethal weapons programme. Instead, police agencies were 'enrolled' into accepting a particular notion of effectiveness (effective against one attacker, and one attacker only), a particular notion of long distance (a few meters), a particular concept of use (use in routine policing, not public order) and a particular notion of acceptability (a point we return to in the following chapter).

\section{Conclusion}

This chapter has examined one of the most far-reaching myths and origin stories around projectile electric-shock weapons, that they provide an alternative to firearms. To say that such statements constitute a 'myth' does not mean that they have no validity at all, and there may well be instances where projectile electric-shock weapons have prevented the use of firearms. Yet, in my opinion, the evidence suggests to the contrary that the introduction of these weapons is not always associated with a reduction in firearms shooting and deaths. They are used when lethal force is not justified-including in ways that are patterned according to ethnicity, mental health, and other socio-demographic characteristics-and are not used when lethal force is justified.

These findings are of interest not only for those concerned with how and when electric-shock weapons and other forms of force are used. They also speak to, and challenge, more fundamental beliefs around technology-in particular, instrumental views that seek to understand technologies with reference to pre-existing human intent, their technological superiority and their ability to address pre-determined problems - views which are often shared by 
so-called 'proponents' and 'opponents' of technologies alike. The alternative origin myth I have proposed draws on Callon's concept of translation (1986) to challenges such notions. It demonstrates that projectile electric-shock weapons are successful not because they have the technical attributes, and technical superiority, necessary to meet pre-existing, fixed, and unchanging criteria. Instead, they are successful because these criteria have been changed, warped, and co-opted to fit such weapons. It is not (just) that technologies in policing and elsewhere are successful because they fit certain criteria-but rather that the criteria are changed, or translated, to fit certain technologies.

This, in turn, challenges the idea that pre-existing human intent is insufficient to determine an outcome. Far from being pre-determined and set in stone, human intent, desires, and ambitions are not determined in advance, but produced through a series of interactions. In this reading, if TASER's success is not due to its 'technical superiority', neither is it due to human 'pioneers' and 'heros' but, rather, the way in which so-called technical, human, and non-human factors have been melded together. This account is, perhaps, as much of a myth as is the conventional 'origin story' outlined in the first part of this chapter-but like many myths, it may yet serve as a useful aide for understanding.

If this alternative account challenges the conventional myth around such weapons, it also challenges the idea of 'mission creep', at least as it is set out by many critics. I suggest that there has not been mission creep from the weapon as an alternative to firearms, to a much broader conception of use. This latter point was always part and parcel of, and inherent in, the stated rationale behind the adoption of the weapon. Instead, the mission creep that has occurred has been from the search for a long range, multiple shot crowd control weapon to the adoption of a short to medium range, single shot weapon often seen as unsuitable for use in crowds.

A focus on projectile electric-shock weapons has, in turn, revealed some implications for Callon's notion of translation. This is particularly important because, as Spyridonidis et al. (2014) argue, translation research has developed over recent years, and the concept has been applied broadly and widely, but has not been subject to much critique. First, the focus of Callon's classic work is how actors are enrolled through a number of strategies including 'concessions', 'negotiations' 'physical violence', 'seduction, transaction (and), consent without discussion' (1986: 10-12) and Callon and Latour (in Barry 2013: 414) define translation as 'negotiations, intrigues, calculations, acts of persuasion and violence'. Silences are mentioned in Callon's classic work only in passing, and only in the discussion on the last phase, mobilisation. Here, Callon notes that 'to speak for others is to first silence those in whose name we speak' (1986: 15). Yet silences and areas of undone science have been crucial to our understanding of the various translation processes around electric-shock weapons. As this case study demonstrates, then, sometimes processes of translation, enrolment, and mobilisation can happen not through 
action and communication but through refraining to act and communicate, through omission rather than commission.

Second, there is a related tendency to trace intent and motivation through published works, speeches, and other declarations. Indeed, in my alternative reading of TASER's origin story and of mission creep, the focus is precisely on statements of intent by powerful actors-police, state officials, company representatives - and what they did, or did not, publicly declare of their intentions at the time. It appears I am not alone in so doing. In Callon's classic work, questions of motivation and intent are literally bracketed off (1986: 8) and dismissed (where the scientists 'came from and why they act is of little importance at this point of the investigation' 1986: 6). Where intent is noted, it is equated with the expressed desires and intentions of actors involved and assessed through analysis of publicly available documents, statements, and rationales. More recent works on translation have also been criticised for dealing with 'surface appearances' and public proclamations (Barry 2013: 427, see also Mungai and Van Belle 2018; Nordin et al 2019).

If this tendency is problematic enough when applied to, say, scallops, it becomes even more problematic when applied to less lethal weapons; an area with a large and growing multi-billion dollar market (Marketwatch 2021). As such, while the laudable aims of saving lives and substituting for firearms may have loomed large in public debates around the weapon, one might usefully question whether such aims are evidence of 'genuine' intent-however, that might be defined, captured, and measured-or a public relations strategy, having more to do with legitimisation and acceptability than intended uses of the weapon. As Rick Guilbault (2007: 1), the then Vice President of Training for TASER International, has stated:

'Many (police) chiefs... (have reportedly said) that being hit by a TASER is better than being hit by a bullet. This is... true, but...misleading. It gives the public the perception that officers will be able to routinely resolve deadly force situations with a TASER'.

Focusing on public statements of intent-even if only to assess these how aims and interests are changing, and to demonstrate that they are not set in stone-risks taking at face value claims made by powerful actors about what are 'intended' and 'unintended' uses of their products, including less lethal weapons. Yet such utterances are highly problematic, with important limitations on what officials are prepared to consciously acknowledge, vocalise, and say in a public, written forum. Nor is this limited to those acting in an official capacity. For example, as Rappert (2004: 24) notes, reflecting on his experiences writing an article on TASER for the New Scientist, the piece was negotiated with an eye to what readers would find most relevant and newsworthy. Hence, there were extensive debates over what was (and wasn't) included, the extent to which personal experience was foregrounded, and 
the degree to which broader context(s) were brought in, so much so that 'the final write-up drew little directly on the first submitted draft'. There are important distinctions, then, between what gets said publicly and what gets said privately, between what may be said backstage, to trusted confidants, and may be said front-stage. Hence, while helpful, the notion of translation also needs to be used with caution.

In closing, I return to the original myth around projectile electric-shock weapons that inspired this debate. The opinion set out here, that such weapons are not, necessarily, an alternative to firearms, does not mean they are not valuable. After all, if the use of projectile electric-shock weapons manages to prevent loss of life in just one case, then the benefits of the technology would be as substantial as they would be difficult to quantify. Yet it does pose a range of additional questions. If the rationale for such weapons use is not that it presents an alternative to firearms, then what are the other rationales used, and (how) can these be substantiated? I contend that another commonly heard myth or rationale is that these weapons are 'nicer' for those on whom it is used, and it is to that myth that we now turn.

\section{Notes}

1. While there may be other ways in which the introduction of projectile electricshock weapons could be said to protect life, I focus here on claims that the weapons are, or can be, an alternative to the use of firearms. As shall be demonstrated, such claims are made frequently, explicitly and are often used to justify the weapons' introduction. They also implicitly underpin, and help frame, broader discussions around the weapon.

2. Including the so-called Patten Report, which we discuss in more detail below.

3. Following an initial pilot, TASER was introduced to firearms officers in September 2004 (BBC News 2004). Official statistics on the number of incidents where firearms were discharged indicate that there were four such incidents in the financial year prior to the introduction of TASER, five such incidents in the financial year during which TASER was introduced, and nine such incidents in the following financial year (Home Office 2012). Data on fatal police shootings in England and Wales, gathered bythe UK NGO INQUEST, indicate that there were 2 such deaths in the calendar year prior to the weapon's introduction, 2 such deaths in the calendar year during which TASER was introduced, and six deaths the following year (INQUEST 2020b).

4. CEW stands for Conducted Electrical Weapon and / or Conducted Energy Weapon.

5. SACMILL is the Scientific Advisory Committee for the Medical Implications of Less Lethal Weapons and provides advice to the UK government on a range of less lethal weapons, including those used, or being considered for use in policing. 


\section{A 'nicer' weapon? Projectile electric-shock weapons and public safety}

\section{Introduction}

The last chapter revealed that electric-shock weapons are used in a broad range of circumstances, including those where lethal force would not be justified. In such cases, their use is often justified via the myth that such weapons are 'nicer' and 'safer' than other 'less lethal' force options that may be used. In examining this myth, I draw on the voices of some of those who have been subjected to or affected by TASER. This is of particular importance because the majority of research on police use of force, including my own, is quantitative in nature and relies on data collected by the police, for the police. As such these sources have been described as 'inherently problematic' (Root et al 2013: 145, see also Rojek et al 2012). Even where qualitative work is conducted, more often than not this tends to focus on interviews with officers (De Angelis and Wolf 2013; Paoline and Terrill 2007) and few studies look at the consequences of police force for those on the receiving end of it, or their views on the matter (Meade et al 2015). In contrast, I intend to 'follow the actors' (Latour 2005: 12)-including people who have experienced TASER discharge - to gain a more nuanced understanding.

I start by setting out the myth that the use of projectile electric-shock is 'better' for members of the public than other forms of force that may be used on them. I argue this myth is comprised of three key elements: a notion of the weapon as 'nicer' for those on whom it is used, a notion of the weapon as more predictable, and a notion of the weapon as less injurious. In the second section, I challenge this myth by drawing out themes emphasised by those who have been 'Tasered'. Instead of seeing it as nicer, predictable, and less injurious, these interviews highlight a range of concerns, including the pain and fear experienced, the unpredictability of the weapon, the psychological symptoms experienced after use, concerns that it is used more frequently on Black people and those experiencing mental health crisis, doubts about whether it was necessary or appropriate to use the weapon, and the humiliation and loss of control suffered. 
In the final section, I move beyond debates around the 'empirical reality' of the weapon and attempts to ascertain whether projectile electric-shock are 'really' nicer or less injurious for members of the public. Drawing on Law's notion of 'heterogeneous engineering' (1987), I look at the engineering 'tactics' that work to establish the myth of electric-shock weapons as a nicer form of force, in the face of concerns about the pain, fear, and loss of control engendered by the weapon. In doing so, I demonstrate that proponents of the weapon have a number of socio-technical techniques and tactics at their disposal. Conversely, those on whom the weapon is used not only lack these resources, but often face multiple vulnerabilities, and difficulties in having their views taken seriously. First, however, it is necessary to discuss some of the methodological complexities in researching this area.

\section{A note on methods}

As Meade observes, very few works have looked at the consequences of police use of force for those subjected to it and, as such, our understanding in this area is 'underdeveloped' (Meade et al 2015: 1). As discussed in Chapter 1, three main methods were used to help fill this gap; a search of academic and non-academic sources (NGO reports, newspaper articles, radio interviews, blogs, and other fora, gathered through systematic online searches); my own voluntary exposure to the weapon; and interviews with people affected by TASER, and/or their representatives. Lawyers and advocacy organisations working with those subjected to TASER were contacted to ask if they would be interested in being interviewed for the research, and if they would be willing to forward details of the research to suitable clients, as well as to lawyers, NGOs and other representatives working in the area.

As a result of these enquiries, I was able to secure interviews with six legal representatives / advocates, who circulated details of my research to their clients. I was subsequently contacted by six individuals affected by TASER and was able to interview three of them. (The other three, despite expressing initial interest, did not respond to follow-up prompts). Two people who wished to remain anonymous, and are referred to by the use of pseudonyms Tom and Chris, had TASER used on them. The third, Lisa Cole, tragically lost her brother, Marc Cole, in 2017. As noted previously, the inquest jury found that the cause of death was 'use of cocaine, episode of altered behaviour including self-harm, exertion, excitement, the use of x26 Taser Device and restraint' (Cornwall and the Isle of Scilly Coroner 2020a) and that the use of a TASER had 'more than a trivial impact on Mr Cole's cardiac arrest' (Cornwall and Isles of Scilly Coroner 2020b).

The small number of interviews conducted should be noted and is a well-documented issue in this area. Rojek et al. (2012) found that a third of people contacted for their study into police use of force declined to participate in the research-and such generic difficulties may be heightened for 
populations on whom electric-shock weapons have been used. As Oliver Feeley-Sprague, Amnesty UK's Programme Director for Military, Security and Police noted, the psychological effects of incidents involving the weapon can be far-reaching:

'(one client has suffered) psychological scarring, he basically can't go outside, he is scared of the outside world. He has become incredibly insular. He doesn't want to talk about what happened to him. His ability to live his life has been has been significantly impaired because of the TASER'.

Indeed, a legal representative explained that one client whom they had advised of the opportunity to participate in the research had not responded as he was: 'trying to work out whether he wants to talk about it all... It's going over it again in detail that he finds quite hard. He is thinking 'do I want to keep on trying to make a point about this? Or do I just draw a line under it?'.

Furthermore, evidence suggests that many of those who feel that the force used on them was excessive are unlikely to seek legal advice, for multiple reasons. Kevin Donoghue, a solicitor specialising in civil actions against the police notes that 'the thing with police use of force is that there are so many people who don't bring cases who should. They think 'well I was wanted for the offense therefore I expected it'. It's a sad acceptance, a sad reality' (interview with author).

Other limitations of these methods should be noted. First, as the participants I spoke to were contacted through lawyers and NGOs, they are by definition more likely to consider that they have had negative experiences with the weapon. Second, focusing on the views of those on whom TASER is used-some of whom may, at least in theory, be threatening others with severe violence-excludes the views of bystanders and those who may have been saved from such violence through the use of the weapon. Further, due to time limitations, I did not conduct similar interviews with individuals who had experienced other forms of police use of force, making it difficult to compare the impact of incidents involving TASER to the impact of incidents involving other weapons. Further, as TASER is the only electric-shock weapon authorised for use in England and Wales, I was not able to speak to people who had experienced different electric-shock devices.

Despite such issues, as noted in the introduction, it is vital to include such experiences here, as they are an important and valid part of a much broader range of experiences around the weapon, and are often neglected in accounts of, and research around, electric-shock weapons. Moreover, such accounts can add useful insights to the dominant perception of the weapon as a 'nicer' form of force; a myth to which we now turn, starting with officer views on the topic. 


\section{The myth of the nicer weapon}

Interviews with some 50 police officers across Countryshire, Townsville, and Big City forces reveal that many see the weapon as offering significant benefits for members of the public, in at least three ways. First, the weapon is seen as 'nicer' than other forms of force, being less painful and intrusive than other force options:

'I don't like CS spray, I've never used it... (Baton) is a big wooden stick and it's not a natural thing for girls to do. I don't like hitting people and its short term. To incapacitate someone is a lot nicer than breaking someone's bones, isn't it? There's less blood, less bone breakage, its indirect control. If I can control someone by not hurting them, I'm happy. It's less physical, less caveman'.

(Officer 1, Countryshire)'

'I tend to use TASER because its... the best option all round and it's the least intrusive. You are not going to injure anybody with it'.

(Officer 16, Countryshire)

'CS, it doesn't sit well with me, hitting people with a baton it's a bit crude. TASER I tend to use more than anything else, just because that is my decision to go to that first'.

(Officer 3, Townsville)

Hence, TASER - seen as a nicer, less physical, less intrusive use of force-is compared favourably to more crude, less sophisticated alternatives. The pain associated with the weapon is seldom mentioned and, where it is acknowledged, is quickly dismissed. For example, officers noted that:

The most recent (incident) I was involved in...(if we) didn't have a TASER it would have been a lot worse for me (and) for him... (Being) Tasered, he'd got barbs in him, but minor, minor injuries, and a slight amount of pain.

(Officer 12, Big City Force)

'Everybody I work with is conscientious and I can't imagine anyone deliberately causing pain and holding it (the TASER) there'.

(Officer 1, Townsville)

'Obviously if you hit someone with a stick its really going to hurt them... (with TASER) they may get 50000 volts but they will actually be fine, might feel a bit tired, but other than that, certainly for me... i'd still look to TASER more than i'd look to (baton or CS) initially'.

(TASER trainer 1, force with-held) 
Hence, where pain is mentioned, it is seen as minor and incidental. Such views are not restricted to police officers. For example, Kroll et al. (2019; 7, emphasis added) note that 'the probe-mode application (of TASER) provides pain, as do all less-lethal force options, but that is not central to its operation. The pain is also usually irrelevant since $80 \%$ of less-lethal force recipient subjects are largely analgised by illegal drugs, alcohol, or psychotic break'.

Second, the weapon is seen as highly predictable in terms of its effects and the amount of force delivered. It is favourably compared to other use of force options which are less predictable and 'can cause lasting injuries' and have 'potentially damaging effects' (see also the IPCC 2014a). Such comparisons are often implicit-but every so often they are made explicit. Thus, for example, the National Police Chief Council (2020: 1) states that:

When dealing with seriously violent people, the police recognise that many types of force carry risk, and these include physical restraint, baton strikes, impact rounds, police dogs and irritant sprays, as well as the CED (Conducted Energy Device). Nevertheless...in the main, the effect of CEDs is more consistent and predictable than many other types of force that the police might need to use (emphasis added).

Moreover, TASER is seen as more predictable due to the limited control officers have over the amount of electricity discharged. The weapon is seen as delivering a consistent dose, especially when compared to other force options that are reliant on the skill, judgement, and emotional self-regulation of the operator. Thus, an officer in Countryshire noted that:

'a lot of people get hurt when you go hands on and start wrestling them on the ground. People get the red mist, officers and suspects as well. When they're kicking off, and you employ arm entanglement and stuff, because they are properly resisting, if you don't get it right you can easily pop a joint, discolate a shoulder or something. And so if you use TASER you can be a little bit more, you can stand back, you're not going to injure them as much'.

(Officer 13, Countryshire)

Third, and relatedly, the weapon is also seen as safer. Injuries are seen as less serious and less frequent than those inflicted by other force options. Officers state that:

'There is no lasting injuries, is there? Whereas with a baton strike you can cause lasting injuries and I think that's the key thing... Generally I would say it's the safest, least damaging... You could end up in a big struggle... everyone gets bruised and hurt... whereas with this it is minimal'.

(Officer 1, Townsville) 
'Having used batons and... (seen) dog handlers before, I know on both of these occasions, the damage that you can do to people... is very high. With the TASER that isn't the case.'

(Taser trainer, interview 5, force withheld)

'if I hit someone with a baton they are going to get seriously injured, if I drag someone to the ground I can get hurt, they could get hurt... TASER seems like a pretty good option really. Two little imprints and they fall over. Hopefully it's not too serious.

(Officer 1, Big City Force)

As we will discuss further in the next chapter, officers also stressed the deterrent value of the weapon. In this viewpoint, not only is it less injurious when used, the mere fact of having the weapon provides a powerful deterrent which stops situations escalating. Indeed, one officer has even called it the 'tool of the pacifist' (Tangye 2016).

As such, TASER injuries are portrayed as minimal, short-lived and less damaging. Indeed, one trainer went as far as to describe the weapon as 'very safe'. In order to maintain this distinction, officers often implicitly, and sometimes explicitly, make a distinction between the effects of the electrical current itself-which was seen as not presenting an 'issue'-and so-called 'secondary injuries' (i.e., the falls resulting from the incapacitation caused by the current). For example, referring to the tragic death of Danielle Maudsley following the use TASER in the United States of America, a TASER trainer (interview 6, force omitted) noted 'the TASER never killed her, its the fact that, being Tasered, she fell on the floor and banged her head - and that's what the officers have to anticipate might happen'. Such injuries are seen as something to be managed on a case-by-case basis. As other TASER trainers stated:

'I think TASER is very safe, I don't think there are any issues with it at all. We have had some extremely well educated and well-funded individuals test that machine until destruction trying to find elements about it that are unsafe. In its basic design and its basic use I don't think it's dangerous at all. The danger comes from the secondary injury... that's where the injuries come into it, not the TASER itself'.

(TASER trainer interview 5, force with-held)

'I can understand why...the public perceive it to be almost brutal at times... They don't realise that, from a health point of view, apart from the risks that we've identified, it's not going to hurt like CS or a baton, or inflict a fatal injury. And unless it's as a result of a fall, I don't think there's any-one whose died from the actual shock'.

(Officer 8, Countryshire) 
Such views about the relative risk of injury from the weapon are largely, although not exclusively, bourne out by the academic literature (see, for example Kaminski et al 2013 c.f. Terrill and Paoline 2012 and, for a summary of the debate, see Neuscheler and Friedlin 2015). Taken as a whole, this tends to show that projectile electric-shock weapons are associated with fewer injuries than other use of force options, although — as we shall see shortly-this literature has been criticised on a number of grounds. In summary, then, there is a widespread view of projectile electric-shock weapons as causing less injury, while being more predictable and 'nicer', than other forms of force, and this view tends to be backed up by the academic evidence. As we will explore further in Chapters 5 and 7, such beliefs point to interesting tensions with the literature on traditional police subculture, which has traditionally glorified the use of force, masculinity, and an 'us versus them' attitude (see Hunt 1985 Reiner 2010; Waddington 1999; 2011); attitudes seemingly belied by an emphasis on TASER as 'the tool of the pacifist'. For now, however, our focus is on examining this myth of the weapon as a nicer form of force.

\section{Challenging the myth}

This myth may well be helpful, up to a point and in certain circumstances. However, following the actors - in this case, people who have been Tasered, and those who represent them-reveals compelling reasons to treat such narratives with caution. Indeed, people who have experienced the weapon highlight issues such as pain, fear, helplessness, loss of control, psychological after-effects, and concerns about excessive and disproportionate use of force, particularly against vulnerable groups.

\section{Electric-shock weapons as 'nicer'... or 'excruciating'?}

In contrast to narratives that sought to position the weapon as 'nicer' than other forms of force, a recurring theme in interviews was the degree of pain and suffering experienced. Participants described the experience of being 'Tasered' thusly:

'It was something I'd never felt it before, do you know what I mean, to say it was shocking was the least, it was really quite bad. I felt it awful in my body and then I just blanked out'.

(interview with Chris)

'I remember the pop going off and the next minute, it's difficult to describe but it's like muscle cramp, very, very severe muscle cramp for those seconds. And you want that turned off, to be quite honest. I remember saying to myself, no don't do it anymore. Whatever you want me to do, I'll do it'. 
Others who have been 'Tasered' describe the pain as 'excruciating' (Rappert 2004) and as 'the most profound pain I have ever felt' (in Sussman 2012: 1353). As such quotes demonstrate, the 'profound' amounts of pain caused are exacerbated by its all-encompassing nature. Whilst baton strikes and handcuffs, for example, tend to be experienced as localised pain, many of those subjected to TASER talk about it affecting everywhere, taking over their whole body:

'I did feel it and not just between the two areas (where the probes hit). If it had been just between the two areas you could probably put up with it, fight against it, you know. But it was the shock of it, it spread all over my back, it paralysed me'.

(interview with Tom)

The familiarity (or otherwise) of the pain experienced is also important, particularly the sense that it was a type of pain they had 'never felt before'. This is a point also made by many of the lawyers I interviewed. One of whom, who wished to remain anonymous, explained that 'it's a very frightening experience (for many clients) because it's so unlike anything else... it is like nothing they've ever experienced'.

Families of those who have tragically lost loved ones similarly highlight the pain experienced. In the case of Marc Cole, the inquest jury found that the use of a TASER had 'more than a trivial impact on Mr Cole's cardiac arrest' (Cornwall and Isles of Scilly Coroner 2020b). His sister, Lisa Cole, noted that 'my brother was tortured with TASER for nearly a minute', and descriptions of the pain of Tasering are often described in similar terms, from a variety of disparate sources. For example, the UN Committee Against Torture (2008) stated its concern that 'the use of these weapons causes severe pain constituting a form of torture'. The manufacturer has previously stated that TASER use 'can cause temporary discomfort, pain, stress, panic, or startle which may be injurious to some people', (TASER International 2010: 4). More recent product warnings state, in part, that 'exposure causes certain effects, including physiologic and metabolic changes, stress, and pain. In some individuals, the risk of death or serious injury may increase with cumulative energy weapon exposure' (Axon 2021: 2). Far from being 'nicer', there is some consensus that being Tasered is an extremely painful event, with such concerns exacerbated by the T7 weapon.

\section{Electric-shock weapons as predictable... or frighteningly unpredictable?}

As these quotes show, pain, panic, fear, and unpredictability are highly connected. While official accounts stress the predictable nature of the weapon, this is a view not always shared by those subjected to TASER. 
Instead, they see the weapon as unpredictable and highly frightening, in (at least) three ways. First, the unfamiliar nature of TASER exposure may exacerbate the anxiety, fear, and 'highly emotional' states (Kroll et al 2014: 93) that many people feel when experiencing use of force. Sussman (2012: 1355) notes that 'the fact that a Taser's ... electrical current (is) unlike anything most people have experienced... exacerbates fear because the brain does not know the extent of the bodily threat'. Second, and relatedly, a belief that they might have died features in many accounts of the experience.

'I could have died out there as far as I was concerned... Once you get Tasered with one TASER, you could have a heart-attack or you could die. There have been people in Britain that have died from being Tasered once...let alone being Tasered several times'.

(interview with Chris)

'The TASER hit me in the back and it started sending all these thousands of volts through me and I was terrified. I mean I had two strokes already caused by stress. When these volts were going through me I dropped the stick involuntarily and I collapsed on the floor face down. I was shaking and I thought 'I'm going to have another stroke any second and this one is going to kill me. I'm being killed. I'm being killed'.

(Colin Farmer, quoted in Carter 2012)

'When the TASER hit me I thought it had killed me. I thought I was dying and I was thinking 'my children and my grandchildren need me'.

(Judah Adunbi, quoted in BBC News 2017)

Thus, while officers highlight the weapon's predictability, those who have been Tasered highlight the unpredictability and the unknown unknowns around the weapon.

Interestingly, too, the safety and predictability that officers ascribe to the weapon is reversed when electric-shock weapons come into the possession of others. For example, officers on one of the training courses were played footage of an incident where a member of the public had taken an officer's TASER. The situation was described as extremely dangerous and it was noted that, armed with the TASER, 'the subject is an extremely high threat to himself and others on the street'.

The weapon is seen as unpredictable in a third way, too. Not knowing, or being able to control, how your 'body is going to react' to the weapon, brings with it a fear of embarrassment, humiliation, and of negative evaluation from others. This is less present with other weapons where, whilst the degree of injury may differ, responses to its use tend to be largely controlled and predictable. For example, following my voluntary exposure to the weapon at the 
headquarters of Axon (then TASER International), I reflected in my research notes that, when given the option to be Tasered:

'I was apprehensive that, in losing control of my body, I would do something to embarrass or humiliate myself (scream, collapse, fall awkwardly, who knows?) and concerned enough that I asked them to Taser me somewhere a little more 'private'. On the face of it, this is itself a trivial concern that is, in itself, slightly embarrassing — after all, who would be superficial enough to worry about how they were perceived whilst being Tasered-but one that points to something more fundamental. Namely that not being able to anticipate how one will respond, or necessarily control that response-whilst simultaneously having one's involuntary bodily responses on show for all to see-is an important element that both adds to the mystique and fear around the weapon and also impacts on (or threatens to impact on) human dignity'.

Whilst under certain conditions exposure to certain weapons-such as tear gas-can actually be a collective experience which facilitates resistance, and increases capacity for action (Roelvink 2010), exposure to TASER and one's bodily reactions is often highly individual and difficult to predict and can be highly humiliating.

\section{'The State took my body': Loss of control}

This loss of control is an important point in its own right and one that challenges the myths both around the 'niceness' of the weapon and its predictability. To some extent loss of control is an issue when experiencing any kind of violence (Macmillan in Meade et al 2015: 3-4) - particularly when it is inflicted by State agents, such as the police. Yet such feelings may also be exacerbated by projectile electric-shock weapons. Whilst members of the public may be subdued or cowed by the application of other forms of force, they nevertheless remain in control of their faculties. Individuals are 'controlled, then, but nonetheless and necessarily in control' (Anais 2009: 56). This control is often taken away when someone is Tasered.

There are some potential issues with such a line of reasoning. One has to be careful neither to overstate the efficacy of TASER (see Ho et al 2012 for further discussion), nor to assume such incapacitation is externally imposed by TASER. Nevertheless, such insights point us to a virtually unique aspect of the TASER experience: the sense of powerlessness invoked and how terrifying this loss of control can be. This is of profound importance to those subjected to the weapon:

'(Individuals exposed to TASER) can't remember much about the incident apart from the overwhelming sense of pain and loss of control... 
There is something that makes it slightly different from a baton strike... the fact that not only is it incredibly painful but you have lost all control... You ignore at your peril that feeling'.

(Oliver Feeley-Sprague, Amnesty UK's Programme

Director for Military, Security and Police)

'(Clients) mention the feeling of incapacitation, feeling like jelly, the helplessness they felt.... Not all of them have secondary injuries but... anybody who has been Tasered will talk to you about having nightmares of being Tasered and feeling helpless and so forth'.

(Solicitor Ian Gould)

'While its operating you can't move at all... You have no control and you don't know when the thing is going to stop, you just want it to stop. That's why I would say it's a horrible thing to use. So it's not a very good thing to have, is it, they can do all sorts of things'.

(interview with Chris)

Similarly, Martyn Underhill, who at the time the research was conducted was the Police and Crime Commissioner for Dorset, recounts a conversation with an individual who had been Tasered, who felt that 'the state took away my body' (interview with Martyn Underhill). Likewise, a journalist compared the experience to being 'taken over. Being Tased is... like what I think it would be to be possessed... Instantly, I was not in charge of me, and there was nothing I could do about it' (Gross 2010: 1). Interestingly, the Chief Executive of Axon, Rick Smith, has expressed a similar observation. He notes that:

'what makes TASER such a wonderful technology for a weapon is (that) we take out command and control... Like we didn't actually damage the wiring of the body, it's all still intact, we've just temporarily taken it over'.

(Rick Smith in Start up Grind 2015: 58, 30-59 minutes, emphasis added)

Thus, while myths and officer narratives position the weapon as a 'nicer' and more predictable form of force, this characterisation was not universally shared by those who had been on the receiving end of the weapon.

\section{Less injurious?}

There are also important reasons to question the third part of the myth; that projectile electric-shock weapons are less injurious than other force. First, the research on physical injury is reliant on a small number of datasets 
(Neuscheler and Friedlin 2015), almost all of which are drawn from the United States of America and may have limited generalisability elsewhere. Moreover, concerns have been raised about the statistical techniques used (Terrill and Paoline 2012), including their inability to compare electric-shock weapons directly to other forms of force and the way in which injuries have been defined and measured (Terrill and Paoline 2012 c.f. Kaminski et al 2013).

Second, characterising projectile electric-shock weapons as safer than other forms of force represents a 'best-case' scenario and requires one to ignore the distinct possibility that individuals might fall and incur significant injuries. As we saw above, officers often square this circle by making a distinction between injuries from 'the shock' itself and so-called 'secondary injuries' and by presenting use of force options as mutually exclusive. However, distinctions between primary and secondary injuries would seem to matter less for those involved in the incident, who may still incur significant injuries irrespective of how they are classified. Moreover, presenting the use of electric-shock weapons as a binary choice-and characterising it as a choice between TASER or baton, or between TASER and empty hand techniques-misses the important point that TASER is often used with other use of force options, not instead of them (Dymond 2018). This limitation is also found in much quantitative work published on the topic (Terrill and Paoline 2012), including my own (Dymond 2018).

Third, aside from physical injury, the psychological effects of the weapon were an important consideration for many interviewees. While the people I spoke to had no physical injuries, they noted the psychological complications associated with incidents involving TASER:

'I don't feel safe or content anymore, do you know what I mean, I'm not the happy person that I was before, as I say psychologically... I've been sort of having nightmares and stuff about it as well. It's not too bad now, though I have panic attacks sometimes when I see police, I don't like to be around them. If I see them, I'd avoid them'.

(interview with Chris)

'There's no physically long lasting effects but mentally it has made me sort of, more scared of police with TASERs. There's been a couple of incidents afterwards, I was assaulted somewhere else (name of location omitted), and I was going to phone the police but it put me off'.

(interview with Tom)

'Since it happened I have been diagnosed with traumatic stress disorder because of what has been going on.... My life has been ruined...the incident has left me terrified'.

(Colin Farmer, quoted in Edmonds 2014 and Disley 2014) 
Similarly, Oliver Feeley-Sprague, Amnesty UK's Programme Director for Military, Security and Police noted that, in several of the cases they reviewed, the weapon has been associated with far-reaching psychological effects. Indeed, for one particular individual the 'TASER event has been linked to a very significant relapse of PTSD-like symptoms... He's clearly not sleeping, he's having more incidents of paranoia, he has clear agoraphobia.' He argues that some cases are notable for the fact that while people have had a variety of force techniques used on them:

'the thing that's causing the flashbacks, causing the traumatic event, has been the use of TASER.... It's clear that the use of the weapon has been deeply psychologically troubling to them and they are reliving those moments time and time again... (That) is evidence of an effect that's not really understood, because it's not really about physical injury'.

As such, while the myth around the weapon stresses its quick, almost 'instantaneous' recovery time, those with lived experience of the weapon stress a range of longer-term issues. Yet it is difficult to trace these directly back to the weapon. Indeed, in some cases, TASER is seen as a broader 'package' causing psychological difficulties. One lawyer noted that, for one of their clients:

'Just the TASER would have been sufficient to give him psychological injuries. If he had just been Tasered and arrested that would still have had an effect on him. But I think the whole package, for him, that's what's caused it, the whole thing. It's flashbacks, its nightmares, it's reliving the experience again...it isn't to do with TASER necessarily'.

Similarly, Kevin Donoghue noted that 'it can be difficult to carve out the specific use of TASER from use of force...(and) the whole injustice of the incident... but it does cause a psychological impact. Clients have had to take time away from work because they can't function, be that (due to) the sense of injustice, the flashbacks, the PTSD type symptoms'.

This is not, necessarily, to suggest that projectile electric-shock weapons cause more psychological distress than other weapons-indeed, as Meade et al. (2015) have found, research suggests that violence, in general (not necessarily that generated by police), may induce PTSD symptoms-but simply that this is an area in need of further research (see also DOMILL 2012).

\section{Concerns about necessity and proportionality}

Comparing the injury potential of electric-shock weapons to other forms of force also misses the important question of whether force actually needed to be used in the first place- a key concern for many. Indeed, noting that officer 
explanations for using TASER include reference to other forms of force causing more injuries, the IPCC commented that in place of such comparisons, they 'would expect to see greater emphasis placed on... using communication and the information they have rather than a quick escalation to use of force'-i.e., a consideration that the use of TASER, regardless of its benefits, may not always be warranted (IPCC 2014a).

This was an important point noted by many who had been Tasered and their representatives. As Solicitor Ian Gould stated, for many clients: 'the thing that has disturbed them the most is (that) the use of TASER... (has) just not been called for at all' (interview with author). Those that I spoke to were keen to explain the incidents in which they were involved, from their perspective, and to explain why they felt the use of TASER had been disproportionate. In one incident, following an argument with individuals in the street, officers went to the house of one of the individuals concerned, who said:

'There are cases when it (TASER) might be the best option, if you've got someone...being very violent... But what I am saying is, in my case, it should never have been used. He (the officer) was on a mission and decided to take a thing against me... He tried to arrest me and they, sort of, tried to push me through the door to put handcuffs on. And of course I held my arms so they couldn't. I wasn't trying to assault them, I was just resisting what was going on. He was straight in (with TASER). It would have been far better if he'd...said 'Excuse me, could we talk to you?'... He should have been composed and calming it down... But he was like a bull in a china shop'.

(interview with Tom)

In another incident police were asked to assist medical staff to section an individual. The individual involved described the incident as he recalls it:

'I parked up, and got out (of my car). The police were asking me my name... they were talking to me at first so why couldn't they carry on in that manner?.. They were saying I was trying to get something out of my trousers... they were saying I was going for a knife... but because my arms were spread, I think I was just trying to get them down, to, like, put my keys in my pocket. (They Tasered me and) I fell to the ground. I was wondering, then, why they didn't arrest me... But they let me walk away, and then Tasered me again. They didn't have to TASER me... they chose to'.

(interview with Chris)

Similarly, Desmond Ziggy Mombeyerara, who was subjected to TASER in an incident that was widely shared on social media, noted that, instead of using TASER, 'all of this could have been dealt with in a fair way. The aspect 
of courtesy, just dealing with people in a normal, gentlemanly way ... (as) a matter of common sense...It comes back to the humane side of dealing with things' (quoted in Stand up to Racism 2020: 54, 1:04 minutes).

Such quotes illustrate the overlapping concerns of many of the individuals involved, who are concerned both about the propriety of using electric-shock weapons specifically, but also have concerns over the necessity of using any force whatsoever in the incidents as they have described them. A common thread was that the communication tactics had not been appropriate, and that opportunities for engagement had not been exhausted before TASER was deployed. They also felt that their cases were not isolated incidents, but part of a larger trend whereby officers used the weapon in circumstances where it was not required. As Tom noted:

'They think they've got a harmless weapon... they just go Tasering everybody, thinking that it's safe. The TASER makes them behave differently, they've got an instant way of control and they're trigger happy, you know. (In my case) I'm quite certain it was the mind-set of the officer, combined with the trigger happy way that officers use it (Taser) and also with the fact that... he didn't like the idea that I was suddenly a citizen standing up for my rights... Using it in situations where a person might harm themselves, commit suicide, or to stop a violent crime... I can understand that but it's being abused'.

(interview with Tom)

Colin Farmer is also quoted as saying that the officer "should never have shot a blind man in the back... If he can (do that) and get away with it what signal is that giving out to people?... I have lost faith in the police, I have had no justice. If it can get to this then god help anybody.' (quoted in Edmonds 2014).

Moreover, such incidents were seen, not as isolated occurrences, but as part of broader structural issues and patterns of discriminatory behaviour. In a high-profile court case in England, Ras Judah Adunbi, a respected community elder and member of the police's race relations advisory group, was Tasered in the face. We will discuss this case in more detail in Chapter 8. However, for now it is important to note Judah Adunbi's views (in Cork 2018) that the use of TASER against him and the subsequent court case was an example of 'a terrible crime against the country... (where) black people don't get justice in this country' and hoped the fact that the 'prosecution was brought will mean that other black people in Bristol will not be Tasered in the face when walking their dog; and that the police will finally realise that not all black people look or act the same' (in Grimshaw 2018). Similarly, Millard Scott, who was Tasered in another high-profile incident partially caught on camera, believes he was Tasered because he was black, saying 'it seems to me we're being singled out and targeted' (as reported in Ray 2020). 
Lisa Cole, sister of Marc Cole, expressed her concerns that officers' treatment of her brother were reflective of broader concerns about how the police deal with those experiencing mental illness and mental health crisis. She described how police 'went charging in towards Marc screaming 'put the knife down', even though wasn't a risk to anyone else at that point, and the eyewitnesses heard Marc say 'why, what have I done, what have I done'. He was confused and scared, and two eye witnesses corroborated that. And instead of saying 'Marc, you haven't done anything', you're safe, we don't want you to hurt yourself, your mum is on the way, treating him like a human being, they went straight into militarisation and aggression. She noted that this was not an isolated incident but part of a pattern of 'excessive use against vulnerable groups':

that's a massive concern because it is showing us there is a lack of understanding of mental illness in the first place and how to deal with mental health crisis (without which they) resort, almost instantaneously, using the TASER... I'm not saying that, in some situations TASERs aren't warranted, I'm not saying that you shouldn't use them against violent offenders but the statistics are telling us a different story. It's not people who are violent who are experiencing death, its people with mental illnesses... They tend to jump straight to the use of force... It's too easy to use this thing in your hand, that's what it is'.

Quotes such as these highlight concerns over inappropriate, even abusive, use of the weapon and show that they are not isolated incidents. They also highlight that many speak about the weapon in complex, nuanced ways. Attention is given to the role of material devices such as TASER, which are not assumed merely to be passive tools, but are seen as having the ability to affect human behaviour, with officers changing their actions due to that 'thing in their hand'. Further, negative outcomes (in this case, the 'abuse' of the weapon) are not seen as determined solely by the weapon, but are seen as resulting from complex interactions between the weapon, beliefs about that weapon (it's 'harmless' nature), individual 'mind-sets', and interactions between human actants (for example, interactions involving 'a citizen' claiming his 'rights' or those with mental illness). Such accounts speak to the need to take technologies seriously, and also highlight that concerns about necessity and proportionality should not be seen in isolation. Instead, they are heavily intertwined with issues around fear, pain, loss of control, and the mental health issues and psychological effects experienced both before and after TASER deployment.

It should not be presumed, however, that such responses are unique to incidents involving TASER. Indeed as one lawyer noted, in all my cases, clients would say that the use of force as a whole is unnecessary. It's not just the TASER, it's the whole thing, and it's difficult to differentiate between them'. 
Rojek et al. (2012: 314-316) observe 'unanimous' themes of 'injustice' and 'excessive force' throughout all citizens' accounts, regardless of the type of force that was used on them. Moreover, whilst some people subjected to the weapon have concerns about its use, this is not universal. Indeed, BBC Radio 4 (2013) quoted a woman who had been sectioned by police after threatening members of the public with a knife. Her account described how she:

'picked up a sharp piece of crockery... I walked towards one officer with the shard in my hand saying I was going to kill him too. It was at that point that he pulled out the TASER. It was very scary. It was the one thing that made me stop... I am really glad they had the TASER with them. Had they not had the TASER, perhaps they would have tried to restrain me physically and it would have been a dangerous situation all round. The police were very professional and they handled it exactly as they should have done'.

(BBC Radio 4 2013, see also Police Ombudsman for Northern Ireland 2014)

Thus, it should not be assumed that all experiences of the weapon are negative, or that all of the negative issues associated with TASER use are restricted solely to that particular force option. Taken together, however, the accounts of pain, fear, loss of control, helplessness, psychological experiences, flashbacks, and excessive use of force recounted above challenge mainstream narratives around electric-shock weapons as a 'nicer', more predictable and less injurious use of force option.

\section{Engineering acceptability}

Thus far, this chapter has been concerned with examining myths and hearing a range of evidence around the 'niceness' of projectile electric-shock weapons such as TASER. Such evidence, claims, and appeals to the 'empirical reality' around the weapon are an important point of consideration. Yet simply trying to isolate the 'empirical reality' around the weapon and clarify the 'facts' of the matter should not be the analyst's (only) job (see, for example, Grint and Woolgar 1992; Rappert 2003). It is also necessary to look at the conditions, networks, and participants (human and non-human) that make 'facts' real (Anais 2015: 47) and taken for granted. Thus, instead (or as well) as trying to find the definitive 'empirical reality' around exposure to the weapon-and whether it is 'really' nicer and safer-we could usefully enquire how such claims are made to seem real.

Answering this question, I argue, requires taking Law's concept of heterogeneous engineering seriously. This notion helps capture the interesting insight that, in order for technologies to be successful, it is not sufficient (or perhaps, in some case, even necessary) for them to be technically sound. 
Instead of solely resolving technical challenges, engineers need to solve challenges that are a 'tangled and complex network' (Law 2011: 5) of the technical (for example, how to harness and transmit electricity), natural (how to interact with biological entities in effective ways), and social (how to do so in a way that will be widely accepted and adopted). The 'tactics' used by these heterogeneous engineers must draw together natural, technical social, and other elements in order to create solutions that are not just technical but inherently socio-technical in form. Successfully developing a product requires 'fitting together...bits and pieces from the social, the technical, the conceptual and the textual' (Law 1992: 381). A key challenge is not just to engineer a 'technical' solution, but to heterogeneously engineer and fuse together 'bits and pieces from the social, the technical, the conceptual and the textual' (Law 1992: 2), so as to ensure the socio-technical acceptability of the weapon and the pain, fear, humiliation, and loss of control associated with it. How, then, might this happen, and what engineering 'tactics' are used in order to do so? I suggest there are several ways in which this happens.

First, the minimal size of the probes, the discrete visual appearance of the weapon and the relative quiet of the electrical discharge when it is working correctly not only secure the functioning of the weapon, but also help secure its acceptability. Pain is often conveyed by documenting the injuries caused and making visible the instruments used to inflict the pain, yet this is difficult in the case of projectile electric-shock weapons. Sometimes the only visible injury from the incident will be the small incisions where probes have entered. Further, while images of, for example, batons or more rudimentary weapons such as nails or sticks allow people to imagine the pain inflicted by the devices, looking at the TASER weapon provides little clue as to the experience of being Tasered. As Scarry (1985: 16: emphasis added) notes, 'the point... is not just that pain can be apprehended in the image of a weapon but that it almost cannot be apprehended without it'.

Furthermore, watching projectile electric-shock weapons being deployed is (often) less visceral than watching people being exposed to other forms of force. Whilst one may hear the thud of a baton hitting the skin, or the closing of handcuffs around someone's wrist, TASER can be almost completely silent. Visually, too, while other force options target the outside of the body, TASER aims to target internal mechanisms, stimulating sensory and motor nerves (Axon undated d: 7). The interaction of these mechanisms with the weapon is much more difficult to observe than, say, the impact of baton strikes, or irritant spray, on eyes, arms and legs. To some extent, then, 'the Taser strike is decidedly less harrowing and easier to answer for than... baton blows' (Anais 2009: 54) - even while the visible effects of the weapon (freezing, immobilisation, paralysis, collapse) are as mysterious as they are impressive to behold. Witnessing a TASER exposure, thus, manages to be both more-but also less-harrowing than traditional forms of force. In such ways, design features of the weapon solve not only 'natural' and 'technical' 
issues - such as the discharge of electricity-but social ones, such as how to discharge electricity in an acceptable fashion.

If one set of tactics are 'technical' in nature, other tactics are more conventionally described as social. For example, marketing materials present "idealised images of the police... as "heroes" while discrediting perceived "villains" (Wozniak and Uggen 2009: 276), thus making it easier to justify the infliction of pain upon the latter. Such themes are also picked up by the media which, at least in the USA, 'cast victims of police killings as physical and social threats and situate police actions within legitimate institutional roles' (Hirschfield and Simon 2010: 155). Such trends contribute to a climate in which the experiences of those who have been shocked-many of whom are already vulnerable and marginalised-are undervalued.

If these tactics minimize the humanity of those exposed to electric-shock weapons, other tactics serve to minimise the seriousness of exposure. This can be done by providing opportunities for people to be exposed to TASER shocks themselves, in highly supportive and artificial settings. Rappert (2004: 23) has noted that, when participants receive shocks together, and recover quickly, such experiences can help to downplay the trauma involveddespite the many differences between collective voluntary exposure and use in real-life conditions. Moreover, conferences sponsored by electric-shock manufacturers provide an occasion to show 'light-hearted' videos of staff members being hit by electric-shock weapons, often met with 'wild cheers and applause', and even laughter, from the audience (Wozniak and Uggen 2009: see also Rappert 2004). Similarly, Lim and Seet (2009: 170) express concern about the 'disregard for the potential hazards of TASER use' shown in 'video vignettes' hosted on video-sharing websites. Showing exposures in such ways is not particularly conducive to sober reflection on the consequences of inflicting pain, humiliation, and loss of control on individuals.

It should not be claimed, however, that these tactics are all intentional, conscious, or deliberate. To do so would be giving too much power to human agency alone, while other factors may also be important. These include, for example, the obduracy of electricity which render certain solutions (e.g., barbed probes attached to wires) more compelling than other solutions (e.g., wireless projectiles) and the broader difficulties people face when expressing pain. It has been argued that the 'in-expressability' of pain is an 'essential' component of it (Scarry 1985: 3) and even highly educated, high-status individuals have found it extremely difficult to convey the experience of being Tasered (Rappert 2004: 25).

These difficulties are compounded as assessments and interpretations of people's experiences-including the pain they have suffered-are often bound up with judgements about their credibility (Rappert 2004). The very factors that may make individuals prone to the use of electric-shock weapons may mean that they may not always be able to describe the experiences as eloquently as they might like and can be seen as less credible witnesses. 
When compared to law enforcement officers who often enjoy the 'presumption of credibility', such voices are often met with scepticism (Sussman 2012: 1377).

The combined effect of these tactics is that those who have been Tasered can be silenced, dismissed, and (once more) humiliated. In the aforementioned Ras Judah Adunbi case, Mr Adunbi (quoted in Cork 2018) expressed his frustration that:

'during the... trial, I played a minor role. When I gave evidence, I was asked only three or four questions. What I saw or felt or thought as a victim... did not matter at all'.

\section{Conclusion}

To date, the literature assessing the use of projectile electric-shock weapons has tended to focus on quantitative assessments of physical injuries (see Neuscheler and Friedlin 2015 for a summary). Yet use of force experiences are not just statistical abstractions but are highly personal and meaningful for those involved. In contrast to much of the literature, this chapter has 'followed the actors', in particular those affected by TASER, and has brought to the fore some of the qualitative experiences of those subjected to the weapon. In so doing, it provides evidence to challenge the myth that projectile electric-shock weapons are a 'safer' form of force for members of the public and, in particular, that they are 'nicer', more predictable, and less injurious than other forms of force. This, in turn, brings into question the claims of trainers and officers that the weapon is 'very safe' and that there are 'no issues with it at all'.

There are powerful reasons why officers might make such claims. As Waddington (2011: 100) states, those who exercise authority 'wish to see their own behaviour as legitimate' and generate 'legitimating myths' for this purpose, which may depart significantly from reality. Furthermore, as research by Collins $(2009 ; 2012)$ and Hunt (1985) has revealed, there are a number of psychological barriers and difficulties involved in using force, with officers often looking for reassurance that their actions are legitimate, both legally and morally. This is often combined with strong, almost messianic beliefs about the weapon amongst some TASER trained officers- a point we return to in the next chapter. But for now, it is important to note that officers may seek, after the event, to portray their use of force as a 'nicer' and 'safer' course of action and to present the use of the weapon as less 'crude' and brutal-both to themselves and to external audiences.

Such myths are troubled, however, by the experiences of those who have been Tasered and by their accounts of the pain, fear, and loss of control experienced as well as the unpredictability of the weapon, the psychological symptoms experienced after use and doubts about its necessity. They are further troubled by the evidence of the extensive heterogeneous engineering 
and tactics employed in order to construct certain facts and claims-for example, that the weapon is 'nicer' and 'less intrusive'-and render them plausible. These tactics include minimizing the humanity of those exposed to electric-shock weapons, minimizing the seriousness of exposure, and providing few visual or auditory clues as to the pain inflicted. In other words, it is not just the 'empirical reality' (Terrill and Paoline 2012) that matters, but the tactics used to make such claims 'real' and to silence those who would claim otherwise. These findings have a number of practical, methodological, and theoretical implications.

First, the literature's preoccupation with quantitative assessments of physical injury is necessary but not sufficient to understand the effects associated with electric-shock weapons. The focus on injury alone may serve to downplay the pain, suffering, fear, and loss of control associated with electricshock technologies - and perhaps with other police weapons too. In this sense, following the actors, as Latour (2005:12) has urged us to do, reveals new insights and concerns that are less amenable to quantitative analysis.

Second, attending to injury, pain, and psychological sequalae draws attention to the outcome of using force, but important questions also need to be asked about the process, and rationale, for having used force in the first place. The focus on the former brackets key questions about proportionality of the force that was used: the latter brings them sharply into focus. Projectile electricshock weapons may, or may not, cause fewer serious injuries than other options available. Yet, as the evidence from those who have experienced TASER reminds us, a focus on such topics can mask another important question: whether any such injuries, pain and suffering arising from the incidentwere justifiable in the first place. Article 1 of the UN Convention Against Torture (1984) excludes from its definition of torture and ill-treatment 'pain or suffering arising only from, inherent in or incidental to lawful sanctions'. If the sanctions are not legal then, irrespective of the nature or severity of any 'injury' incurred, attention must also be given to the pain and suffering inflicted. Whether or not a weapon such as TASER is 'nicer' and 'safer' than other use of force options is immaterial if it is used in situations where it is inappropriate, disproportionate, and unnecessary, and if it is used in situations where force is not required.

Third, and relatedly, the concerns raised here about the longer psychological impact of exposure to police force-including electric-shock weaponsreinforce Meade et al.'s (2015: 2) call for more attention to be paid to how use of force impacts long-term psychological well-being. As Meade et al. (2015: 2) noted, 'police use of force may function as a trauma, similar to violent victimisation. Researchers have observed that youths exposed to violence in the home or in the community display greater...aggressive behaviour, and anti-social attitudes'. Similar tendencies may be at play following police use of force-and are all the more likely when that force is seen to be disproportionate. If this is the case, using such force may create as many problems as 
it solves. However, it is important that such effects can be captured systematically, and attempts made to analyse whether particular weapons have a bigger psychological footprint than others, and under what conditions.

Fourth, this chapter has demonstrated the practical value of key conceptssuch as the notion of 'following the actors' and 'heterogenous engineering'found in Science and Technology Studies. While following the actors seems like an obvious insight, it is all too often lost in the largely quantitative debate around police use of force. Moreover, the process by which being 'shocked' is rendered acceptable - to the extent that it is - resonates with Law's notion of heterogeneous engineering. The challenge here is not purely a technical one. It is not to produce a weapon that causes pain, but to produce a weapon that may cause pain in a way that can be deemed 'nice', 'less intrusive', and socially acceptable. Multiple tactics and engineering solutions-including minimizing the humanity of those exposed to electric-shock weapons, minimizing the seriousness of exposure, and providing few visual or auditory clues as to the pain inflicted-are used to try and render acceptable the device and the pain associated with it.

It is noteworthy, too, that many who speak about their experiences with the weapon do so in ways which are distinctly socio-technical. In such descriptions it is neither the inherent nature of the social or the technical that matters but, rather, the ways in which they interact. In such descriptions, too, weapons are much more than mere tools but can have multiple effects, including encouraging officers to 'use the thing in (their) hand'. Yet, as we shall see, this contrasts markedly with how officers speak about the weapon and the decisions they make around it. We will return to this topic throughout the book, including in Chapter 7. For the time being, however, we turn in the next chapter to officers' views on a slightly narrower topic: the relationship between the weapon and officer safety. 


\section{'There's nothing bad I can say about TASER' TASER and officer safety}

\section{Introduction}

While claims about the benefits of projectile electric-shock weapons for members of the public are disputed, they are commonly seen as being beneficial for officers. Indeed, it is often claimed that they are so popular because of their ability to protect officers, minimising-or entirely preventingassaults, minor injuries, and even serious injury and death. This chapter seeks to examine the claims around officer safety in more detail. After examining the (largely quantitative) academic literature on officer safety in Part 1, the chapter complements this with officer views on TASER and officer safetythe first time that this research has been done outside of the USA. This is particularly valuable because, as De Angelis and Wolf (2013: 4) note, little research has explored the views of the officers armed with the weapon (see also Paoline and Terrill 2011; Rojek et al 2012; Sierra-Arévalo 2019, who highlight the lack of research in this area). The account that officers present, and which is advanced in Part 2, is broadly positive, suggesting that officers perceive electric-shock weapons (specifically TASER, which is the only brand in use in England and Wales) as safer and more effective than other alternatives - a finding which is often (but not always) borne out in the academic literature on officer injury.

While these officer accounts are highly valuable, a range of factors - including canteen culture (Waddington 1999) and broader beliefs around technologies more generally (Feenberg 2010) — might help explain why officers tend towards one particular account, and tell one set of stories (Shearing and Ericson 1991) instead of others. After examining some of these factors, in Part 3, I then present an alternative account, one that draws on officer views to highlight slightly different, and less positive, features of the relationship between projectile electric-shock weapons and officer safety.

In doing so, I challenge the mainstream myths around projectile electricshock weapons and officer safety. I also underscore the importance of looking not just at the technical features of such weapons - which might lead one to conclude that they are, indeed, safer for officers-but, instead, looking 
more broadly at the socio-technical network surrounding them, which supports the opposite conclusion. Further, I highlight the need to carefully investigate claims about the benefits, limits, and effectiveness of technologies, including electric-shock weapons, instead of regarding such assessments as true or self-evident. Bloor's symmetry - the notion that the same type of explanations should be sought for decisions, actions, claims, and statements whether or not they are seen as 'true' or 'false'-reminds us that they deserve further examination (see for e.g., Bloor 1999). Building on discussions in the last chapter around how claims about the weapon being 'nicer' for members of the public are fashioned and made real, in this chapter, I highlight the processes that make claims about the benefits of the weapon for officer safety seem real to those directly affected. We start, however, by considering the academic literature on officer safety.

\section{The academic literature on officer safety}

The traditional narrative or myth around the use of projectile electric-shock weapons is that they result in fewer injuries and assaults to officers, thanks to their technical features; in particular, their effectiveness, ability to incapacitate, and ability to be used at a distance. This can help to prevent officers from getting close to violent individuals and putting themselves in harm's way (see, for example, Ariel et al 2019; Jauchem 2015; Paoline et al 2012). Indeed, the majority of studies on projectile electric-shock weapons and officer injury suggest that their use is associated with decreased rates of injury to officers (Alpert and Dunham 2010; Ba and Grogger 2018; Jenkinson et al 2006; National Institute of Justice 2009; 2011; Neuscheler and Freidlin 2015; Stevenson and Drummond-Smith 2020). Whilst the majority of these studies focused on analysing data from forces that had already adopted the weapons, other researchers have been able to look at officer injury data in forces prior to, and following, the introduction of the technology - and tend to come to similar conclusions (Lin and Jones 2010; Macdonald et al 2009, Police Executive Research Forum 2009). As such, although a couple of studies report both significant and insignificant results in this area (Macdonald et al 2009; Smith et al 2007), the majority of studies find that projectile electric-shock weapons are associated with significant reductions in officer injury.

These studies have markedly advanced our understanding and seem intuitively appealing, chiming with common sense. As such, the idea that the weapon is effective and safer for officers is generally accepted (Paoline et al 2012:115), and even seen as 'an article of faith' (Lin and Jones 2010: 153) amongst academics and officers alike. This view is also espoused by some manufacturers and suppliers, with early marketing materials even reportedly claiming a 'field success rate' of '97\%' and more 'stopping power' than a .38 special firearm (quoted in Gilbert 2019). 
Furthermore, for many, the effectiveness and technical merits of such weapons explain their popularity and success. For example, in White's account, the 'key features' of the weapon are its 'benefits', specifically 'it's relatively short duration of recovery time among those who are exposed, its reliability from a distance... its compact size and utility' and its efficacy (2014: 6). As a result, the 'traditional inflexibility that defines police departments' have been overcome by the 'effectiveness of the TASER' (2014: 293). Jauchem (2015: 53) notes that 'as CEWs became more effective, they were then more widely adopted' and Jenkinson et al state that 'indirect evidence for the efficacy of TASER weaponry comes from the continually increasing sale of stun devices to law enforcement agencies'. Overall, White summarises, 'innovations with greater upsides', such as TASER, will 'diffuse rapidly' compared to innovations with 'more risks than rewards' (2014: 284).

Valuable though this literature is, it has a number of conceptual and practical limitations. When beliefs around the weapon are positive, and take up of the weapon has been rapid, these developments are seen as logical conclusions. They are seen as inevitable, 'rational' (White 2014: 293) responses to objective qualities of projectile electric-shock weapons-in short, not really as beliefs at all, and not worthy of further investigation or explanation. In contrast, when beliefs around the weapon are more negative, citing risks and disadvantages, these are seen as 'false' accounts that can only be explained by social factors. For example, there is some consideration, in White's interesting and complex work, of how social factors - including 'social networks' and 'laws, values, norms, ideologies, and belief systems'-can either facilitate or hinder the adoption of a technology (2014: 292). There is also talk, in passing, of 'interplay' between technology, human actors, and environmental context (2014: 282). Yet these are often invoked to explain misconceptions and erroneous beliefs. Hence, in White's account, 'interest groups' and 'politicized city councils' are invoked as delaying the spread of the device (2014: 291). Similarly, in Chief Executive Rick Smith's interesting account of the rise of the TASER weapon (2019: 261), there were 'powerful...forces ... arrayed against social and technical progress', with initial obstacles including meddling managers, federal government, 'tradition bound' culture, and certain 'groups that seek to reduce excessive force in policing' $(2019: 38,87)$.

There is a fundamental asymmetry here: as Bloor (1999) has noted more broadly, 'false' beliefs are seen as something in need of explanation, 'true' beliefs are not. The social is a resource to be drawn on to explain why misconceptions around the weapon exist, but is not as relevant when looking at the positive features of the weapon, which are to be explained with reference to its technical features and inherent qualities. Further, in such accounts, the social is seen as fixed, unchanging context into which technologies such as electric-shock weapons are introduced, with greater or lesser success. For example, quoting Wejnert, White notes that innovations 'evolve in a specific ecological and cultural context and their successful transfer depends on their 
suitability to the new environments they enter' (in White 2014: 14). So the social can impact the reception of a given technology, but there is little consideration of the inverse: how technologies, such as TASER, can impact 'the social'.

Such views exemplify what Feenberg (2010: 15) has called the 'paradox of the frame'; the assumption that the efficacy and usefulness of a given technology explains its success. Applied to projectile electric-shock weapons, such reasoning would lead one to assume-as the authors above do-that they are popular because they are effective. Yet Feenberg argues the reverse is true: 'efficiency does not explain success, success explains efficiency' (2010: 15). The technology must have been more or less efficient in the first place-and, in the case of projectile electric-shock weapons, there is evidence to suggest important differences between brands (Mesloh et al 2008) and between different models from the same brand (Home Office 2016; Stevenson and Drummond-Smith 2020) ${ }^{1}$ - but that alone does not explain why such a technology came to be adopted.

Instead, as we saw in the preceding chapters, a range of heterogeneous tactics and solutions have to be applied in order to make a device acceptable and widely adopted. Once adopted, additional resources, research, and development are then devoted to such devices, helping to increase their efficiency and producing a self-fulfilling prophecy. Yet such possibilities are seldom considered in the literature. Instead, while studies may look at upsides, risks, and rewards (White 2014) — in this case, the 'upsides' of effectiveness, enhanced officer safety, and reduced injury-they are often seen as preexisting, objective qualities, and taken for granted. Seldom are they seen as characteristics that are socially constructed and, in turn, are worthy of further attention in their own right.

The literature also suffers from more practical limitations, many of which parallel the limitations of the literature on the injuries to members of the public, discussed in the last chapter. First, the majority of this work has been based on the United States of America and is reliant on a small number of datasets (Neuscheler and Friedlin 2015). Second, many of these previous studies failed to differentiate between instances where projectile electric-shock weapons were used by itself and instances where it was used in conjunction with other forms of force. After making this distinction, Paoline et al. (2012) found that such weapons were associated with a decreased probability of officer injury when used by themselves, but an increased probability of injury when used with other forms of force. This is perhaps particularly important in countries like England and Wales, where TASER is frequently used alongside, not instead of, other use of force options (Dymond 2018).

Third, while many studies have understandably focused on the odds of officer injury, there are a range of broader questions around the weapon that may also affect officer safety (Ariel et al 2019; Ba and Grogger 2018). These 
include, for example, the impact that the presence of projectile electric-shock weapons may have on the behaviour and decision making of police officers and members of the public and it's impact on police use of force (Ariel et al 2019). In order to address such issues, Ariel et al's (2019) randomised controlled trial in the City of London Police found that TASERs were associated with statistically significant increases in the use of force by the police and with a doubling of assaults on police officers. They theorised that the presence of TASER encouraged suspects to become more violent towards officers, thus putting them at increased risk of assault.

Studies such as these point towards nuances in how such weapons may be received. They hint that there may be some exceptions to the logical assumption that they enhance officer safety due to their effectiveness and technical features. As such, while quantitative studies such as those detailed above are highly valuable, they can only go so far. It is also important to explore officers' own understandings of how such weapons may impact their safety (De Angelis and Wolf 2013; Sierra-Arévalo 2019), to look at the broader network around the weapon, and to understand when officers feel more or less at risk-the topic of the next section.

\section{Officer views on safety}

In general, officers in England and Wales are highly positive about TASER. They identify several ways in which the weapon advances their safety, and this was often a key motivation for wanting to carry it. TASER is particularly valued given relatively low staffing numbers, which some officers felt had been exacerbated recently. For example, officers noted the importance of:

'The safety aspect - we are now in a rural area and I cover an area which is... I'd say 8 times what it was before...I have got less staff so I'm very that aware we are single crewed... I want to have the confidence to stop a car, go to an incident and just be a little bit more protected'.

(Officer 1, Countryshire)

'I cover over 100 square miles around (location omitted) and I just thought that it is such a large area and it's a useful tool to have for myself and my colleagues. Because it's not necessarily me that would be in a situation to need it, but it's a useful tool to have as a backup for my colleagues as well'.

(Officer 2, Townsville)

'With so many people you know or work with... being assaulted and stuff and maybe a TASER won't stop that happening but it just gives you a better, safer option'.

(Officer 12, Big City) 
More specifically, the weapon is seen as enhancing officer safety in multiple ways. First, the majority of officers speak about the value of the 'red-dot' function. One officer, for example, described it as 'the best thing about TASER'. Officers also note that the weapon can act as a 'deterrent' by its' mere presence. For example, an officer in Townsville stated that 'merely having it as an option is a deterrent to a lot of people. You don't even need to draw it... You turn up to somebody who recognises...that you could be carrying it, it just changes their state of mind' (Officer 2, Townsville). Such findings are in keeping with De Angelis and Wolf's research, which found that officers felt that the weapon allowed them to de-escalate encounters without the use of 'dangerous types of physical force' (2013: 9-10). The deterrence effect of the weapon, and its seeming ability to prevent use of force incidents, is highly valued.

Officers also feel that, when they do need to fire TASER, it helps ensure their physical safety more readily than other forms of force, for several, interconnected reasons. Officers value the extra distance they feel the weapon gives them:

'It gives you a bit of distance and I think that's the key thing - it's the distance. Whereas (with) the other PPE (personal protective equipment), you've got to be close.

(Officer 1, Townsville)

'I would always, more often than not, go straight for my TASER rather than CS or baton, as long as the circumstances dictated. Its proximity, rather than having to be fighting and get myself injured as well'.

(Officer 7, Countryshire)

This was also emphasised in training, with trainers reinforcing to course participants during scenario exercises that 'it's a distance control device'. In addition to distance, officers also stress the perceived effectiveness and benefits of (neuro-muscular) incapacitation:

'It's nice to have something extra that you know would work. Baton might not work, I don't really fight with a baton if I can help it. CS... could affect me as much as it will affect them... I guess it (TASER) gives you the option to control. They have no choice: if you are accurate they will go down'.

(Officer 2, Countryshire)

'(With TASER) It can just be a couple of seconds to get that compliance, and then they'll suddenly think right OK I am going to comply and there's no more fighting. Whereas (without TASER) you could end up in a big struggle, everyone on a heap on the floor'.

(Officer 1, Townsville) 
'The impact is high in terms of its ability to stop people in in their tracks but the ability to recover instantaneously once the device is switched off is also there'.

(TASER Trainer 5, force omitted)

As such, the incapacitation associated with TASER is highly valued and, more broadly, the weapon is seen as highly consistent, predictable and reliable, and as likely to be effective-especially when compared to other forms of force. The targeted, accurate nature of TASER is also compared favourably to the other force options available, in particular, CS irritant spray, and especially in confined spaces. Officers note that:

'I tend to use TASER because it's far better... It has got so many benefits that you think about. The environment's one of the key issues. You're in confined spaces a lot of the time and you can't swing your arm back for the baton you're not going to go to CS... TASER is the go-to'.

(Officer 4, Countryshire)

'(I was faced with a situation) the initial threat was 'where's the knife'... I had a foot (of distance) to work with. CS spray would not have worked in a confined space... (baton) there's not enough room... TASER with the drive stun, it was the best option available'.

(Officer 3, Townsville)

Indeed, when asked for their views on the weapon, few officers $(\mathrm{N}=4)$ proactively mentioned limitations of, or downsides to, the weapon. The vast majority of interviews (with perhaps one exception) were overwhelmingly positive about the weapon, with many officers talking about it in glowing, almost messianic, terms. Officers noted that:

'It's an extra piece of equipment that is essentially completely safe and that's becoming far more essential working in the rurals'.

(Officer 1, Countryshire)

'It's a brilliant piece of kit so long as it's used properly'.

(TASER trainer 2, force omitted)

'You have to take certain things into account, your surroundings and things, have to be careful but it is a tool that's good, I don't think there's anything bad that I can say about TASER'.

(Officer 6, Countryshire)

Such views are broadly in keeping with American research which found a pattern of 'widespread support' (De Angelis and Wolf 2013) for the weapon. 
At this point in the argument, one might be tempted to make several conclusions. First, officers tend to report to outsiders that they view TASER as enhancing their personal safety, due to its perceived efficacy and reliability, its ability to incapacitate, and the fact that it can be used both at distance and at relatively close quarters. The academic literature also tends to reinforce this view, showing (with some exceptions) that the weapon is associated with decreased injury to officers. Second, one might be tempted to trace these benefits back to the material features of the weapon, and its inherent, innate qualities (see, for example, White 2014) - for example, the red-dot laser sights, the wired probes that can be fired at a distance, the electricity that can produce incapacitation.

Yet, as Bloor (1999: 84) reminds us, it is important to subject both so-called 'true and false', and 'rational and irrational' ideas to 'sociological curiosity'. Rather than seeing some ideas, 'facts', shared beliefs and conventions (in this case, the benefits, effectiveness and prevalence of electric-shock weapons) as natural, self-evident and genuine-and not in need of further investigation or interrogation-and seeing other views (for example, concerns about such technologies, or reluctance to adopt such devices) as profoundly misconstrued, and necessitating recourse to the 'social' in order to dismiss and explain them away, he asks us to identify the 'local, contingent causes' behind both types of belief. For my purposes here, then, if we are interested in examining the impact of projectile electric-shock weapons on officer safety, this challenges us not simply to take officer beliefs at face value-but to examine those beliefs more closely; the task of the remainder of this chapter.

\section{Going beyond officer accounts}

But why might one need to go beyond officer accounts in the first place? There are a number of reasons why such accounts deserve careful examination. First, it is not just academics that fall prey to the 'paradox of the frame'-or the assumption that the efficacy and usefulness of a given technology explains its success. Amongst officers, too, the ubiquity and popularity of projectile electric-shock weapons may be seen as evidence of their effectiveness, and may subconsciously shape officers' subsequent views about such weapons, their performance and the impact on their safety. Even if officers are not fully convinced, however, forming and expressing dissenting views about a given technology becomes more difficult over time (Pinch and Bijker 1984). Immediately after the adoption of a new technology, there is considerable 'interpretive flexibility' in how people think of, and receive, the innovation, with multiple meanings and interpretations that can be attached to the same object or artefact. However, over time the degree of interpretive flexibility erodes and a broad consensus emerges - a process known as closure. Under conditions of closure differing opinions can be held, but it may be harder for officers to express reservations about the weapon-perhaps particularly to 
'outsiders' - whilst any lingering doubts may again be assuaged by the degree of consensus that does exist around its utility and its popularity.

Such considerations may be heightened in policing, with talk of its distinctive subculture and pressure to act a certain way. Thus, an officer in Big City noted the disdain that was felt for a colleague who voiced objections to the weapon:

'there's one girl on my team who... she has, I don't want to say an attitude problem, but she thinks the force will change for her and she's very forthright in her ideas... She thinks that TASER is immoral. She thinks 'why should I have that ability to do that'. Which is her personal view. We're all a bit like 'why are you a police officer then?'

Second, confirmation bias-the tendency for individuals to 'bolster a hypothesis by seeking consistent evidence while minimizing inconsistent evidence' (O'Brien 2009: 315) — may also have a role to play here. This tendency has been well documented in the social psychology literature amongst the general population, as well as in serving police officers. Whilst studies of confirmation bias in the police have traditionally been focused on presumptions of guilt or innocence of suspects during interrogation (see Powell et al 2012; Taslitz 2010), the issue of confirmation bias is perhaps particularly salient here. Because officers in England and Wales are not automatically issued with the weapon but have to volunteer to carry it, it is highly likely that self-selection effects apply, and that volunteers already believe it is effective and that it will improve their safety. Conversely, those who are more sceptical about the weapon may be more reluctant to apply in the first place.

Third, these social-psychological processes must also be understood in the context of the traditional 'hyper-masculine' (Wozniak and Uggen 2009) police subculture. Reiner's classic definition of 'police culture' sees it as 'complex ensembles of values, attitudes, symbols, rules, recipes, and practices, emerging as people react to the exigencies and situations they confront, interpreted through the cognitive frames, and orientations they carry with them from prior experiences' (Reiner, 2010: 116). These values and attitudes include a desire for action and excitement set alongside a concern with danger and safety, a belief (sometimes even a glorification) in the use of force as acceptable and necessary (Westley in Griffin and Bernard 2003: 6) and an 'us vs them' attitude (Grint et al 2017; Herbert 1998; Waddington 2011). In order to fit into this 'adventure/machismo normative order' (Herbert 1998; 357), officers - in particular, 'street cops' (Grint et al 2017) — must demonstrate their bravery and fearlessness by engaging in proactive policing and voluntarily placing themselves in dangerous, risky situations. In other words, and more colloquially, they are expected to 'show balls' (Reuess-Innani in Herbert 1998). 
With some notable exceptions-for example, the views expressed in the last chapter that TASER is valued because it allows officers to avoid confrontation and force-officer views on the weapon often closely reflect themes found in the traditional police subculture (TPC). Thus, many officers stress concerns about their safety, and the safety of their colleagues as a key reason for carrying the weapon. These concerns are often set against a backdrop of an increasingly violent public and declining levels of respect for the police (e.g., an 'us vs them' mentality). For example, an officer in Townsville commented that 'even in the short time that I've been doing this job, I think that the level of violence in general displayed across the board by the public is getting worse... people that I'm dealing with just don't have any respect for the uniform anymore' (Townsville, officer 2), and similar views were expressed in all three forces.

Moreover, some officers couch the appeal of the weapon in terms of their desire to be proactive and their desire for action and excitement. As one officer explains, 'I like to be frontline and the first to get there. I like to be proactive rather than reactive and I just thought it could be a good role for me' (Officer 3, Countryshire). Another officer from Big City (Officer 8) explains that the weapon appealed because he likes 'being in a proactive role...we can get called to any incident and I think that's just sort of part of the excitement, it goes with having TASER'. Other officers placed an emphasis on the ability of the weapon to help them protect themselves. Such officers commented that 'before anyone is going to hit me, they're going to get Tasered' (Officer 15, Countryshire) and 'I use it as I feel fit, at the end of the day I want to go home' (Officer 3, Townsville). The views of officers cannot be understood without reference to these broader subcultural norms-especially as this traditional subculture simultaneously emphasises secrecy, suspicion of outsiders, and may lead officers to be less than forthcoming.

As such, officer views on the weapon both reflect, and cannot be understood without, reference to canteen culture as well as broader assumptions made about the role of technologies and the existence of confirmation bias. The possibility that officer views are subconsciously influenced by such factors must be taken into account.

\section{An alternative account}

It is, therefore, worth exploring what an alternative account of officer safety might look like. In providing this alternative reading of the evidence, I do not intend to demolish the 'myth' that projectile electric-shock weapons can improve the safety of officers but simply seek to demonstrate that other plausible interpretations are available. Specifically, while projectile electric-shock weapons are often seen as 'better' and 'safer' for officers when seen in isolation and considered in terms of its technical features, once they are considered in terms of the broader socio-technical network around the weapon, 
their impact on their safety might be slightly more complex. There are (at least) four reasons why this might be the case.

\section{Limits to effectiveness}

First, there are limits to the effectiveness of such weapons. While the red-dot is often seen as a positive technical feature that prevents situations from escalating, it's effects are not guaranteed. For example, officers in one of the forces received explicit training on how to maximise the deterrent of the 'red-dot'. The trainer noted that 'the red-dot is a really effective tool but in order for it to be effective, we have to make it effective' (emphasis added). As such, officers in this force were instructed to use 'really dominant comms (communications)', to aim high on the chest so the member of the public can see the red-dot, and to try to "win the psychological battle with that person' in order to deploy the red-dot to best effect. The red-dot is not necessarily a technical solution or a 'quick-fix'.

Similarly, firing the weapon is not always effective. Research by Ho et al. (2012) indicates that TASER is less effective at very close ranges and reported effectiveness rates vary from 55\% to $80 \%$ across police forces (Gilbert 2019; see also Brandl and Stroshine, 2017; Somers et al 2020; White and Ready, 2010 , who found effectiveness rates of $78 \%$ or higher). Previous studies have also found the models produced by alternative manufacturers to be less reliable than the TASER brand (see, for example, Mesloh et al 2008). Moreover, using the weapon in drive-stun mode- a type of use where the weapon is pressed directly up against an individual to deliver an electric-shock which, although painful, does not produce incapacitation-is also limiting and may exacerbate the situation. Indeed, the IPCC note that in 'several' cases, the use of drive stun 'either did not result in the control the officers were hoping to achieve or made the person involved struggle and resist further' (2014a: 21).

Moreover, officers often adopt a fluid definition of success in cases where they use the weapon in probe firing mode. Thus, an officer described the weapon as 'useful' in the following situation:

'The first cartridge didn't work. He dropped to the ground on the first cycle (of the second strike), but he was that angry that he pulled the barbs out and I had to go hands on... It's a very useful tool. He was in a place where he was (still) fighting. But it gave me that advantage to be able to go hands on with him'.

(Officer 20, Countryshire)

Another officer described the weapon as being effective in the following incident:

'I had a chap... being arrested for an... assault (details omitted)... (he) pulled out a weapon (details omitted). So I tasered him but he broke 
them (the wires) with the (weapon). And I had to exit quite rapidly and I tasered him again as he came out the door, so a messy one'.

(Officer 3, Townsville)

Such accounts indicate that projectile electric-shock weapons do not always incapacitate and, whilst they are often described as preventing the need to use hand-on tactics, this is not always the case. As noted in Chapter 3 , should the weapon be ineffective, officers may find themselves in a dangerous situation quite rapidly.

Relatedly, depending on the cartridges and model used, the TASERs currently in use in England and Wales have a maximum range of either 6.4 or 7.6 metres (College of Policing, 2020a) - and are at their most effective when used at shorter distances than this. Thus, officers may be tempted to get within range of particular individuals so that they have the option to use the weapon, should they need to. Yet this action could not only put them more at risk if an individual was to turn violent, but could also further risk inflaming the situation. The possibility of officers responding differently-in this case, getting in too close-because of the presence of projectile electric-shock weapons and, as such, affecting the event outcome were testified to by various trainers. One trainer stated that:

'In our force (we had a situation) where the (TASER trained) officer was just simply too close... (when someone) was kicking off and he jumped him. Distance, distance, that's what we try to teach our non-firearms officers (on TASER courses), don't jump on... Because they have spent their whole career jumping on, getting hands on but actually if you think about... maybe thinking about it, talking about it, getting some space will resolve the issue'.

(TASER trainer, Force omitted, comments made during training)

Another trainer backed up these concerns and explicitly linked them to TASER:

'Conventional tactics with vulnerable people is to give them distance and space... The thing with TASER is, it is very good... but you have to be at a relatively close distance in for it be effective. If I'm $7-15$ feet from you and you are in an agitated state that might not be great. The person could now be thinking 'You are starting to close me down', the subject is feeling threatened. If you go into TASER range you could up the ante with the subject'.

(TASER trainer 2, Force omitted)

Moreover, many of the stories officers tell to demonstrate the safety benefits of projectile electric-shock weapons involve situations where one officer 
is engaging one individual. However, as discussed in Chapter 3, the weapon is less well suited for use against multiple individuals, or in crowds of people ${ }^{2}$. As an officer in Countryshire notes, 'if I'm going up to a car (by myself) and there are four people in there, I don't necessarily want to be stuck to someone with a TASER...(when) there are three other people presenting themselves to me' (Officer 16). As such, while these weapons are often described as 'effective', they may be so only in certain circumstances. In other circumstances, they may actually enhance the risks faced by officers, if they are less able to address multiple threats. Moreover, far from being successful because it is effective, the weapon's success encourages officers to see, and reinterpret, certain outcomes as effective. It also encourages officers to dismiss and ignore situations where it is less likely to be effective.

\section{Over-confidence}

Every weapon has limitations like those described above, and projectile electric-shock weapons are no exception. However-and this is my second point-such limitations are important precisely because of the confidence officers have in the weapon. There is a fine line between a healthy level of confidence, and a potentially dangerous level of complacency, particularly if this confidence leads officers to handle situations differently. Thus, officers note, explicitly, that 'it'll give me the confidence to be a bit more proactive where I think... people would be far less confident' (Officer 1, Countryshire) and explain how the weapon has directly impacted their behaviour:

'It lets you deal with situations you possibly couldn't deal with before. Whereas you might have had to back off, wait for more units to come in, or (have) more force used in a different way by shield teams, things like that'.

(Officer 9, Countryshire)

'people with a knife, how would you have approached them before? You would have had to wait for armed support or you tackle them with the knife itself... A lot of the time, if you draw your TASER and point it at them...generally they stop and you've got your outcome earlier'.

(Officer 15, Countryshire)

'It does make you feel a bit safer. Because I'm not a huge person like some of the other guys. If I was on my own and a large man was to kick up, it's something else that I can think about'.

(Officer 1, Townsville)

'I was involved in a situation with a male who... was wanted... (and) had 17 markers for violence against police... Having that TASER I felt much 
more confident being able to deal with him because I can stand 15 feet away, point that at him and if he makes any moves towards me I can deal with the situation'.

(Officer 4, Big City Force)

Whilst on occasions such strategies may have positive outcomes, they may also expose officers to more risk. As one officer noted; 'some people think because they've got a TASER, they're immune, they're superhuman' (Officer 13, Countryshire)'. This risk is also exacerbated because, as some officers and trainers suggested, those with TASER are expected to 'take control of the situation' and to be 'the first through the door', potentially putting them at more risk. Thus officers' views about the safety and capabilities of the weapon may encourage them to handle situations in different ways-ways that may, at times, risk compromising their safety.

\section{Higher risk incidents}

Third, once officers are equipped with TASER, the type of incidents to which they are sent may change. Some officers feel that, once TASER trained, they are sent to riskier incidents than had previously been the case (see also Dymond 2020). For example, officers explain that:

'The biggest issue you have sometimes is with spontaneous incidents where you have bladed weapons... I get sent to jobs with 'presence in public with knives'... (We) get deployed as TASER now. That would have been a firearms job... If that TASER fails they become a victim'.

(Officer 17, Countryshire)

'The jobs with weapons and stuff, you start hearing 'any TASER officers on duty', whereas before it was always 'we will see if we can get you a firearms unit'... I feel we definitely get called a lot more to jobs for violence... The only thing that puts us in more danger is because of the jobs they send us to.'

(Officer 3, Townsville)

'(as a TASER trained officer) you go to more dangerous things. So there's a little bit of a trade-off. Like if there was someone running round with a knife I'm now more likely...to go. So there is that sort of element of being exposed to more dangerous incidents. But at the same time I was kind of going to those incidents already'.

(Officer 16, in Big City)

As the ambiguity in the quote above indicates, this trend should not be overstated. However, there is some evidence to suggest that the presence 
of projectile electric-shock weapons do not necessarily enhance officer safety-or, at the very least, that there is a 'trade off' between being sent to the 'more dangerous' incidents and being able to handle them with lower risk of injury.

\section{Single crewing}

Fourth, in around a quarter of interviews in Countryshire and Townsville, officers indicated that they are more likely to be single crewed. Trainers and officers noted that:

'Our recommendation is that there is a double TASER crew... However the assessment scenarios are single crewed as that's what you guys will be... If you've got three staff, one TASER trained, the TASER trained officer will be single-crewed. That person is you - you are going on your own'.

(TASER trainer, Force omitted, comments made during training)

'My understanding of how I was trained was that officers would attend a scene, supported by TASER officers... (who) could then concentrate on their use of TASER if it was needed. Numbers wise in the police service it doesn't happen so much now... Now you've got officers who are wearing it routinely going to the job, so they've got to deal with the job, and also think about the TASER... That increases the pressure'.

(TASER trainer, Force omitted, comments made during training)

'TASER officers are single crewed every day... If you have a TASER, you volunteer to go, to up the numbers... (But) single crewing is never safe in any front-line situation, TASER or not' (Officer 17, Countryshire).

Officers are less likely to be single crewed in the Big City force and, due to it's urban nature, are more likely to have other officers nearby for back up. However, they describe a process of prioritisation, whereby TASER officers are more likely to kept on active duty to be available to answer calls. Thus, one officer noted that numbers of officers on shift are 'under strength' to begin with, and non-TASER trained officers often get called away to nonresponse tasks:

'So let's say, you (need officers) at the hospital...(officers) with someone whose been extremely violent in custody... officers for a road closure.... When we're really short you can guarantee that more or less every single person that's going to be available for calls is gonna be TASER (trained)... because they have to be available... for everyone to be safe basically'.

(Officer 16, Big City) 
Single-crewing TASER officers is particularly of concern as some research indicates that the mere presence of projectile electric-shock weapons can encourage members of the public to act aggressively. Ariel's et al. (2019) randomised controlled trial compared shifts where officers were equipped with TASER to control shifts (where officers were not equipped with TASER). They found that officers with TASER were more likely to be assaulted and theorised that 'the presence of a TASER precipitates a pattern where suspects become more aggressive toward officers, who in turn retort with more forceful responses' (Ariel et al 2019: 17)—potentially placing them more at risk.

\section{Conclusion}

In this chapter, I have presented two differing accounts around projectile electric-shock weapons and officer safety: a traditional account, or myth, which stresses the benefits of the weapon, and a second, more skeptical account. This second account highlighted that, whilst many officers view the weapon as enhancing their safety, carrying it may place them at more risk in multiple ways. Specifically, they may be more likely to be single crewed, to be sent to more dangerous jobs, and to take the lead in managing such situations when there.

In making such points, my intention is not to dismiss officers' views around the weapon. Officers are generally highly positive about TASER and believe that it keeps them safe-something generally echoed in the quantitative academic literature, which finds that the weapon is associated with decreased odds of officer injury. Nor do I wish to suggest that the second account presented here is 'better' than the former. Ultimately, it is up to the reader to decide which account, or blending of accounts, they find most convincing.

Rather, in drawing attention to aspects under-appreciated in traditional accounts of the 'success' and 'effectiveness' of the weapon and its impacts on officer safety, I hope to have demonstrated a number of broader points. Firstly, that various factors-including the generic human tendencies towards confirmation bias, to assume that the success of a technology means that it is effective, and to interpret situations in line with the traditional policing subculture-may lead one to underestimate the disadvantages of the weapon and the socio-technical network surrounding it. We return to the topic of the traditional policing subculture in Chapter 7 but, for now, it is important to recognise these risk factors and unintended consequences in order to help ensure officer safety.

Secondly, and relatedly, I hope to have demonstrated the conceptual and analytical value of expanding one's gaze from the 'technology' to the 'socio-technical network'. If looked at in isolation, the so-called 'technical' features of projectile electric-shock weapons appear to enhance officer safety, but the broader socio-technical network around the weapon-the decisions and assumptions that are made around the incidents that it is suitable for 
officers to attend, the ways in which officers and members of the public may interact with the weapon-may appear to put them at more risk. Looking at the technology in isolation may reveal one picture; looking at the broader socio-technical network may reveal a different picture.

Thirdly, I hope to have opened up discussions around oft taken-forgranted categories and terms such as 'safety', 'effectiveness' and 'better'-both in general, and as they pertain to TASER in particular. Assessments and pronouncements of effectiveness should not be taken at face value, and assumed to be a reason for the weapons' success, but should be carefully evaluated. In so doing, Bloor's symmetry (1999) has been an important aide. In the last chapter, we noted that beliefs around the impact and niceness of the weapon for members of the public should not be considered simple reflections of fact, or of the 'empirical reality' behind the weapon, but instead need to be seen as socio-technical constructions and products of heterogeneous engineering. In the same way, this chapter has demonstrated that views about the weapon, its effectiveness and benefits for officers should be seen not as 'just-so-stories' but as worthy of investigation in their own right. In particular, the popularity of a technology should not be (circuitously) explained by the 'fact' that it is successful or effective: instead, the fact that it is seen by many to be successful or effective is exactly what needs to be explained in the first place.

It is possible that the weapon's popularity and perceived effectiveness, in turn, influence officer's perceptions and assessments of the weapon. Instead of just assuming that the weapon is successful and popular because it is effective, its success and reputation may mean that individuals perceive and interpret events and possibilities (including the likelihood of injury, and an effective outcome) in particular (more favourable) ways. This serves as a useful reminder that accounts of the weapon's safety and efficacy-including my own - should not be seen as objective fact explaining the weapon's success, but as subjective features in need of further investigation. Moving beyond projectile electric-shock weapons, it also challenges us to question the received wisdom about the 'success' and 'effectiveness' of technologiesboth inside and outside of policing - more broadly, instead of taking these qualities at face value.

Ultimately, it is clear that the impact of projectile electric-shock weapons on officer safety is complex, with the 'technical' and 'social' facets of the weapon inextricably linked. These facets need to be carefully studied, and appropriate mitigation measures considered, before making any pronouncements about their impact on officer safety.

\section{Notes}

1. For example, in the UK the Home Office Commercial Directorate-Police Commercial division were tasked with conducting a 'procurement process on behalf of UK police forces to identify a suitable replacement CED for the X26' that was 
previously in use and assessing submissions against police operational requirements (Home Office 2016: 3). They found that, of all the devices submitted, only onethe TASER X2-met 'the requirements to proceed to a technical assessment'. Following this technical assessment, the X2 was subsequently authorised for use by the Home Secretary in 2017. Previous assessments of a range of projectile electric-shock weapons in the United States of America (e.g., Mesloh et al 2008: 8) found that 'the TASER X26 system...(was) much more reliable than its Stinger S200 counterpart'.

2. While the introduction of dual shot weapons, such as the X2 and the T7, may appear to allow officers to target more than one individual, officers were not taught how to do this on the training courses, I observed. Indeed, SACMILL (2016: 13) notes that, while 'the training curriculum neither prohibits nor endorses probe discharge from a single TASER X2 device on two subjects....the training does emphasise that use against two subjects would be challenging and may make it difficult for the officer to regulate the parallel discharges appropriately and proportionately'. 


\section{'There's no right or wrong' \\ Laws, policies and training}

\section{Introduction}

Previous chapters have interrogated myths around the use of projectile electricshock weapons as a substitute for firearms, their role in officer safety and the safety of members of the public, and their use in practice. While these are valuable topics, they are inherently linked to questions around the law, guidance and training given to officers on the use of the weapon. Guidance and training are key vehicles through which States can discharge their obligations to prevent torture and ill-treatment and make clear to officers when such weapons should (or shouldn't) be used. They can also represent critical mechanisms in holding officers to account (an issue we return to in Chapter 8).

Given their importance, I dedicate the next two chapters to interrogating the law, guidance, and training in England and Wales and internationally. This draws on my unique access to and observations of TASER and use of force training in Countryshire, Townsville and Big City, the College of Policing's Lead Instructor Training, and over 50 interviews with TASER trainers, Personal Safety Trainers, and other officers. In this chapter, I introduce readers to the substance of these mechanisms and offer an empirically informed critique of their content, length, and delivery in order to challenge prevailing claims that they are sufficient and fit for purpose. I start by outlining the law and guidance in England and Wales and put this into international context by looking at international norms and standards as well as policies around the use of projectile electric-shock technologies worldwide. I then discuss and critique training in England and Wales, drawing on unique access to College of Policing Lead Instructor TASER Training and training in three forces in the jurisdiction.

This is particularly important because there is consensus amongst multiple stakeholders that the guidance and training is fit for purpose. The National Police Chiefs' Council (NPCC)—which co-ordinates national police responses, operations, standards and policies between the different police agencies in England and Wales - states that 'the guidance on the use of CEDs is continually reviewed to ensure it remains fit for purpose' (NPCC 2020), 
SACMILL (2016: point 47) note that 'the College of Policing's guidance and training documentation has been reviewed and appears to be fit for purpose (although still subject to validation and potential modification as a result of operational experience)'.

Moreover, oversight bodies have traditionally not critiqued police guidance in this crucial area. As Casalie found in her review of the IPCC, the organisation's role has, in the past, tended to be too narrowly focused on 'assessing officers' actions against criteria and standards derived from the police guidance applicable at the time instead of 'holding the system to account... (by) review(ing) (this) guidance, to identify any shortcomings' (Casalie 2012: 14). An IPPC report into TASER in 2014 recommended that 'guidance is needed on the use of Taser in custody' in particular (IPCC 2014a: 26), but did not recommend a wholesale review of the guidance or threshold for use more broadly.

Similarly HMICFRS has historically not looked at the issue of TASER use. Although this is changing, their new approach assesses officers against the decision-making framework - the 'National Decision Model', or NDM, to which we return later-instead of critically interrogating the NDM itself. Under the HMIC's Police Effectiveness, Efficiency and Legitimacy (PEEL) inspections, HMIC investigators considered, in their 2015 inspection, 'whether Taser-trained officers are acting in accordance with the College of Policing's Authorised Professional Practice each time it is used' (HMIC 2016a: 52). Again, whilst valuable, this assumes that the current guidance (Authorised Professional Practice) is fit for purposes and misses a valuable opportunity to question the guidance itself ${ }^{1}$. Under such circumstances, a careful examination of the current guidance is crucial.

While the empirical data on TASER training discussed here is based on a case study in one jurisdiction, it has global implications. It is important not to over-generalise, nor to make global judgements on the content and adequacy of training worldwide, from an assessment of training in just one jurisdiction. At the same time, however, a careful examination of TASER training in England and Wales is likely to exemplify broader issues that may arise with training on projectile electric-shock weapons worldwide (see, for example, Oram et al 1991 and, more recently, Jackson 2020 for the benefits that case studies, particularly those involving observations and ethnographies can bring to police studies and criminology more broadly). Police guidance and training in England and Wales are often held up as good examples internationally (NPCC 2020). Moreover, other countries have explicitly noted that their guidance on projectile electric-shock weapons is based on material and documentation supplied by the UK. For example, New Zealand's Standard Operating Procedures for TASER were 'based on documentation supplied by law enforcement, police, and justice sector agencies from the United Kingdom, the United States of America and Canada, as well as meetings with the Home Office Secretariat (UK) and New Scotland Yard (UK)' 
(New Zealand Police 2008). As such, a careful examination of law, guidance, and training around TASER in England and Wales has global relevanceand any shortcomings found here may point to issues that need to be explored elsewhere.

In offering this analysis, my intention is not to disparage the training curriculum in its entirety, nor to criticise the trainers, many of whom are dedicated to providing high-quality training, often in difficult circumstances and under time and budget constraints. Indeed, there are some positive elements to the training in England and Wales and some resonance to claims that it amongst the best in the world - not least given the meagre time dedicated to training in many other jurisdictions.

Ultimately, however, as this chapter will show, the law, guidance, and training fails to provide sufficient advice to officers about when, how, and under what conditions the weapon should be used. Instead, they devolve these decisions, the uncertainties and controversies around them down to individuals, seeing such calculations as ones to be made on a case by case basis by rank and file officers (see also Rappert 2003). I return to this theme in the next chapter when I complement the substantive critique of guidance and training offered in this chapter with a conceptual critique of the myths and implicit beliefs that underpin it. For now, however, I start by outlining the content of law and guidance on the use of projectile electric-shock weapons.

\section{Laws and policies in England and Wales}

The English and Welsh legal system sets out some loose criteria pertaining to officers' use of force, while simultaneously framing decisions around the use of projectile electric-shock weapons (and the use of force more generally) as ones for individual officers. Section 3(1) of the Criminal Law Act 1967 states that: 'a person may use such force as is reasonable in the circumstances in the prevention of crime, or in effecting or assisting in the lawful arrest of offenders or suspected offenders or of persons unlawfully at large'. The Police and Criminal Evidence Act (1984, Section 117, Chapter 60) similarly states that an officer can use 'reasonable force, if necessary, in the exercise of the power'. Section 76 of the Criminal Justice and Immigration Act 2008, building on Section 3 of the Criminal Law Act 1967, clarifies that 'the question whether the degree of force used by... (the officer) was reasonable in the circumstances is to be decided by reference to the circumstances as (the officer) believed them to be'. Whilst the Act notes that 'the reasonableness... of that belief' is 'relevant' to the question of whether or not the officer genuinely believed it, if it is determined that the belief was genuinely held, then it doesn't matter whether the belief was 'mistaken', or whether it was 'reasonable' for the officer to hold it.

The European Convention on Human Rights and its case law, with its emphasis on proportionality and necessity as criteria for helping to assess 
the reasonableness of force used is also highly relevant here. Similarly, UN soft law-including norms, standards, and documents such as the UN Basic Principles on the Use of Force and Firearms, the UN Code of Conduct for Law Enforcement Officials, the UN Resource Book on the use of force and firearms in Law Enforcement Office of the United Nations High Commissioner for Human Rights and United Nations Office on Drugs and Crime 2017), and the United Nations Human Rights Guidance on Less Lethal Weapons in Law Enforcement (United Nations Human Rights Office of the High Commissioner 2020a), amongst others-stress a set of principles commonly referred by the acronym 'PLAN'. That is, that any force used must be proportionate (to the threat posed and/or offense that has been or is about to be committed), lawful (i.e., in accordance with the law and used to achieve a lawful law enforcement objective), accountable (including to independent accountability mechanisms) and necessary (that is, that force should be used only when strictly necessary).

Regional and international standards do broaden the focus out from decisions made by individual officers to some degree. For example, case law under Article 2 of the ECHR does encompass a focus on the control and planning of a particular operation and on the training officers receive (Skinner 2014). Similarly, the UN Guidance on Less Lethal Weapons (United Nations Human Rights Office of the High Commissioner 2020a: 5) also stress two further important principles. These are the precautionary principle, namely that 'law enforcement operations and actions shall be planned and conducted while taking all necessary precautions to prevent or at least minimize the risk of recourse to force by law enforcement officials and members of the public, and to minimize the severity of any injury that may be caused' and the principle of non-discrimination. The latter states that 'law enforcement officials shall not discriminate against any person on the basis of race, ethnicity, colour, sex, sexual orientation, language, religion, political or other opinion, national or social origin, disability, property or birth, or other similar criteria' and notes that monitoring the use of force is a 'critical element... to ensure that force is not used in a discriminatory manner' (United Nations Human Rights Office of the High Commissioner 2020a: 7).

However, as De Sanctis (2006: 32) notes with reference to the ECHR, there is a need to consider issues around rules of engagement and training in a more thoughtful and comprehensive way'. Moreover, as the introduction to the United Nations Human Rights Guidance on Less Lethal Weapons in Law Enforcement (United Nations Human Rights Office of the High Commissioner 2020a: v) makes clear, more detailed guidance-including that contained within the document—is needed to regulate less-lethal weapons. As Michelle Bachelet, United Nations High Commissioner for Human Rights, notes in the same document (2020a: iii), 'law enforcement officials bear the immense responsibility of determining whether force is necessary in a particular situation and, if so, precisely how much is proportional to the threat they face'. 
Hence, despite these helpful principles, when making decisions about the proportionality, necessity, and reasonableness of force used, as we shall see, all too often the locus of responsibility, legal, and otherwise is placed firmly on the individual officer. Relatively little support or specifics are given to them to help discharge this responsibility (see also Squires and Kennison 2010: 335). For example, national guidance in England and Wales for the use of projectile electric-shock weapons (i.e., College of Policing Authorised Professional Practice for Conducted Energy Devices, College of Policing 2020a) sets few, if any, parameters on the use of the weapon. It notes that 'it is not practicable or possible to provide a definitive list of circumstances where...(the weapon) would be appropriate', but instead states that it can be used 'when dealing with an incident with the potential for conflict' - which could be virtually any situation. Further, although there is a section of the guidance which deals with 'risk factors' and 'vulnerable people', this totals less than 150 words (although it does signpost readers to sources of further information). It consists, mainly, of a list of bullet points of factors, such as 'repeated and/or prolonged applications', to consider, with no additional information provided about each factor in the guidance itself.

The guidance further stresses that whether or not to use the weapon is 'a decision for the individual officer for which they remain accountable' and notes that officers should apply the National Decision Model (NDM) to assist them. Indeed, one Trainer explained to me that 'there are no specific deployment criteria for TASER officers to meet: no other standard. The NDM is the standard' (trainer 4, force omitted).

However, the NDM is a general decision-making model intended for use in any situation where decisions have to be made in policing. It is not specific to decisions involving the use of force, much less projectile electric-shock weapons. Centred around the Code of Ethics, the model sets out five areas that should be considered by officers before making a decision. Officers must try to consider, define, and clarify the information and intelligence available to them, analyse the threat posed by the situation or individual and consider the powers, policies, and legislation that apply. Using the results of this information and analysis they are then required to identify the different options and contingencies at their disposal, before taking action. Thus, officers in England and Wales are provided with very little specific assistance, from international and regional standards and laws, the national legal framework, the APP or from the National Decision Model, as to when the use of projectile electric-shock weapons, such as TASER, may be more or less appropriate.

\section{Laws and policies worldwide}

This devolution of decision making around less-lethal weapons is not something that is unique to England and Wales, but is found in many other jurisdictions worldwide. For example, in the United States of America, Terrill 
and Paoline (2012) found that departmental policies on use of projectile electric-shock weapons varied considerably across police forces. The authors note that, overall, officers using force 'have a great deal of latitude depending on their individual interpretations of the encounter before them' (2012: 59). Furthermore, the National Decision Model is actively being considered for use, with the Police Executive Research Forum noting that it has 'great potential for police agencies in the United States' (Marker and Daigle 2016).

In Australasia, New Zealand guidance on TASER states, in part, that officers can use TASER if they 'fear physical injury to yourself or others', 'have an honest belief that the subject...is capable of carrying out the threat posed', and cannot reasonably protect yourself or others less forcefully' (New Zealand Police undated, a). In reaching this determination, officers are asked to use the Tactical Options Framework. Similar to the NDM, this model spells out considerations that officers should take into account and reminds them it is your decision to escalate or de-escalate your response, and... choose the most reasonable option' (New Zealand Police, undated, b).

Vague standards and the devolution of decision making down to officers is a feature of use of force policies in other contexts, too. For example, in the Balkans and Eastern Europe, the 2016 Law on Police of Serbia stipulates that projectile electric-shock weapons 'may be used to repel an attack or subdue active resistance of a person' (cited in Policing Law Info 2019a). In Ukraine, the 2015 Law of Ukraine on the National Police states that a 'selected police measure shall be legitimate, necessary, proportionate and efficient' and that electric-shock weapons may be used for 'repulsing an attack on a person, police officer and/or protected facility' (cited in Policing Law Info 2019b).

In Asia, the 2017 Act on the Performance of Duties by Police Officers in South Korea does not address police use of force, apart from stating that the authority of police officers under the Act 'shall be exercised to the minimum extent necessary for performing their duties and shall not be abused' (Policing Law Info 2019c)—a broad, vague stipulation. The UN Committee Against Torture (2017) has further noted concerns about the use of 'electrical discharge weapons (tasers)' in the country and called for revisions to tactics and training in order to ensure that such weapons, alongside other uses of force, 'are not applied indiscriminately and excessively'. In India, Choudhary and Sabri describe the threshold around the use of TASER as follows: 'it is legal to use TASER or any force by the police if it is found reasonable as measured from the perspective of a reasonable officer at the scene. The government has approved their use against individuals fighting against the police... the proposed TASER use policy for the Indian Police Department would allow for the use of the TASER against an individual only if that person is actively resisting arrest or in circumstances where deadly force is authorized' (emphasis added 2010: 350).

In Africa, it is reported that the Inspector General of Police (IGP) in Nigeria is planning to introduce "electro-muscular disruption technology, 
commonly known as taser or stun guns' in 'by police...(for) routine patrols as a strategic approach towards reducing incidents of fatalities associated with misapplication of lethal weapons by the police' (All Africa 2019). No details of the applicable standards were available at the time of writing but it has been noted that Nigerian laws on police use of force fail to comply with international law around use of force more broadly (Law Policing Info 2019d).

Turning to Latin America, in Argentina, it was reported that the use of projectile electric-shock weapons was declared constitutional by a Supreme Court of Justice ruling in 2016 and was subsequently introduced in Buenos Aires. The Argentinian Security ministry is reported to have said that electric weapons are 'a middle ground' to be used in 'situations of conflict involving violent or threatening people'-a standard somewhat similar to that in England and Wales (The Santiago Times 2019).

While there is no space here to conduct an exhaustive review of policies worldwide, nevertheless the evidence indicates that England and Wales are not alone in setting broad guidance and thresholds for projectile electricshock weapons that allow for its use in a wide range of circumstances and, thus, devolve decision making down to individual officers. In such a situation, without hard and fast rules and with a large scope for discretion, it becomes all the more important to look at the training provided to officers.

\section{Training curriculum and delivery}

Training in England and Wales is presided over by the College of Policing, who work with what the NPCC describe as 'an experienced group of CED instructors and practitioners' to develop a standardised, national curriculum, and training package which is 'subject to regular update and review' (NPCC 2020). According to the NPCC (2020), the content of the training is 'robustly scrutinised by the National Less-Lethal Weapons Working Group, the Home Office Centre for Applied Science and Technology (CAST) and the Scientific Advisory Committee on the Medical Implications of Less-Lethal Weapons (SACMILL)'. The College provide 'Lead Instructors' training-similar to a training of the trainers-for (at least) one instructor in each force. In turn, these instructors then preside over trainers, and training, in their home forces. The result is that officers are trained by their own in-force trainers backed up by a national package. As such, the theory is that every training course is no more than two steps removed from the College of Policing and this structure provides a high degree of standardisation while still allowing some room for local flexibility and making space for in-force knowledge.

Two distinct training packages are provided under this format, with potential TASER officers having to pass an initial training course with a minimum contact time of 18 hours. Once qualified, officers are mandated to undertake yearly 'refresher training' which must be no less than 6 hours long. 
According to the College, 'officers can be authorised for no longer than 12 months from the date of their last period of CED training' (College of Policing 2020a).

As a result of such factors, the NPCC (2020) claim-with some justification - that 'the CED training package in the UK is one of longest and most comprehensive in the world... (and) is among the best training in the world'. In comparison, one study reported that forces in the United States of America gave their officers between five and eight hours training, and that TASER International recommended a minimum of four hours training on the weapon (Kedir 2006). A second study, based on a national survey of forces in the United States of America, also found that 'most agencies provide initial training lasting four hours $(28.8 \%$ ) or eight hours (46.6\%); although some agencies provide significantly less training. Concerningly, it found that almost one in five forces did not require any refresher retraining at all. Of those that did require refresher training, two thirds required annual retraining, with the remaining third of forces requiring it less frequently. Moreover, over half of forces that gave refresher training spent four hours or less on the course (Alpert and Dunham, 2010). Disappointingly, little or no information is available about training outside of the USA.

No official version of the initial or refresher TASER training curriculum in England and Wales is publicly available, so although the minimum number of training hours is given, it is difficult to reach a definitive, official position of how these hours are broken down. Moreover, the curriculum itself can be subject to change, both between forces and between TASER models, as well as over time. However, from my unique access to TASER training, some observations can be made about content.

First, the course is intended to cover a lot of ground. In addition to sessions on how to use and safely handle the weapon, topics such as benefits and risks associated with its use, medical implications, vulnerable groups, tactical considerations and limits to effectiveness, weapons retention, incident handling, use of the national decision model, record keeping, and post-incident procedures are all discussed. The course is a mixture of classroom-based power-point sessions, practical sessions on the range, scenario exercises, and a range of formative and summative assessments.

Secondly, within this overall portfolio, a large component of the course is devoted to technical understanding of the weapon and practical training on how to use it. This is combined with 'qualification shoots'-assessed tests, often conducted under timed conditions, which examine whether officers are technically proficient and able to safely handle, draw, and fire the deviceand formative exercises building up to, and practicing for, these assessed shoots. As a result, a large proportion (between $50 \%$ and $70 \%$ as a rough estimation) of both initial and refresher courses are focused on technical proficiency and assessment thereof. While this is a crucial aspect-and should not be neglected - given the overall length of the course, this raises concerns 
that insufficient time is available to look at other important aspects of the weapon-a point to which we will shortly return.

Third, the course uses elements of scenario training. Officers are formally assessed on how they handle scenarios and are also given the opportunity to engage in a range of different formative scenarios prior to this assessment. Typically, these scenarios involve one or more officers being given a brief that they are on duty and have been instructed to attend an incident involving a member of the public (for example, an individual who is wanted for grievous bodily harm, or someone who is suspected of breaking and entering). They are faced with an instructor role-playing the member of the public, who is suited up in a thick, protective outfit intended to protect them from the metal barbs. Officers, who may be paired with other officers, or working individually, are then expected to handle the situation and respond to the interaction. They are given the option to use a training version of the weapon and are also told that they have other force options available to them. However, they are not required to demonstrate their skills using other forms of force and are often instructed simply to name the technique they are using (for example handcuffing). Feedback is given to officers from trainers (and sometimes from peers) on their performance in the scenarios, as well as points to consider.

Finally, the course is pass/fail. Theoretically, students can fail on multiple aspects of the course. They can fail on their technical proficiency and ability to use the weapon, on a classroom-based test of their knowledge and/or on their ability to handle scenarios safely and appropriately.

\section{Assessment of training}

As this overview indicates, there are several positive aspects to the current training system. Scenario training has been noted as a key component of police training by the United Nations, with the Office of the United Nations High Commissioner for Human Rights and United Nations Office on Drugs and Crime noting that training on use of force should be 'scenario-based, with emphasis on those scenarios that the new recruit is most likely to encounter in practice' (2017: 55). Similarly, academic studies also emphasise the importance of scenario training under certain conditions (Rajakaruna et al 2017). Throughout the course, officers are provided with multiple scenarios (both formative and summative) during their training, which are drawn from real life examples. Moreover, the course is - at times - very instructor intensive. Providing scenario training, and detailed feedback afterwards, is highly reliant on having a sufficient number of trainers.

Relatedly, the dedication and commitment of the trainers on the courses I observed is noteworthy. For example, I was impressed by the trainers commitment to provide detailed individual briefings for officers following the scenarios on the course, their desire to make the course accessible and non-threatening to officers with a range of skills and backgrounds and to provide encouraging 
but also constructive feedback where necessary, in a compassionate manner. These observations were also echoed by students, who often voiced their appreciation for instructors and the training as a whole:

'the instructors are really good and helpful, really approachable'.

(Officer 7, Big City)

'I'm not your classic firearms officer, yet it's pitched to my level and I get it. I was worried that I wouldn't get it, but I think it's pitched really well. They've mixed up practical and talking and that's really good'.

(Officer 1, Countryshire)

This is vitally important in ensuring that a range of officers from a wide range of backgrounds and with a wide range of experiences feel confident on TASER training.

Further, power-point material provided by the College of Policing, as relayed by trainers, was clear on many crucial issues. For example, the risks of flammability associated with the weapon and limits to the weapons effectiveness-including reasons why it may not be effective and considerations to bear in mind-were well covered. These power-point sessions were accompanied by a number of scenarios where officers were able to practice using the weapon in various situations, including situations in which it was deemed ineffective, to further reinforce their learning on this issue.

Moreover, video material was often used to good effect. Videos were used not just to reinforce messages about flammability, but also to offer views and personal experiences about the weapon. Some of the later training courses I observed benefitted from the inclusion of a video showing a police officer being Tasered under controlled conditions and subsequently reflecting on the experience. Her clear and vivid description helped underscore the pain and trauma of the experience. This was particularly useful as most trainers and officers had never experienced TASER discharge and, unlike in other jurisdictions, TASER exposure is prohibited as part of the course.

Finally, the assessed nature of the course, and the fact that it is passfail, is an essential element. In this respect, TASER training differs from other police use of force training in England and Wales. For example, the Personal Safety Training (PST) provided in officers-which covers the use of other force options, including handcuffing, baton use, and irritant spray and which is discussed in the next chapter-does not formally assess officers on their proficiency with these techniques. The only way that officers can fail PST training is if they fail the fitness test; a necessary but insufficient test of competence. In contrast, in theory officers can fail the TASER training in multiple ways and participants are assessed via a written test, a qualification shoot and scenario exercises. It is also encouraging to note that, in some ways, the criteria for passing the course have been made more difficult 
in recent years. Specifically, over the course of this research, the qualification shoot-the part of the course which assesses technical proficiency with the weapon-has been made more difficult and altered to better approximate real-life conditions.

\section{Limitations}

Despite these positive features, the training is limited by insufficient quality assurance processes, insufficient length, and insufficient advice given to officers about when, how and in what circumstances it is appropriate to use the weapon. This stems from the training's (understandable) reliance on TASER guidance (Authorised Professional Practice) which, as noted above, is itself too vague on these crucial points. I now turn to each of these points in turn.

\section{Lack of quality assurance processes}

While there is an attempt at quality assurance via the national materials provided from the College of Policing, there is room for more standardisation, and further checks. Of course, there will always be local differences in how national training packages are operationalised and received, and it is beneficial that forces are able, to some degree, to supplement the materials in order to ensure that local issues are covered. Moreover, the 18 hours of training is a minimum requirement and it is to be encouraged that forces should provide additional training, and longer courses, if they are able to.

However, the current process not only allows for, but almost guarantees, that courses will differ from force to force given the large amount of material to be covered and the short time in which to do so. In this situation, it is almost inevitable that some degree of prioritisation and weighting will occur, with different trainers emphasising different elements of the training package. Further, it is only natural to expect that that trainers' views of the weapon, and their (largely positive) beliefs about its safety-as discussed in previous chapters - will implicitly (and sometimes explicitly) influence how the course is delivered and received.

On some occasions, this is very helpful. Comments made by trainers can serve the useful function of 'translating' medical terminology into more easily understandable language. For example, trainings I observed included two power-point slides which set out extracts from SACMILL's statements on the weapon and risk factors associated with its use. This includes, amongst other information, reference to a higher risk of cardiac arrythmia in persons of very small stature and small children, and a recommendation that the duration of electrical discharge should be kept to a minimum. However, trainers can, and do, supplement this with their own interpretations, explanations and views on the safety of the weapon. On one course I attended, the trainer complemented the information on the SACMILL 
slides by giving a clear and accessible description of how using the weapon on people of short stature and using the weapon near the heart was likely to exacerbate health risks. This helpfully contextualised, and gave additional weight to, SACMILL advice.

Yet on other occasions, comments made by trainers can be more problematic. For example, on one initial course, while reading the same slides, a trainer opined to participants that 'TASER won't kill you but it could be a contributory factor'. Later on in the same course, when advising officers on handcuffing someone with a knife in an incident involving TASER, the trainer noted that 'SACMILL say keeping the duration to a minimum and keeping it running while you are handcuffing them is a good way of doing this, rather than firing it, they get the knife again, you fire it again'. While the first part of this advice-keeping the duration to a minimum-is an accurate reflection of SACMILL's expert opinion, support for the second part of the sadvice is not found in the SACMILL statement available at the time (SACMILL, 2016). Comments like this appear to reflect the views of trainers and are not necessarily supported by SACMILL advice. They risk, at best, confusing and, at worst, misinforming students on crucial issues regarding the safety of the weapon.

Nor was this a practice isolated to this one particular course. On a different initial course, a different trainer ran through the prescribed slides with the medical committee warnings but then noted 'they would never have signed anything off that wasn't safe'. This is a fundamental (if understandable) misunderstanding of the Committee's role. The Committee does not sign off, or approve weapons for use, but rather gives advice on their medical implications. Again, this risks undermining, or at least muddying, the information given.

Similarly, while SACMILL's warnings about prolonged exposure were mentioned at the start the course, these were not always fully reinforced when students were practicing on the range. Instead, on both initial and refresher trainings, officers practiced on multiple occasions delivering an extended electricshock for an additional 10 seconds, under the rationale that this would give colleagues time to handcuff the person. On only one occasion on the refresher training did these exercises come with a reminder that 'SACMILL said to limit the length of the cycle', and this reminder was not given to the class at all during practical exercises on the initial training. When asked about this afterwards, the trainer replied by noting that people had been Tasered for over a minute without 'any medical issues'. He did note that there were some associated risks' but explained that this would be 'for the courts to decide'.

Such issues are vitally important, as the prevention of future deaths (Regulation 28 notice) following the death of Marc Cole has vividly underscored. In his report, the Coroner recommended:

'a wholesale review of the effects of multiple Taser activations and the effects of sustained activations (whether in isolation or in combination) 
so that fuller and more comprehensive advice, guidance and training can be given to those officers who are authorised to carry Tasers'.

(Cornwall and the Isle of Scilly Coroner 2020)

At the same time, they speak to the need both more for specificity and detailed material in the training and guidance. They also call for further quality assurance practices to ensure that the content that does exist is delivered accurately and not undermined by trainers pre-existing beliefs and views.

\section{Time constraints}

While the views of trainers likely have a role to play in terms of explaining the lack of reinforcement of SACMILL statements so, too, do the time constraints under which they are operating. Indeed, the strong consensus amongst trainers and course participants is that more time for training was needed overall, for multiple reasons. For example, trainers said:

'We would like to do a lot more, because their muscle memory (with Taser) does save their lives, and there has been a recent incident where that's happened. We need to drill that into people.... They can't practice on their own. They book a TASER out, they can't do anything else with it... So, the more hours we can give them the better'.

(TASER trainer 13, force with-held)

'I think most of us would prefer to have more time...going through some different scenarios that may have some different outcomes and just forcing them to have to think on their feet a little bit more. I mean any more practice time will lead to safer handling. Hopefully more proportionally used, it has a knock on effect to everyone doesn't it? It's not just as police officers and keeping them safe, (it's) the public and how they trust us'.

(TASER trainer 11, force with-held)

'We would love to have a longer course... At the end of the day you're taking somebody that has potentially has never fired a pea shooter before not only through how to use the weapon but also then to incorporate it into the tactics. I would like more time on the scenario-based training to embed the... tactical skills and the ability to use the TASER. It's a very whistle-stop tour'.

(trainer 4, force with-held)

Students also made similar observations, commenting that 'it is too much to do in three days, it is a lot to process' and one of the students who failed noted that 'it needs to be five days, we need to have a whole day of scenarios... (weapons handling) seems simple, but under pressure, it seems a bit much'. 
Such time constraints mean that trainers are not always able to give sufficient time to the important material covered on the course. Nor are they able to re-emphasise and reinforce critical points throughout the course in order to maximise learning and recall outside of the classroom. Examples of content (or lack thereof) in three crucial areas-vulnerable groups, the desired outcome of scenario exercises, and the use of assumptions in situations involving conflict-serve to illustrate both the need to improve training provision on these critical topics and also provide concrete examples of the need to lengthen training.

\section{Vulnerable groups}

First, while the training course contains some power-point material included on vulnerable groups, time constraints mean that the attention given to this is limited and the pedagogy leaves much to be desired. Indeed, on one initial course, just one 45 minute session was explicitly dedicated to 'dealing with vulnerable people'. According to my contemporaneous notes, this was intended to cover numerous areas, including people with 'mental ill health, who are vulnerable and in mental health crisis', those who are 'emotionally and mentally disturbed', people with 'learning disabilities, learning difficulties, neuro-disability and autism' and those with 'medical conditions (including) epilepsy and physical disability'. This was then complemented by the two slides at the start of the training, discussed above, which explicitly referenced SACMILL medical statements on the weapon and population groups that may be at enhanced risk. It was also complemented by a brief mention of 'enhanced risk factors' in the context of a broader section on post-deployment.

As well as being short in duration, the material on vulnerable individuals largely comprises a list of bullet points for officers to take into consideration, with minimal time for discussion. For example, at the end of the session on vulnerability, students were asked if they had any questions. However, this was quickly followed by the instructor asking again if there were 'any questions? We have to move on really quickly'.

The limitations of this practice have been noted both by families who have lost loved ones and by police trainers alike. Lisa Cole, the sister of Marc Cole, noted the limitations to TASER training, drawing on the information provided at the Inquest. She explained that the limited information and minimal power-point material provided:

'can't be right... unless you ask questions (of that material), you are not going to break down what a vulnerable person is, you are not going to talk about the enhanced risk factors, you are not going to talk about mental illnesses, you are not going to do that. It is just beyond ridiculous that you have got one power-point slide on how to deal with somebody who is vulnerable'. 
A TASER trainer (interview 14) also noted limitations with the material on vulnerable people:

'The classroom input, the content can be quite difficult to deliver because it's a lot of lists. I as a user would sit there and not be able to take a great deal of that in... Vulnerability is an issue, you know, and everybody's on board with that and when these people will be working around vulnerable people all day every day, does it need to be done in list form? Possibly not. Couldn't there be another way of doing it?... A good way (is) talking about it; sharing experiences ... (but) the difficulty comes when you promote a discussion. You have to try and control that and rein it in...you want them to be heard and you want them to get involved, but the time factor is quite difficult'.

The lack of material around vulnerable people is a crucial issue in its own right but also speaks to the time constraints that trainers were operating under. As such, it is an issue that needs addressing at the national level.

Second, the course contained little training on, or assessment of, officer's ability to communicate and de-escalate situations without using TASER. Across the many training course I observed, almost all the scenarios-whether formative or summative-involved people who were armed with weapons. This, it was explained, was due to the fact that officers had to be assessed on their use and firing of TASER not just on the range and against a static target, but in a scenario more akin to 'real-life'. In other words, officers needed to be assessed against their ability to fire the weapon safely, under pressure, in a fast-moving scenario.

While it is crucial that officers are assessed on their use of the weapon, they should also be assessed on their ability to refrain from using it. It seems important to include more scenarios where use is more marginal, as these are often the most contentious, and also to include some scenarios where the desired outcome is no use of the weapon at all. In this respect, practice varied between forces. In one force, there were no scenarios where the desired outcome was no use of TASER at all (although there were a few scenarios where red-dotting, not firing, was the desired outcome) and officers were, therefore, not formally assessed on their ability to de-escalate situations without using force. As trainers themselves noted:

'Essentially the course just gives us time to teach them how to use a TASER in TASER only situations. If we can expand that training to explore situations where a TASER wasn't appropriate so they don't just resort to TASER, (that) would be great'.

(trainer 16, force with-held)

'Additional training would come in really well because you could start throwing in scenarios that don't result in the use of TASER'.

(trainer 8, force with-held) 
As such, additional time is crucial to give officers further training in de-escalation tactics and practice in resolving challenging incidents, where possible, without using force. This should also consistently form part of the assessment, such that only those officers with sufficient communication and conflict management skills - and those with a proven ability to refrain from using TASER - are able to carry the weapon.

A third and final example of why the length of training is insufficient comes from the discourse around the use of assumptions. In both initial and refresher training, trainers mentioned the practice of making assumptions while engaging in police work. This was done in positive ways, and in ways which reaffirmed and legitimised this practice. For example, officers were asked the rhetorical question:

'Can we make assumptions? Yes because we have to make a split second decision. If I walk towards you with a knife, you can assume I will stab you. Sometimes assumptions will be wrong but if it's based on reasonable evidence, facts, it's not unreasonable to make an assumption'.

(TASER trainer, comments made during training, force with-held)

'We all make assumptions, I'm going to make an assumption about this person that might keep me safe'.

(TASER trainer, comments made during training, force with-held)

While assumptions may sometimes be based, fully or partially, on 'reasonable evidence', much research-including research focused specifically on police use of force-suggests that assumptions are also often based on stereotypes and bias, implicit or otherwise (Fridell and Lim 2016; Nix et al 2017). Implicit bias training has had mixed results and there are reasons to be cautious about its ability to alter practice (Quinton and Packham 2016; Smith 2015). Nevertheless, it seems important that officers are reminded that such biases exist and can inform the assumptions on which use of force decisions are predicated (see also Keating-Jones 2017) — a theme that could be further integrated throughout the course (for example, in scenario training). If officers are being told to rely on assumptions - and told that this is a perfectly acceptable and legitimate practice to engage in - they should also be made aware that these assumptions may be faulty and biased, and potentially impacted by the ethnicity and other socio-demographic characteristics of the person subjected to force. While additional training time is not a panacea for such issues, the current time constraints make it difficult, if not impossible, for trainers to delve into such crucial issues.

\section{Insufficient guidance}

Thus far the training has been criticised due to time constraints and a lack of quality assurance. Yet there is one more final, yet fundamental, flaw, 
which pertains to standards around the use of TASER and the advice (or lack thereof) given on appropriate use. Drawing, as it does, on the College of Policing guidance and the NDM, it should be no surprise that TASER training in England and Wales is often unable to give specifics to officers about when use might be appropriate, or to flag up questionable decisions or policing styles. Instead, officers are advised that a vast range of decisions could be appropriate and compatible with the NDM. Hence, trainee TASER officers are advised that:

'You want us to say 'if that happens, do this' (but) there are so many different scenarios it would take us 4 months! No-one can say you should have done something differently. It's all relative, we just want to know you are thinking about why to use it. It is your threat assessment'.

(TASER trainer, Force omitted, comments made during training)

Trainers across all three forces noted the number of divergent ways in which officers might handle a situation and made comments such as 'there's no right or wrong, just bounds of reason', 'you can't say never', 'never say never', 'no-one can say you should have done something differently', and 'we can't say do this or that... it's up to you to justify (it)' (comments made during multiple training courses).

One trainer described to me how 'I can go into certain circumstances and deal with it by talking whereas... there might be somebody else who goes straight into the same situation and... go straight for TASER'. He explained, however, that:

'I don't have an issue with that because that is their threat perception... As a department we tend not to criticise people, we would say to people 'did you consider this option, that option, before you Tasered them?'.

(TASER trainer, interview 4, force with-held)

Moreover, some officers on training courses had policing styles that were a lot more confrontational than others. For example, my contemporaneous observations from one training course describe how different officers reacted to a training scenario where they were faced with 'an individual breaking and entering a property, holding a crowbar'. My notes state that, of the three officers I observed face the scenario on a particular day:

'The first two situations were peacefully handled without drawing.... TASER. The third officer came in and immediately pointed TASER, asked him (the suspect) several times to drop the weapon and then tasered him. In the debrief, the officer was described as being 'proactive straight away' - but he wasn't criticised for this. It was noted that 'you could have spent longer talking but you had asked him three times'. 
As this example shows, some policing styles might encourage officers to use the weapon relatively early on, or to use the weapon in situations where a different approach might have negated the need to use force (see also Squires and Kennison 2010: 32-33, who note the risk of officers discharging firearms as 'necessary' responses to a situation that their 'own interventions may have provoked'). However, across all three forces, trainers did not see it as their job to alter policing styles, stating that 'it's not for us to change your policing style' and that 'we're not out to change how officers police'. While scenario training is useful, without such crucial feedback and points for improvement, it is difficult for the full benefit of scenarios to be felt, and for officers' situation handling to improve.

Trainers also noted the practical difficulties involved in questioning officers' handling of situations. When explaining to me how officers could fail the training, an instructor said that: 'the usual thing (that causes officers to fail) is people that can't fire it... that's quite black and white. You could say "well, I'm not sure that person's tactics are right" but that's a subjective thing from our experiences and we could argue with the student about that' (TASER trainer, interview 4). This observation-important in its own right - also feeds into broader concerns about the pass-fail rate. Indeed, trainers on another course were quick to reassure students that, with regards to the written test, 'those people that don't pass the knowledge check in writing will be taken into a room and asked verbally, because not everyone is good at writing things down. We have never turned anyone away for that section'. Concerns about the written test not withstanding, however, the crucial point here is that officers are taught, via the training, to make their own decisions about when to use the weapon-but these decisions are not always open to challenge. Even highly specialist trainers find it difficult to question and critique officers' decisions. This is a fundamental flaw at the heart of the training package and one that cannot be resolved until guidance is revised.

\section{Conclusion}

This chapter has provided a critique of the law, guidance, and training around electric-shock weapons in England and Wales and internationally. There are some positive elements to the training, and some resonance to claims that it is amongst the best in the world. Ultimately, however, the training-and the law and guidance on which it is based-are largely empty of specifics about when the weapon should be used and the threshold for appropriate use. Instead, they collectively devolve such critical decisions down to individual officers, while giving them little information about when such use may be appropriate to help inform their deliberations.

Such a system exacerbates inconsistency, makes it difficult to fail officers for reasons other than lack of technical proficiency with the weapon, and acts to devolve the burden of decision making down to individual officers (see also 
Rappert 2003). Broad, far-ranging decisions around when it is appropriate to use the weapon are being made not by the public or their democratically elected representatives, nor by senior civil servants, police officials, trainers, and those higher up in the policing hierarchy, but by grass-roots officers. Difficult questions around TASER use-when the weapon should be used, on whom, for how long, and what kinds of use might be considered proportionate, necessary, reasonable, and acceptable and in what circumstancesare being sidestepped, deferred, and dismissed. Such questions, ambiguities and uncertainties are left unanswered by law, training, or guidance and it falls to the officers carrying the weapon to attempt to resolve such thorny issues in the heat of the moment.

Amongst other consequences-including concerns about officer decision making and the use of the weapon (which we discuss in the next chapter), and concerns about accountability (which we discuss in Chapter 8) - this can put a big burden on officers. Such decisions can weigh heavily upon them. As officers in Countryshire noted:

'TASER is useful but it's a lot of pressure that comes with the responsibility of carrying one. It can be quite pressured (for officers) because you are the person that's making that decision'.

(Officer 8)

'It's not for everybody... Not everybody can carry a firearm, not everybody wants to take the responsibility of carrying (TASER)... some people wouldn't have the confidence (to do so)'.

(Officer 3).

For such reasons, this lack of specificity could be considered a fundamental flaw with policies and training, compounded by the insufficient time mandated for the course. Although the minimum contact time of 18 hours is generous if compared to the United States of America, it is insufficient to ensure that crucial topics - including the treatment of vulnerable individuals, the risks with prolonged and repeated exposures and practice using de-escalation skills - are given the attention that they deserve. In addition, despite the advent of a national curriculum, in practice the training content and assessment of officers differs from force to force.

Nor are such issues restricted to England and Wales. As the survey of guidance around electric-shock weapons has indicated, similar issues are found in policies worldwide. Likewise, concerns about training are also likely to be found worldwide, given that many countries are even less generous with their training allocation than England and Wales.

These findings suggest the need for substantive changes to guidance and training, policies, and practices - to which we will return in the conclusionand suggest that further conceptual work is required, too. The law, guidance, and 
training, both in England and Wales and in other jurisdictions, implicitly and explicitly conceives of use of force decisions as a responsibility almost exclusively for the individual officer armed with the weapon. Not only this is problematic for the reasons detailed above but, as we shall see in the next chapter, both this assumption and the parallel assumption that underpins itthat TASER is 'just another tool in the tool box'-are fundamentally flawed. Such myths deserve to be challenged and, in turn, challenge us to fundamentally rethink the nature of training, guidance, and command responsibility for use of force. It is to this topic that we now turn.

\section{Note}

1. As this book went to press, HMIC are releasing a report into disproportionate use of police powers (HMIC 2021), and the IOPC have announced a forthcoming report into the use of Taser, as yet unpublished. Due to issues of timing, these recent / forthcoming publications are not discussed here. 


\section{'Just a tool' \\ Revisiting human and non-human agency}

\section{Introduction}

The previous chapter introduced the legal framework, policies, and training offered around projectile electric-shock weapons in England and Wales and provided a critique based around the lack of quality assurance, the lack of time available for training, and the lack of concrete guidance. In this chapter, I complement this substantive critique by providing a more conceptual critique of two foundational myths that (implicitly or explicitly) underpin these mechanisms. These are: the myth that decision making around electric-shock weapons (and other forms of force) are an individual responsibility for individual officers and a complementary myth that such weapons are neutral tools.

The chapter challenges these two myths head-on. I explore the possibility that, far from being individualised, officer decision making is impacted by police culture, by officer safety training, and by projectile electric-shock weapons. In order to do this, I pick up the invitation from the philosopher Latour-and the approach, Actor Network Theory (ANT), with which he is closely associated - to consider the ways in which technologies may be able to 'make others do things' (Latour in Waltz 2006: 58). Such an undertaking draws on the classic ANT notion of generalised symmetry (Callon 1986), in other words the desire to be agnostic about, and not assume a priori, which kinds of actants (be they human, non-human, technologies, weapons, animals, etc.) have agency, and to focus on the inter-relations and 'dance of agency' (Pickering 2005) between them. This requires, as Callon (1986: 3) has noted, for us 'not to change registers when we move from the technical to the social aspects of the problem studied', but to use the same vocabulary, terms, and analytical concepts throughout.

In keeping with this intriguing notion, I demonstrate that three influences - the presence of projectile electric-shock weapons, culture, and training-may combine to make officers more likely to use the weapon and call into question the sufficiency of current guidance. Theoretically, too, I demonstrate that such findings have implications for the literature on police 
discretion and police culture, which has traditionally been very human centric. First, however, it is necessary to examine the myths themselves.

\section{A decision for individual officers?}

As the last chapter demonstrated, the notion of use of force as an individual decision for grass roots officers is widespread throughout, and a foundational tenet of, law, guidance, and policy. Thus, use of force decisions are seen as 'a decision for the individual officer for which they remain accountable' (College of Policing 2020a). Whether or not such decisions, and any force used, was 'reasonable', are to be judged against 'the circumstances as (the officer) believed them to be' (Section 76 of the Criminal Justice and Immigration Act 2008). As previously noted, trainers, too, underscore that we 'never say never' and explained to students that 'we can't say do this or that... It's up to you to justify (it)' (comments made during training, force with-held).

This emphasis on use of force (and the exercise of other powers) as a decision for the individual officer is also prevalent within academia, with the literature highlighting the importance and inevitability of police discretion and decision making. Davis' (in Holmberg 2000: 181, emphasis added) original definition of discretion argued that a 'public officer has discretion whenever the effective limits on his power leave him free to make a choice among possible courses of action or inaction' and Dworkin's classic formulation sees discretion as 'the hole in the doughnut... an area left open by a surrounding belt of restriction' (in Campbell 1999: 80).

As discussed in Chapter 2, much of the literature on police discretion puts the emphasis firmly on the agency of individual officers in making decisions and, more specifically, on conscious decision-making processes. For example, Goldstein's classic article (1960) gave several examples of discretion in practice, with officers often using rational cost-benefit calculations. Rowe's (2007: 298) study of police officers' exercise of discretion in domestic violence incidents in the UK similarly posited a largely rational, conscious process of weighing up various factors - for example, the possibility of getting into 'trouble' with their superior officers and risks of the perpetrator offending again-when deciding whether or not to make an arrest.

Even when other influences on discretion and officer decision-making are acknowledged, as we saw in Chapter 2, there is still a strong focus on human factors and the people involved. Indeed, Pepinksy has argued that the 'discretionary' choices officers make are, in reality, 'as much as product of social control' and as 'fully influenced by people' as outcomes governed by formal rules (1984: 266). For example, research has demonstrated the importance of officer-level variables, including their age, experience, norms and attitudes (Buvik 2016), characteristics of the member of the public, and the incident in question (Bolger 2015; Terrill and Mastrofski 2002; Terrill and Paoline 
2012). More recently, the emphasis on 'implicit bias' (see, for example, the College of Policing 2015) speaks to the continued interest in the importance of less conscious processes in informing individual decision making. Thus, the focus is on the characteristics, behaviours, and values of the individuals present.

\section{TASER as a tool}

The active consideration given to human actors is accompanied by a lack of consideration given to technologies, with projectile electric-shock weapons frequently described as a simple tool to assist officers in achieving their aims and objectives. At the highest levels of policing, the NPCC note that 'on some occasions officers will have to use force and of course there will always be a risk... whether the tool chosen is an open hand, baton, CS spray or indeed a Taser' (NPCC 2015, emphasis added). Similarly, trainers stated, for example, that TASER is simply a 'tool to (help you) do the job' (TASER trainer 3), a 'very useful tool because it is a less lethal option' (TASER trainer interview 4 , force omitted) and an 'effective tool for the job' (TASER trainer, interview 11, force omitted).

TASER officers, too, talked about the weapon in similar terms, noting that it is 'another tool in the box' (Townsville, Officer 1), a 'useful tool to have for myself and my colleagues' (Townsville, Officer 2), and a 'great tool' (Officer 5, Big City), with such descriptions widespread across all three forces. Such phrases are also used by oversight bodies, with the IPCC (2014a: 3) noting that the weapon 'can be a valuable tool in assisting police officers to manage difficult and challenging situations, provided it is used appropriately'.

As we saw in Chapter 2, in the criminology literature, too, the weapon is commonly referred to as a tool (Anais 2015), be it for legitimate "law enforcement activities' (Jauchem 2010: 53), the safe incapacitation of 'belligerent drug and alcohol users' (Spriggs 2009: 515) or, less positively, for 'mass repression', 'socio-political control' (Wright 1991: 35), and for 'terrorising' the 'downtrodden' and 'socially disempowered' (Oriola et al 2012: 66). Indeed, as Anais notes in her analysis of the literature on less-lethal weapons more broadly, the most common conception is of weapons as 'neutral objects that do not do anything until human beings pick them up...and use them to act on... intent' (2015: 27). Overall, then, both policing and the academic sources provide a highly human-centric account of police decision making, focusing on the role of the rank and file officer and dismissing technologies as mere tools.

\section{Examining the myths}

It is perfectly understandable why the common sense term 'tool' is used (Latour 1991: 31) and why many academics and practitioners alike stress the 
importance of individual decisions to use force. The use of projectile electricshock weapons cannot be understood without an emphasis on the decision making of the officers charged with using the weapon. However, while understandable, this focus risks ignoring other important influences, including decisions made by senior officers and policy makers, and the role that non-humans can play. The result is a 'shrinking definition of the social' and, in this case, a 'shrinking definition' of the kind of factors that might influence so-called individual decision making (Latour 2005: 21). In the next part of this chapter, I counteract these trends by demonstrating how three other influences-projectile electric-shock weapons, police officer safety training and police sub-culture-may impact officer decision making.

\section{The role of weapons}

The academic literature, civil society, and the police alike have long noted the risk of officers being 'trigger-happy' (Adams and Jennison 2007: 456, see also Sierra-Arévalo 2019: 246). For example, police trainers in England and Wales acknowledged the risk of over-use of TASER, with one trainer commenting during training that 'it's amazing how I give you this yellow bit of kit and you forget to use your mouth'. On another course, a trainer noted that 'the big problem I've got is that some of the ones who are not firearms officers... are jumping far too quickly to... thinking about Tasering', thus reinforcing concerns held by many about the over-use and over-reliance on electric-shock weapons when other alternative methods may be available. Such statements may well have been exaggerated and need to be considered in the context of relatively low rates of TASER use in England and Wales (Ariel et al. 2019, Home Office 2019b). Nevertheless, they do speak to the potential for the presence of the weapon to impact officer decision making, subtly incentivising their use of force (see also the 'weapon effects' literature, in Ariel et al 2019).

Latour's notion of delegation - the idea that competencies, work, and effort can be shifted from humans to non-humans-suggests one way in which projectile electric-shock weapons could impact decision making and is useful in helping us understand why officers could be 'trigger happy' with such weapons to hand. Latour (1992: 155) advises us that 'every time you want to know what a nonhuman does, simply imagine what other humans or other nonhumans would have to do were this character not present'. This challenge is insightful here, particularly when combined with Collin's (2012) work on the 'tunnel of violence'. Collins demonstrates that it is difficult for individuals to use force, let alone to do so competently. In order to do, individuals must be able to overcome various barriers, including the tension and fear that they experience and which acts as a powerful constraint on action. Yet I argue that, with the introduction of the projectile electric-shock weapons, the work of tackling these barriers has been 'delegated' from emotional 
human beings to an emotionless, inhuman weapon, thus reducing their salience (see also Dymond 2020).

This 'delegation' happens in multiple ways. It has been argued, with reference to military weapons, that force becomes more palatable at long distances. Hence, Collins (2009) notes that aerial bombs and rockets are psychologically easier to use than guns. While projectile electric-shock weapons are used at closer ranges than much military weaponry, still they can be used at a longer distance than empty hand techniques, baton or pepper spray. This lessens an important psychological hurdle involved with the use of violence-especially as using force at a distance can also offer protective benefits for officers. This was explicitly stated by some officers, with an officer in Countryshire noting:

'it's not that I don't feel comfortable with the baton, I'm quite apt at using the baton, but I'd rather use either spray, or deploy TASER instead... Because I always feel it, to be that up close and personal to someone with a baton, I would rather push someone away or get my spray'.

(Officer 19, Countryshire)

Moreover, using projectile electric-shock weapons outsources the need to physically make contact with the human body from the police officer to the weapon. Were such weapons unavailable, officers would have to strike individuals with their hands, fists, feet and batons, or discharge irritant spray into their face. With electric-shock weapons, however, officers simply have to squeeze a trigger, transforming a 'major effort' - the work of physically inflicting blows on the human body - into a 'tiny effort' (Latour 1992: 154); that of moving a finger. Officers themselves note the comfort that this can afford them. As we saw previously, in Chapter 4, officers made statements like:

'there's less blood, less bone breakage, its indirect control (compared to the baton). If I can control someone by not hurting them, I'm happy... It's less physical, less caveman'.

(Officer 1, Countryshire)'

'CS, it doesn't sit well with me, hitting people with a baton it's a bit crude. TASER I tend to use more than anything else, just because that is my decision to go to that first'.

(Officer 3, Townsville)

Thus 'delegating' violence to a weapon, instead of having to physically strike someone, allows officers to rationalise their use of force as 'nicer' than alternative options-particularly as the effects of projectile electric-shock weapons are often less visible than injuries caused by, for example, dogs or batons (Anais 2009). 
Moreover, many of the decisions about how much force to inflict are delegated to the weapon, which exerts an amount of electrical charge over which the officer has no control, and (in certain models) does so for a predetermined length of time. Decisions around knowing how much force to use and assessing how much violence to apply are again taken away from the officer and 'delegated' to the weapon. All these factors may make it easier for officers to contemplate using force, lowering the psychological barriers to be overcome. As such, decisions that officers make around the use of force may be subtly shaped by the weapons they are carrying (see also Dymond 2020) and, in keeping with the notion of generalized symmetry, these weapons can be more than just tools but can, in certain circumstances, have considerable influence and impact.

\section{Personal safety training}

It is not just technologies, however, that can impact decisions around use of force. Another important consideration is the training given to officers. It is not just the training on TASER (discussed in the last chapter) that is important here. The training around the use of other force options (commonly referred to in England and Wales as Officer Safety Training, OST, or Personal Safety Training, PST) is of equal importance. Such training is crucial: as Geller and Toch note, officers need to be highly skilled in order to be competent users of force (in Buttle 2007). It is also imperative that officers have a range of options at their disposal if they are genuinely to be able to choose which tactic to use. This necessitates providing officers with a range of communication skills and tactics to enable them to resolve situations without recourse to any force whatsoever. It also requires that officers receive sufficient training on force techniques other than electric-shock weapons, including empty hand techniques, baton strikes, or use of irritant spray.

However, evidence suggests that training in each of these areas could do with improvement. The IPCC has highlighted room for improvement around officer communication skills. They found that, of the 191 cases of police use of force which were independently investigated or managed by the IPCC between 2009 and 2014, inadequate communication was found to have taken place in $10 \%$ of them. The IPCC have, thus, recommended that the police 'provide training for their officers in communication techniques to help them manage and de-escalate situations without using force... (this) can be particularly useful to give officers the skills and confidence to communicate with groups with specific needs' (IPCC 2016a: 76). The College of Policing has produced new national Conflict Management Guidelines, which aim to support officers to 'assess and respond to situations in ways that minimise the chance that force will be needed' (2020b: 2). They note that the Guidelines are intended as 'the first stage in a programme of work... to develop the national curriculum on personal safety' (College of Policing 
2020b: 1), noting that 'much of the current focus of personal safety training is on the physical techniques for containing and managing aggressive individuals... there is generally much less investment in the development of more specialist negotiation skills that are necessary for the safe resolution of these encounters' (College of Policing 2020: 2).

In terms of competency on the use of force, ACPO historically recommended that a minimum of two days a year was spent on personal safety training (HMIC 2007). Yet it is not clear whether two days training is sufficient to cover the use of empty hand techniques, handcuffing, irritant spray, restraint belts, and other techniques. Personal safety trainers, who admittedly depend on such courses for their livelihoods, noted that if we were to go with the minimum time for everything that is included in the pack, that needs to be taught (in line with) the recommendations from ACPO, we'd need three days. (With two days) we can get them back to where they should be, (doing) maintenance rather than development' (Personal Safety Trainer 1, Force location omitted). These findings also fit in with the IPCC's research, which found that 'officers considered the training (on police use of force) provided to be sufficient, but...(raised) some concerns about the reduction in time dedicated to training... Some training modules around personal safety were considered insufficient and too infrequent to ensure that knowledge stayed up to date' (2016: 16). Similarly, a College of Policing survey (ClarkDarby and Quinton 2020: 38-42) of over 40,000 officers, staff, and volunteers found that roughly a third of respondents were not satisfied with the personal safety training they had received, with less than half saying that they had opportunities to practice their de-escalation skills in training, and only a quarter saying enough time was spent on training communication skills.

Insufficient training has consequences for both officers and members of the public. Crucially for the purposes of our discussion here, it may mean that officers are not fully equipped to choose between different use of force options. These themes came out strongly in interviews, with trainers noting:

'(Post-incident, officers will) be asked to justify why they've used a level of force... (and) maybe they can, but there's a greater potential that they could use excessive force and not be able to justify it (because) they couldn't reproduce the skills necessary'.

(Personal Safety Trainer 1, Force location omitted)

'Officers need to know they must be able to justify their decision-making process with regard to 'is it proportionate, is it legal'? 'Am I using a recognised technique'? If they don't know how to do it... then they are very literally taking their career into their own hands. They risk injuries to themselves, injuries to their colleagues, injuries to the subjects they are dealing with.

(Personal Safety Trainer 4, Force location omitted) 
In practice, then, officers may have less use of force options available to them-and, moreover, may be less able to make clear, conscious decisions about the use of force options that they do have. This could mean that they fall back on using projectile electric-shock weapons, given their lack of confidence with other techniques. Indeed, whilst not mentioning electric-shock weapons specifically, one personal safety trainer (interview 2) noted that those with fewer empty handed techniques 'do rely on their kit quite a lot. They shouldn't have to, they should be able to rely on their empty handed techniques'.

\section{Traditional police subculture}

Thus, far from being an individual decision, it could be argued that officers' choices around whether to use projectile electric-shock weapons are influenced by a number of factors. These include the very presence of the weapon and the (lack of) training they receive-both of which may incentivise officers to use the weapon. Yet these factors do not occur in isolation. Rather, they occur within a broader cultural context and a traditional police subculture (TPC) often described as negative and even malign. Previous research has indicated glorification of the use of force, masculinity, sexism, racism, and an 'us versus them' attitude, amongst other issues (see Hunt 1985, Reiner 2010 and Waddington 1999 for a critique). Given the centrality of police culture research in the criminology literature, no discussion on decision making would be complete without discussing police subculture and the impact it may have on police use of force and electric-shock weapons specifically.

The TPC is not just reflected in the ways in which officers speak about the weapon (as discussed in Chapter 5) but can also subtly influence individual officers' decisions around use of force and TASER in several ways. Firstly, it can incentivise them to carry the weapon in the first place. Volunteering for the role can enhance officers' credibility, career potential, and demonstrate their desire to meet the challenges of the job head on. It can also provide them with valuable opportunities to demonstrate their 'street cred' and operational credibility, which Grint et al. (2017: 166) describe as a 'cultural lodestone' in policing. As one officer noted, being selected to carry the weapon demonstrates 'progression in the job...(and) a trust from your superior officers' (Officer 18, Big City). Learning how to use the archetypal 'masculine modern weapon' (Wozniak and Uggen 2009: 286), becoming familiar with weapons handling, and developing their decision-making skills under pressure can further enhance TASER officers' status. Indeed, appeals to masculinity and traditional subcultural values are explicit in the marketing around electric-shock weapons, which is designed to appeal to 'hyper-masculinity', stressing aggression, dominance, and 'control through coercive force' (Wozniak and Uggan 2009: 276).

Moreover, once officers are equipped with the weapon, being sent to risky, dangerous situations where they are expected to take charge can provide officers 
with multiple opportunities to live up to traditional subcultural norms and to highlight their bravery and leadership. As a TASER trainer noted to students on one of the courses, you 'may only have two years' experience but you will be deferred to over more experienced officers without TASER' when attending potentially violent incidents. Hence, volunteering to carry the weapon can be an important way for officers to try and fit in-perhaps particularly for officers that feel less attached to, or are more on the outside of, the TPC.

Indeed, TASER trainers in multiple forces noted the 'pressure' to carry the weapon. A trainer on one of the initial courses started the first day of training by noting to students in his introductory comments that 'this course is not for everyone. Some people are put on undue pressure to come on this course. The door is there if you want to leave'. On another course, trainers were discussing current and past students who failed the course in a quick break between practical sessions. One of them explained to me that "nothing will happen to you (i.e., students on the course) if you don't do it, you will still have a job'. However, he stated that 'it might be a bit disappointing going back to your colleagues, you feel like you've let them down. You have a sense of pride, of professional pride. But it's not the end of the world'. Such statements may be intended to be supportive and reassuring to students, but at the same time still speak to the broader cultural norms, pressures and expectations around carrying the weapon.

Moreover, TASER trained officers, particularly female officers, explicitly talked about the pressure they perceived from their colleagues to take the TASER training. For example, one female officer in Big City explained her decision to come on the course because 'there is an amount of respect you get on the team if you carry TASER, you are seen as competent' (Officer 6, Big City). A female officer in Countryshire noted that, amongst her current colleagues: 'all the guys want to (carry TASER) but the females don't.... I have to be able to prove myself $150 \%$. I could almost feel it... feel "oh, i'm with a girl" is what they might be thinking. I have to prove I could do just a good job as them' (Officer 2, Countryshire).

Such experiences resonate with Hunt's (1985) observations that while male officers are assumed to be competent users of force unless the evidence indicates otherwise, female officers are assumed to be passive, a liability and reluctant to use force until proven otherwise. As Hunt observes, it is therefore crucial for female officers to create opportunities to display their prowess and prove themselves to overcome these biases - and carrying TASER can provide one such opportunity.

There is also some evidence that such cultural pressures also came to bear when making decisions around the use of the weapon. For example, an officer in Countryshire noted that:

There tends to be a sort of mentality sometimes where we go to arrest somebody... and (colleagues) say 'if he plays up you can TASER him.' 
There is that mentality, that pressure (from officers that aren't TASER trained)...They don't understand, they just think 'they'll be able to stop it'.

Another officer from the same force stated:

'A lot of the officers that don't carry TASER think that you can just save the day with it... That's not always the case... some of them perhaps might shout to you to go and resolve it.... So it can be really pressured... you have a responsibly to yourself, to the person, but also to your colleagues as well and that's sometimes really difficult'.

(Officer 8, Countryshire)

Such pressures may not necessarily be external in nature; indeed, previous research has demonstrated that officers who more strongly identify with the traditional subculture also show greater support for police use of force (Silver et al 2017; Terrill et al 2003). Indeed, Terrill et al. (2003: 1001) found that 'officers who closely embody the values of the police culture are more coercive compared with those that differentially align with the culture'. As noted in Chapter 5, officers often—although not always—speak about the weapon in ways that are closely aligned with the police subculture, suggesting a degree of internalisation.

Of course, even when officers claim to closely embody traditional cultural values, the extent to which these may shape their actions should not be overstated. As Waddington (1999: 289) notes, 'police are not unusual in saying one thing and doing another' and thus police subculture may provide 'little explanation' of police behaviour. However, in light of the studies demonstrating a link between cultural attitudes and police behaviours (see Ingram et al 2018 for a review of the literature), as well as studies in the UK which have found a significant impact of police subculture (Westmarland and Rowe 2018), it seems possible that subcultural beliefs may well impact decision making. At the very least, the possibility cannot be discounted outof-hand. Ultimately, then, the notion of, and debates around, police subculture highlights the limits to decisions around use of force and electric-shock weapons being seen purely as an individual action and, in turn, challenges the sufficiency of the guidance and training given.

\section{(Non)human agency and subculture}

Thus far, this chapter has been at pains to demonstrate the way in which multiple influences-including police subculture-impact officer decision making around projectile electric-shock weapons. While this is helpful up to a point and helps underscore the broader insight that decisions that appear to be personal and individualised are nothing of the kind, it is important not 
to imply that subculture is somehow passively transmitted. If police subculture impacts the use of projectile electric-shock weapons, so the latter may also impact police subculture and its expression. Perhaps officers, electric-shock weapons and the interactions between them-what Pickering (2005) might call the 'dance of agency'-are not just receiving, but are also actively shaping, police subculture.

I contend that this happens in three multiple (and sometimes contradictory) ways. First, projectile electric-shock weapons arguably remove some traditional subcultural restraints on the use of force. In her seminal study into police culture, Hunt (1985) notes that officers have their own norms and calculations about whether the force used was appropriate. They provide reassurance and moral support to officers who they believe have acted appropriately and also have informal control measures to reprimand officers' whose force is seen as inappropriate. If officers perceive that the force used is excessive-especially if it is used randomly or in an uncontrolled fashion, or there is no 'rough equation' of equivalence between the behaviour of the civilian and the force used-then colleagues will intervene and/or provide feedback to the officer in question. Such informal mechanisms can be an important way of calibrating police use of force and preventing some of the worst excesses-even if the definitions of acceptable force used by police officers may differ from those outside of the police.

However, these calculations are rendered more difficult in the case of projectile electric-shock weapons. As we saw previously, colleagues accompanying TASER trained officers, particularly those who have not received training on the weapon, may be unaware of the power of the weapon and may perceive its use to be relatively innocuous. While officers may intervene to stop beatings that they consider excessive, and where they perceive that the officer has 'lost control' (Hunt 1985), it may be more difficult to make such determinations around electric-shock weapons. As discussed in Chapter 5, officers see only the pressing of a trigger and the discharge of probes. They may lack the readily observable visual clues and auditory accompaniments (the sound of blows being struck, the power that officers are putting into their blows) that may be present in the case of a beating. TASER is perceived and understood as 'less physical, less caveman' (Officer 1, Countryshire) than other options. On this reading, the very mechanisms that make it easier for officers to use force and to 'enter the tunnel of violence' (Collins 2012) may also make it more difficult for colleagues to hold them to account and uphold cultural norms that limit the use of force.

Second, while in some cases, projectile electric-shock weapons may help reinforce traditional subcultural norms, in other cases, the introduction of these weapons allows officers to challenge such norms. While some officers may value the weapon because of its' hyper-masculinity, other officers-perhaps those who have a 'guardian mindset' (McLean et al 2019: 1) or 'peacekeeping' orientation (Paoline 2004: 224) and who place a high emphasis on 
'non-aggressive order maintenance' (Paoline 2004: 224)—may value projectile electric-shock weapons because they perceive it allows them to use less force, and more pleasant forms of force, than might otherwise be used. As discussed in Chapter 4, many officers stated that they valued the weapon because it was 'nicer' for those subjected to it. Other officers have praised the weapon not for its coercive capacities, but for its use as 'the tool of the pacifist' (Tangye 2016). Other officers have talked about their reluctance to go 'hands-on'.

The point here is not (just) that there are different subcultural values at work. It is also that the status and 'respect' that comes with carrying projectile electric-shock weapons may allow officers both to showcase their adherence to traditional subcultural values while simultaneously challenging these norms. It is as if the status and prestige of carrying TASER confers a legitimacy on officers that allows them to subvert cultural norms by expressing their dislike of force, their desire to avoid conflict, and their preference to use the minimal amount of force necessary.

Third, it is not just individual officers who are engaged in rewriting subculture. While multinational corporations market their weapons in such a way that it appeals to strands of the traditional, masculine police subculture, much of their success has come from the way in which they are able to repurpose and reorient notions of masculinity (Wozniak and Uggen 2009). Masculinity has been recasted and expanded so that it includes not just carrying firearms, but carrying electric-shock weapons; valuing weapons that are not just powerful, but that are powerful and safe; and preferring the use of a distance weapon to going 'hands on'. Marketing materials around policing equipment and weaponry more broadly highlight not just the image of the 'warrior', but the 'vulnerable warrior' who is both brave and (almost inevitably) male, yet simultaneously at risk and in need of protection (Feigenbaum and Weissmann 2016). Fashioning and heterogeneously engineering projectile electric-shock weapons, then, involves not only engaging in goal translation and finding ways to make the infliction of severe pain palatable (as discussed in Chapters 3 and 4). It also involves finding ways to appeal to, yet simultaneously recast, traditional masculine notions of what it means to be a police officer.

Hence, while it is important to recognise the ways in which traditional subculture may impact officer actions, it is also important to recognise the ways in which electric-shock weapons, officers, and the interactions and 'dance of agency' between them may simultaneously be influencing subcultural values.

\section{Conclusion}

This chapter has discussed the guidance and training around the weapon and found that it places a strong emphasis on the notion of projectile electricshock weapons as a neutral tool and on decision making as an individual responsibility for officers. These myths are not necessarily inaccurate, but 
they are incomplete. The decisions that officers take should not be considered solely their personal responsibility. Instead, they are often impacted by the result of a variety of phenomena and influences on human agency. These include the influence of technologies (in this case, the delegation of force to projectile electric-shock weapons), the content and length of TASER training and officer safety training, and traditional police culture. Taken as a whole, such factors may combine to subtly influence and incentivise officers to use the weapon, either substituting it for other forms of force, or using force in situations where it may not be required.

Such ways of understanding decision making serve to highlight the limits of thinking of weapon technologies as mere tools. Instead, focusing on technologies, and the ways in which violence is 'delegated', has proved productive. This approach has generated new insights about projectile electric-shock weapons and so-called 'trigger happy' officers, while drawing attention to the ways in which the 'missing masses' (Latour 1991) of technology may influence discretionary decisions and police subculture alike. We return to the theoretical implications that these findings may have for discretion and subculture, as well as for the concepts of delegation and generalised symmetry, in the concluding chapter. For now, though, having explored in this chapter, two of the myths that accompany TASER use in England and WalesTASER as a neutral tool, and decisions around TASER as the responsibility of individual officers - it is time to turn to another myth: that of 'robust' accountability mechanisms. This belief plays a key role shoring up the other myths discussed in this chapter: after all, the devolution of decisions down to individual officers is often justified with reference to the intense scrutiny and accountability they face. It is to a closer examination of these accountability mechanisms that I now turn. 


\section{Chapter 8}

\section{'You cannot obtain accountability' Officer accountability for use of force}

\section{Introduction}

It is often argued that 'rank and file' officers are accountable for their use of force, in particular, their use of projectile electric-shock weapons, and that there are 'robust' mechanisms - both internally (via professional standards and internal complaints handling) and externally (via the Independent Office for Police Conduct, its predecessor the Independent Police Complaints Commission and, ultimately, the courts) - in place in order to ensure this. This myth is the topic of this penultimate chapter and my argument here is as follows.

First, I suggest that, far from there being robust accountability, it is exceptionally difficult to hold officers to account following their use of TASER, and other forms of force. There have been a few cases where officers have been found guilty of gross misconduct following electric-shock weapons (see, for example, Thomas 2013). College of Policing (2019: 6) figures indicate that, between March 2018 and 2019, 11 officers were dismissed for use of 'excess force' (which may, or may not, have involved the use of electricshock weapons), during a period in which 428,000 use of force incidents were recorded (Home Office 2019b). Yet, overall, concerns about a lack of police accountability seem well-founded and it is difficult to disagree with the characterisation of Lisa Cole, the sister of Marc Cole, that 'you cannot obtain justice or accountability' (interview with author).

This chapter suggests that multiple factors contribute to this lack of accountability. These include the test in criminal law for use of force in England and Wales - the 'honestly held belief standard'-and a police decision-making model called the National Decision Model, or NDM, which has made it more difficult for officers to be held accountable. This is important not only in its own right, but also because, as we saw in Chapter 6, similar decision-making models are used (or being considered for use) in a number of countries worldwide, including New Zealand and the United States of America. Instead of praising existing police accountability measures, then, we need to urgently build new ones. However, and this is my second point, the academic literature on police officer accountability is ill-equipped to tackle this challenge. 
This literature, and its proposed remedies, have traditionally been human centric. Yet, as previous chapters have demonstrated, decisions about whether, and how much force to use, are impacted by the materiality of projectile electric-shock weapons and the socio-technical network around them. The problem of excessive use of force is not something that can be addressed at the level of the individual officer alone. Rather, we need to ensure that the responsibility for the use of force, the pressure that comes with making decisions on such an important topic, and accountability for such decisions are shared amongst senior police officials, decision makers, and broader network around the weapon. This is not a way of detracting from the accountability and responsibility of individual officers, but as a way of augmenting it.

In order to progress my argument, I first review the existing literature around police accountability and around accountability for TASER more specifically, arguing that it focuses on human centric remedies. In Part 2, I challenge the myth of accountable, TASER-trained officers in England and Wales, looking first at internal review mechanisms and complaints handling, before addressing external accountability in the form of the IOPC and IPCC. In Part 3, I then turn my attention to the courts and, drawing on a number of TASER related cases - including those involving Colin Farmer, Judah Adunbi and Marc Cole-demonstrate that there are significant barriers to accountability in criminal and civil cases.

While this covers a lot of ground, there is much more to be said. In a chapter of this length, it is impossible to focus on every aspect of accountability, and this should not be considered an exhaustive treatment of the subject. I focus on formal accountability mechanisms because, more often than not, they take centre stage in discussions around accountability and are often pointed to as examples of 'robust' oversight. I focus on what Reiner calls 'individual accountability' of particular officers rather than broader 'policy accountability' (in Jones 2008: 1), given the emphasis that is placed on the actions and decisions of rank and file officers (as discussed in Chapters 6 and 7). Finally, I note that, at the time of writing the police complaints system is being altered. Reforms include an enhanced role for Police and Crime Commissioners in reviewing complaints (Home Office 2020, Office of the Police and Crime Commissioner Devon and Cornwall 2020). However, it is too early to be able to meaningfully assess this new system and this chapter makes no claims to do so. Relatedly, while I touch on the role of the IOPC, it was only introduced in 2018. As such, it is the IPCC that was the relevant external complaints body for most of the period during which the research was conducted.

\section{Police and accountability}

While there has been little work on accountability for projectile electricshock weapons per se, there is a rich literature on police accountability more broadly. However, this tends to be anthropomorphic in focus. For example, 
Prenzler et al.'s (2013) systematic review of programmes addressing use of force found that interventions have traditionally focused on individual strategies (such as early warning systems), cultural strategies (such as civilian review boards, which can challenge inappropriate norms), and organisational strategies (such as revisions to guidance and complaints policies). Koslicki's (2019: 366) analysis of body worn cameras - seen by many as a panacea for police accountability-highlights the limits of the technology in contributing towards accountability. She argues for solutions to police misconduct that are distinctly human in nature, recommending that police forces should redirect their focus away from technology and towards officer selection and training.

Austin and Bocco (2016) note that initiatives to prevent torture and excessive use of force by the police and security forces tend to focus either on individual pathologies (such as the bad apples explanation), combatted by vetting initiatives, or norm dissemination and institutional reform, including prosecution for crimes. Armacost (2019) argues that accountability paradigms are focused on 'the officer who pulled the trigger'-or, in this case, fired the TASER - and their individual misconduct, or lack thereof. Concomitantly, it is assumed that police reforms should focus on changing the behaviour of officers, including via lawsuits. As such, there is a need for the literature to look beyond this and to examine how technical features and interactions with humans may shape, assist, or problematise police accountability. Indeed, both Austin and Bocco (2016) and Armacost (2019) call for more work looking at the role of the non-human in police accountability.

Turning specifically to TASER in England and Wales, police and oversight bodies alike speak positively about the potential for accountability. The NPCC have argued that the weapon is 'heavily scrutinised. Every time it is used-even simply drawn from its holster-this must be recorded and examined by a supervisor. If the force used is disproportionate or breaches their training, officers can be investigated and face misconduct or even criminal charges' (NPCC 2015). They further state that 'every use of Taser is reported and scrutinised... (and) comprehensive training packages, governance and monitoring are in place' (NPCC 2020).

The IPCC (now replaced by the IOPC) has stated that it is satisfied with how police forces are handling complaints around TASER, so much so that it no longer requires complaints about the weapon to be referred directly to it (NPCC 2015). It notes that the rate of appeals upheld around TASER is less than the overall rate of appeals upheld more broadly (IPCC 2014a). The IOPC further states that it's own 'operational decision-making is independent from the police or government. Neither our Director General, Director for Wales or any of the Regional Directors have worked for the police in any capacity. These are the people with oversight of our investigative work and they ensure that our investigations are robust and impartial' (IOPC undated, 1). Moreover, HMIC's (2016a: 55) assessment of TASER use in England and 
Wales found not only that 'Taser had been used fairly and appropriately in almost all the cases where we made an assessment' but that, in general, there were 'robust oversight systems in place' ${ }^{1}$.

Hence, accountability mechanisms around TASER are seen as robust by both the police and by external oversight bodies alike. In keeping with the academic literature, there is also an emphasis on accountability as it pertains to, and is enacted by, human actors. There is a focus here on the actions, backgrounds, and roles of those surrounding TASER-trained officers, including their immediate supervisors, national staff, and those in charge of IPCC investigations, as well as mechanisms such as training and criminal courts.

Yet TASER cannot be understood without a focus on the technical features of the weapon and the accountability benefits associated with it. The manufacturer claims that "no other law enforcement tool can claim such unique and proven accountability systems that provide a check and balances system in place for each local law enforcement agency' (TASER International, quoted in Wolf and De Angelis 2011: 667). For example, Axon note that the TASER $\mathrm{X} 2$ collects a range of information, including the date and time that the weapon was armed (and made safe), when it was discharged and for how long, the type of cartridge used and details of each electrical pulse (Axon undated d, see also Home Office 2016). Thus, unlike other weapon technologies-and even other brands of projectile electric-shock weapons ${ }^{2}$ - in built monitoring within the TASER weapon can capture an extensive range of information and detail that may prove key in holding officers to account for their use of the weapon. Moreover, Axon now makes compatible body worn cameras that begin recording whenever a TASER weapon is armed, providing another opportunity for enhanced accountability.

Such features call to mind Latour's notion of 'prescription', the process through which behaviour is imposed back onto the human by nonhuman actors. In the same way that, in Latour's example, car seat-belt alarms render driving without a seat belt 'logically inconceivable as well as morally unbearable' (1992; 152), so the inbuilt recording features of the TASER render it 'logically inconceivable' for officers to deny using the weapon, or for inaccurate accounts around its use to prevail. The point here is not just that such accountability features exist; it is also that they 'prescribe' (Latour 1992) or attempt to impose certain actions and decisions on police officers, making certain behaviours 'logically inconceivable' (1992: 152).

This is not to say that this process is automatic, nor to downplay the difficulties individuals face when seeking to recollect high pressured, fast moving events. Just as the drivers in Latour's account can try to subvert and challenge the car seat alarm, so too TASER officers can challenge TASER download records and (intentionally or unintentionally) recollect events differently. For example, the length of TASER discharge was an important consideration into the Inquest following the death of Marc Cole, at which the use of TASER was found to have a 'more than trivial impact' on his subsequent 
death (Cornwall and Isles of Scilly Coroner 2020b). It was reported that 'the officer who Tasered Marc admitted during the inquest that he had given inaccurate initial statements to the Independent Office for Police Conduct investigation. He said this was on the advice of the Police Federation solicitors, who encouraged him not to "express uncertainty" and to state he had discharged the Taser only twice' (INQUEST 2020a). However, during the Inquest, the officer admitted discharging the TASER three consecutive times-something confirmed by the TASER download record.

As such, the material features of the weapon exert a powerful impact and may help enhance accountability. Indeed, according to the manufacturer they 'may help protect a user from claims of excessive force by providing documentation of the time and date for each CEW deployment...(and) also provide agencies with a powerful management tool to track usage patterns and help prevent misuse' (Axon undated, d: 47).

\section{Internal mechanisms}

Thus far, we have seen that accountability mechanisms around projectile electric-shock weapons, and, in particular, TASER, are seen as robust-but there are important reasons to question such characterisations. I turn, first, to internal accountability mechanisms. Internal mechanisms are often seen as crucial in spotting patterns of concern early and preventing further issues. For Markham and Punch (2007), internal accountability is paramount and the foundation of all other forms of accountability.

TASER officers in England and Wales are required to account for their use of force in their pocket notebook. They are also required to fill out a standardised form after every use of the TASER weapon (or other form of force) and the College of Policing APP (2020a) states that 'the CED single point of contact (SPOC) is responsible for reviewing TASER use'. However, the quality of internal review varies from force to force. For example, the IPCC investigation into the repeated use of TASER by Merseyside Police on an individual, Kyle Ardle, who was detained in a police van, found that it was 'of concern that Merseyside's lead Taser instructor lacked objectivity and presented as fact the officers' version of events without challenge' (Thomas 2013). Nor was this an isolated incident-indeed, the IPCC have further noted that:

Many of the appeals... (we have) upheld have shown that police forces take a police officer's account at face value without any further probing. It is important that police officers record their rationale for using Taser with reference to the specific circumstances of the case. When that rationale is investigated by police forces it should be subject to robust challenge where required.

(IPCC 2014a: 4) 
HMIC also found evidence that there were issues with the internal accountability mechanisms in place more broadly in certain forces. For example, in Humberside, HMIC (2016b: 7, 41) stated that 'more needs to be done to ensure sufficient supervision and oversight... Taser forms are not regularly reviewed comprehensively to identify trends and there is no convincing explanation for the comparatively high use of Taser'. Further, Derbyshire police have themselves noted the need for 'increased scrutiny of decision-making in relation to "lower-level" Taser use such as "red-dotting". HMIC's inspection further stated that 'although the constabulary does carry out some reviews this is currently not systematic and... the constabulary (cannot) be completely confident that Taser use is consistently fair and appropriate' (HMIC 2016c). These examples raise concerns about routine internal monitoring, suggesting that it varies from force to force.

Whilst on-going monitoring is crucial for picking up patterns and trends around the use of TASER, so too is the robust internal handling of complaints. However, HMIC (2016a: 22, 25) has noted wide variations across forces, with no 'consistent approach... to complaint handling'. Clients and those representing them have had similar experiences, noting concern over the use of 'local resolution'; a process deemed suitable for 'lower level complaints, such as rudeness or incivility' (HMIC 2016a: 22) and which cannot lead to disciplinary action for the officer(s) concerned. For example, Solicitor Iain Gould has noted that:

'I have come across certain police forces who are very good... (but in other cases) the complaint route is a complete white-wash... For example (one client) who was Tasered put a complaint in himself... the police went along to see him and his complaint was locally resolved. So you can imagine the chat that they had with this man who clearly has mental health issues, "just sign here to say local resolution is acceptable"... (even though at the time there was) clear guidance that any complaint of TASER must be referred to the IPCC'.

(interview with author)

Such practices have also been criticized by HMIC (2016a: 24), which noted its concern over cases 'where complaints had been locally resolved when, in our opinion, they should have been investigated as potential misconduct' and cited as an example a case involving 'allegations of unlawful arrest and unnecessary use of force'. Overall, then, the evidence presented in this section raises concerns that not all forces have been able to monitor TASER use effectively, or to deal appropriately with complaints around the use of TASER when these do arise. What, then, about the role of external oversight mechanisms? 


\section{External mechanisms}

Police and Crime Commissioners, HMICFRS and the IOPC (and, before that, the IPCC) have different, yet complementary, roles to play in ensuring effective oversight of, and accountability for, TASER and police use of force more broadly. As our interest here is on the accountability of individual officers, I focus on the IPCC and IOPC, which has a mandate to investigate the most serious complaints and incidents involving the police, including those around police use of force. In contrast, HMICFRS's role is to assess the effectiveness and efficiency of police forces more broadly. However, it is worth briefly noting that, by its own admission, as recently as 2015, HMIC had 'not inspected how Taser is used either in, or between, forces' (HMIC 2016a: 57). Whilst this is now changing-a point I pick up on in greater detail below-the fact remains that the organization was not traditionally well placed to provide oversight of TASER use.

The role and effectiveness of the IPCC has been the subject of multiple reports (Casalie 2012; Chapman 2014; Home Affairs Select Committee 2013; Jenkins 2014; NAO 2008), including one by the IPCC itself (IPCC 2013). The broad consensus from these sources was that the degree of independent oversight exerted by the IPCC had been comprised by several factors, all of which can be expected to impact how, if at all, the organization is able to investigate cases of TASER use. Thus, the Home Affairs Select Committee found that:

'The IPCC is woefully underequipped and hamstrung in achieving its original objectives. It has neither the powers nor the resources that it needs to get to the truth... It is not yet capable of delivering powerful, objective scrutiny'.

(Home Affairs Select Committee 2013: 3)

While the IPCC was replaced with the IOPC in January 2018, the IOPC director has noted that the organisation continues to "work through many legacy issues, including improving timeliness of investigations' (Lockwood 2019). There are five concerns that I pick up here.

First, as the quote from the Home Affairs Select Committee above indicates, inadequate resourcing has been both a problem in itself and lies at the heart of many of the issues subsequently discussed here (IPCC 2013). The IPCC was smaller than, for example, the Metropolitan Police's Professional Standards Department (Home Affairs Select Committee 2013: 3). While its successor, the IOPC, claims that 'we have doubled in size and now take on six times as many investigations' compared to 2013 (IOPC undated, b), the length of time that cases can take to get to court means that it is not yet possible to fully assess the extent of these changes. Crucially, then, it can be considered to have been inadequately resourced for the majority of the time that TASER has been introduced. 
Second, the ability of the IOPC (and IPCC) to investigate a case relies on the organization being aware of it in the first place-and there are concerns that they have not been sighted on all relevant cases. For example, the IPCC (2014b: 6) expressed concern about a case in an anonymised police force where an individual subject to TASER complained about the weapon's use whilst he was still in custody but this complaint was not referred to the IPCC, as required at the time. Moreover, the IPCC's broader review into incidents referred by police forces to the organization found that 'all of the forces we sampled lacked a formal process for assessing whether cases needed to be reported to their Professional Standards Department (PSD)' and, in turn, that PSD staff 'had only minimal training on the referral grounds' (IPCC 2015: 2). The requirement for all TASER complaints to be referred to the IPCC was dropped in 2015 (NPCC 2015), further impeding their ability to offer independent oversight.

Third, there are concerns about the number of cases the IPCC refers back to forces to investigate. Although a recent legal case, specifically relating to alleged misuse of TASER, found that referring cases back to the force for investigation wasn't inherently problematic (Morrison $v$ The Independent Police Complaints Commission and Others, 2009), the practice has continued to generate concern with the Home Affairs Select Committee (2013: 10) describing such investigations as 'no better than a placebo'. Yet, of the 434 complaints about TASER use that the IPCC received between 2004 and 2013, the IPCC decided that the vast majority $(78 \%)$ could be investigated by the police force that was the subject of the complaint in the first place (IPCC 2014a: 19). While the introduction of the IOPC increased capacity and a move to reduce 'managed' and 'supervised' inspections (IOPC 2018b: 13) may alleviate some of these issues, they still remain pertinent. As the IOPC notes (undated, b), 'police forces deal with the majority of complaints against police officers and police staff'.

Fourth, concern has been raised about the quality of the investigations conducted. The IPCC (2013: 2) has stated that, with 'only 100 investigators and increasingly stretched support services-(it) is not adequately resourced to carry out its investigative work to the standard and timeliness which the public and bereaved families expect'. The Casalie review into the investigation into the death of Sean Rigg noted the need for further training for investigators (Casalie 2012: 17) and the Home Affairs Select Committee (2013: 5) made several criticisms of IPCC investigations, including a failure to locate evidence, to challenge police explanations for missing evidence, a lack of 'thorough investigation', and 'slowness in conducting investigations'. The Committee also expressed concern that about the significant number of former police officers employed by the organisation - and such concerns continue today with the IOPC. As of March 2020, 23\% of IOPC staff overall came from a police background (IOPC communication with author, dated 10 September 2020). 
While it would be hoped that the situation has improved with the advent of the IOPC, the inquest into the tragic death of Marc Cole raised a number of concerns with the investigation ${ }^{3}$, many of which were echoed in a listening day held by INQUEST. This found that 'few in the room that had positive accounts of investigations', with families raising concerns including evidence gathering, inconsistent approaches to interviewing officers, delays and a failure to involve families during the investigation (INQUEST 2018: 14). Such issues are, understandably, of great concern to family members, with Marc Cole's sister, Lisa Cole, noting that 'it is very difficult when the investigation is flawed, if you've got an independent body who is supposed to be obtaining evidence transparently and clearly cannot do so in the way that they should be doing' (interview with author). The IOPC state that, since this Listening Day, they have made various improvements, including holding their own listening days with bereaved families, appointing Family Liaison Officers, and expanding and strengthening the Stakeholder Engagement Team (IOPC communication with author, dated 10 September 2020).

Fifth, there are limits to the role of the IPCC and, latterly, the IOPC. These organisations can determine whether there are questions of (gross) misconduct and/or criminal conduct to answer, but cannot determine the answer to these questions. The IOPC can pass a case to the Crown Prosecution Service and, thanks to new powers, can decide that forces must hold a misconduct hearing and present a case at these hearings - but the outcome of such processes is independent of the IOPC. The IPCC's own figures show that disciplinary hearings rarely result in dismissal and court cases rarely result in prosecution. The IPCC report into police use of force (2016a: viii) notes that, for all 62 cases where disciplinary hearings have been held for either misconduct or gross misconduct involving the use of force, only nine resulted in dismissal. Further, of the 191 cases relating to police use of force that were independently investigated or managed by the IPCC, 24 were sent to the CPS for consideration (IPCC 2016a). Criminal proceedings were taken against 18 individuals, with 6 of those ultimately being found guilty ${ }^{4}$. In sum, then, as a former IPCC Commissioner has stated (Glass 2014: 8) 'the IPCC is simply unable to do what it says on the tin: it is not an independent body investigating police complaints'-and there are valid concerns this may continue with the IOPC.

\section{Barriers in criminal court}

Thus far, I have demonstrated concerns around internal and external accountability mechanisms around officers' use of force, including TASER, in England and Wales. Nevertheless, it might be objected, individuals who feel they have been subjected to excessive force have another important mechanism for accountability - the legal process. In this section, then, 
I examine some of the challenges associated with individuals getting their 'day' in court - be it criminal or civil — and the challenges faced when there.

One key difficulty in bringing a successful criminal prosecution is that England and Wales has a test for the use of force-the so-called 'honestly held belief standard' - that is arguably weaker and more permissive than laws in many other jurisdictions (see, for example, Hessbruegge 2016). Section 76 of the Criminal Justice and Immigration Act 2008, building on Section 3 of the Criminal Law Act 1967, notes that 'the question whether the degree of force used by... (the officer) was reasonable in the circumstances is to be decided by reference to the circumstances as (the officer) believed them to be'. The Act states that 'the reasonableness... of that belief' is 'relevant' to the question of whether or not the officer genuinely believed it (see also $R(W 80)$ v. Director General of the Independent Office for Police Conduct, paragraph 49). However, if it is determined that the belief was genuinely held, then it doesn't matter whether the belief was 'mistaken', or whether it was 'reasonable' for the officer to hold it - a term sometimes referred to as the 'honestly held belief' standard.

The reasonableness of the belief is considered relevant as to whether it is honestly held - after all, it may be more difficult to claim that one honestly holds a deeply unreasonable, implausible belief than a less implausible one. However, if after taking such factors into account, it is determined that the belief was indeed honestly held, it does not then have to be reasonably held for the force to be considered justifiable (Equality and Human Rights Commission 2015). If it 'was in fact held, its unreasonableness... is neither here nor there' (Regina v Williams (Gladstone) 1983). Thus, the first question one must ask is 'what were the circumstances the officer honestly believed they were faced with'.

The second question one must ask is whether the degree of force used was reasonable in those circumstances. In weighing up this second question, one must assess whether the force used was necessary and proportionate. The necessity test (absolute necessity for Article 2 cases) asks whether it would have been possible to use less violent means, instead of those that were deployed, in order to meet the permitted and lawful objectives (McCann $v$. United Kingdom 1995: paragraph 148). The proportionality test asks whether the force used is proportionate to or consistent with the legitimate aim that is to be achieved, the danger to 'life and limb' posed by the situation, and the risk that the force used might result in loss of life (Stewart $v$ United Kingdom, paragraph 19, and McCann v. United Kingdom 1995: paragraph 149). Thus, for example, the level of force that is considered proportionate to stop a petty thief, or a shop-lifter, who is posing no risk to themselves or others will be less than that used to stop an individual posing an imminent risk of death or serious injury to those around them. In applying the tests of necessity and proportionality, the law states that one must 'take into account', amongst other considerations, that it is not always possible to "weigh to a nicety the 
exact measure of any necessary action' (Section 76.7 of the Criminal Justice and Immigration Act, 2008).

While the 'honestly held belief standard' serves a useful purpose-allowing officers, who often have to make split second decisions, to be assessed on the circumstances as they believed them to be at the time, not with the benefit of hindsight - it makes it extremely difficult to prosecute officers for excessive use of force, including the misuse of projectile electric-shock weapons. Trying to disprove an officer's internal state of mind and what they did, nor did not believe, at the time they acted is an almost impossible task (see Norrie 2010, for an overview of the debate and Hessbruegge 2016). Indeed, as Simon (quoted in Squires and Kennison 2010: 11-12) argues: the genuine belief standard contains 'a hole large enough for the proverbial truck'. Two high profile cases around the use of TASER in England and Wales illustrate how this test works in practice.

\section{Declining to prosecute: The case of Colin Farmer}

The first of these cases involves Mr Colin Farmer, who was Tasered by a Lancashire police officer, Stuart Wright, in 2012. The officer in question was responding to reports of a young male, a 'skin-head with jeans', in public with a two-foot long sword, whilst Colin Farmer was partially sighted and described by a witness as 'quite elderly and walk(ing) very slowly' (IPCC 2012: 15-16). The officer explained that he saw a 'shiny and reflective object' in Colin Farmer's hand-in fact his walking stick-and mistook this for 'a sword'. He described Colin Farmer as not responding to his verbal warnings and walking towards members of the public, who he considered to be in 'immediate danger' (IPCC 2012: 15-16). The officer then fired the weapon in dart-firing mode at $\mathrm{Mr}$ Farmer and handcuffed him.

The IPCC investigation found that 'PC Wright could have and should have dealt with Mr Farmer in an altogether different way rather than discharging his TASER at him'. They found that 'there were no members of the public within close proximity of Mr Farmer... and therefore any perception that PC Wright may have had of an immediate threat to the public is flawed', though the 'radio transmissions made... indicate that he did hold the belief that he was confronting a man with a sword' (IPCC 2012: 27-8). They found that 'PC Wright does have a case to answer for gross misconduct in respect of the allegation that he used a level of force upon Mr Farmer that was unnecessary and disproportionate to the circumstances' and referred the case to the CPS (IPCC 2012: 32). The CPS, however, declined to bring charges, with a representative reportedly saying, in part, that officers are entitled to deploy 'reasonable force... to effect an arrest and where the officer is under a mistaken belief...the question is whether, in the circumstances as he believed them to be, the force was reasonable. (The officer was told there were) reports 
a man was...carrying a sword... The walking aid...(was mistaken by) members of the public for a weapon. The officer... made the same mistake' (The Telegraph 2013, emphasis added).

In this case, the honestly held belief standard prevented the case from reaching court in the first place. Moreover, as the next example shows, even when cases do reach court, this standard means that officers are unlikely to be found guilty.

\section{Reaching a not guilty verdict: The case of Ras Judah Adunbi}

In a widely reported case in January 2017, that was filmed by a bystander and widely shared on social media, Ras Judah Adunbi was mistaken for an individual wanted on warrant and was subsequently Tasered by an Avon and Somerset police officer. The incident was investigated by the IPCC, who referred the matter to the CPS and the case was subsequently bought to court in 2018. In finding the officer not guilty of common assault, the District Judge explained his reasoning, in part, as follows:

'The law asks me to look through her (the officer's) eyes, at what she saw at the time. A person may use such force as is reasonable in the circumstances as he or she believed them to be... (The officer) made the mistake that he was a wanted man, who was also noted as prone to use violence. So I look through Officer Boddie's eyes with that information in mind... She used Taser. She says she felt it was necessary, given his demeanour, the aggression, the swing, the punch. The issue for me is whether the prosecution have persuaded me that she didn't act in self defence. The prosecution have failed to persuade me that she did not, as she saw it, act reasonably'.

(author's contemporaneous notes)

This judgement underscores that, even when cases reach court, the current legal test is an exceptionally high bar to reach. As the District Judge states, the prosecution 'failed to persuade him that she did not, as she saw it, act reasonably'-but, virtually by definition, officers are almost always going to think their actions are reasonable. Proving (or, rather, disproving) what an individual was thinking, and their internal state of mind, is an almost impossible standard to meet, particularly beyond a reasonable doubt. Taking this argument a step further, imagine a purely hypothetical situation in which an officer used force on someone in anger, for no other reason that they had temporarily lost control. It would be very easy for the officer to claim, in retrospect, and indeed come to genuinely believe that they used force because of a threat they perceived at the time. Under the current standard it would be very difficult to challenge such assertions. 


\section{Issues of process: The Colin Farmer case}

Thus far, I have put forward a credible case that the subjective, honestly held belief standard not only prevents many cases from reaching court in the first place but also makes it difficult for officers to be found guilty when they get to court. Yet the Colin Farmer case also points to an additional issue in domestic criminal law. For it is tempting to conceive of tests of reasonableness in terms of the presence (or lack thereof) of external evidence that corroborates the officer's belief and that would make such a (mistaken) belief understandable. However, external evidence is rarely available in a convenient, easy to use, ready-made format: instead, attempts have to be made to actively gather the necessary information, intelligence and evidence, and to piece it together. There is, thus, a difference between a belief that is 'unreasonable' due to the fact that there is no evidence to support it, and a belief that is 'unreasonable' because there have been no attempts made to ascertain whether such evidence exists, or not, in the first place. I would, therefore, argue that it is necessary to consider not just how reasonable the belief is, but how reasonable is the process the individual officer has taken in order to arrive at this belief: whether the officer has taken sufficient action to try and corroborate this belief, and turn it from a supposition into a solid fact.

At present, such considerations can be taken into account in assessing whether any belief is 'honestly' held-but once it has been determined that this is the case, they are not then taken into account in assessing the reasonableness of the officer's response. However, according to soft law, officers have a responsibility to use force only when 'unavoidable' (UN Basic Principles on the Use of Force and Firearms (1990), Principle 5), so it could, therefore, be argued that they have a responsibility to put their 'honest' and 'instinctive' beliefs to the test, where possible, before using force.

In this case, it would appear that the officer did genuinely believe Mr Farmer to be armed with a sword-but, equally, that he only believed this because he had failed to take the necessary action to avail himself of information that would have likely changed his beliefs. Of course, in many situations that police face, this is an issue of little or no importance because they do not have sufficient time to enable them to corroborate their (initially reasonably held) beliefs. In this situation, however-and potentially in many others-the police officer in question had a short amount of time in which to ascertain the reasonableness of his honestly held belief. As the IPCC report (2012: 30-31) noted, in this case, the officer had sufficient time to 'reposition and gain a better view of the man who he was challenging' - an action which would have 'allowed... (him) to see that (Colin Farmer) was not carrying a sword'. Yet Officer Wright failed to take these actions and, as such, failed to do anything that might either confirm or deny his original (genuinely held and arguably initially reasonable) belief.

In cases involving the use of force, it is sometimes presumed that officers are thrust into a situation where their beliefs (reasonable or otherwise) lead 
them to use force. Yet this case shows that the reverse is also true-that officers can use force too quickly, in turn denying themselves the opportunity to ascertain the reasonableness of their beliefs. This is, perhaps, particularly important given the argument presented in the previous chapter, which suggests that such processes can be influenced by the presence or absence of different weapons and that the presence of electric-shock weapons can influence human behaviour. In other words, failing to explicitly include a test for the process through which officers arrive at, and check, their beliefs-cognisant of the difficulties and caveats noted above-may leave the window open for officers to use unnecessary force too quickly and make criminal prosecution more difficult.

\section{The national decision model}

Concerns about the legal standard in England and Wales are compounded by a number of other advantages that officers have at their disposal in court and inquest proceedings. These advantages - the vulnerability and perceived credibility deficit of many subjected to force, jury reluctance to find officers guilty, resource imbalances-have been well documented elsewhere (Angiolini 2017; Root et al 2013; Sussman 2012), and I want to focus on one issue that has received less attention: the role of the National Decision Model, introduced in the last chapter.

At the time of its introduction, ACPO (2012: 1) described the NDM 'as a values-based tool to provide a simple, logical, and evidence-based approach to... decisions'. The document stressed the importance of officers being accountable and prepared to 'provide a rationale for what they did and why' (ACPO 2012: 5). Paradoxically, however, while the NDM may have been intended to help officers make decisions and assist others in reviewing them - in other words, to enhance accountability - I argue that it simultaneously also minimises accountability and makes it more difficult for officers to be held to account. Thus, personal safety trainers and TASER trainers noted, both to their students, and during interviews that:

'If we ever end up in court justifying our actions, the barrister will be questioning us on the NDM. As soon as... they realise you know it, then the questions stop because they know they are not going to catch you out... The barrister sits down, so the actual justification and use (of force) can never be questioned.

(Personal Safety Trainer 4, Force location omitted, emphasis added)

'The NDM is brilliant, really good, it's just how the mind would work. It's giving police officers permission to go and use force because, contrary to popular belief, a lot of officers aren't going in heavy handed, if anything they are worried about themselves getting into trouble. But this gives 
them the power. If you think you are doing the right thing you probably are, (and) it gives them that confidence to deal with the situation and not get themselves sued'.

(TASER trainer 8 , force location omitted, emphasis added)

'The threat and risk (box on the NDM is) completely your personalised view of the world. Every decision you make is influenced by what you put in that box - it influences everything that comes after it. 'I was scared' - personalising that threat assessment is the key to your success. It's irrefutable in court'.

(TASER trainer, Force omitted, comments made during training)

In the words of another TASER trainer, the NDM is the 'get out of jail free card' (Taser trainer 2, force omitted).

Similar views are sometimes expressed by those in the legal profession. Kevin Donoghue noted that there is a broader context where 'the police are quite often given quite a lot of leeway to justify their thought process and the use of TASER - they can say these are operational decisions, it was a dynamic incident - and its easy, almost as an escape route for a judge or jury' (interview with author). He notes that this has 'absolutely' been exacerbated by the National Decision Model, as it allows you, 'if you are clever enough with your words (to) justify any course of action. (if) the officer says he felt the threat was right, the justification is there...(and from) past experience, I have found that judges are reluctant to award aggravated and exemplary damages. They too easily accept arguments that the police officers involved were following training, the National Decision Model, and "agony of the moment" arguments' (interview with author).

The NDM, thus, appears to enhance officer's 'account-ability' - that is, the 'capacity to provide a record of activities that explains them in a credible manner so that they appear to satisfy the(ir) rights and obligations'-at the expense of accountability understood in a broader sense (Ericson in Young 2015: 42). Such consequences seem at odds with the stated rationale of the NDM. They demonstrate that texts, such as the NDM, can become far more than tools to assist officers in making decisions, but may-as the ANT notion of generalised symmetry, discussed in the last chapter, asks us to consideralso interact with human agency in various ways to have a variety of unexpected consequences; in this case, making accountability more difficult.

\section{Barriers in civil court}

Those seeking to bring their case to court also have another route at their disposal: the civil courts. However, the Legal Aid, Sentencing, and Punishment of Offenders Act of 2012 has introduced additional difficulties which have had the cumulative effect of making people 'think again before deciding to 
sue the police' (Donoghue 2014). These reforms are said to impact on claimants bringing (or thinking about bringing) civil claims by a Conditional Fee Agreement. Under the old arrangement, if claimants were successful, they were entitled to claim the cost of their legal fees (including any success fee that may be payable, as well as their legal team's hourly rate and standard charges), their disbursements (i.e., costs for goods and services associated with the case, such as court fees and medical reports), and the cost of any After the Event Insurance they may have taken out, from the Defendants in addition to any compensation they may have received.

Under the new arrangement, if claimants using Conditional Fee Agreements are successful, although they will recover their basic legal fees from the Defendant, they can no longer recover their success fee, or the cost of insurance (if taken out) separately from the defendants, but have to pay it out of their compensation. However, in cases against the police, the amount of compensation paid is relatively low, and insurance premiums are relatively high, or simply not available (see Police Action Lawyer's Group, or PALG 2014). Kevin Donoghue, a solicitor specialising in actions against the police notes that:

'its' a highly specialist industry with two or three providers. The insurance premium could be $\mathcal{K}^{3} 30,000$ if a case goes to trial. If it is settled early, it could be $\AA^{4,000}$ to $\mathcal{E}^{9}, 000$. The premiums are so high because the costs of litigation are so high, the risks are so high'.

(interview with author)

On the other hand, if claimants lose their case, in certain cases they could face having to pay the defendant police force's legal costs. In theory, personal injury claims - which use of force cases are likely to involve-benefit from Qualified One Way Cost Shifting (QOCS), which should shield unsuccessful claimants from the other side's legal costs. Yet Solicitor Kevin Donoghue notes that, in his experience: 'You can't really carve it up so that cases just focus on personal injury. You would be negligent if you were bringing a claim purely for, say, head injury, psychological injury but not saying there were aggravating features. So you are caught in a catch-22 situation where solicitors must advise claimants not to pursue potentially viable claims for aggravated and exemplary damages because they risk losing QOCS costs protection, but then the lawyer risks being sued afterwards for not insisting that the client bring such claims' (interview with author). The PALG further note that, in practice, uncertainties over the applicability of QOCS to claims against the police could create a potential barrier to litigation in some cases.

The solicitors explained the impact on their clients as follows:

'The very poor qualify for legal aid, the problem is for the middle income group, which is a big group... I have to say to them: "I think you've got 
a viable case here. But I'm not going to guarantee success, because I can't. And guess what? If you lose... you are going to have a cost bill of $\mathcal{E}^{25}$, $000-£ 30,000 "$ "You... are going to say "I'm not doing that". As a result there is a huge vacuum, and that is a major, major problem'.

(Iain Gould, interview with author)

'They brought these changes in to deal with the mass personal injury market but they have captured the work that we do. Before people could bring claims against (organisations like) the government, G4S because you had access to funds, you were on a level playing field without fear of being pursued for their costs... (but now) I have a handful of cases every year go to the wall not because they are not winnable-they are winnable-but simply because clients say, "I can't take the risk. It will kill me for ever, it will be lump in the back of my throat but I can't take the risk". The system is very much skewed to the state without any shadow of a doubt. Access to justice is completely extinguished apart from those clients that have the financial resources, or simply those whom care very little about the financial implications of an adverse cost order'.

(Kevin Donoghue, interview with author).

Lisa Cole similarly explained the barriers she was faced with following the inquest into the death of her brother, Marc Cole:

'if I want to pursue a civil claim, that... would be funded by no-win, no-fee. (But if I lose I've been told that) I am liable not just for the costs of the police barrister but I am also liable for the costs of the entire inquest proceedings for all of the officers that were involved. (I've been advised that) adverse costs that may be awarded against me in relation to the defendants' costs (and that) in view of the linked inquest case this means not only that the defendants' costs defending the civil action but also potentially the costs in relation to the entire inquest proceedings

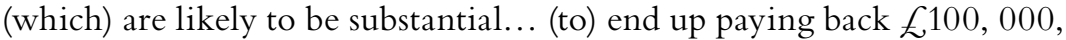
that's nonsensical'.

(interview with author)

As such, concerns that these new reforms have created additional barriers to justice and accountability - on top of the significant difficulties that already existed-seem well founded.

\section{Conclusion}

This chapter has argued that, far from being 'robust', accountability mechanisms are not fit for purpose and make it difficult to hold officers to account for their use of force, including projectile electric-shock weapons. In at least 
some forces, internal investigators take officer accounts at 'face value' and the processes for reviewing and remedying issues around TASER leave room for improvement. Meanwhile, external accountability mechanisms have traditionally provided less than robust levels of oversight and a host of challenges face those who would seek to have their case heard in criminal and/or civil court. This includes not only an entirely 'subjective' test as to whether the officer's use of force was reasonable, but the use of a decision-making modelthe NDM - in ways which have been described as a 'get out of jail free' card. This has far-reaching implications not only for accountability in England and Wales, but also for police accountability in countries worldwide, including New Zealand and the United States of America, where similar models are in use or are being considered for use (as discussed in Chapter 6).

While much attention focuses on the human aspects of accountability, the in-built $\log$ and recording mechanisms that are found in many projectile electric-shock weapons-together with the potential for body worn video cameras to automatically record whenever the weapons are armed-would appear to have many benefits. It seems plausible that such mechanisms can influence or prescribe human behaviour, facilitating full and frank recording, and can aide accountability by providing an additional record of key, often disputed events, such as the length of time that electricity was discharged for.

Yet the value of such records must be put into broader context. As noted throughout the book, evidence on the effects of repeated or prolonged discharge of projectile electric-shock weapons is limited (DOMILL 2012); much research is funded by, or affiliated with, the manufacturer (Azadani et al 2011) and TASER International has reportedly pursued litigation against medical examiners who found the weapon to be a contributory factor in fatalities (Reid and Seligson 2017). The company maintain that they 'did not sue... (individuals) because of...(their) medical opinion' (Reid and Seligson 2017) but a survey of 222 medical examiners in the United States of America found that nearly $14 \%$ admitted to having modified their diagnostic findings due to threat of litigation, and nearly $33 \%$ stated such considerations would affect their decision making in the future (Oliver 2011). Against this backdrop, the value of internal records for accountability should not be under-estimated but neither should they be over-estimated.

Despite all of these challenges, achieving effective accountability for the use of projectile electric-shock weapons, and other forms of force, remains particularly important. This is not just because of the broader imperative to hold the police to account for their actions, nor just because, as I have argued in the last couple of chapters, several factors subtly incentivise officers to use such weapons. It is also important because the promise of effective accountability is a key pillar used to justify the relative lack of clear standards and guidelines around when force options, such as TASER, should be deployed. We are asked to accept officers making their own decisions on when to use the weapon-and the considerable variation that comes along with that - on 
the promise that if their use is found to be inappropriate, they can and will be held to account. Yet this chapter has demonstrated that, for a variety of reasons, this may not always be the case. This, in turn, asks us to consider what standards, recommendations, and improvements may be appropriate-and for this, and much more, we turn to the next and final chapter.

\section{Notes}

1. As this book went to press, HMIC are releasing a report into disproportionate use of police powers (HMIC 2021), and the IOPC have announced a forthcoming report into the use of Taser, as yet unpublished. Due to issues of timing, these recent / forthcoming publications are not discussed here.

2. For example, promotional material for March Group's AIR 'M-140' model states that it has a 'dataport (with) integrated charge level LED power indicator, time; stores date and time of firing' (March Group, undated b). The Condor Spark DSK700 is advertised as having an 'internal memory... digital, coded, integrated inside the ECD, records the date, time and duration of the last 1,000 discharges (Dave Shear Guns 2020).

3. The IPCC was still in existence at the time of Marc Cole's death in 2017, but it became the IOPC at the start of 2018.

4. Please note that, as these figures were produced in 2016, they may now be dated, in particular, as it has been announced that charges of murder and assault will be brought against the officers involved in the Dalian Atkinson case (Crown Prosecution Service, 2019). 


\section{Chapter 9}

\section{Conclusion}

\section{Introduction}

In this final chapter, I draw together the various myths and threads encountered throughout the book. While there is much to discuss around projectile electric-shock weapons, including TASER, multiple issues have also been highlighted that go beyond this specific concern. As such, these concluding observations and thoughts fall into five strands: projectile electricshock weapons and the myths associated with them, (policing) technologies and their adoption and use, key concepts in policing, theoretical developments, and implications for policy and practice. I start first with a focus on projectile electric-shock weapons, challenging the mainstream myths used by advocates of the weapon and examining their functions and legitimising effects.

However, myths about such weapons do not arise in isolation but are underpinned by broader, often implicit assumptions about the role of technology in policing and wider society. In the second section of this chapter, I argue that questioning the received myths around projectile electric-shock weapons can also lead us to re-examine more fundamental beliefs about technologies more broadly. In section three, I demonstrate that this, in turn, has implications for several foundational concepts in policing, including discretion and police subculture. In doing so, sections 1-3 help demonstrate the added value that can come from using Science and Technology Studies (STS) in policing studies, and in section four, I explicitly examine the theoretical implications arising from this book, both for STS and criminology, and point to future research avenues. Finally, I close the book by providing some policy recommendations for projectile electric-shock weapons and police use of force. In the spirit of the American campaigns around police use of force-' 8 can't wait' (Campaign Zero, 2020) and ' 8 to abolition' (8 to Abolition, 2020) - I generate eight recommendations around police use of force. 


\section{Electric-shock weapons, myths, and realities}

This book has interrogated some of the most common myths around projectile electric-shock weapons, expressed by academics, police officers, and other practitioners alike, and which tend to be favourable towards, and help justify, the use of the weapon. These include the belief that such weapons are an alternative to firearms and that they are nicer for members of the public and safer for police officers (Chapters 3-5, respectively) than alternative options that may be used. Such beliefs about the use and effects of these weapons are accompanied by myths about the regulatory framework surrounding it. These include the assumptions that projectile electric-shock weapons are a neutral tool that appropriate use is a responsibility for, and at the discretion of, individual officers alone; that the guidance, training, and accountability mechanisms around the weapon are robust and that officers are held accountable for their use of the weapon (Chapters 6-8).

As I have demonstrated throughout the book, these myths resonate with many. It has not been my intention, even if this were possible, to prove them wrong once and for all, or to somehow provide the 'final word' on the matter. Nor has it been my intention to provide a sharp demarcation between myth, on the one hand, and reality on the other. I am drawn, instead, to Latour's (2011) notion of the 'factish', which reminds us that distinctions between 'fact' and 'fetish' are not so easily made. Yet using the framing of myths has helped to achieve two objectives.

\section{Challenging received wisdom}

First, it has helped to remind us that claims around the weapon-in particular, claims about its safety, efficacy, and effects - should not be taken for granted and seen as the starting point for empirical work, but should themselves be subject to investigation and exploration. Opening up such categories and concepts has raised challenges both for those who are critical of the weapon and its' use in practice and for those who are proponents of it. For example, the idea of 'mission creep'-and the notion of the weapon straying from its intended purpose as an alternative to firearms - is often invoked by the former. While this contains elements of plausibility, and the term mission creep points to some interesting insights, a close reading of public statements made at the time indicate that projectile electric-shock weapons were not universally intended to be solely used as an alternative to firearms and were conceived of much more broadly. As such, claims that such weapons have strayed from their intended objectives may miss the mark. This is not only because the intent around the weapon appears to have been more broad and nuanced than is sometimes suggested. It is also because of the difficulties involved in divining what the intent of key actors 'really' was and the challenges in assuming that intent was somehow 
pre-formed and pre-determined, prior to the development and marketing around the weapon.

Yet the book also challenges and troubles the myths and rationalisations often put forward by the proponents and users of the weapon. I suggest that, while the myths detailed above contain elements of plausibility, they are all too often limited and incomplete. Projectile electric-shock weapons do not appear to be used as an alternative to firearms, nor to have had a readily observable impact on the number of shootings in a number of jurisdictions worldwide, including England and Wales. Instead, the use of such weapons is patterned in terms of ethnicity, mental health, and other factors. Moreover, it appears that such weapons are used when lethal force is not justified and are not used when lethal force is justified. Nor are these weapons necessarily experienced as a 'nicer' form of force by those exposed to it. Officers in England and Wales tend to see TASER as more sophisticated, 'less intrusive', and preferable to other forms of force-but these views are often at odds with the perceptions of those who have been subjected to it. While the weapon, considered in isolation, may offer safety benefits to officers, the broader socio-technical network around the weapon-including tendencies for officers to be single crewed when carrying the weapon and to be deployed to riskier incidents-may make them less safe.

Further, while a focus on the decision-making abilities of individual officers is important, decisions that are made elsewhere can also impact on whether, when and how projectile electric-shock weapons are used, and act to incentivise or dis-incentivise its use. For example, decisions that have been taken about the content and frequency of police use of force training may impact officer's decisions on whether or not to use the weapon. Similarly, rather than electric-shock weapons being an interchangeable, neutral tool, the interaction between such weapons and the officer wielding them may also subtly influence decision-making in ways that risk facilitating (over)use.

In such a situation, training, policy, and accountability mechanisms can have a role to play in helping to ensure that the weapon is only used in appropriate circumstances (Bishopp et al 2014). However, I have made the case throughout the book that the system currently in use in England and Wales - and echoed in other jurisdictions worldwide - gives officers very little guidance about when to use the weapon, either in policy or in training. This has a number of different implications. It may mean that different officers faced with a similar situation may handle it in markedly different ways - and may, on some occasions, resort to what many would consider inappropriate and excessive use of the weapon.

It may also mean that, as discussed in Chapters 6 and 7, officers are put under a lot of pressure. Instead of decisions around when, and how, it is appropriate to use the weapon being made by senior police officers, by parliamentarians, or by public discussion and debate, they are made by individual officers, often in the heat of the moment. While police officers will always 
have final responsibility for the level of force that they use, this already challenging role is made all the more difficult by the lack of concrete guidance and the absence of a clear threshold for use. In the account presented here, then, stating, as the guidance does, that the weapon is 'one of a number of tactical options available when dealing with an incident with the potential for conflict' (College of Policing 2020a) seems unfair to officers and members of the public alike.

Concerns about the training and guidance are exacerbated by concerns around accountability mechanisms. The account put forward here suggests that these accountability mechanisms are not always as robust as is claimed. Despite claims that are made around the technological prowess and advanced technical capacities of the weapon, it is extremely difficult to hold officers to account for their use of the weapon, and their use of force more broadly, due to a number of interlinked considerations. These include the vague guidance detailed above, the way in which the National Decision Model operates, issues around the legal criminal test for use of force, and barriers in civil court.

Overall, while analysts such as Dror (2007: 269) are optimistic about the potential of technology to 'contribute to higher quality decision making in policing', this analysis cautions that socio-technical interactions may not always be positive. Many of the factors discussed above-the myth of electricshock weapons as simple tools, the ease with which they allow officers to enter the 'tunnel of violence' (Collins 2012), traditional subcultural norms, and the relative absence of training on communication skills and other uses of force-have the potential to impact officer decision making, subtlety incentivising officers to use the weapon in situations where its use could be avoided. As such, it could be argued that such weapons are over-used and under-regulated.

Far from being just a 'bit of kit', projectile electric-shock weapons may interact with human agency, and other factors, to have surprising, and unpredictable, effects. Viewing commonly held beliefs around projectile electricshock weapons as myths - instead of simply taking them for granted, as many previous authors have done (see Lin and Jones 2010) - has helped to open up and unpack such possibilities.

\section{The functions of myths}

Second, using the language of myths has also allowed us to explore what functions such stories fulfil, their legitimising effects and how they might be usefully challenged and reformed. In this case, myths around projectile electric-shock weapons may help shore up the technology's popularity and what has been described as an attendant 'police-industrial complex' (Brodeur 2010). This legitimisation happens in multiple ways. As we saw in Chapter 3, the mere idea that TASER acted as an alternative to firearms-although 
not strictly supported by a close reading of key statements at the time-was nevertheless amplified and acted as a powerful public relations strategy. This made it difficult to argue against the introduction of the weapon and, according to TASER International's Vice President of Training, misled the public about its role and capabilities (Guilbault 2007). Similarly, Police and Crime Commissioner Martyn Underhill (in an interview with the author) noted:

'the reason the public accepted (TASER) was that it was sold as a lie. The public were told "we shot 12 people last year, If you let us bring in TASER, firearms officers will have two choices, lethal or non-lethal. We can save lives". Who wouldn't sign up to that?'.

Further, now that the weapon has been introduced, myths around its safety benefits for officers and members of the public help further justify its use and expansion, while distracting from criticisms that the weapon does not prevent firearms use. However, proposing decontextualized technological solutions to complex, 'wicked' (Rittel and Webber 1973) socio-technical problems is unlikely to be successful and may make the issue worse. Take officer safety, for example. In September 2019, the Home Office announced f10 million in 'additional funding to significantly increase the number of officers carrying Taser' with the then Home Secretary the Rt. Hon Priti Patel quoted as saying: 'I've been completely appalled by the recent spate of serious assaults on police officers, which is why I'm giving chief constables the resources to dramatically increase the number of their officers who carry tasers. They keep us safe and now I'm giving them what they need to keep themselves safe on the job' (Home Office 2019c). Chapter 5 questions claims about whether projectile electric-shock weapons 'really' make officers safer and highlights that the impact of this technology on officer safety cannot be understood without looking at how it interacts with crewing patterns, interactional dynamics between officers and members of the public, and the kinds of incidents to which officers are sent. Yet, even if such weaponry does make officers safer, there may be a whole range of other ways to achieve this end-for example, by altering crewing patterns, providing more officers, providing additional training, and providing additional protective equipment-without resorting to further arming them. Such important discussions are side-lined, even ignored, if the debate focuses narrowly on whether projectile electric-shock weapons make officers safer compared to other use of force options.

Relatedly, as we saw in Chapter 4, debates around injury-and whether the weapon is 'truly' less injurious to members of the public-distract from important, arguably more fundamental, questions about whether force should have been used in the first place and the division of labour between the police and other agencies. Myths about the safety and injury potential of projectile electric-shock weapons imply a binary choice between such weapons and other forms of force. This not only distracts from the evidence suggesting that 
TASER is often used alongside other uses of force (Dymond 2018), but also frames the debate in a way that presumes force is necessary-and the only question to be resolved is what type of force should be used. Yet in many of the controversial, and often tragic, cases discussed in Chapter 8, and throughout the book, it is far from clear that force was strictly necessary. In such situations, debating the merits of different force options detracts from much larger concerns about police powers, legitimacy, and appropriate use of force.

This also points to the need for further research on the impact that police weaponry may have on public perceptions of the police and police legitimacy. Work by Yesberg et al. (2020: 9) found that providing officers with firearms could significantly alter the way people view the police, with the presence of a firearm associated with more negative responses towards them. This work did not look at projectile electric-shock weapons or other 'less lethal' forms of force but this would be a valuable addition to further understand the links between police weaponry, legitimacy, and use of force-as well as how myths around such weapons are received by members of the public and different socio-economic groups.

Finally, and relatedly, appeals to the 'robust' accountability mechanisms around projectile electric-shock weapons act to deflect criticisms of guidance and training. We are asked to accept vague guidance and a large amount of leeway for officer decision making and discretion, at least in part, because of the (allegedly) comprehensive accountability mechanisms around the weapon. This assumes that there are some final checks and balances that can act as a corrective in cases where projectile electric-shock weapons have been used inappropriately. However, as we have seen in Chapter 8 , there are significant barriers and difficulties in holding officers to account and thus, important reasons to question whether this is the case. Instead of justifying vague guidance with appeals to accountability, we need to engage in a wholesale, fundamental review of guidance, practice, and accountability-a topic to which I return shortly.

\section{Myths and technologies}

Thus far I have demonstrated the insufficiency of the dominant myths around projectile electric-shock weapons, while highlighting the role they play in enhancing the weapon's legitimacy. Yet myths around such weapons do not arise in isolation. They are underpinned by powerful vested interests (Stanbrook 2008: 1401) and by broader, often implicit assumptions about the role of technology in policing and contemporary society. As such, questioning myths around electric-shock weapons also leads us to re-examine more fundamental myths about the role of technologies, both in policing and in society more broadly.

As we saw in Chapter 2, and throughout the book, by far the most common approach both inside and outside academic is a lack of treatment and 
consideration of technologies. Anthropomorphic assumptions and an inattention to technologies are found in each of the main theories of policing, from macro approaches (consensus, conflict, and predatory policing approaches) to interactionist approaches and the 'transformational' thesis. Where the topic is addressed, technologies are seen as simple tools and neutral carriers of human will. It is often simply assumed that humans see a problem, gap, or area to address (such as deaths from firearms shootings), that technologies (such as less lethal weapons) are designed to fulfil that gap, that those that have been well-designed and are technically superior are adopted and that, once adopted, they fulfil their promise and help to resolve the initial problem. In this predominant view of technology, the success and effectiveness of technologies are often taken for granted and considered in isolation from their broader context. Where such features are investigated further, the focus is on revealing the (singular and often highly quantitative) 'empirical reality' and 'facts' around the weapon, rather than attending to process, precariousness, and construction of such 'facts'.

In addressing myths around projectile electric-shock weapons, this book has simultaneously tackled these pervasive myths about technology, drawing on classic concepts from Science and Technology Studies. In Chapters 3 and 5, I demonstrated that, far from technologies being successful because they satisfy pre-determined objectives, interests, and intentions, they are successful because they alter and translate these objectives. I suggested that, instead of assuming that electric-shock weapons are safe and effective based on the available empirical evidence-much of which comes from officers themselves - it is also possible that the weapon's popularity and perceived effectiveness influence officer's perceptions and assessments of the weapon. In turn, instead of just assuming that a technology is successful and popular because it is effective, its success and reputation may mean that individuals perceive and interpret events and possibilities (including the likelihood of injury and what constitutes an effective outcome) in particular and more favourable ways.

It follows that, as discussed in Chapter 4, we need to attend not only to (allegedly) self-evident 'facts' and claims around technologies-such as whether they are 'really' less intrusive, less injurious, and 'nicer'-but how they are 'heterogeneously engineered' (Law 1987) and how such facts and claims are assembled and come to be seen as real and credible. In Chapter 5, I argued that instead of looking at the technical features of new inventions, we need to look at the socio-technical network surrounding them. Further, I demonstrated that sharp distinctions between the social and the technical are not easily defined in practice. So-called 'technical' features (e.g., the reddot laser sight) seamlessly interact with so-called 'social' features (the fear of being Tasered, the way in which officers aim the weapon) to produce particular results and outcomes that cannot easily be attributed to either 'technical' or 'social' factors, nor easily predicted. Relatedly, in Chapter 7, I argued 
against the clam that technologies such as TASER are mere tools. Instead, I argued, they can have unforeseen effects and can make people do things they might not otherwise do. Rather than relying on conventional assumptions around technologies, there is a need to attend carefully to non-human actors and the contributions they may make in policing research.

These chapters show that looking afresh at often taken for granted concepts (such as power and intentions) and claims about technology (such as effectiveness and success) and seeing them not just as consequences and explanations, but as effects and processes, can help us to highlight different policy implications and different points of leverage to bring about change. If we cede to weapon manufacturers, for example, pre-existing ideas about projectile electric-shock weapons' technological superiority, and assess such weapons on whether they can achieve, or stay 'true' to some set of 'original' objectives and intentions, then we lose an important point of purchase. Similarly, if we adopt tautological explanations of what senior police officials and powerful multinational corporations 'want', and what their interests are, we ignore important questions about how they came to be powerful, how this power can be challenged and how seemingly immutable goals and interests can shift — or be made to shift-over time.

In contrast, if we see technologies as successful not because of their technical superiority, but because of translations, power struggles, and definitional debates, this gives us new ways to challenge developments of concern and to 'demystify the power of the powerful' (Law in Acuto 2011: 556). As Brodeur notes in his discussion of the 'police-industrial complex' attending to the 'mutual support' the police and corporate establishment may provide to each other is an important endeavour (2010: 348), as is analysing the 'ties that bind these actors together' (see O'Reilly 2010). Challenging pre-conceived, traditional notions of technology and power-as I have done here by drawing on STS concepts and sensibilities-may help us to do just that.

\section{Implications for policing concepts and theories}

This STS-inspired way of looking at technologies and policing has a number of implications that go beyond projectile electric-shock weapons and extend to discretion, police subculture, and criminological theory, broadly conceived, which are worth discussing in detail.

\section{Discretion}

Turning, first, to discretion, the focus on the interactions between, and blurring of, human, technology, and society helps demonstrate that the traditional definition of discretion as an arena in which officers able to exercise 'free will' can be overstated. Decisions that might appear to be free from any legal or policy restriction, and subject to the whims of officers, may well 
be structured not only by the human agency of others (for example, choices made in the training curriculum) but also by the presence of non-humans and the socio-technical networks within which they are embedded. Whilst the literature on discretion has traditionally recognised the human and societal influences impacting officer decision making, it may also need to make space to consider the role of the non-human, and of interactions between human and non-human, in influencing the exercise of discretion.

As discretion is a pervasive feature of the work done by many 'street level bureaucrats' (Lipsky 2010, this has ramifications beyond the policing literature. It would seem important not just to investigate how technologies can impact decisions made by police officers, but how a broader range of nonhuman actors may impact the decisions made by officials in a wide range of arenas, including social work, teaching, corrections, and probation. This, in turn, points to the importance of studying the interactions not just between human actors - as analysts such as Rojek et al. (2012) have been keen to dobut looking at human and non-human interactions, too.

\section{Police subculture}

There are implications, too, for traditional police subculture (TPC). The empirical findings in this monograph have partly confirmed that the TPC may influence use of force decision making-or, at the very least, that this possibility cannot be discounted, the issues around 'tautological' reasoning not withstanding (Shearing and Ericson 1991). Peer pressure and a desire to live up to subcultural values loom large in the officer accounts of TASER discussed in Chapters 5 and 7, and the marketing around the weapon is designed to appeal to the 'hyper-masculine' side of police subculture. Indeed, as Wozniak and Uggen (2009: 5) note, 'it is difficult to imagine a nonlethal weapon penetrating this important market unless it is... appropriately masculine'. Such conclusions partly reinforce the conventional assumptions in the literature around police subculture; specifically, that police culture impacts decision making, and that culture also exerts an influence on technological development, with only those technologies that are able to successfully position themselves within the broader subculture likely to succeed.

In such assumptions, directionality is one way: police sub-culture shapes human decision making and the design and reception of technologies. As this book has shown, however, the reverse may also occur: the agency of officers, technologies, and 'dance of agency' (Pickering 2005) between them may also influence police subculture. This switch in emphasis challenges the traditional literature on subculture in three ways. First, it highlights the need to focus on the non-human. The 'search' for police subculture was initially inspired by a drive to explain regularities in police behaviour and discretion (Shearing and Ericson 2001) that were not explained by formal legislation. In so doing, the literature on police subculture has traditionally 
tried to replace written, formal rules with unwritten ones. In their important critique of the subculture literature, and their search for 'conceptual contenders' to subcultural rules, Shearing and Ericson have convincingly argued that subculture should be understood more as a 'sensibility' (2001: 481) than a set of rules, and that one needs to make space for the exercise of human agency within this.

Taking this argument, and the constructive challenge to the traditional police subculture a step further, it seems important not just to focus on human agency, but to look at how this may be combined with material objects (such as electric-shock weapons) and non-human agency to construct, reinforce, and challenge sub-culture. As Waddington (2011) notes, this is frequently overlooked. Classic definitions of police culture, including Reiner's definition-referenced in earlier chapters-of 'police culture' as complex ensembles of values, attitudes, symbols, rules, recipes, and practices, emerging as people react to the exigencies and situations they confront' (Reiner 2010: 116) leaves out the role and impact of 'artefacts' and 'material items' (Waddington 2011: 91.

Yet officers and the weapons they carry are not just being shaped by, but are also shaping, police culture. While some TASER trained officers in England and Wales talk about force in ways that are in keeping with the traditional subculture, others use their position to challenge it. The status that comes with carrying TASER may allow officers both to showcase their adherence to traditional subcultural values while simultaneously challenging these norms. Hence, a close focus on electric-shock weaponry has revealed that attention needs to be paid not just to how culture impacts officers, but how officers use their agency to actively construct culture (Shearing and Ericson 1991) and how non-human actors can be an important part of these attempts. As such, the 'alternative' explanations for patterned behaviour and conceptual contenders to the idea of subcultural rules for which Shearing and Ericson are looking may not be exclusively human in nature. The 'missing masses' (Latour 1991) of technologies and socio-technical networks may also help explain regularities in human behaviour, be this particular styles of policing, levels of confidence, or a propensity to use police weapons.

Second, this also highlights the range of attitudes and opinions amongst TASER-trained officers. Not all officers speak about weapon in terms that are in keeping with canteen culture. While some officers talk about it in ways that align with the traditional police subculture, others state that they value the weapon for less traditional reasons. As such, this research lends support to those (such as Paoline 2004) who claim that traditional policing subculture is less monolithic than has been traditionally supposed and posit a range of subcultural attitudes, including those of 'warriors' and 'guardians'. It appears that the weapon may appeal to different officers for different reasons. Further research into what pre-existing attitudes and beliefs the weapon is appealing to, and how such attitudes may, in turn, affect what kinds of force officers use, 
and the frequency with which they use it, is a matter for further research (see also Klahm et al 2011; Terrill et al 2003). Such research would not only help advance our understanding of how and why projectile electric-shock weapons are used, and how it impacts on officer and subject safety, but would also advance the literature on police culture and police subcultures.

Third, the research also points to an additional implication for the literature on police subculture. Not only is police subculture shaped from the 'bottom up', by interactions between projectile electric-shock weapons and the officers that carry them, it is also shaped from the 'top down' by powerful multinational corporations. The story here is not just a case of subculture impacting the design and reception of technology (Bijker 2010) but is also one of technologies and marketing strategies impacting subculture. Far from being successful because they fit in with cultural norms and ideas, classic studies in Science and Technology Studies have underscored how the process of heterogeneous engineering can reshape these very norms and values, creating values, needs and consumers, where none existed before. While police subculture is often considered to arise from a unique combination of danger (occupational pressures) and the demands of the job (occupational isolation), and seen as arising from 'shared experiences associated with particular locations in the social structure' (Griffin and Bernard 2003), this demonstrates that it can also be influenced by outside sources. External influences and powerful corporate entities can shape police subculture by deliberately drawing on, and subverting, notions of safety and danger in order to offer commercially available solutions. This sits at odds with traditional notions of police subculture, which is seen it as insular, secretive, and resistant to change, particularly when changes are directed from outside. The extent of this change should not be over-estimated-for, as Wozniak

and Uggen (2009) observe, marketing appeals that are too far outside of the masculine norm are unlikely to be successful-but neither should it be underestimated.

\section{Theoretical considerations}

As the above discussion indicate, STS has much to add to criminology. Yet several issues and limitations with STS-inspired approaches have also been identified throughout the book. First, this book lends some credence to the long-standing criticism that STS inspired analysis is at risk of generating 'trivial', familiar insights (Latour 1994: 45, see also Fuller 2000 and Michael 2017: 7). In this case, following the actors has revealed that they are often talking already talking about technologies in similar ways. This was not always the case-for example, Chapter 7 revealed that officers often see TASER as a simple tool-yet, as we saw in Chapter 3, many actors stressed the socio-technical network around the weapon and implicitly shared ideas around non-human agency. 
Moreover, the STS concepts discussed here should not be seen as infallible, or as providing some kind of final, universalising vocabulary (see Lee and Brown 1994). While in Chapter 7, I have highlighted a range of instances where projectile electric-weapons and the socio-technical network around them have impacted human decision-making, this is only part of the story and one can imagine other instances where the weapon may, indeed, be more akin to a tool. For example, Sousa et al's work (2010) demonstrates that, in at least some cases, the presence of projectile electric-shock weapons had no discernible, statistically significant effect on the decisions made by officers. Under certain circumstances, more traditional, simple stories that stress the strong pull exerted by 'social' factors and human agency may still be persuasive.

Secondly, while classic STS concepts are often intriguing thought experiments and help one to think about technologies in different ways, it is not always possible to demonstrate these concepts empirically. Classic examples and concepts, such as delegation, often work because they are highly theoretical and abstract. In Latour's examples (e.g., Latour 1991), the analyst has the ability to accurately discern the intent of another (for example, a 'would be' shooter) and then to measure how this changes over time with the introduction of a technology or other non-human actant (such as a gun). However, in practice, this is seldom possible when conducting empirical research. It is perhaps particularly problematic in policing scenarios, as expecting officers to accurately remember and recount their rationales for using force to a relative outsider is a big ask (see, for example, Rojek et al 2012). As such, while concepts such as delegation seem plausible and helpful, it is difficult to somehow comprehensively 'prove' that a technology such as TASER has somehow altered human thought processes and interactions.

Faced with such difficulties, it is important to avoid the temptation to equate publicly stated rationales with intent. Focusing uncritically on public statements of intent-even if only to assess how these are evolving over time-risks accepting the claims made by powerful actors about their motivations and, relatedly, what are 'intended' and 'unintended' uses of their products, including less-lethal weapons. Relatedly, there is also a need to focus on silences and areas of undone science (Frickel et al 2010), as well as to the more conventional STS focus on negotiations, actions, and communications. A topic like less-lethal weaponry-and, one might hazard, multiple other technologies - cannot be understood without a focus on the studies that have not been done, the stories that have not been told, the voices that have not been heard, and the implications that are left unstated. Sometimes processes of translation, enrolment and mobilisation can happen not through action and communication but through refraining to act and communicate, through omission rather than commission.

Third, while the emphasis on process, micro-level interactions, and power and interests as an effect is helpful, it does risk bracketing off powerful 
corporate, financial, and state interests, as well as vulnerabilities pertaining to class, ethnicity, mental health, and other considerations. As such, it may leave us unable to make important claims about broader forces, trends and objects, and the impacts associated with them (Castree 2002; Haraway 2016; Woodhouse et al 2002). Such issues are problematic at the best of times but are all the more concerning when the topic under consideration-in this case, electric-shock weaponry-is intertwined with state powers, coercive use of force by the police, and powerful multinational corporations. The market for less lethal weapons is lucrative and growing and Axon has a reported revenue of $\$ 531$ million in 2019 alone (Axon 2020). Just as Feigenbaum's work reminds us that 'protest profiteering is a global phenomenon' (2015: 102) so, too, is the market for less lethal weapons, with ties between police agencies, officers, governments, and multinational corporations that we dismiss at our peril. While the success of the TASER weapon was never guaranteed, now that it is successful, and a global player, attending to contingency, limits on agency and power as an effect is no longer sufficient-if it ever were. Focusing on the micro-interactions and dance of agency between officer and weapon risks missing this important context.

Finally, while Science and Technology's insistence in troubling binary divides between society and technology, human and non-human, has been helpful throughout the book, it has also posed difficulties for the author. It is much easier to criticise other analysts for reproducing binary human/ non-human distinctions than it is to reject such distinctions oneself. In the final analysis, policy recommendations-including, arguably, those cited at the end of this chapter-tend to focus either on the human or the nonhuman. It is not that those putting forward such recommendations fail to grasp the nuances and complexities in the debate: it is more that, all too often, there is no way to enhance regulation without falling back on binary distinctions (Rappert 2007b).

Relatedly, the focus of many in STS on how seemingly innocuous and taken-for-granted 'facts' are 'constructed', objects are plural, and realities multiple (Law 2009; Mol 2002; Savoie et al 2019) has been a helpful and productive sensitivity to carry with me throughout the book. Yet I have also struggled with the tension around (de)constructing the myths and accounts provided by others, whilst attempting to put forward my own (inherently subjective, partial and emergent) accounts and recommendations. Such debates and dilemmas are nothing new (see, for example, Castree 2002; Rappert 2007b; Seale 1999; Woodhouse et al 2002). In response, I have tried to be open about my background and interest in the topic; the processes of construction that have occurred throughout the research and writing process; and the limitations of the accounts, opinions, and recommendations set out here as well as my inability to claim that they have any privileged status.

The existence of such dilemmas, however, not only chimes with concerns about the ability of approaches within STS to challenge the status quo 
(Fuller 2000; Pels 1996; Winner 1993). It also reveals another important point; that transparency, reflection, and accountability are not characteristics that should be demanded only of police officers - a point I return to in the next section-but characteristics that should also be demanded of academics, too. While the partial and limited nature of the insights and recommendations discussed here may be seen by some as a source of weakness, I hope that it may yet be a refreshing approach in an often strident debate.

It would appear, then, that STS can add much to criminological concepts and theories, yet is also limited in certain key ways. This opens up the intriguing suggestion that, rather than seeing theoretical approaches as a series of binary oppositions and as mutually opposed to each other (see, for example Butler 2017; Vitale 2017), perhaps STS can add value to, yet simultaneously learn from, conflict perspectives and interactionist perspectives in criminology.

Such an approach could work with a more moderate, nuanced version of STS, which would still stress the need to attend to technologies and 'morethan-human' influences. It would highlight the contingency and unpredictability of human and non-human relations, drawing on interactionist approaches to look at individual interactions between civilians, officers, and the technologies they carry. At the same time, drawing on conflict approaches, such an approach would also recognise the importance of pre-existing inequalities and powerful forces. As such, it would look at power and interests both as causes and effects, as dispersed but also centred.

Such an approach would still stress the notion of multiple and constructed objects, facts, realities, and multiple actor-networks, but would recognise that the notion of an 'empirical reality' cannot be dismissed so easily. It would continue to remind analysts to be sensitive to, and respectful of, differing points of view-but would allow, even encourage, them to be politically active in policing and criminological debates, as opposed to politically inert. It would also recognise that disputes and ambiguities around what might be said to constitute the 'empirical reality' of technologies like TASER can also be an important source of conflict and of power. As such, analysis should also look at how, where, and by whom such disputes and ambiguities are resolved. In this case, it would appear that important decisions around the use of force and electric-shock weapons are not made by the public, parliamentarians, or senior officials. Instead, they are deferred and devolved to rank-and-file officers who carry the burden of making decisions around appropriate use, and when and what conditions the weapon is safe to deploy (see also Rappert 2003). Yet, as I detail in my recommendations, there are many other ways of handling disputes, hearing a range of voices and deciding on contentious issues in policing, many of which have compelling precedents.

Such an endeavour would no doubt be subject to criticism (e.g, Fine 2005) but has important allies outside criminology, in human geography (see, e.g., Castree 2002: 135), sociology (Frickel 1996), and from within Science 
and Technology Studies (e.g., Mol 2010). Seen as an adaptable, exploratory experiment - and used to further, not detract from, critical and interactionist approaches-STS may have much to offer criminology and the sociology of policing, helping to rectify the human centric bias of mainstream criminological theories (as discussed in Chapter 2) and creating a more visible role for technologies and other non-humans within the discipline.

Such an experimental theoretical assemblage points to exciting areas for future research building on the accounts suggested in the book, of which I will briefly discuss four. Firstly, building on the notion of the police industrial complex, further work looking at electric-shock technologies and exploring the links between corporate actors, governmental, and policing interests in more detail than has been possible here would be most needed. Second, and relatedly, the implications that STS has for police culture-discussed in detail above-could be explored further with, for example, attention given to the ways in which TASER-trained officers, perhaps particularly those on the margins of the traditional policing culture, are able to interact with the weapon to push back and reshape canteen culture. Another important focus of attention would be the ways in which police subculture is not only shaped by occupational pressures and the demands of the job but is also impacted by external actors (such as multinational corporations) and technological change. Third, while much space has been given in this book to discussing officer accounts of the weapon, much more work needs to be done in order to listen to, and act upon, the accounts of those who have been on the receiving end of police force, as discussed in Chapter 4.

Building on these ideas, a fourth research agenda would be interactional studies of how officers, members of the public, and weapons interact in situations of heightened tension to produce more or less positive outcomes. Body worn cameras and mobile phone footage point to new ways of conceptualising and studying how weapons may intervene and have distinct effects in such interactions, as well as how dynamics may differ according to more conventionally 'social' considerations, such as authority maintenance, ethnicity, and gender dynamics. Thus far, studies have tended to focus on human to human interactions but using new possibilities presented by video footage to study human and non-human interactions would be an exciting possibility.

\section{Recommendations}

Having discussed the implications of this research, there is one crucial task remaining: to generate recommendations for the use of projectile electric-shock weapons in England and Wales, and internationally. I do so in a way that is mindful of the tensions and difficulties listed above, that acknowledges complexities, controversies, and ambiguities instead of trying to resolve them once and for all, and that is attentive to the ways in which such ambiguities are handled and by whom. Despite these difficulties, I am conscious that 
if we are part of the socio-technical networks that we seek to analyse, then surely it is our responsibility to attempt to actively alter them in ways that allow us to 'protect and care' (Latour 2004: 232) for all, particularly the most vulnerable. As Woodhouse et al. (2002: 300) argue, 'there is considerable opportunity' - and, one might argue, even a duty - 'for science studies scholars who mostly pursue their own academic-disciplinary inquiries to move... (to a) normative stance'. I offer some tentative suggestions in this vein.

The recommendations below are not intended to be exhaustive but, rather, to capture key insights and policy suggestions emerging from the research presented here. Nor should they be seen as narrowly focused on projectile electric-shock weapons, as many of the patterns of concern identified in this book are not isolated to this use of force option. Concerns around, for example, mental health, disproportionate use on ethnic minorities, and insufficient training and guidance are highly relevant to police use of force in general and, thus, these recommendations have a broader relevance.

Moreover, they are intended to complement, and not to replace, undermine or distract from, longer-term thinking and action around defunding the police, reflecting on their role and working towards a society in which such agencies are no longer necessary. As Vitale (2017) reminds us, the police role has been radically reimagined in the past and can be again. In this spirit, the recommendations that follow are offered not as definitive suggestions but more as prompts for further discussion.

\section{Ensure that police officers who use force, including but not lim- ited to electric-shock weapons, are held to account via legal reform.}

This necessitates genuinely independent investigations into use of force incidents, reforms to civil law that prevent those affected by police use of force from bringing civil cases, and reforms to the criminal law standard of 'honestly held belief'. Although legal changes are not a panacea, unless and until the law is reformed, it will remain difficult to hold officers to account for their actions.

There are useful models overseas that may be of assistance here. Many other bodies and jurisdictions, including the USA, the Inter-American Human Rights Commission, the African Human Rights Commission and, arguably, the European Court of Human Rights, in their interpretation of Article 2 of the European Convention on Human Rights in the McCann judgement, already 'employ a hybrid test that combines a subjective and an objective element' (Hessbruegge 2016). Under this test, the defendant still has to have an honest belief, but that belief 'must have been objectively reasonable under the circumstances' (Hessbruegge 2016: emphasis added, see also Norrie 2010). For example, the test set out by the McCann ruling-and repeated in subsequent ECtHR case law-is of 'an honest belief which is perceived, for good reasons, to be valid at the 
time but which subsequently turns out to be mistaken' (McCann v United Kingdom, para. 200, emphasis added).

Nor would those seeking to reform the law necessarily have to look overseas for examples of alternative wording. As the College of Policing's Code of Ethics notes, police officers should only use force 'to the extent that it is necessary, proportionate and reasonable in all the circumstances' (College of Policing 2014, Section 4.4, see also the so-called 'W80' case) ${ }^{1}$. The wording of 'reasonable in all the circumstances' does not negate the need to attend to what the officer honestly believed at the time-but neither does it reduce the calculation just to this singular consideration. It would appear, then, that there is a need to consider clarifying and amending the current criminal test.

While most of these changes are national in scope, there is much that can be done locally. Some forces have additional local policies to enhance accountability around the use of the weapon. For example, Martyn Underhill, who at the time of writing was the Dorset Police and Crime Commissioner, has introduced a local agreement that the PCC has to be told within 24 hours if someone is Tasered in custody with an explanation given. Underhill also notes that, in keeping with an increasing number of forces nationwide, Dorset has an independent use of force panel with independent members of the public which examines Taser and other use of force, looking at body worn camera footage' (interview with author). Such bodies, if they can indeed be genuinely independent, avoid regulatory capture and be respected and meaningfully listened to by key local police decision makers, may offer an interesting additional avenue for accountability and change.

2 A full and public debate about the current law, guidance, and policy around TASER and other use of force options, and the role that they should play in policing, which informs policy. While this will involve legal expertise, as detailed above, it is important to recognise that this is not some dry, arcane legal debate but one with far-ranging impacts and implications.

It is crucial that this debate involves listening and acting on the views of affected communities (including BAME people, children and young people and those with lived experience of mental health issues); people who have experienced the weapon used on them, and those who have lost loved ones following the use of projectile electric-shock weapons. In order to do so meaningfully and effectively, it is important that everyone who wishes to is able to contribute in a way in which they feel comfortable and in a manner which minimises the risk of further traumatisation, and that commitments are made to act on the results of the debate. As Dame Angiolini noted in the Report of the Independent Review of Deaths and Serious Incidents in Police Custody, as 'a result of the tragic experience of the loss of a loved one in police custody many next of kin 
have become experts on a range of issues following a death in police custody and exposing officers to these families and listening to them is an invaluable training resource for all levels of command' (2017: 245). These, and the other recommendations from the Angiolini report, many of which pertain to the issues raised in this book, must be implemented without further delay.

3 Further research into the effects, both physical and psychological, of projectile electric-shock weapons. This programme of work needs to include research both into the comparative and relative risks of electricshock weapons compared to other use of force options, a crucial issue often (quite literally) bracketed off in information given to police officers. It should also include-and research into the absolute and relative safety of different types of electric-shock weapons and modes of usage, including prolonged and multiple discharges, taking into account the complex interplay between officers, members of the public, weapons and other technologies. As a key part of this endeavour, it is vitally important that, as Delsol has noted (as captured in Pandian 2020), work is carried out 'on the diverse ways in which Tasers engender trauma within over-policed BME communities'.

4 Alternatives to police force. Many of the cases quoted in this book involved the use of force on people who were in mental health crisis, using drugs and alcohol and/or who were vulnerable on multiple counts. In the case of Marc Cole, there are broader questions about whether there were, or could have been, other ways of handling cases where people are 'acting in a paranoid and psychotic manner' (Cornwall and the Isle of Scilly Coroner 2020a), including earlier intervention and a focus on agencies other than the police. As Marc's sister Lisa Cole noted, 'there is a lack of understanding of mental illness in the first place and how to deal with mental health crisis that you need to resort, almost instantaneously, using the TASER. In an ideal world, they (the police) wouldn't be called. We'd have mental health cars going out and paramedics and specialist psychiatrists' (interview with author, see also Vitale 2020).

Similar points have been made by former police officers. As former Chief Superintendent Owen West (2020: 1) has noted, 'because of the systematic and purposeful cuts in social care, children's social care, youth services, outreach, homelessness services, addiction services, and many others, it's the police who are left to pick up the pieces ...The police are the service of last resort... because those agencies too have been starved of cash, under-resourced, and undervalued'. Instead of assuming that weapons and force techniques are the solution to multifaceted social problems, tackle these crucial issues, including by funding other services-including mental health teams, drug and alcohol services, social services-where the evidence suggests that these will do more good than harm and will minimise, not expand, coercive, and discriminatory practices. 


\section{Minimise police weaponry and restrict the number of officers} carrying such weapons. Where police intervention is necessary, equip officers with ways of handling situations without using force and assess them on their ability to do so. Officers need to be further given training on de-escalation and communication skills, and the training already provided on TASER and use of force in England and Wales needs to incorporate and test officers on such skills (see Chapters 6 and 7) on a pass-fail basis, annually. This would mean that officers who are unable to demonstrate their ability to de-escalate situations effectively and to refrain from use force where appropriate are not only unable to carry projectile electric-shock weapons but are unable to take on public facing roles in which the use of force may be required.

Assessment of officers' decision making should not be an exercise isolated to annual training events. Rather, supervisors, oversight bodies, and external reference groups should regularly randomly sample and review body worn camera footage of events where officers have used force and analyse their use of force statistics in order to identify patterns, including indicators of concern, taking action where necessary. This would assist police forces in identifying whether individual officers, or groups of officers, may be, for example, jumping to TASER too quickly or using force in discriminatory ways and provide a way of routinely assessing officers' use of force in real-life situations in-between training courses. It would not only allow officers to be given additional emotional, psychological and other support where needed (for example, following traumatic incidents involving the weapon), but would also help to hold them to account where necessary, including removing their ability to carry the weapon where appropriate. Indeed, officers who have been involved in a complaint, death or serious injury or other serious incident involving projectile electric-shock weapons should have their license to carry the weapon removed unless and until an independent investigatory process has concluded in their favour. In such ways, senior officials can ensure that, whilst the appropriate use of force is an individual responsibility for the officer concerned, it is not solely their responsibility, but a responsibility that is shared by others in the network.

Additional analysis of use of force statistics should also be conducted nationally and by external agencies, in order to proactively pick up patterns and trends of concerns; to monitor the ways in which weapons (including new technologies) are being used both collectively and by individual officers; and to look at the weapons in context. Such analysis must feed directly back into and, where necessary, result in evidence-based changes to deployment, guidance, training, and accountability mechanismswhich could include prohibiting particular use of force tactics altogether.

Recommendations $1-5$ are intended to enhance accountability in cases where projectile electric-shock weapons and other forms of force 
have been (mis)used; ensure a broader public debate and meaningful action and provide workable alternatives to police use of force (both through utilising agencies other than the police and utilising other methods within the police service) where possible. Yet it is likely that there will remain occasions where force has to be used, and cases where the use of projectile electric-shock weapons are strictly necessary. This leads us to the final three recommendations, specifically.

\section{Tighter Guidance, informed by public debate (see also recom- mendation 2).}

The English and Welsh guidance in its current form-which states that TASER is 'one of a number of tactical options available when dealing with an incident with the potential for conflict' (College of Policing 2020a) - is vague and leaves the door open to excessive, discriminatory, and disproportionate policing. Such unclear policies also result in additional pressure for officers, who are faced with making decisions around the use of the weapon with minimal guidance about when such use is, or isn't, appropriate.

Without wishing to prejudge the consultation and discussion process discussed above, there are many examples, both current and historical, that could be useful models for England, Wales, and other jurisdictions to follow. These include the 2008 Police Service of Northern Ireland (PSNI) guidance which specified that 'the use of TASER will be justified where the officer honestly and reasonably believes that it is necessary in order to prevent a risk of death or serious injury' (PSNI 2008, emphasis added) and the Canadian Braidwood Commission of Enquiry (Braidwood 2009: 19). This recommended that officers 'be prohibited from deploying a conducted energy weapon unless... the subject is causing bodily harm; or the officer is satisfied, on reasonable grounds, that the subject's behaviour will imminently cause bodily harm' and then only when 'the officer is satisfied, on reasonable grounds, that no lesser force option has been, or will be, effective in eliminating the risk of bodily harm; and de-escalation and/or crisis intervention techniques have not been or will not be effective'. United Nations bodies have also advised on appropriate standards, with the UN Committee Against Torture (2013) stating that "electrical discharge weapons should be used exclusively in extreme limited situations where there is a real and immediate threat to life or risk of serious injury, as a substitute for lethal weapons'.

Consideration should be given to the implications of any policy change on the safety of officers and the public and police legitimacy more broadly (see Ba and Grogger 2018; Womack et al 2016) and any policy shift should be informed by human rights standards, academic evidence, and public consultation. In revising the guidance, one potential model to build on would be the Guideline Committee process adopted by the College of Policing for drafting policy documents (see, for example, College 
of Policing 2020c). This process involves establishing an independent advisory group (in this case, with a focus on projectile electric-shock weapons and police use of force), termed a 'guideline committee' that considers the evidence and develops the guideline recommendations, which are then issued for public consultation. This guideline committee comprises specialist and generalist practitioners, subject matter experts from academia and partner agencies, and the third sector. The intention is that it is informed by systematic reviews, which are supplemented with unbiased consensus of expert opinion (systematically elicited), before the recommendations are issued for public consultation.

7 Enhanced training on projectile electric-shock weapons, including on associated risks.

As discussed in Chapters 6 and 7, the training on TASER is largely empty of specifics about when the weapon should be used, and the threshold for appropriate use. Instead, it devolves such critical decisions down to individual officers, while giving them little information about when such use may be appropriate to help inform their deliberations. Clearer guidance (as detailed in the previous recommendation) is necessary but not sufficient to improve training. Additional time for the training is needed, with a particular focus on vulnerable groups, risks associated with the weapon (including prolonged and repeated discharges), and summative assessments of officers ability to de-escalate and refrain from using the weapon.

Further quality assurance processes, both by internal agencies (the College of Policing and the National Police Chiefs' Council) and external agencies (including SACMILL, HMICFRS, the IOPC) are also necessary. Additional resources should be invested, not only in the length of the training and material covered, but in independent oversight of training so as to ensure quality, minimise discrepancies between forces, and ensure robust, appropriate assessments, and pass/fail rates. Indeed, there is evidence to suggest that enhanced auditing of training would be welcomed by trainers themselves. One trainer (Taser trainer 5) noted that internal audit and accreditation processes would 'drive up standards... as it focuses people's attention on 'what is it that we are delivering and how does that lesson reach that requirement?' That's not always straightforward because standards of trainers are so different'.

\section{Look beyond the human and the nation-state.}

Many of the policy suggestions I have proposed focus on law, policies, and interpretations of them. Yet while the accountability literature and many of it's proposed recommendations focus on human actors and legal remedies, we need to be more imaginative in devising new accountability mechanisms to complement these solutions. If weapons manufacturers and others can engage in a process of 'heterogeneous engineering' (Law 1987, see Rejali 2009), we similarly need to become 'heterogeneous 
engineers' (Woodhouse 2002) in the service of enhanced police accountability. For example, the TASER weapon's in-built recording mechanisms have proven particularly useful in providing an additional record of officers' uses of the weapon. Additional solutions might include a 5 second cut off for all projectile electric-shock weapons to prevent the officer from inadvertently discharging lengthy electric-shocks ${ }^{2}$, use of Body Worn Cameras which automatically record whenever the weapon is armed, and a section on the use of force reporting form that asks officers to provide a qualitative, descriptive account of the circumstances surrounding their use of force. Far from being mere technological 'solutions', these measures can work to prescribe far-reaching changes in the behaviour of officers who use the weapon. Interactions, and the 'dance of agency' (Pickering 2005), between officers and TASER can often result in negative consequences, but interactions of the kind detailed above may yet lead to more positive outcomes-or at least to enhanced scrutiny when force is used.

As such recommendations indicate, too, there is a need to focus more broadly not just on officers but on questions of corporate and state responsibility. Corporations should discharge their responsibility to respect human rights by conducting due diligence (Ruggie 2010); government should ensuring that weapons (less lethal and otherwise) undergo thorough, human rights compliant testing, and selection in line with United Nations guidance before being adopted; and the trade in police weapons and equipment which can easily be misused for torture and ill-treatment should be subject to international regulation (see also United Nations Special Rapporteur on Torture and Other Cruel, Inhuman or Degrading Treatment or Punishment 2017 and United Nations Human Rights Office of the High Commissioner 2020a).

In sum, projectile electric-shock weapons and other use of force options should not be (further) rolled out, either in the UK or internationally unless and until clear, effective and human-rights compliant guidance and accountability mechanisms are put in place for officers when they use any use of force, electric-shock or otherwise, and genuine, meaningful public and parliamentary debate has been had about the weapons that are under consideration, and the proposed guidelines for use. The alternative risks further entrenching unfair and discriminatory policing, undermining policing by consent and increasing inappropriate use of projectile electric-shock weapons and other types of force-with far reaching consequences both for officers and members of the public alike. Further, police weaponry should only be rolled out by Chief Constables when there is clear evidence that, to use the language of the UN Basic Principles on the Use of Force and Firearms (1990, principle 2 ), they will 'restrain the application of means capable of causing death or injury to persons'; that is, that they will reduce, not enhance, the negative 
consequences of using force. Going forward, the recommendations listed above are intended to help to ensure-for the benefit of all-that projectile electric-shock weapons are only used by highly trained officers in exceptional circumstances, when strictly necessary, and that weapons are only introduced when they fill a well-defined operational gap and when they are safer and less injurious than the alternative.

\section{Closing reflections}

In proposing such recommendations, I am all too aware of the lack of evidence as to 'what works' with regards to police use of force and, indeed, some mixed evidence regarding some of the proposals suggested above. For example, Engel et al (2020: 1) found that, although there was some evidence of 'de-escalation trainings lead(ing) to slight-to moderate individual and organizational improvements, conclusions... are limited by the questionable quality of almost all evaluation research designs'. It is naive to assume that such measures will 'solve' such an intractable and 'wicked' (Rittel and Webber 1974) problem as police use of force and so-called 'liberal' approaches have been widely criticised for assuming this is the case. Yet, at the same time, other evidence (Bishopp et al 2014; Terrill and Paoline 2017) suggests that changes to use of force guidance can be effective in changing officer behaviourand in an area as important as police use of force, even 'slight to moderate' improvements could make a real difference to many.

I am also highly conscious that such reforms should not be a substitute for deeper thinking and reimagining around the police role that needs to occur. I suggest such reforms in the hope that they will complement, not detract from, such necessary long-term work-and that STS, when allied with critical approaches in the ways that I suggest above, can point to new ways of bringing about more fundamental transformations that may be necessary.

I opened the book by speaking about my own experience of being Tasered. In the spirit of 'following the actors', I would like to close it by highlighting the experience of those affected by the weapon, albeit in very different ways. The following two quotes - the first from a TASER-trained officer and the second from Lisa Cole, who lost her brother, Marc Cole, following police use of TASER - are from markedly different sources. Yet they both, in their own ways, demonstrate the profound impact of police use of force; highlight that the current system, with vague guidance and over-reliance on officer discretion, is failing members of the public and officers alike, and powerfully underscore the need for change. Without further ado, I give the last few words of the book over to them directly.

Officer 8, Countryshire: 'I wish people could understand (that using TASER) is not an easy decision to make. It can be quite pressured (for officers) because you are the person that's making that decision. I had an 
incident I couldn't get out of my head for days and days. You make that decision and you've got to live with that'.

Lisa Cole: 'the trauma has affected all of us profoundly, it's destroyed our lives in ways that I can't even explain. You cannot access justice or accountability. Everything is left to discretion and that's not good enough. They need to change things now, they have to'.

\section{Notes}

1. This debate is all the more important given the ECHR's ruling in the Armani Da Silva case (Armani Da Silva v United Kingdom,) and the recent so-called 'W80' case in the UK (see $R(W 80) v$. Director General of the Independent Office for Police Conduct) which had just been published as this book went to press. Although there is not space to discuss the complexity of these rulings here, both cases serve to highlight that discussions around the interpretation and status of existing law, and possible amendments, are urgently needed.

2. Some TASER models can be equipped with an optional 'APPM' battery pack capable of shutting down the electrical output after 5 seconds (Axon undated e). 


\section{Reference list}

ACPO (Association of Chief Police Officers) (2012) The National Decision Model. ACPO; London.

Acuto, M., (2011) 'Putting ANTs into the mille-feuille', City 15 (5): 552-562.

Adams, K., and Jennison, V., (2007) 'What we do not know about police use of Tasers', Policing: An International Journal of Police Strategies and Management 30 (3): 447-465.

All Africa (2019) Nigeria: Extra-Judicial Killings - Police to Stop Firearms Use for Routine Patrols Available online at https://allafrica.com/stories/201904160158.html (accessed 11/11/2020).

Allen, R. E., \& Wiles, J. L. (2016) 'A rose by any other name: Participants choosing research pseudonyms' Qualitative Research in Psychology 13 (2): 149-165.

Alpert, G., and Dunham, R., (2010) 'Policy and training recommendations related to police use of CEDs: Overview of findings from a comprehensive national Study' police', Quarterly 13 (3): 235-259.

Alternative Africa (2019) Nigerian Police to Migrate from Use of Lethal Weapons to Taser Guns Available online at https://alternativeafrica.com/2019/04/26/nigerian-police-tomigrate-from-use-of-lethal-weapons-to-taser-guns/ (accessed 06/08/2020).

Amnesty International (2008) Less than Lethal? The Use of in Law Enforcement, Amnesty International; London.

Amnesty International and Omega Research Foundation (2014) China's Trade in Tools of Torture and Repression, Amnesty International; London. Available online at https:// omegaresearchfoundation.org/sites/default/files/uploads/Publications/asa170422014 en\%20\%282\%29.pdf (accessed 08/11/2020).

Anais, S., (2009) 'Conducted Energy Weapons: Governing Through Neutralisation'. In Dam, S. and Hall, J., (eds), Inside and Outside the Law: Perspectives on Evil, Law and the State, Interdisciplinary Press; Oxford.

Anais, S., (2015) Disarming Intervention: A Critical History of Non-Lethality. UBU Press; University of British Columbia.

Andrejevic, M., and Selwyn, N., (2020) 'Facial recognition technology in schools: Critical questions and concerns' Learning', Media and Technology 45 (2): 115-128.

Angiolini, E., (2017) Report of the Independent Review of Deaths and Serious Incidents in Police Custody. HM Government; London.

Ariel, B., Lawes, D., Weinborn, C., Henry, R., Chen, K., and Sabo, H. B., (2019) 'The 'lessthan-lethal weapons effect' - IntroducingTASERs to routine police operations in England and Wales: A randomized controlled trial', Criminal Justice and Behavior 46 (2): 280-300. 
Armacost, B. E., (2019) 'Police shootings: Is accountability the enemy of Prevention', Ohio State Law Journal 80: 907-986.

Armani da Silva v. The United Kingdom (2016) European Court of Human Rights, Application Number 5878/08.

Austin, J. L., and Bocco, R., (2016) 'Becoming a torturer: Towards a global ergonomics of care', International Review of the Red Cross 98 (903): 859-888.

Avdi,A., (2013) 'Police use of force: An analysis of factors that affect police Officer's decision to use force on Suspects', International Research Journal of Social Sciences 2 (9): 1-6.

Axon (2020) Axon 2019 Revenue Grows 26\% to \$531 Million; SaaS ARR up 49\%, Setting Foundation for Continued Growth $\mathcal{E}$ Momentum Available online at https://investor.axon. com/press-releases/press-release-details/2020/Axon-2019-Revenue-Grows-26-to-531Million-SaaS-ARR-up-49-Setting-Foundation-for-Continued-Growth-Momentum/ default.aspx (accessed 04/08/2020).

Axon (2021) TASER Handheld Energy Weapon Warnings, Instructions, and Information: Law Enforcement; Axon Enterprises Inc, Arizona. Available online at https://axon-2. cdn.prismic.io/axon-2/19c2d86c-c983-4d9f-bac4-dd6bdb8ce29c_Law+Enforcement+ Warnings+8_5x11.pdf (accessed 05/08/2021).

Axon (undated, a) About Axon. Webpage available at https://global.axon.com/company (accessed 27/07/2020).

Axon (undated, b) How safe are Taser Weapons? Webpage available at axon.com/how-safe-areTaser-weapons (accessed 05/11/2020).

Axon (undated, c) Our leadership. Webpage available at https://www.axon.com/leadership (accessed 3/8/2020).

Axon (undated, d) TASER ${ }^{\circledR} 2^{\mathrm{TM}}$ CEW User Manual Available online at https://taser. cdn.prismic.io/taser\%2Fed6b19eb-4410-46a8-9559-90ad95d66aba_x2-user-manual.pdf (accessed 3/8/2020).

Axon (undated, e) APPM (Automatic Shut-Down PPM) Configuration Available online at https://help.axon.com/hc/en-us/articles/221370328-APPM-Automatic-Shut-DownPPM-configuration (accessed 05/11/2020).

Azadani, P., Tseng, Z. H., Ermakov, S., Marcus, G., and Lee, B., (2011) 'Funding source and author affiliation in TASER research are strongly associated with a conclusion of device safety', American Heart Journal 162 (3): 533-537.

Ba, B., and Grogger, J., (2018) The introduction of Taser and police use of force: evidence from the Chicago police department. NBER Working Paper 24202, National Bureau of Economic Research. Available online at https://www.nber.org/ papers/w24202 (accessed 03/08/2020).

Banton, M., (1964) The Policeman in the Community Tavistock Publications; London.

Barnett, T. P. M., (2019) 'Capability Gaps Threatening CBP's Present and Future Operations' Homeland Security Affairs 15, 3. Available online at https://www.hsaj.org/articles/15389 (accessed 3/8/2020).

Barry, A., (2013) 'The translation zone: Between actor-network theory and international Relations', Millennium 41 (3): 413-429.

BBC News. (2004) Police offered stun guns option 15th September edition. Available online at http://news.bbc.co.uk/1/hi/uk/3659068.stm\#: :text=\%22Chief\%20officers\%20can\% 20now\%20make,only\%20short\%2Dterm\%20skin\%20irritation (accessed 03/08/2020).

BBC News (2017) Police Taser race group founder in the face BBC News; London. Available online https://www.bbc.co.uk/news/uk-england-bristol-38691162 (accessed 05/08/2020). 
BBC Radio 4 (2013) The Report: Police Tasers. First broadcast Thursday 19 $9^{\text {th }}$ September 2013. Available online at http://www.bbc.co.uk/programmes/b03b2vyn (accessed 03/08/2020). Becker, H. S., (1967) 'Whose side are we on?' Social problems, 14(3): 239-247.

Bijker, W., (2010) 'How is technology made?-That is the question.' Cambridge Journal of Economics 34: 63-76.

Bishopp, S., Klinger, D., and Morris, R., (2014) 'An examination of the effect of a policy change on police use of TASERs' Criminal Justice Policy Review 21:1-20.

Bittner, E., (1974) 'Florence Nightingale in Pursuit of Willie Sutton: a Theory of the police'. In Jacobs, $\mathrm{H}$ (ed). The Potential for Reform of Criminal Justice.Vol. 3. Sage; Beverly Hills, CA, 233-268.

Bleetman, A., Steyn, R., and Lee, C., (2004) 'Introduction of the Taser into British policing. Implications for UK emergency departments: An overview of electronic weaponry', Emergency Medicine Journal 21 (2): 136-140.

Bloor, D., (1999) 'Anti-Latour', Studies in History and Philosophy of Science 30 (1): 81-112.

Bolger, P. C., (2015) 'Just following orders: A meta-analysis of the correlates of American police officer use of force decisions' American Journal of Criminal Justice 40: 466-492.

Bourne, M., (2012) 'Guns don't kill people, cyborgs do: A Latourian provocation for transformatory arms control and disarmament', Global change, Peace E Security 24 (1): 141-163.

Bowling, B., and Marks, A., (2008) 'Crime Control Technologies: Towards an Analytical Framework and Research Agenda'. In Brownsword, R. and Yeung, K., (eds), Regulating Technologies: Legal Futures, Regulatory Frames and Technological Fixes, Bloomsbury Publishing; Oxford and Portland, Oregon.

Bozeman,W. P., and Winslow,J. E., (2005) 'Medical aspects of less lethal weapons', International Journal of Rescue and Disaster Medicine 5 (1): 37-47.

Braidwood, T. R. (2009). Restoring Public Confidence: Restricting the Use of Conducted Energy Weapons in British Columbia. Braidwood Commission on Conducted Energy Weapon Use.

Brandl, S., and Stroshine, M., (2017) 'Oleoresin capsicum spray and TASERs: A comparison of factors predicting use and Effectiveness’, Criminal Justice Policy Review 28 (3): 279-306.

Brodeur, J. P., (2010) The Policing Web, Oxford University Press; Oxford.

Brown, A. D., (1994) 'Politics, symbolic action and myth making in pursuit of Legitimacy', Organisational Studies 15 (6): 861-878.

Brown, S., (2006) 'The criminology of hybrids: Rethinking crime and law in techno-social networks', Theoretical Criminology 10 (2): 223-244.

Busby, M., (2020) 'Rights groups quit police body over stun gun use against BAME people' The Guardian 17th April edition, https://www.theguardian.com/uk-news/ 2020/apr/17/rights-groups-quit-uk-police-body-stun-gun-use-bame-people (accessed $13 / 10 / 2020)$.

Butler, P., (2017) Chokehold: Policing Black Men, The New Press; New York.

Buttle,J., (2007) 'A constructive critique of the officer safety programme used in England and Wales', Policing and Society: An International Journal of Research and Policy 17 (2): 164-181.

Buvik, K., (2016) 'The hole in the doughnut: A study of police discretion in a nightlife setting', Policing and Society 26 (7): 771-788.

Callon, M., (1986) 'Some elements of a sociology of translation: domestication of the scallops and the fishermen of St Brieuc Bay' in Law, J (Ed), Power, Action and Belief: A New Sociology of Knowledge, Routledge; London, 196-223.

Campaign Zero (2020) 8 Can't Wait, Available at https://8cantwait.org/ (accessed 19/08/2020). 
Campbell, E., (1999) 'Towards a sociological theory of discretion' International Journal of the Sociology of Law 27: 79-101.

Carter, H., (2012) 'Police Taser blind man mistaking his white stick for a samurai sword' The Guardian, 18th October edition. Available online at https://www.theguardian.com/ uk/2012/oct/17/police-taser-blind-man-stick (accessed 05/08/2020)

Casalie, S., (2012) Report of the independent external review of the IPCC investigation into the death of Sean Rigg, IPCC; London.

Castillo, E. M., Prabhakar, N., \& Luu, B., (2012) 'Factors associated with law enforcementrelated use-of-force injury' The American journal of emergency medicine, 30 (4): 526-531.

Castree, N., (2002) 'False antitheses? Marxism, nature and actor-Networks', Antipode 34 (1): 111-146.

Chapman, C., (2014) An Independent Review of the Police Disciplinary System in England and Wales. Home Office; London. Available online at https://www.gov.uk/government/ publications/the-police-disciplinary-system-in-england-and-wales (accessed 06/08/2020).

Choudhary, R., and Sabri, I., (2010) 'Review paper taser technology: Medical, legal, ethical and social implications of introduction of taser gun in India', The Journal of the Indian Academy of Forensic Medicine 32 (4): 349.

Clark-Darby, O., and Quinton, P., (2020) National Police Safety Survey: Headline Findings, College of Policing; London. Available online at https://paas-s3-broker-prod-lon6453d964-1d1a-432a-9260-5e0ba7d2fc51.s3.eu-west-2.amazonaws.com/s3fs-public/ 2020-09/200818-National-police-safety-survey-Final-results-1.0.pdf (accessed 16/11/2020).

College of Policing (2014) Code of Ethics, College of Policing; London. Available online at https://www.college.police.uk/What-we-do/Ethics/Ethics-home/Pages/Code-ofEthics.aspx (accessed 12/08/2020).

College of Policing (2015) Tackling Unconscious Bias in Recruitment, Selection and Promotion Process. A Rapid Evidence Assessment: Executive Summary, College of Policing; London. Available online at http://whatworks.college.police.uk/Research/Documents/Unconscious_bias_ REA_exec_sum.pdf (accessed 12/08/2020).

College of Policing (2019) Police Dismissals (Home Office forces) Available online at https:// www.college.police.uk/News/College-news/Documents/Barred_List_2019.pdf (accessed 18/08/2020)

College of Policing (2020a) Authorised Professional Practice: Conducted energy devices (Taser) Available online at https://www.app.college.police.uk/app-content/armed-policing/ conducted-energy-devices-taser/ (accessed 03/08/2020).

College of Policing (2020b) Authorised Professional Practice: Armed Policing - Use of Force, Firearms and Less Lethal Weapons Available online at https://www.app.college.police.uk/ app-content/armed-policing/use-of-force-firearms-and-less-lethal-weapons/\# (accessed 03/08/2020).

College of Policing (2020c) Conflict Management Using De-Escalation, Communication and Negotiation: Guidelines, College of Policing; London. Available online at https:// paas-s3-broker-prod-lon-6453d964-1d1a-432a-9260-5e0ba7d2fc51.s3. eu-west-2. amazonaws.com/s3fs-public/2020-09/Conflict-management-guidelines.pdf (accessed $16 / 11 / 2020)$

Collins, R., (2009) 'Micro and macro theories ofViolence', International Journal of Conflict and Violence 3 (1): 9-22.

Collins, R., (2012) 'Entering and leaving the tunnel of violence: Micro-sociological dynamics of emotional entrainment in violent interactions', Current Sociology Monograph 61 (2): $132-151$. 
Condor Non-Lethal Technologies (undated) The history of Condor Non-Lethal Technologies Available online at http://www.condornaoletal.com.br/eng/institucional.php (accessed 08/11/2020).

Cork, R., (2018) 'Exclusive: Judah Adunbi - why I didn't give my name and why I'm suing the police' The Bristol Post, 11th October edition. Available online at https://www.bristolpost. co.uk/news/bristol-news/exclusive-judah-adunbi-didnt-give-2096279 (accessed 04/08 2020).

Cornwall and the Isle of Scilly Coroner, Assistant Coroner Williams, G. U, Assistant Coroner (2020a) Regulation 28: Report to prevent future deaths: Re: Marc Antony Cole, deceased. Available online at https://www.judiciary.uk/publications/marc-cole/ (accessed 10/08/2020).

Cornwall and Isles of Scilly Coroner (2020b) Record of Inquest Marc Antony Cole: Continuation sheet author's personal copy. Available on request from the Coroners Court.

Corruption and Crime Commission (2010) The Use of Taser Weapons by Western Australian Police. Corruption and Crime Commission; Perth.

Council of Canadian Academies and Canadian Academy of Health Sciences. (2013) The Health Effects of Conducted Energy Weapons: The Expert Panel on the Medical and Physiological Impacts of Conducted Energy Weapons Self-published; Ottowa Available online at http:// www.scienceadvice.ca/uploads/eng/assessments\%20and\%20publications $\% 20$ and $\% 20$ news\%20releases/CEW/CEW_fullreportEN.pdf (accessed 03/08/2020).

Criminal Justice and Immigration Act 2008, Chapter 4 http://www.legislation.gov.uk/ ukpga/2008/4/contents (accessed 14/08/2020).

Criminal Law Act 1967, Chapter 58 Available online at http://www.legislation.gov.uk/ ukpga/1967/58 (accessed 11/08/2020).

Crow, M., and Adrion, B., (2011) 'Focal concerns and police use of force: Examining the factors associated with taser use', Police Quarterly 14 (4): 366-387.

Crown Prosecution Service (2019) Death of Dalian Atkinson: CPS statement Available online at https://www.cps.gov.uk/west-midlands/news/death-dalian-atkinson-statement (accessed 27/05/2020).

Cushion, C. J., (2020) 'Exploring the delivery of officer safety training: A case Study', Policing: A Journal of Policy and Practice 14 (1): 166-180.

Dave Shear Guns., (2020) Condor Spark DSK700 Taser Available online at https://www. davesheer.com/condor-spark-dsk700-taser/ (accessed 18/11/2020).

Davison, N., (2006) The Early History of 'Non-Lethal' Weapons: Occasional Paper No. 1. Bradford Non-Lethal Weapons Research Project; Bradford.

De Angelis, J., and Wolf, B., (2013) 'Tasers and community controversy: Investigating training officer perceptions of public concern over conducted energy Weapons', The Qualitative Report 18 (13): 1-20.

De Sanctis, F., (2006) 'What duties do states have with regard to the rules of engagement and the training of security forces under article 2 of the European Convention on Human Rights?', The International Journal of Human Rights 10 (1): 31-44.

Diphoorn, T., and Grassiani, E., (2016) 'Securitizing capital: A processual-relational approach to pluralized security', Theoretical Criminology, 20 (4): 430-445.

Disley, J (2014) 'Blind man's fury as police officer who wrongly Tasered him keeps job' The Express March $27^{\text {th }}$ edition. Available online at

DOMILL (Defence Scientific Advisory Council Sub-Committee on the Medical Implications of Less-Lethal Weapons) (2012) Statement on the Medical Implications of Use of the Taser X26 and M26 Less-Lethal Systems on Children and Vulnerable Adults Available online at http://data.parliament.uk/DepositedPapers/Files/DEP2012-0729/96605\%20 Library\%20Deposit.pdf (accessed 03/08/2020). 
Donoghue, K., (2014) 'Will Paul Gambaccini sue the police?' Donoghue Solicitor's Blog Available online at www.donoghue-solicitors.co.uk/will-paul-gambaccini-sue-thepolice/ (accessed 06/08/2020).

Dror, I., (2007) 'Perception of risk and the decision to use force', Policing 1 (3): 265-272.

Dymond, A., (2018) 'Taser, taser': Exploring factors associated with taser use in England and Wales', Policing and Society 30 (4): 1-15.

Dymond, A., (2020) 'Towards A socio-technical understanding of discretion: A case study of taser and police use of force', Policing and Society 30 (9): 998-1012.

Dymond,A., and Corney, N., (2014). The Use of 'Less-Lethal'Weapons in Law Enforcement. Weapons Under International Human Rights Law, Cambridge University Press: Cambridge, 32-52.

Eastman, A. L., Metzger, J. C., and Pepe, P. E., (2008) 'Conductive electrical devices: A prospective, population-based study of the medical safety of law enforcement use', The Journal of Trauma 64 (6): 1567-1572.

Edelman, L. B., Uggen, C and Erlanger, H. S., (1999) 'The endogeneity of legal regulation: Grievance procedures as rational myth' American journal of Sociology, 105 (2): 406-54.

Edmonds, L., (2014), 'A policeman can shoot a blind man in the back and get away with it?' Fury of Taser attack victim as blundering officer who mistook his white stick for a samurai sword is let off with an order to apologise' Daily Mail Online Available online at http://www.dailymail.co.uk/news/article-2589819/A-policeman-shoot-blind-manaway-Fury-Taser-attack-victim-blundering-officer-mistook-white-stick-samurai-swordlet-order-APOLOGISE.html\#ixzz4H78JegND (accessed 18/12/2020).

Eight to Abolition (2020) 8 to Abolition website Available at https://www.8toabolition.com/ (accessed 19/08/2020).

Einhorn, J., (2001) 'The World Bank's mission Creep', Foreign Affairs 80 (5): 22-35.

Engel, D., (1993) 'Origin myths: Narratives of authority, resistance, disability, and Law', Law E Society Review 27 (4): 785-826.

Engel, R.S, McManus, H.D, Herold, T.D., (2020) 'Does de-escalation training work? A systematic review and call for evidence in police use-of-force reform' Criminology and Public Policy 19: 721-759.

English and Welsh High Court, Queen's Bench Division (2019) Gilchrist vs Greater Manchester Police. 2019- EWHC-1233-(QB). Available online at https://www.casemine.com/ judgement/uk/5ce26e9f2c94e01eda977141 (accessed 05/11/2020).

Equality and Human Rights Commission (2015) Third Party Intervention Submissions of the Equality and Human Rights Commission: Armani Da Silva $v$ United Kingdom Available online at https://www.google.co.uk/url?sa=t\&rct=j\&q=\&esrc=s\&source=web\&cd=1\&cad $=$ rja $\&$ uact $=8 \&$ ved $=0$ ahUKEwjxwfnJ0bnPAhVHxRQKHX1_BocQFggcMAA \&url=https $\% 3 \mathrm{~A} \% 2 \mathrm{~F} \% 2 \mathrm{Fwww}$.equalityhumanrights.com $\% 2 \mathrm{Fsites} \% 2 \mathrm{Fdefault} \% 2 \mathrm{Ffiles} \% 2$ Farmani_da_silva_v_uk_ehrc_submission_ecthr.docx\&usg=AFQjCNFEEE5BD6hUqg HXUXPrIc5C5115KQ\&bvm=bv.134495766,d.bGg (accessed 06/08/2020).

Feenberg, A., (2010) ‘Ten paradoxes of' Technology' Techné 14 (1): 3-15.

Feigenbaum, A., (2015) 'Riot control agents: The case for Regulation'. SUR: International Journal on Human Rights, 22: 1-6. Available online at https://sur.conectas.org/en/riotcontrol-agents-case-regulation/ (accessed 06/08/2020).

Feigenbaum,A., and Weissmann, D., (2016) 'Vulnerable warriors:The atmospheric marketing of military and policing equipment before and after 9/11', Critical Studies on Terrorism 9 (3): 482-498. 
Ferdik, F. V., Kaminski, R. J., Cooney, M. D., and Sevigny, E. L., (2014) 'The influence of agency policies on conducted energy device use and police use of lethal Force', Police Quarterly 17 (4): 328-358.

Fine, B., (2005) 'From actor-network theory to political economy', Capitalism Nature Socialism 16 (4): 91-108.

Frickel, S., (1996) 'Engineering heterogeneous accounts: The case of submarine thermal reactor mark-I' science', Technology Human Values 21 (1): 28-53.

Frickel, S., Gibbon, S., Howard, J., Kempner, J., Ottinger, G., \& Hess, D. J. (2010) ‘Undone science: Charting social movement and civil society challenges to research agenda setting' Science, Technology, \& Human Values, 35 (4): 444-473.

Fridell, L., and Lim, H., (2016) 'Assessing the racial aspects of police force using the implicitand counter-bias perspectives' Journal of Criminal Justice 44: 36-48.

Fuller, S., (2000) 'Why science studies has never been critical of science: Some recent lessons on how to be a helpful nuisance and a harmless radical', Philosophy of the Social Sciences 30 (1): 5-32.

Gau, J. M., Mosher, C., and Pratt, T., (2010) 'An inquiry into the impact of suspect race on police use of Tasers', Police Quarterly 13 (1): 27-48.

Gayle, D., (2015) 'Black People 'Three Times More Likely' to be Tasered. The Guardian, $13^{\text {th }}$ October edition. Available online at https://www.theguardian.com/uk-news/2015/ oct/13/black-people-three-times-more-likely-to-have-taser-usedagainst-them (accessed 03/08/2020).

Gerber, T. P., and Mendelson, S. E., (2008) 'Public experiences of police violence and corruption in contemporary Russia: A case of predatory policing?' Law \& Society Review, 42: $1-44$.

Gilbert, C., (2019) Despite Widespread Use, Police Rate Tasers as Less Effective Than Believed National Public Radio.Available online at https://www.npr.org/2019/06/27/729922975/ despite-widespread-use-police-rate-tasers-as-less-effective-than-believed?t=1592493051 $339 \& \mathrm{t}=1596548625944$ (accessed 04/08/2020).

Gimbel,V. N., and Muhammad, C., (2019) 'Are police obsolete? Breaking cycles of violence through abolition Democracy', Cardozo Law Review 40 (4): 1453-1542.

Glass, D., (2014) Towards Greater Public Confidence: A Personal Review of the Current Police Complaints System for England and Wales IPCC; London Available online at https://www. policeaccountability.org.au/wp-content/uploads/2016/04/A-review-of-the-complaintssystem-by-Deborah-Glass-March-2014.pdf (accessed 11/08/2020).

Goldstein, J., (1960) Police Discretion Not to Invoke the Criminal Process: Low-Visibility Decisions in the Administration of Justice Available online at http://digitalcommons.law.yale.edu/fss_ papers/2426 (accessed 05/08/2020).

Gonzales, L. D., (2013) 'Faculty sensemaking and mission creep: Interrogating institutionalized ways of knowing and doing Legitimacy', The Review of Higher Education 36 (2): 179-209.

Griffin, S. P., and Bernard, T. J., (2003) 'Angry aggression among police officers', Police Quarterly 6 (1): 3-21.

Grimshaw, E., (2018) 'Judah Adunbi breaks silence saying he hopes his ordeal will stop other black men being 'Tasered in face' The Bristol Post Available online at https://www. bristolpost.co.uk/news/bristol-news/judah-adunbi-breaks-silence-saying-1585498 (accessed 04/08/2020).

Grint, K., and Woolgar, S., (1992) 'Computers, guns and roses: What's social about being Shot', Science, Technology, \& Human Values 17 (3): 366-380. 
Grint, K., Holt, C., and Neyroud, P., (2017) 'Cultural change and lodestones in the british police', International Journal of Emergency Services 6 (3): 166-176.

Gross, M., (2010) 'Shock and Ow.' GQ Magazine, July 2010 issue. Available online at http://www.gq.com/story/shock-ow-taser-protector-axon-company-profile (accessed 5/08/2020).

Guilbault, R., (2007) 'Never Bring a TASER to a Gunfight' Police Law Enforcement Solutions $1^{\text {st }}$ June edition. Available online at https://www.policemag.com/339759/never-bring-ataser-to-a-gunfight (03/08/2020).

Haar, R. J., Iacopino,V., Ranadive, N., Dandu, M., and Weiser, S. D., (2017) 'Death, injury and disability from kinetic impact projectiles in crowd-control settings: A systematic review', BMJ Open 7 (12): 1-9.

Haggerty, K. D., and Ericson, R.V., (2000) 'The surveillant assemblage' The British Journal of Sociology 51: 605-622.

Hallsworth, S., and Lea, J., (2011) 'Reconstructing leviathan: Emerging contours of the security state', Theoretical Criminology 15 (2): 141-157.

Haraway, D., (2016) A Cyborg Manifesto University of Minnesota Press; Minnesota.

Herbert, S., (1998) 'Police subculture reconsidered', Criminology 36 (2): 343-370.

Hessbruegge, J., (2016) 'ECtHR Armani Da Silva v UK: Unreasonable police killings in putative self-defence?' European Journal of International Law Blog, April $14^{\text {th }}$ entry. Available online at http://www.ejiltalk.org/author/janhessbruegge/ (accessed 06/08/2020).

Hirschfield, P., and Simon, D., (2010) 'Legitimating police violence: Newspaper narratives of deadly force', Theoretical Criminology 14 (2): 155-182.

HMIC (Her Majesty's Inspectorate of the Constabulary) (2007) Safety Matters: A Review of Officer (Personal) Safety Training. HMIC; London. Available online at https://www. justiceinspectorates.gov.uk/hmic/media/safety-matters-20070330.pdf (accessed 31/07/2020).

HMIC (Her Majesty's Inspectorate of the Constabulary) (2016a) PEEL Police Legitimacy 2015: A National Overview Self-published; London.

HMIC (Her Majesty's Inspectorate of the Constabulary) (2016b) PEEL Police Legitimacy 2015: An Inspection of Humbershire Police Self-published; London.

HMIC (Her Majesty's Inspectorate of the Constabulary) (2016c) PEEL Police Legitimacy 2015: An Inspection of Derbyshire Police Self-published; London.

HMIC (Her Majesty's Inspectorate of the Constabulary) (2021) Disproportionate use of police powers: A spotlight on stop and search and use of force Self-published; London. Available online at https://www.justiceinspectorates.gov.uk/hmicfrs/wp-content/uploads/disproportionateuse-of-police-powers-spotlight-on-stop-search-and-use-of-force.pdf (accessed 10/08/2021).

Ho, J., (2009) 'Can there be truth about TASERs?' Academic Emergency Medicine 16 (8): 771-773.

Ho, J. D., Dawes, D. M., Johnson, M. A., Lundin, E. J., and Miner, J. R., (2007) 'Impact of conducted electrical weapons in a mentally ill population: A brief report', The American Journal of Emergency Medicine 25 (7): 780-785.

Ho, J. D., Dawes, D. M., Miner, J. R., Kunz, S., Nelson, R., and Sweeney, J., (2012) ‘Conducted electrical weapon incapacitation during a goal-directed task as a function of probe spread', Forensic Science Medicine Pathology, 8 (4): 358-366.

Holmberg, L., (2000) 'Discretionary leniency and typological guilt: Results from a Danish study of police Discretion', Journal of Scandinavian Studies in Criminology and Crime Prevention, 1 (2): 179-194.

Home Affairs Select Committee (2013) House of Commons Home Affairs Committee Independent Police Complaints Commission Eleventh Report of Session 2012-13 Self-published; London. 
Home Office (2012) Statistics on Police use of Firearms in England and Wales 2010-11 Available online at https://assets.publishing.service.gov.uk/government/uploads/ system/uploads/attachment_data/file/183401/police-firearms-use-2010-2011.pdf (accessed $12 / 08 / 2020)$

Home Office (2016) CED Replacement Project: Assessment of the Taser X2 Against the Police Operational Requirements Home Office; London. Available online at https://assets. publishing.service.gov.uk/government/uploads/system/uploads/attachment_data/file/ 676911/CAST_Assessment_of_the_Taser_X2_against....pdf (accessed 12/11/2020).

Home Office (2019a) Police use of Force Statistics, England and Wales:April 2018 to March 2019: data tables available online at https://www.gov.uk/government/statistics/police-use-offorce-statistics-england-and-wales-april-2018-to-march-2019 (accessed 08/11/2020).

Home Office (2019b) Police Use of Force Statistics, England and Wales April 2018 to March 2019 Home Office; London. Available online at https://assets.publishing.service. gov.uk/government/uploads/system/uploads/attachment_data/file/853204/policeuse-of-force-apr2018-mar2019-hosb3319.pdf (accessed 08/11/2020).

Home Office (2019c) Home Office Announces £10 Million for Taser Uplift Available online at https://www.gov.uk/government/news/home-office-announces-10-million-for-taseruplift (accessed 06/08/2020).

Home Office (2020) Home Office Overhauls Police Complaints and Discipline Process Available online at https://www.gov.uk/government/news/home-office-overhaulspolice-complaints-and-discipline-process (accessed 06/08/2020).

Hunt, J., (1985) 'Police accounts of normal Force', Urban Life 13 (4): 315-341.

Independent Commission on Policing for Northern Ireland (1999) A New Beginning: Policing in Northern Ireland Available online at https://cain.ulster.ac.uk/issues/police/patten/ patten99.pdf (accessed 03/08/2020).

Indian Express (2020) 'Gujarat Police first in India to introduce taser guns' The Indian Express, 19th March edition Available online at https://www.msn.com/en-in/news/ newsindia/gujarat-police-first-in-india-to-introduce-taser-guns/ar-BB11q0X8 (accessed 03/08/2020).

Ingram, J. R., Terrill, W., and Paoline, E. A., (2018) 'Police culture and officer behavior: Application of a multilevel framework', Criminology 56 (4): 780-811.

Innes, M., Fielding, N., and Cope, N., (2005) 'The appliance of science? The theory and practice of crime Intelligence', The British Journal of Criminology 45 (1):39-57.

INQUEST (2018) Report of the Family Listening Day for the Independent Police Complaints Commission Available online at https://www.inquest.org.uk/Handlers/Download.ashx? IDMF=6df8ac79-3c8a-4fc9-8761-289d1d652558 (accessed 06/08/2020).

INQUEST (2020a) Inquest Finds use of Taser by Devon and Cornwall Police Contributed to Death of Marc Cole When Experiencing Paranoia Available online at https://www.inquest.org.uk/ marc-cole-close (accessed 06/08/2020).

INQUEST (2020b) Deaths in Police Custody Available online at https://www.inquest.org. uk/deaths-in-police-custody (accessed 12/08/2020).

Institute for Security Studies (2016) Tools of Torture? Use of Electric Shock Equipment Among African Police: Policy Brief 85. Self-published, Available online at https://omegaresearch foundation.org/sites/default/files/uploads/Publications/Tools\%20of\%20Torture.pdf (accessed 05/11/2020).

IOPC (Independent Office for Police Conduct) (2018a) Jordan Begley: Independent Investigation Report Available online at https://policeconduct.gov.uk/sites/default/files/ Jordan_Begley_Final_report_0.pdf (accessed 02/11/2020). 
IOPC (Independent Office for Police Conduct) (2018b) Business Plan 2018/2019 Available online at https://www.policeconduct.gov.uk/sites/default/files/Documents/ Who-we-are/accountability-performance/IPCC_business_plan_2018-19.pdf (accessed 06/08/2020).

IOPC (Independent Office for Police Conduct) (2019) 'Testing the law: reasonable or unreasonable use of force' IOPC Podcasts and Blogs Available online at https://www. policeconduct.gov.uk/news/our-podcasts-and-blogs (accessed 20/08/2020).

IOPC (Independent Office for Police Conduct) (undated,1) Becoming the IOPC Available at https://policeconduct.gov.uk/becoming-iopc (accessed 06/08/2020).

IOPC (Independent Office for Police Conduct) (undated, b) Who we are Available at https:// www.policeconduct.gov.uk/who-we-are (accessed 06/08/2020).

IPCC (Independent Police Complaints Commission) (2012) Mr Colin Farmer: Investigation of the Circumstances Surrounding the Use of Taser by a Lancashire Constabulary Officer on $12^{\text {th }}$ October 2012. Self-published, London.

IPCC (Independent Police Complaints Commission) (2013) IPCC Response to the Home Secretary's Proposals on Police Integrity Self-published; London.

IPCC (Independent Police Complaints Commission) (2014a) IPCC Review of Taser Complaints and Incidents $2004-2013$ IPCC; London. Available online at: https://www. policeconduct.gov.uk/sites/default/files/Documents/research-learning/use_of_force_ review_of_taser_complaints_and_incidents.pdf (accessed 10/08/2020).

IPCC (Independent Police Complaints Commission) (2014b) Learning the Lessons: Bulletin 21 - Taser available online at https://www.statewatch.org/media/documents/news/2014/ jul/uk-tasers-ippc.pdf (accessed 10/08/2020).

IPCC (Independent Police Complaints Commission) (2015) Referring Complaints, Conduct Matters and Death or Serious Injury Matters to the IPCC - A Review of Current Police Force Practice Available online at https://www.policeconduct.gov.uk/sites/default/files/ Documents/research-learning/IPCC_referrals_review.pdf (accessed 10/08/2020).

IPCC (Independent Police Complaints Commission) (2016a) Police Use of Force: Evidence from Complaints, Investigations and Public Perception Available online at https://www. policeconduct.gov.uk/sites/default/files/Documents/research-learning/IPCC_Use_Of_ Force_Report.pdf (accessed 10/08/2020).

IPCC (Independent Police Complaints Commission) (2016b) National recommendation ACPO and the College of Policing - April 2016 Available online at https://policeconduct.gov. $\mathrm{uk} /$ recommendations/national-recommendation-acpo-and-college-policing-april-2016 (accessed 10/08/2020).

Jackson, W., (2020) 'Researching the policed: Critical ethnography and the study of protest policing', Policing and Society, 30 (2): 169-185.

Jauchem, J. R., (2010) 'Repeated or long-duration taser ${ }^{\circledR}$ electronic control device exposures:Acidemia and lack of respiration', Forensic Science, Medicine, and Pathology, 6 (1): 46-53.

Jauchem, J. R., (2015) 'TASER ${ }^{\circledR}$ conducted electrical weapons: Misconceptions in the scientific/medical and other literature', Forensic Science, Medicine and Pathology 11 (1): 53-64.

Jefferson, T., (1987) 'Beyond Paramilitarism', British Journal of Criminology 27 (1): 47-53.

Jefferson,T., (1990) The Case Against Paramilitary Policing Open University Press; Milton Keynes. Jenkins, J., (2014) Triennial Review Report: Scientific Advisory Committee on the Medical Implications of Less-Lethal Weapons (SACMILL) Ministry of Defence; Porton Down.

Jenkinson, E., Neeson, C., and Bleetman, A., (2006) 'The relative risk of police use-of-force options: Evaluating the potential for deployment of electronic weaponry' Journal of Clinical Forensic Medicine 13: 229-241. 
Joh, E. E., (2016) 'The new surveillance discretion: Automated suspicion, big data, and policing', Harvard law and policy review 10 (1): 15-42.

Jones, T., (2008) 'Accountability and Governance' in Newburn, T and Neyroud, P (eds) Dictionary of Policing Willan Publishing, Uffculme.

Kaminski, R. J., Engel, R., Rojek, J., Smith, M., and Alpert, J., (2013) 'A quantum of force: The consequences of counting routine conducted energy weapon punctures as injuries', Justice Quarterly 32 (4): 598-625.

Kaplan, D. M., (2009) 'Philosophical Perspectives'. In Kaplan, D. M., (ed), Readings in the Philosophy of Technology, Rowman and Littlefield publishers; Maryland.

Keating-Jones, W., (2017) Red-dotted: A Case Study Analysing How the National Taser Training Standards are Received, Interpreted and Operationalised by Specially Trained Officers; $\mathrm{PhD}$ thesis, University of Portsmouth. Available online at https://ethos.bl.uk/OrderDetails. do?uin=uk.bl.ethos.749255 (accessed 30/07/2020).

Kedir, S. H., (2006) 'Stunning trends in shocking crimes: A comprehensive analysis of taser weapons' Journal of Law and Health 20: 357-384.

Kitossa, T., (2016) 'Making sense of repression in police studies: Whither theorizing in the descent toward fascism' Radical Criminology 6:247-322.

Klahm, C., Frank, J., and Brown, R., (2011) 'Police use of force: Tales from another city', Journal of Crime and Justice 34 (3): 205-220.

Kling, R., (1992) 'When gunfire shatters bone: Reducing sociotechnical systems to social Relationships' science', Technology and Human Values 17 (3): 381-385.

Koslicki, W. M., (2019) 'Accountability or efficiency? Body-worn cameras as replicative technology', Criminal Justice Review 44 (3): 356-368.

Kroll, M.W., and Ho, J. D., (Eds.) (2009) TASER ${ }^{\circledR}$ Conducted Electrical Weapons: Physiology, Pathology, and Law, Springer Science and Business Media; New York.

Kroll, M. W., Adamec, J., Wetli, C.V., and Williams, H. E., (2016) 'Fatal traumatic brain injury with electrical weapon falls' Journal of Forensic and Legal Medicine 43: 12-19.

Kroll, M., Lakkireddy, D., Stone, J., and Luceri, R., (2014) 'Can TASER electronic control devices cause cardiac arrest? TASER electronic control devices and cardiac arrests: Coincidental or causal?, Circulation 129 (1): 93-100.

Kroll, M.W., Brave, M. A., and Pratt, H. M. O., (2019) 'Benefits, risks, and myths of taser ${ }^{\circledR}$ handheld electrical Weapons', Human Factors and Mechanical Engineering for Defence and Safety 3 (7): 1-13.

Kunz, S. N., (2012) 'Biases in TASER research', American Heart Journal 163 (3): 7-8.

Kurki, M., (2017) 'Causality, democracy support and the cult of the factish gods' Journal of International Relations and Development 20:760-781.

Latour, B., (1991) 'Technology is Society Made Durable' in Law, J. (Ed) Sociology of Monsters: Essays on Power, Technology and Domination, Routledge; London, 103-131.

Latour, B., (1992) 'Where Are the Missing Masses?' In Bijker,W. and Law,J. (eds) Shaping Technology/ Building Society: Studies in Sociotechnical Change, MIT Press; Cambridge, MA, 225-258.

Latour, B., (1994) 'On technical mediation' Common knowledge, 3 (2): 29-64.

Latour, B., (2004) 'Why has critique run out of steam? From matters of fact to matters of concern', Critical inquiry 30 (2): 225-248.

Latour, B., (2005) Reassembling The Social, The Social Oxford University Press, Oxford.

Latour, B., (2011) 'Fetish—factish', Material Religion 7 (1): 42-49.

Law,J., (1987) 'Technology, Closure and Heterogeneous Engineering: the Case of the Portuguese expansion'. In Bijker,W.E., Hughes,T. and Pinch, P., (eds), The Social Construction of Technological Systems, New Directions in the Sociology and History of Technology, MIT Press; Cambridge, Mass. 
Law, J., (1992) 'Notes on the theory of the actor-network: Ordering, strategy, and heterogeneity’, Systems Practice 5 (4): 379-393.

Law, J., (1999) 'After ANT: Complexity, naming and topology', The Sociological Review 47 (1): $1-14$.

Law, J., (2009) The Materials of STS, version of 9th April 2009 Available at http://www. heterogeneities.net/publications/Law2008MaterialsofSTS.pdf (accessed 02/11/2020).

Law, J., (2011) Heterogeneous Engineering and Tinkering Available online at http://www. heterogeneities.net/publications/Law2011HeterogeneousEngineeringAndTinkering.pdf (accessed 09/08/2020).

Lawson, E., (2019) 'Trends: Police militarization and the use of lethal Force', Political Research Quarterly 72 (1): 177-189

Lee, N. (1999) 'The challenge of childhood: distributions of childhood's ambiguity in adult institutions' Childhood, 6 (4): 455-474.

Lee, J., Zhang,Y., and Hoover, L. T., (2013) 'Police response to domestic violence: Multilevel factors of arrest decision', Policing: An International Journal of Police Strategies and Management 36 (1): 157-174.

Lee, N., and Brown, S., (1994) 'Otherness and the actor-network: The undiscovered continent', American Behavioural Scientist 37 (6): 772-790.

Lim, E., and Seet, R., (2009) 'Taser usage and neurological Sequelae', Journal of Emergency Medicine 37 (2): 170-171.

Lin,Y., and Jones, J., (2010) 'Electronic control devices and use of force outcomes: Incidence and severity of use of force, and frequency of injuries to arrestees and police officers', Policing: An International Journal of Police Strategies and Management 33 (1): 152-178.

Lipsky, M., 2010. Street level bureaucracy: dilemmas of the individual in public services. 30th anniversary edition. Russell Sage Foundation, New York.

Lockwood, M., (2019) Operation Midland made mistakes, but the presumption of innocence must prevail The Guardian, 8th October edition. Available online at https://www. theguardian.com/commentisfree/2019/oct/08/mistakes-operation-midland-iopcinvestigation-carl-beech (accessed 06/08/2020).

London Assembly Police and Crime Committee (2013) Taser Working Group - 16 May 2013 Transcript of Item 6: Governance of Taser Available online at https://www.london.gov.uk/ moderngov/documents/s25924/Taser\%20Minutes\%20-\%20Appendix\%201\%20-\%20 Transcript.pdf (accessed 09/08/2020).

MacDonald, J., Kaminski, R. J., and Smith, M., (2009) 'The effect of less-lethal weapons on injuries in police use-of-force Events', American Journal of Public Health 99 (12): 2268-2274.

MacKenzie, D., and Wajcman, J., (1999) 'Introductory Essay: The Social Shaping of Technology' in MacKenzie, D and Wajcman, J (eds) The Social Shaping of Technology, Open University Press, Buckingham pp. 3-27.

Manchester Coroners Court (2016) Record of Inquest: Inquest into the Death of Jordan Lee Begley. Author's personal copy; available on request from Manchester Coroners Court.

Manning, P. K., (2008) The Technology of Policing — crime Mapping, Information Technology, and the Rationality of Crime Control, New York: New York University Press.

March Group (undated a) Non-Lethal Weapons and Security Equipment self-published.Available online at https://russian-shockers.com/uploads/documents/reclame/catalog_eng.pdf (accessed 08/11/2020).

March Group (undated b) $A I R$ «M-140» (manuf. P) Available online at https://russianshockers.com/products/power/air-m-140-p.html (accessed 18/11/2020). 
Marenin, O., (1982) 'Parking tickets and class repression - the concept of policing in critical theories of criminal justice', Contemporary Crises 6 (3): 241-266.

Marker, J., and Daigle, E., (2016) Why the United Kingdom's 'National Decision Making Model' For Force is Not a Viable Option Daigle Law Group; United States of America. Available online at https://daiglelawgroup.com/wp-content/uploads/2016/10/UKs-NationalDecision-Model-is-not-a-viable-option.pdf (accessed 06/08/2020).

Marketwatch (2021) Non-lethal weapons Market Analysis, Revenue, Share, Growth Rate \& Forecast To 2027 Available online at https://www.marketwatch.com/press-release/nonlethal-weapons-market-analysis-revenue-share-growth-rate-forecast-to-2027-202106-14 (accessed 10/08/2020).

Markham, G., and Punch, M., (2007) 'Embracing accountability: The way forward-Part one', Policing: A Journal of Policy and Practice 1 (3): 300-308.

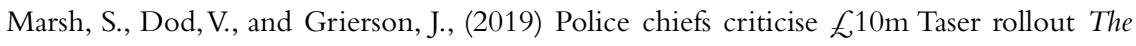
Guardian, 27th September edition. Available online at https://www.theguardian.com/ uk-news/2019/sep/27/police-in-england-and-wales-to-be-given-more-tasers-in-10mrollout (accessed 05/11/2020).

McCann and Others Vs the United Kingdom (1995) European Court of Human Rights, Application Number 18984/91.

McLean, K., Wolfe, S. E., Rojek, J., Alpert, G. P., and Smith, M. R., (2019) 'Police officers as warriors or guardians: Empirical reality or intriguing rhetoric?', Justice Quarterly 37 (6): 1096-1118.

McMichael, M., (2017) 'Pacification and police:A critique of the police militarization thesis', Capital and Class 41 (1): 115-132.

Meade, B., Steiner, B., and Klahm, C., (2015) 'The effect of police use of force on mental health problems of prisoners', Policing and Society: An International Journal of Research and Policy 27 (2): 229-244.

Mesloh, C., Wolf, R., Henych, M., and Thompson, F. L., (2008) Less Lethal Weapons for Law Enforcement: A Performance-Based Analysis Law Enforcement Executive Forum; Western Illinois University. Available online at https://iletsbeiforumjournal.com/images/Issues/ FreeIssues/ILEEF\%202008-8.1.pdf\#page=140 (accessed 03/08/2020).

Meyer, J.W., and Rowan, B., (1977) 'Institutionalized organizations: Formal structure as myth and Ceremony' American Journal of Sociology, 83: 340-363.

Michael, M., (2017) Actor-Network Theory: Trials, Trails and Translations, Sage; Los Angeles.

Mitrani, S., (2014) 'Stop Kidding Yourself: The Police Were Created to Control Working Class and Poor People' Labour Online, 29th December edition. Available online at https:// www.lawcha.org/2014/12/29/stop-kidding-police-created-control-working-classpoor-people/ (accessed 10/08/2020).

Mol, A., (2002) The Body Multiple: Ontology in Medical Practice, Duke University Press; Duhram.

Mol, A., (2010) 'Actor-network theory: Sensitive terms and enduring Tensions', Kölner Zeitschrift für Soziologie und Sozialpsychologie 50 (1): 253-269.

Moreau de Bellaing, C., (2015) 'Can Electricity Soothe the Savage Beast? What Tasers Do to the Police Use of Force'. In Robert, D. and Dufresne, M., (eds), Actor Network Theory and Crime Studies: Explorations in Science and Technology, Ashgate; Surrey.

Morris, S., (2020) “"Horrendous sound": family of man who died after Tasering demand answers'The Guardian 28th January edition. Available online at https://www.theguardian. com/world/2020/jan/28/horrendous-sound-family-of-man-who-died-after-taseringdemand-answers (accessed 27/07/2020). 
Mungai, P. W., and Van Belle, J. P., (2018) 'Understanding the Kenya open data initiative trajectory based on Callon's moments of translation', The African Journal of Information Systems 10 (4): 339-348.

Mutsaers, P., (2019) Police Unlimited: Policing, Migrants, and the Values of Bureaucracy, Oxford University Press; Oxford.

National Audit Office (2008) The Independent Police Complaints Commission: Report by the Comptroller and Auditor General Self-published London.

National Institute of Justice (2009) Comparing Safety Outcomes in Police Use-of-Force Cases for Law Enforcement Agencies That Have Deployed Conducted Energy Devices and a Matched Comparison Group That Have Not: A Quasi-Experimental Evaluation, US Department of Justice: Washington.

National Institute of Justice (2011) Research in Brief: Police Use of Force, Tasers and Other LessLethal Weapons, US Department of Justice: Washington.

Neuscheler, J., and Friedlin, A., (2015) Report on Electronic Control Weapons (ECWs) Submitted to the City of Berkeley, Stanford: Stanford Criminal Justice Center.

New York Times (2016) 'Saving Lives With Tasers: Police Commissioner Bratton's View' New York Times, New York. Available online at https://www.nytimes.com/ 2016/08/09/opinion/saving-lives-with-tasers-police-commissioner-brattons-view.html (accessed 09/09/2020).

New Zealand Police (2008) Operational Evaluation of the New Zealand Taser Trial A report prepared by Police Operations Group and the Evaluation Team at Police National Headquarters Available online at https://www.police.govt.nz/resources/2008/operationalevaluation-of-nz-taser-trial/operational-evaluation-of-nz-taser-trial-2008.pdf (accessed 05/08/2020)

New Zealand Police (2018) Police Tactical Options Research Report: Report 7: 1 January to 31 December 2018. New Zealand Police; Auckland.

New Zealand Police (undated, a) TASER (Electronic Control Devices): version 9.0 Available online at https://fyi.org.nz/request/5014/response/16479/attach/6/TASER.pdf (accessed 03/08/2020).

New Zealand Police (undated, b) Tactical Options Framework Available online at https://fyi. org.nz/request/5014/response/16479/attach/5/Tactical\%20Options\%20Framework.pdf (accessed 05/08/2020).

Neyroud, P., (2014) 'policing 'Facts' and policing evidence: system 1 and system 2', Policing: $A$ Journal of Policy and Practice 8 (2): 93-95.

Neyroud, P., and Disley, E., (2008) 'Technology and policing: Implications for fairness and Legitimacy', Policing: A Journal of Policy and Practice 2 (2): 226-232.

Nix, J., Campbell, B. A., Byers, E. H., and Alpert, G. P., (2017) 'A Bird's eye view of civilians killed by police in 2015', Criminology and Public Policy 16 (1): 309-340.

Nordin, L. L., Jourdan, D., and Simovska,V., (2019) '(re)framing school as A setting for promoting health and well-being: A double translation process', Critical Public Health 29 (3): 325-336.

Norrie, A., (2010) 'The problem of mistaken self-defense: Citizenship, chiasmus, and legal Form', New Criminal Law Review: An International and Interdisciplinary Journal 13 (2): 357-378.

NPCC (National Police Chief's Council) (2015) NPCC Less-Lethal Weapons Lead Requests Independent Review of Taser Safety Advice, NPCC;London. Available online at http://news. npcc.police.uk/releases/npcc-less-lethal-weapons-lead-requests-independent-review-oftaser-safety-advice (accessed 06/08/2020). 
NPCC (National Police Chiefs Council) (2020) Frequently Asked Questions about TASER Available online https://www.npcc.police.uk/ThePoliceChiefsBlog/NPCC QuestionsandAnswersonTaser.aspx (accessed 04/08/2020).

NPCC (National Police Chiefs Council) and College of Policing (2020) Disproportionality in Police Use of Taser: Independent Panel Chair Announced. Available online at https:// news.npcc.police.uk/releases/disproportionality-in-police-use-of-taser-independentpanel-chair-announced (accessed 04/01/2021).

O'Brien, B., (2009) 'Prime suspect: An examination of factors that aggravate and counteract confirmation bias in criminal investigations', Psychology, Public Policy, and Law 15 (4): $315-334$.

O'Neill, M., and Loftus, B., (2013) 'Policing and the surveillance of the marginal: Everyday contexts of social control', Theoretical Criminology 17 (4): 437-454.

O'Brien, A., and Thom, K., (2014) 'Police use of TASER devices in mental health emergencies: A review', International Journal of Law and Psychiatry 37 (4): 420-426.

O'Brien, A., McKenna, B., Thom, K., Diesfeld, K., and Simpson, A., (2011) 'Use of Tasers on people with mental illness: A New Zealand database study', International Journal of Law and Psychiatry 34 (1): 39-43.

Office of the Police and Crime Commissioner, Devon and Cornwall (2020) Police Complaints and Conduct Reform Available online at https://www.devonandcornwall-pcc.gov.uk/ about-us/complaints/police-complaints-reform/ (accessed 06/08/2020).

Oliver, W. R. (2011) 'The effect of threat of litigation on forensic pathologist diagnostic decision making' The American Journal of Forensic Medicine and Pathology 32 (4), 383-386.

Ombudsman of New South Wales (2012) How are Taser weapons used by the NSW Police Force? A Special Report to Parliament under s. 31 of the Ombudsman Act 1974. Available online at https://webarchive.nla.gov.au/awa/20121022224003/http://pandora.nla.gov. au/pan/136902/20121024-0923/www.ombo.nsw.gov.au/_data/assets/pdf_file/0004/ 6970/SR_Taser_Report_Oct2012_web.pdf (accessed 09/11/2020).

Omega Research Foundation (2020) Coronavirus: Mapping Cases of Excessive Use of Force by Law Enforcement. Available online at https://omegaresearchfoundation.org/covid.php (accessed 27/07/2020).

Oram, A. M., Feagin, J. R., and Sjoberg, G., (1991) 'The Nature of the Case Study' in Feagin, J. R., Orum, A. M., and Sjoberg, G. (Eds.) A Case for the Case Study, UNC Press Books; NC.

O'Reilly, C., (2010) 'The transnational security consultancy industry: A case of statecorporate symbiosis', Theoretical Criminology 14 (2): 183-210.

Oriola, T., Neverson, N., and Adeyanju, C., (2012) 'They should have just taken a gun and shot my son': Taser deployment and the downtrodden in Canada', Social Identities: Journal for the Study of Race, Nation and Culture 18 (1): 65-83.

Ouellet, M., Hashimi, S., Gravel, J., and Papachristos, A. V., (2019) 'Network exposure and excessive use of force: Investigating the social transmission of police misconduct' Criminology and Public Policy 18: 675- 704.

PALG (Police Action Lawyer's Group) (2014) The Impact of the Jackson Reforms on Costs and Case Management Response by Police Actions Lawyers' Group to Consultation by Civil Justice Council March 2014, Self-published; London. Available online at https://www. judiciary.gov.uk/wp-content/uploads/JCO/Documents/CJC/Publications/consultation+ responses/Police+Actions+Lawyers+Group.pdf (accessed 06/08/2020).

Pandian, J (2020) 'Taser trauma: an increasingly British phenomenon' Institute of Race Relations; London. Available online at https://irr.org.uk/article/taser-trauma-anincreasingly-british-phenomenon/ (accessed 04/01/2021). 
Paoline, E., and Terrill, W., (2011) 'Listen to me. Police officers' views of appropriate use of force', Journal of Crime and Justice 34 (3): 178-189.

Paoline, E., (2004) 'Shedding light on police culture: An examination of Officer's occupational Attitudes', Police Quarterly 7 (2): 205-236.

Paoline, E., Terrill, W., and Ingram, J., (2012) 'Police use of force and officer injuries: Comparing conducted energy devices (CEDs) to hands- and weapon-based Tactics', Police Quarterly, 15 (2): 115-136.

Paoline, E. A., and Terrill, W., (2007) 'Police education experience and the use of force', Criminal Justice and Behaviour 34 (2): 179-196.

Pels, D., (1996) 'The politics of Symmetry' Social Studies of Science 26: 277-304.

Penn State University (2001) First Assessment of Less-Than-Lethal Munitions Finds Accuracy Lacking Available online at https://www.psu.edu/ur/2001/lessthanlethal.html (accessed 09/08/2020).

Pepinsky, H., (1984) 'Better living through police discretion', Law and Contemporary Problems 47 (4): 249-267.

PERF (Police Executive Research Forum) (2009) Comparing safety outcomes in police use-of-force cases for law enforcement agencies that have deployed Conducted Energy Devices and a matched comparison group that have not: A quasi-experimental evaluation. Available online at http://www. policeforum.org/assets/docs/Free_Online_Documents/Use_of_Force/conducted $\% 20$ energy\%20devices\%20matched\%20agency\%20study\%202009.pdf (accessed 09/08/2020).

Petrocelli, M., Piquero, A. R., and Smith, M. R., (2003) 'Conflict theory and racial profiling: An empirical analysis of police traffic stop data' Journal of Criminal Justice 31: 1-11.

Pickering,A., (2005) 'Asian Eels and global warming: A post-humanist perspective on society and the Environment', Ethics and the Environment 10 (2): 29-43.

Pinch, T., and Bijker, W., (1984) 'The social construction of facts and artefacts: Or how the sociology of science and the sociology of technology might benefit each Other', Social Studies of Science 14 (3): 399-441.

Police and Criminal Evidence Act, 1984, Chapter 60. Available online at http://www. legislation.gov.uk/ukpga/1984/60

Police Ombudsman for Northern Ireland (2014) Man Says He Might Have Died if Police Had Not Used Taser Available online at https://www.policeombudsman.org/InvestigationReports/Man-says-he-might-have-died-if-police-had-not-used (accessed 04/08/2020).

Police Scientific Development Branch (2001) Less Lethal Technologies Initial Prioritisation and Evaluation, Publication No 12/01. Home Office, St Albans.

Policing Law Info (2019a) Serbia Available online at https://www.policinglaw.info/country/ serbia (accessed 05/08/2020).

Policing Law Info (2019b) Ukraine Available online at https://www.policinglaw.info/ country/ukraine (accessed 05/08/2020).

Policing Law Info (2019c) South Korea Available online at https://www.policinglaw.info/ country?search=south+korea (accessed 05/08/2020).

Policing Law Info (2019d) Nigeria Available online at https://www.policinglaw.info/ country/nigeria (accessed 05/08/2020).

Powell, M., Hughes-Scholes, C., and Sharman, S., (2012) 'Skill in interviewing reduces confirmation Bias', Journal of Investigative Psychology and Offender Profiling 9 (2): 126-113.

Prenzler, T., Porter, L., and Alpert, G., (2013) 'Reducing police use of force: Case studies and prospects', Aggression and Violent Behaviour 18 (2): 343-356.

PricewaterhouseCoopers (2004) Association of Chief Police Officers: Independent Evaluation of the Operational Trial of Taser PricewaterhouseCoopers; London, UK. 
PSNI (Police Service of Northern Ireland) (2008) Police Service of Northern Ireland Guidelines on the Operational Use of Taser SP6/08 Available online at http://www.psni.police.uk/ service_procedure_0608.pdf (accessed 05/08/2020).

Quinton, P., and Packham, D., (2016) College of Policing Stop and Search Training Experiment. College of Policing; London.

Quinton, P., Dymond, A., Boyd, K., and Teers, R., (2020) Police Use of Force:Tactics, Assaults and Safety. College of Policing; London. Available online at: https://whatworks.college.police. uk/Research/Documents/Use_of_force_report.pdf (accessed 13/10/2020).

$R$ (W80) v. Director General of the Independent Office for Police Conduct (2020) Court of Appeal, Civil Division, EWCA Civ 1301. Available online at https://www.judiciary.uk/ judgments/rw80-v-director-general-of-the-independent-office-for-police-conduct/ (accessed 05/11/2020).

Rajakaruna, N., Henry, P. J., Cutler, A., and Fairman, G., (2017) 'Ensuring the validity of police use of force training', Police Practice and Research 18 (5): 507-521.

Rappert, B., (2003) 'Technologies, texts and possibilities: A reply to Hutchby', Sociology 37 (3): 565-580.

Rappert, B., (2004) 'Moralizing violence: Debating the acceptability of electrical weapons', Science as Culture 13 (1): 3-35.

Rappert, B., (2007a) 'Continuing the discussion on use of Force', Policing: A Journal of Policy and Practice 1 (4): 472-484.

Rappert, B., (2007b) 'On the mid range: An exercise in disposing (or minding the gaps)', Science, Technology, and Human Values 32 (6): 693-712.

Rappert, B., Moyes, R., and Other, A. N., (2011) 'Statecrafting Ignorance: Strategies for Managing Burdens, Secrecy, and Conflict' In: Maret, S. (ed.), Government Secrecy Research in Social Problems and Public Policy. Emerald; London, 301-324.

Ray, J., (2020) 'Rapper Wretch 32 and his father speak out about 'police brutality' after taser incident' ITV News, $9^{\text {th }}$ June edition. Available online at https://www.itv.com/ news/2020-06-09/rapper-wretch-32-and-his-father-speak-out-about-police-brutalityafter-taser-incident (accessed 04/08/2020).

Regina $v$ Williams (Gladstone) (1983) CACD $28^{\text {th }}$ November

Reid,T., and Seligson, P., (2017) Taser's defense tactics include lawsuits against coroners and experts Reuters Available online at https://www.reuters.com/article/us-usa-taser-strikeback/ tasers-defense-tactics-include-lawsuits-against-coroners-and-experts-idUSKCN1B4182 (accessed 06/08/2020).

Reiner, R., (2010) The Politics of the Police. Oxford University Press, Oxford.

Reiner, R., (2012) 'Policing and social democracy: Resuscitating a lost perspective', Journal of Police Studies 25 (4): 97-114.

Rejali, D., (2009) Torture and Democracy, Princetown University Press; Princetown.

Resistance Lab (2020) A Growing Threat to Life: Taser Usage by Greater Manchester Police, Manchester, UK. Available online at resistancelab.network/taser-report (accessed 13/10/2020).

Reuters Investigates (2017) Shock Tactics Available online at https://www.reuters.com/ investigates/special-report/usa-taser-database/ (accessed 03/08/2020)

Rittel, H.W. J., and Webber, M. M., (1973) 'Dilemmas in a general theory of planning', Policy Sciences 4 (2): 155-169.

Robert, D., and Dufresne, M., (2015) 'Introduction:Thinking Through Networks, Reaching for Objects and Witnessing Facticity' in Robert, D., and Dufresne, M., Actor Network Theory and Crime Studies: Explorations in Science and Technology Ashgate; Surrey, 1-4. 
Roelvink, G., (2010) 'Collective action and the politics of affect', Emotion, Space and Society 3 (2): 111-118.

Rojek, J., Alpert, G., and Smith, H., (2012) 'Examining officer and citizen accounts of police use-of-force Incidents', Crime and Delinquency 58 (2): 301-327.

Root, C., et al., (2013) 'Brutal serendipity: Criminological verstehen and victimization', Critical Criminology, 21 (2): 141-155.

Rowe, M., (2007) 'Rendering visible the invisible: Police discretion, professionalism and decision-making', Policing and Society: An International Journal of Research and Policy 17 (3): 279-294.

Royds Withy King., (2015) Inquest jury concludes police taser is most likely cause of death of Andrew Pimlott: A press release by Royds Withy King on a case supported by INQUEST. Dated $2^{\text {nd }}$ October, Available online at https://www.inquest.org.uk/inquest-jury-concludes-policetaser-is-most-likely-cause-of-death-of-andrew-pimlott (accessed 03/08/2020).

Ruggie, J., (2010) The UN 'Protect, Respect and Remedy' Framework for Business and Human Rights Available online at https://www.business-humanrights.org/sites/default/files/reports-andmaterials/Ruggie-protect-respect-remedy-framework.pdf (accessed 06/08/2020).

Ryan, E., (2008) 'Shocked and stunned: A consideration of the implications of tasers in Australia', Current Issues in Criminal Justice 20 (2): 293-302.

Savoie, P., Dufresne, M., and Robert, D., (2019) 'Toward a slow criminology of sociotechnical orderings: A tale of many youth repellents', Theoretical Criminology 23 (1): 78-95.

Scarry, E., (1985) The Body in Pain:The Making and Unmaking of the World, Oxford University Press; Oxford.

Scientific Advisory Committee on the Medical Implications of Less-Lethal Weapons (SACMILL) (2016) Scientific Advisory Committee on the Medical Implications of Less-Lethal Weapons (SACMILL) Statement on the Medical Implications of Use of the TASER X2 Conducted Energy Device System Available online at https://assets.publishing.service.gov.uk/ government/uploads/system/uploads/attachment_data/file/595242/Medical_Statement_ on_the_TASER_X2_system.pdf

Seale, C., (1999) 'Quality in qualitative Research', Qualitative Inquiry 5 (4): 465-478.

Shantz, J., (2016) 'They have always been military: On so-called militarized policing in Canada'. Journal of Social Justice, 6: 1-26.

Shearing, C., (2005) 'Nodal Security', Police Quarterly 8 (1): 57-63.

Shearing, C., and Ericson, R., (1991) 'Culture as figurative Action', The British Journal of Sociology 42 (4): 481-506.

Shearing, C., and Johnston, L., (2010) 'Nodal wars and network fallacies: A genealogical analysis of global insecurities', Theoretical Criminology, 14 (4): 495-514

Sheptycki, J., (2002) 'Accountability across the policing field: Towards a general cartography of accountability for post-modern policing', Policing and Society 12 (4): 323-338.

Sheridan, R., (2014) 'Letter by Sheridan regarding articles, 'TASER electronic control devices can cause cardiac arrest in Humans' and 'TASER electronic control devices and cardiac arrests: Coincidental or causal?, Circulation 130 (19): 167.

Sherman, L. W., (1980) 'The police and violence', The Annals of the American Academy of Political and Social Science 452: 1-12.

Sierra-Arévalo, M., (2019) 'Technological innovation and police officers' understanding and use of force', Law and Society Review 53: 420-451.

Silver, J. R., Roche, S. P., Bilach, T. J., and Bontrager, R., (2017) 'Traditional police culture, use of force, and procedural justice: Investigating individual, organizational, and contextual factors', Justice Quarterly 34 (7): 1272-1309. 
Skinner, S., (2014) 'Deference, proportionality and the margin of appreciation in lethal force case law under article 2 ECHR' European Human Rights Law Review (1):32-38.

Smith, M., Kaminiski, R., Rojek, J., Alpert, G., and Mathis, J., (2007) 'The impact of conducted energy devices and other types of force and resistance on officer and suspect injuries', Policing: An International Journal of Police Strategies and Management 30 (3): 423-446.

Smith, M., Kaminski, R. J., Alpert, G., Fridell, L., MacDonald, J., and Kubu, B., (2010) A Multi-Method Evaluation of Police Use of Force Outcomes: Final Report to the National Institute of Justice, National Institute of Justice; Washington.

Smith, R., (2019) The End of Killing Page Two Books; Kindle Edition.

Smith, R. J., (2015). 'Reducing racially disparate policing outcomes: Is implicit bias training the Answer'. University of Hawai'i. Law Review 37: 295-312.

Somers, L. J., Terrill, W., Rossler, M. T., and Ingram, J. R., (2020) 'Examining the effectiveness of TASERS ${ }^{\circ}$ at gaining citizen Compliance', Criminal Justice Policy Review 31 (8): $1234-1255$.

Sousa, W., Ready, J., and Ault, M., (2010) 'The impact of TASERs on police use-of-force decisions: Findings from a randomized field-training experiment', Journal of Experimental Criminology 6 (1): 35-55.

Southworth, P., (2020) 'Rights groups quit police taser body over their use on BAME groups' The Telegraph 27th April edition. Available online at https://www.telegraph. co.uk/news/2020/04/17/rights-groups-quit-police-taser-body-use-bame-groups/ (accessed 13/10/2020).

Spriggs, M., (2009) 'Don't tase me bro.' An argument for clear and effective taser regulation' Ohio State Law Journal 70: 487-518.

Spyridonidis, D., Currie, G., Heusinkveld, S., Strauss, K., and Sturdy, A., (2014) ‘New developments in translation research', International Journal of Management Reviews 16 (2): 245-248.

Squires, P., and Kennison, P., (2010) Shooting to Kill? Policing Firearms and Armed Response, Wiley-Blackwell; Chichester, England.

Stanbrook, M. B., (2008) 'Tasers in medicine: An irreverent call for proposals', Canadian Medical Association Journal 178 (11): 1401-1402.

Stand up to Racism (2020) After the death of George Floyd: Black Lives Matter. Racism, COVID19 and police brutality livestream Available online at https://www.facebook.com/watch/live $/$ ?v=930940200681326\&ref=watch_permalink (accessed 04/08/2020).

Start Up Grind (2015) Rick Smith (Taser) - The CEO Journey: Lessons Learned Available online at https://www.npr.org/2019/06/27/729922975/despite-widespread-use-police-ratetasers-as-less-effective-than-believed?t=1592493051339 (accessed 11/08/2020).

Stevenson, R., and Drummond-Smith, I., (2020) 'Medical implications of conducted energy devices in law enforcement' Journal of Forensic and Legal Medicine 73: 1-10.

Stewart v. United Kingdom, Decision on the admissibility of the E. Comm. H.R. 10 July 1984.

Stoke on Trent and North Staffordshire Coroners Court (2018) Record of Inquest: Adrian Nashon McDonald. Author's copy, available on request from the Coroners Court.

Stopwatch (2016) Policy Briefing: The Use of Tasers in London. Stopwatch, London. Available online at https://www.stop-watch.org/uploads/documents/Briefing.Tasers.pdf (accessed 14/10/2020).

Stroshine, M. S., and Brandl, S. G., (2019) 'The use, effectiveness, and hazards associated with police use of force: The unique case of weaponless physical force', Police Practice and Research 21 (6): 591-608.

Sussman, A., (2012) 'Shocking the conscience: What police tasers and weapon technology reveal about excessive force Law' UCLA Law Review 59: 1344-1414. 
Tangye, H., (2016) Taser - A Tool of Pacifists Available online at https://dcarvsgt.wordpress. com/2016/04/14/taser-a-tool-of-pacifists/ (accessed 12/08/2020).

TASER International (2010) TASER ${ }^{\circledR} X 3^{\mathrm{TM}}, X 26^{\mathrm{TM}}$, and $M 26^{\mathrm{TM}}$ ECD Warnings, Instructions, and Information: Law Enforcement available online at https://fingfx. thomsonreuters.com/gfx/rngs/USA-TASER/0100503907S/images/warnings-2010.pdf (accessed 05/08/2021).

TASER International (2013) United States Securities and Exchange Commission Form 8-K. Current report Pursuant to Section 13 or 15(d) of The Securities Exchange Act of 1934. TASER International, Inc 001-16391; Washington, DC.

TASER International (2016) TASER International, Inc: Trademark policy and Use Guidelines. Available online at https://axon.cdn.prismic.io/axon\%2Fd3a98564-98d0-44c7-85af7aaf3a29eff9_trademark+policy+and+use+guidelines.pdf (accessed 03/11/2020).

Taslitz, A., (2010) 'police are people too: Cognitive obstacles to, and opportunities for, police getting the individualized suspicion judgment Right', Ohio State Journal of Criminal Law 8 (7): 7-71.

Taylor, B., and Woods, D., (2010) 'Injuries to officers and suspects in police use-of-force cases: A quasi-experimental Evaluation', Police Quarterly 13 (3): 260-289.

Terpestra, J. B., (2011) 'Two theories on the police. The relevance of max weber and emile durkheim to the study of the police', International Journal of Law, Crime and Justice 39 (1): $1-11$.

Terrill,W., (2014) 'Police Coercion' in Reisig, M.D and Kane, R.J. (eds) The Oxford Handbook of Police and Policing, Oxford University Press; Oxford, 260-279.

Terrill, W., and Mastrofski, S. D., (2002) 'Situational and officer-based determinants of police coercion', Justice Quarterly 19 (2): 215-248.

Terrill, W., and Paoline, E. A., (2012) 'Conducted energy devices and citizen injuries: The shocking empirical reality', Justice Quarterly 29 (2): 153-182.

Terrill, W., and Paoline, E. A., (2013) 'Less lethal force policy and the force continuum: Results from a national use-of-force Study', Police Quarterly 16 (1): 38-65.

Terrill,W., and Paoline, E.A., (2017) 'Police use of less lethal force: Does administrative policy matter?', Justice Quarterly 34 (2): 193-216.

Terrill, W., Paoline, E. A., and Manning, K., (2003) 'Police culture and coercion', Criminology 41 (4): 1003-1034.

The Independent (2009) Jack Cover: Inventor of the Taser stun gun $2^{\text {nd }}$ March edition, Available online at https://www.independent.co.uk/news/obituaries/jack-cover-inventor-of-thetaser-stun-gun-1635270.html (accessed 03/08/2020)

The Police Foundation (2009) The Briefing: Tasers. Self-published Available online at https:// www.police-foundation.org.uk/2017/wp-content/uploads/2017/08/tasers_briefing.pdf

The Santiago Times (2019) 'Argentina's security forces allowed to use electric tasers' The Santiago Times, May 8th Available online at https://santiagotimes.cl/2019/05/08/argentinassecurity-forces-allowed-to-use-electric-tasers/ (accessed 05/08/2020).

The Telegraph (2013) 'No action against police officer who mistakenly Tasered blind man' $30^{\text {th }}$ August online edition Available online at http://www.telegraph.co.uk/news/ uknews/law-and-order/10275892/No-action-against-police-officer-who-mistakenlyTasered-blind-man.html (accessed 06/08/2020).

Thomas, J., (2013) 'Two Merseyside police officers sacked for Tasering innocent man' Liverpool Echo, 22nd October edition. Available online at https://www.liverpoolecho. co.uk/news/liverpool-news/two-merseyside-police-officers-sacked-6221131 (accessed 10/08/2020). 
Thomas, K., Collins, P., and Lovrich, N., (2010) 'Conducted energy device use in municipal policing: Results of a national survey on policy and effectiveness Assessments', Police Quarterly 13 (3): 290-315.

Truth Not TASERs (2008) Submission to the House of Commons Committee On Public Safety and National Security. Available online at http://truthnottasers.blogspot.com/2008/05/ my-submission-to-house-of-commons.html (accessed 10/08/2020).

UK Steering Group (2006) Patten report recommendations 69 and 70 relating to public order equipment Available online at http://library.college.police.uk/docs/nio/less-lethal-weaponrysteering-group-phase-5-report-2006.pdf (accessed 03/08/2020).

Office of the United Nations High Commissioner for Human Rights and United Nations Office on Drugs and Crime (2017) Resource book on the use of force and firearms United Nations, New York.

United Nations (1984) Convention Against Torture and Other Cruel, Inhuman or Degrading Treatment or Punishment, United Nations; Geneva.

United Nations (1990) Basic Principles on the Use of Force and Firearms: Adopted by the Eighth United Nations Congress on the Prevention of Crime and the Treatment of Offenders, Havana, Cuba, 27 August to 7 September 1990. United Nations; Geneva.

United Nations Committee Against Torture (2008) Conclusions and Recommendations of the Committee Against Torture on Portugal; Thirty-Ninth Session, 19 February 2008, United Nations; Geneva.

United Nations Committee Against Torture (2013) Concluding Observations on the Fifth Periodic Report of the United Kingdom, Adopted by the Committee at its Fiftieth Session (6-31 May 2013). United Nations; Geneva.

United Nations Committee Against Torture (2017) Committee Against Torture Concluding Observations on the Combined Third to Fifth Periodic Reports of the Republic of Korea May 2017 CAT/C/KOR/CO/3-5, United Nations; Geneva.

United Nations Human Rights Office of the High Commissioner (2020a) United Nations Human Rights Guidance on Less Lethal Weapons in Law Enforcement Available online at https://www. ohchr.org/Documents/HRBodies/CCPR/LLW_Guidance.pdf (accessed 27/07/2020).

United Nations Human Rights Office of the High Commissioner (2020b) COVID19 Security Measures no Excuse for Excessive Use of Force, say UN Special Rapporteurs. Available online at https://www.ohchr.org/EN/NewsEvents/Pages/DisplayNews.aspx? NewsID=25802\&LangID=E (accessed 27/07/2020).

United Nations Human Rights Office of the High Commissioner (2020c) United States: UN experts Condemn Crackdown on Peaceful Protests and Highlight Calls to Overhaul Policing Available online at https://www.ohchr.org/EN/NewsEvents/Pages/DisplayNews.aspx? NewsID=25948\&LangID=E (accessed 27/07/2020).

United Nations Special Rapporteur on Torture and Other Cruel, Inhuman or Degrading Treatment or Punishment (2017) Report of the Special Rapporteur on torture and other cruel, inhuman or degrading treatment or punishment Human Rights Council Thirty-fourth session 27 February-24 March 2017.

Vilke, G. M., Sloane, C. M., and Chan, T., (2012) 'Funding source and author affiliation in TASER research are strongly associated with a conclusion of device safety', American Heart Journal 163 (3): 5-9.

Vitale, A., (2017) The End of Policing Verso; London.

Vitale, A., (2020) 'Policing won't solve our problems', In The Paris Review, 4th June edition Available online at https://www.theparisreview.org/blog/2020/06/04/policing-wontsolve-our-problems/ (accessed 06/08/2020). 
Wacquant, L., (2009) Punishing the Poor: The Neoliberal Government of Social Insecurity. Duke University Press; Durham, NC.

Waddington, P. A. J., (1987) 'Towards paramilitarism? Dilemmas in policing civil disorder', The British Journal of Criminology 27 (1): 37-46.

Waddington, P. A. J., (1993) 'The case against paramilitary policing considered', The British Journal of Criminology 33 (3): 353-373.

Waddington, P. A. J., (1994) 'Coercion and accommodation: Policing public order after the public order Act', The British Journal of Sociology 45 (3): 367-385.

Waddington, P.A. J., (1999) 'Police (canteen) sub-culture. An appreciation', The British Journal of Criminology 39 (2): 287-309.

Waddington, P. A. J., (2011) 'Cop Culture', In Tim Newburn and Jill Peay (eds), Policing Politics, Culture and Control: Essays in Honour of Robert Reiner, Hart Publishing; London, 89-110.

Waltz, S. B., (2006) 'Nonhumans unbound:Actor-network theory and the reconsideration of 'Things', Educational Foundations 20 (3): 51-68.

Warwickshire Coroners Court (2018a) Record of Inquest: Darren Keith Cumberbatch. Author's own copy. Available on request from Warwickshire Coroners Court.

Warwickshire Coroners Court (2018b) Inquest touching on the death of Darren Keith Cumberbatch: Narrative Conclusion. Author's own copy. Available on request from Warwickshire Coroners Court.

West, O., (2020) 'The de-fund movement is an opportunity for UK policing, not a threat' Policing Insight, 8th July edition. Available online at https://policinginsight.com/ features/opinion/the-de-fund-movement-is-an-opportunity-for-uk-policing-not-athreat/ (accessed 06/08/2020).

Westmarland, L., and Rowe, M., (2018) 'Police ethics and integrity: Can a new code overturn the blue code?, Policing and Society 28 (7): 854-870.

White, M., (2014) 'Restraint and Technology: Exploring Police Use of the Taser Through the Diffusion of Innovation Framework', In Reisig, M. and Kane, R., (eds), The Oxford Handbook of Police and Policing, Oxford University Press; Oxford.

White, M., and Ready, J., (2010) 'The impact of the taser on suspect resistance: Identifying predictors of effectiveness', Crime and Delinquency 56 (1): 70-102.

Whittle, A., and Spicer, A., (2008) 'Is actor network theory critique?', Organisation Studies 29 (4): 611-629.

Wilcken., B., (2018) 'Newborn screening for lysosomal disease: Mission creep and a taste of things to come?', International Journal of Neonatal Screening 4 (3): 21.

Willis, J., Koper, C. S., and Lum, C., (2018) 'Technology use and constituting structures: Accounting for the consequences of information technology on police organisational change', Policing and Society 30 (5): 483-501.

Winner, L., (1993) 'Upon opening the black-box and finding it empty: Social constructivism and the philosophy of Technology', Science, Technology and Human Values 18 (3):362-378.

Wolf, B., and De Angelis, J., (2011) 'Tasers, accountability, and less lethal force: Keying in on the contentious construction of police electroshock weapons', International Journal of Criminology and Sociological Theory 4 (2): 657-673.

Womack,V. G., Morris, R. G., and Bishopp, S. A., (2016) 'Do changes in TASER use policy affect police officer injury rates?', Police Quarterly 19 (4): 410-434.

Woo, E. (2009) 'Jack Cover dies at 88; scientist invented the Taser stun gun' Los Angeles Times 13th February edition Available online at https://www.latimes.com/local/obituaries/ la-me-jack-cover13-2009feb13-story.html (accessed 03/08/2020). 
Woodhouse, E., Hess, D., Breyman, S., and Martin, B., (2002) 'Science studies and activism: Possibilities and problems for reconstructivist agendas', Social Studies of Science 32 (2): 297-319.

Wozniak, J., and Uggen, C., (2009) 'Real men use nonlethals: Appeals to masculinity in marketing police weaponry', Feminist Criminology 4 (3): 275-293.

Wright, S., (1991) 'The new technologies of political repression: A new case for arms control?', Philosophy and Social Action 17 (3-4): 31-54.

Yesberg, J. A., Bradford, B., and Dawson, P., (2020). 'An experimental study of responses to armed police in Great Britain.' Journal of Experimental Criminology, 17: 1-13.

Young, R., (2015) 'The Rise and Fall of 'stop and account': Lessons for Police accountability', In Lister, S and Rowe, M (Eds.) Accountability of Policing, Routledge; London 18-48. 


\section{Index}

Acceptability, of less-lethal weapons 42-45, 47, 65-68, 70

Accountability 5, 16-17, 122-126, 138-139, 144, 146-147; internal 126-128; via court 130-138; see also Independent Police Complaints Commission (IPCC); Independent Office for Police Conduct (IOPC)

actants 44, 64, 109, 152

Actor Network Theory (ANT) 109, 136, 154

Adunbi, J. 3, 57, 63, 68, 133

Amnesty International 2, 39

Anais, S. 21, 58, 65-66, 111, 113

Angiolini, E. F. 135, 157-158

Ariel, B. 74-75, 86

assemblage 27-28, 155

Association of Chief Police Officers (ACPO) 11, 44-45, 115, 135; see also National Police Chiefs Council (NPCC)

Atkinson, D. R. 38, 140

Authorised Professional Practice (APP) 40, 90, 93, 99, 126; see also guidance on Taser

Australia 4, 34

Axon Enterprise, Inc (Axon) 1, 3, 17, 31, $38,58-59,125-126,153$

Baker, J. 13

baton $37,40,52-54,56,59,66,76-77,113$

Begley, J. L. 13, 38

Beynon, S. 38

Bijker, W. E. 18, 78, 151

Bittner, E. 6, 22

Bloor's symmetry 72-73, 78, 87

body worn cameras (BWCs) 6, 124, 126, 139, 155, 157, 159, 162
Brodeur, J. P. 15, 26, 28, 144, 148

Callon, M. 31, 42-48

Canada 36, 160

Casalie Review 90, 128-129

Code of Ethics 93, 157

Cole, M. A. 4, 13, 39, 50, 56, 100-102, 122

College of Policing 4-5, 12, 40-41, 90, 95-96, 98-99, 114-115, 157, 160-161

Collins, R. 112-113, 119, 144

Condor Non-Lethal Technologies 2-3, 31, 140

conflict theories 23-25, 29, 147, 154

consensus theories 23-25, 29, 147

Coroner 4, 37-39, 50, 100-101, 126, 158

Coroner's Court see Coroner

Crow, M. 4, 21, 40

CS spray see irritant spray

Cumberbatch, D. K. 37

'dance of agency' 109, 119, 149, 162

deaths following use of weapon 37-39, 50, 54, 56, 64, 100-101

decision-making, officer 5, 16, 19-21, 25-26, 28-29, 52-55, 75-80, 83-84, 93-95, 106-108, 110-111, 113-118, 121, 123, 125-126, 135-136, 143-144, 148-149

Delegation, Latourian 112-114, 152

deterrent effect, of Taser 54, 76; of red-dot function 76, 78, 81

disability 4, 18, 92, 102-104

discretion 5, 9, 19-21, 28, 95, 110-114, 121, 148-149; see also decision-making, officer

discrimination 4-6, 24, 40-42, 61-65, 92, 158-160 
DOMILL 37-38, 41, 44-45, 61, 139; see also SACMILL

Dziekański, R. 4

effectiveness, electric-shock weapons $6-7,21,23,40,42-45,72-78,81-83$, $86-87,98,111,147-148$

ethnic minorities, use on 4, 6, 20, 29-30, 40-41, 45, 92, 104, 143, 153, 155-156

European Convention on Human Rights 92

European Court of Human Rights 156-157

excessive force $6,20-21,37,51,55-65$, 115, 119-120, 124-126, 143; see also human rights

Farmer, C. 3, 57, 60, 63, 132-134,

Feigenbaum, A. 121, 153

firearms, alternatives to $2-3,30-40$, $42-43,45,48,72,84-85,142-145$

Gau, J. M. 4, 20, 40

Generalised symmetry 109, 114, 121, 136

Gilchrist, M. 3-4

guidance on Taser: in Argentina 95; in Australia 32; in Canada 160; in England and Wales see APP; in India 32, 94; in New Zealand 40, 90-91, 94; in Nigeria 32, 94-95; in Northern Ireland 160; in Serbia 94; in South Korea 94; in Ukraine 94; in USA 32, 39-40, 93-94; United Nations 6, 92, 97, 160, 162

Her Majesty's Inspectorate of the Constabulary (and Fire and Rescue Services) HMIC (FRS) 90, 108, 124-128, 140, 161

heterogeneous engineering 16, 65-68, 70, 87, 120, 151, 161-162

Home Affairs Select Committee 128-129

home office 2, 4, 17, 41, 87-88, 95, 145

human rights 6,32 , 56, 59-65, 91-92, 131-132, 156-157; see also deaths following use of weapon; excessive force; firearms; injury; proportionality, of force used vis-à-vis the situation

Hunt, J. 68, 116-117, 119

Independent Office for Police Conduct (IOPC) 13, 108, 123-124, 128-130, 140, 161; see also Independent Police Complaints Commission (IPCC)
Independent Police Complaints Commission (IPCC) 34, 62, 81, 90, 111, 114-115, 124-126, 128-130, 132-134; see also Independent Office for Police Conduct (IOPC)

injury 6-7, 21, 69-70, 137-138, 145-146; of members of the public $3-4,31-32,38$, 54-57, 59-61; of officers 72-78, 81-85, 87; psychological injury 60-61; views of members of the public 56-57, 59-61; views of officers 54-55, 75-78, 81-85

inquest see Coroner

INQUEST, the organisation 4, 48, 130

interactionist approaches 25-26, 28-29, 147, 154-155

interpretive flexibility 78-79

interviews, methodological issues 12-14, 18, 49-51

irritant spray 5, 43, 53, 66, 98, 113-115; CS spray 3, 77, 111; PAVA spray 37

Jauchem, J. R. 7, 21-22, 73, 111

kinetic impact projectiles see plastic baton rounds

Kroll, M. W. 32, 37, 53, 57

Latour, B. 14-15, 22, 109-113, 121, 125-126, 150-152, 156

Law, J. 65-66, 147-148, 154, 161-162

legitimacy of the police 3, 6-7, 145-147, 160 161; of police officers 120

less-lethal weapons 2-6, 8-9, 17-19, 23, 32-33, 36, 39, 42-45, 47, 53, 92-4, 111, 147-148, 152-153, 155-156

Maudsley, D. C. 54

McDonald, A, N. 37

media coverage $3,62,67,133$

mental health 4, 40-42, 64-65, 102-103, 127, 156-158

methods, mixed 11-14, 50-51, 69; see also interviews

militarisation 21-22, 29, 64

myths, functions of $8-11,13,14-17$, 68-69, 142-148, 153

National Decision Model (NDM) 90, 93-94, 105, 122, 135-136, 139

National Police Chiefs Council (NPCC) 4, 41, 89, 95-96, 111, 124; see also Association of Chief Police Officers (ACPO) 
necessity, of force used see excessive force neuro-muscular incapacitation (NMI) 2 ,

17, 54, 58-59, 76-78, 81

Neyroud, P. 6-7, 32, 43

Nigeria 32, 94-95

nodal security $6,26-28$

non-human agency 20-28, 44, 46, 65, 109-110, 112-113, 124-125, 148-150, 153-155

non-lethal weapons see less-lethal weapons

Northern Ireland 43, 160

Nova Technologies 30-31

Officer Safety Training 114-116, 143-144, 159-160

Omega Research Foundation 2, 6

pain $52-53,55-56,58-59,66-70,98$

Paoline, E. A. 20, 71, 74, 119-120, 150

PAVA spray see irritant spray

Personal Safety Training see Officer Safety Training

Pickering, A. 109, 119, 149, 162

Pimlott, A. J. 38

plastic baton rounds $42-44$

Police and Crime Commissioners (PCCs) $59,123,145,157$

police subculture 79-80, 86, 116-120, 149-151

policies see guidance on Taser

power, conceptualisation of $8-9,26,29$, 47,148

'predatory policing' 19, 24, 29, 147

prescription 125-126, 139, 162

pressure, of Taser carrying 79, 85, 101, 107-108, 117-118, 143-144, 149, 160-164

proportionality, of force used vis-à-vis the situation $61-66,69,91-92,131$

quantitative methods $6-7,13,21,29,49$, $60,68-69,70,75,86,147$

racism $6,62-63,116$

Rappert, B. 9, 48-49, 67, 153, 155

recommendations 156-163

red-dotting see deterrent effect, of Taser

Reiner, R. 7, 19, 23, 24, 26-29, 79, 116, 123, 150

Rejali, D. 1, 161

Rigg, S. 129

Rojek, J. 25-26, 29, 50-51, 64-65
SACMILL 17, 48, 88, 90, 99-101

Science and Technology Studies (STS) 6, 8-10, 15-16, 141, 158-155, 163

security governance see nodal security

Sierra-Arévalo, M. 7, 71, 75, 112

single-crewing 76, 85-86, 143

Smith, R 31, 34, 59, 73

social construction 7,26

socio-technical 50, 66, 70, 72, 80, 86-87, 123, 143-145, 147, 149-152

Squires, P. 93, 106, 132

statistical analysis see quantitative methods Stinger Systems 88

Taser International 33, 36, 39, 44, 47, 56, 58, 96, 125, 139, 145

Taser models: Taser T7 17, 56, 88; Taser X2 17, 38, 87-88; Taser X26 4, 17, 37, $38,50,87-88$

Taser 'Single Point of Contact' (SPOCs) 18, 126

Taser training 39, 57, 76, 81, 88, 91, 95-106, 117, 143, 159-160

Terrill, P. 7, 9, 19-21, 29, 39, 49, 55, 60, 69, 71, 93, 110, 118, 151, 163

training see Officer Safety Training;

Taser training

transformational approaches 19, 23, 26, $27,28,29,147$

translation $31,42,43,45,46,47,120$, 148,152

'trigger-happy', with Taser 63, 112-114, 121

UN Convention Against Torture (UNCAT) 69

UN Office on Drugs and Crime (UNODC) 92, 97

UN Office of the High Commissioner for Human Rights (OHCHR) 92, 97

UN standards see guidance on Taser

United States of America 4, 6, 32-33, 36-37, 39-40, 54, 60, 74, 93-94, 96, 139

use of force statistics, official 40-41, 48, 159

Vitale, A. S. 11, 23, 24, 154, 156, 158

W80 13, 131, 157, 164

Waddington, P. A. J. 15, 22-24, 28, 55, $68,71,79,116,118,150$

weapons effects 75,112

White, M. D. 7, 20, 21, 33, 73, 78, 81 